\title{
MULTICULTURALISM AND THE HISTORY OF CANADIAN DIVERSITY
}

\author{
by \\ Richard J.F. Day \\ M.A., York University, 1989
}

THESIS SUBMITTED IN PARTIAL FULFILLMENT OF

THE REQUIREMENTS FOR THE DEGREE OF

DOCTOR OF PHILOSOPHY

in the Department

of

Sociology and Anthropology

(C) Richard J.F. Day 1998

SIMON FRASER UNIVERSITY

August, 1998

All rights reserved. This work may not be reproduced in whole or in part, by photocopy or other means, without permission of the author. 
National Library

of Canada

Acquisitions and

Bibliographic Services

395 Wellington Street

Ottawa ON K1A ON4

Canada
Bibliothèque nationale

du Canada

Acquisitions et services bibliographiques

395, ne Wellington

Ottawa ON KIA ONA

Canada
The author has granted a nonexclusive licence allowing the National Library of Canada to reproduce, loan, distribute or sell copies of this thesis in microform, paper or electronic formats.

The author retains ownership of the copyright in this thesis. Neither the thesis nor substantial extracts from it may be printed or otherwise reproduced without the author's permission.
L'auteur a accordé une licence non exclusive permettant à la Bibliothèque nationale du Canada de reproduire, prêter, distribuer ou vendre des copies de cette thèse sous la forme de microfiche/film, de reproduction sur papier ou sur format électronique.

L'auteur conserve la propriété du droit d'auteur qui protège cette thèse. $\mathrm{Ni}$ la thèse ni des extraits substantiels de celle-ci ne doivent être imprimés ou autrement reproduits sans son autorisation. 
In this dissertation I set out to show how Canadian multiculturalism as state policy liberal pluralist philosophy has emerged out of, and forms part of, an older discourse on human diversity with roots in ancient Ionian Hellenism. I use a genealogical method to trace the regularities, continuities and ruptures in this discourse, or field, as they appear in three subfields: colonial and state policy; philosophical-theoretical analyses; and popular culture. After setting up the ancient Ionian, Roman imperial, and early Christian archetypes for the creation and management of problematic Otherness, the analysis turns to the application and transformation of these methods in the British, French, and Canadian colonization of those parts of the 'New World' that have become known as 'Canada'.

Having presented the genealogical evidence, I argue that while Canadian multiculturalism as state policy presents itself as a new solution to an ancient problem of human diversity, it is better seen as a creative reproduction of that problem which not only ensures its continued existence, but also its proliferation. By this I mean that each attempt to 'solve' the problem has led to an increase in both the number of problematic subject positions and in the amount of rationalbureaucratic intervention in the daily lives of those who occupy these positions. Thus, Canadian multiculturalism appears as neither a generous gift of liberal democracy, nor a divisive practice threatening to destroy the enjoyment of Canadianness for all. Rather, it is the passive nihilistic fulfillment of a rationalbureaucratic ethnocultural economy which takes as its raw material the 'objective contents' of Canadian diversity and hopes to produce out of it a simulacrum of Canadian unity.

Producing and maintaining this simulacrum is necessary because the discourse on Canadian diversity also contains the possibility of abandoning the 
formation of state-designed, singular identities through mass Self-acceptance and Other-exclusion (culture), and orienting instead to an emergent and multiple (postcultural) experience of subjectivity. I refer to this possibility as a state-free emergence theory of identity, as it can be realized only by a flight from the designed idsratities offered by the Canadian state. 


\section{Dedication}

This dissertation is dedicated to all those smiths, of the past, present, and future, whose goal it is to ward off state forms. 


\section{Acknowledgments}

I would like to thank the SFU Department of Sociology and Anthropology and the Social Sciences and Humanities Research Council for their financial support during the writing of this dissertation. Ideas and methods that appear here have emerged out of conversations with Ian Angus, Lori Barkley, David Firman, Marilyn Gates, Krista Henriksen, Dany Lacombe, Guy Letts, and Richard Toews. Finally, Alison Gowan shall have her name inscribed on microfilm as a reward for sticking with me through the absurdly difficult process of completing a $\mathrm{Ph} . \mathrm{D}$. while raising a young family in one of the most expensive cities in the world. 


\section{Table of Contents}

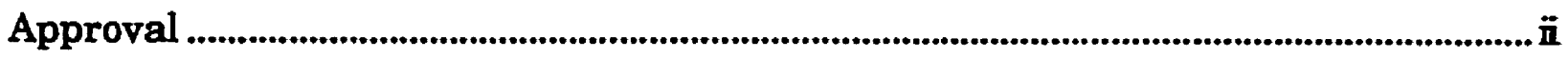

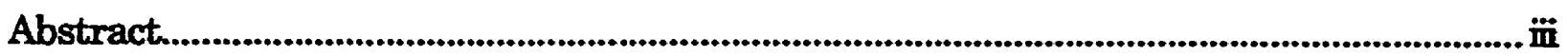

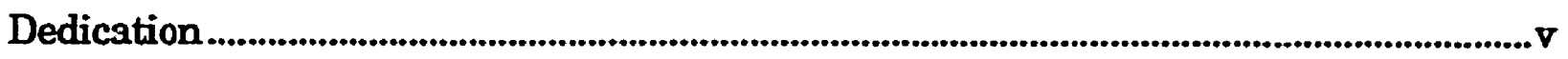

Acknowledgments ..............................................................................................................................vi

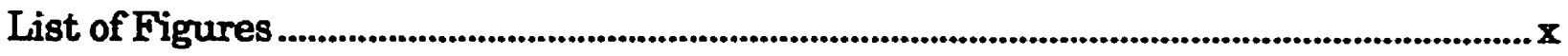

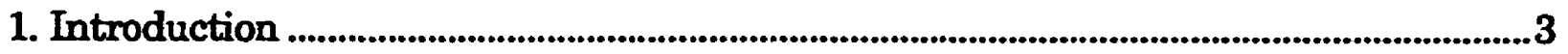

The Problem of the Problem of Diversity .........................................................................3

The Field of Canadian Diversity..................................................................................18

Canadian Diversity in State Policy ................................................................................20

Canadian Diversity in Popular Culture ......................................................................26

Canadian Diversity and the Academy.............................................................30

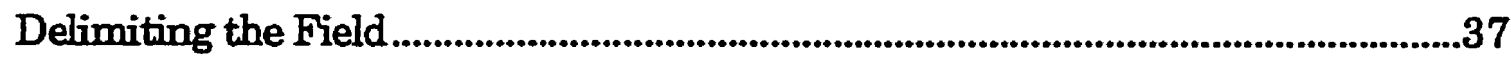

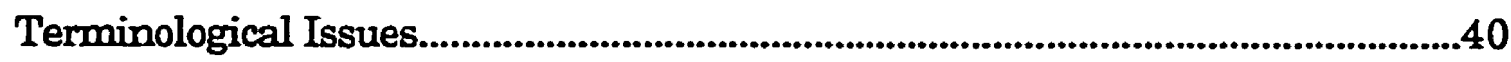

2. Theoretical-Methodological Concerns........................................................................45

Genealcgy, Complexity, and the State Form .....................................................45

3. European Antecedents to the Problem of Canadian Diversity ....................................58

How Difference Changes, How it Remains the Same ...........................................58

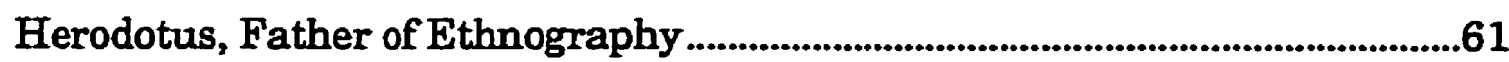

Ancient Ionian Hellenism and the Destruction of the Inferior Other..................71

Incorporation of the Other in Roman Imperialism .................................................77

Early Christianity - The Missionary Urge....................................................................81

Renaissance Exploration and the New World Savage ..........................................84

From Prehistory to History - A Summary of European Contributions to the Problem of Canadian Diversity ............................................................8

4. Two Canadian Solutions to the Problem of Diversity .................................................... 
The First Others of the New World

Conversion and Extermination - The Cases of the Huron and the

Iroquois.

The Coureurs de Bois as a Repressed Hybrid Identity ........................................ 105

The System of Difference in French Colonial Discourse ...................................... 108

How Canada Became British .................................................................................. 111

Ignorance and Extermination in the New Founde Landes .................................. 113

Microcontrol and Hybridity - The Hudson's Bay Company and the

British Fur Trade

The Early Colonial History of Canadian Diversity ................................................. 124

5. Integration and Administration in British North America ......................................... 128

The Conquest / Cession of New France ...................................................................... 130

The Emergence of the Two Founding Races......................................................... 136

Rational-Bureaucratic Tutelage - The Indian Problem Under British

Rule

Group Identity in British Canada .............................................................................. 147

6. The Canadian Nation and the Immigrant Other .................................................... 149

Clearing the 'Empty' West........................................................................................... 150

An Explosion of Racial Subject Positions............................................................... 157

Restoring Order - J.S. Woodsworth and the Great Chain of Race .................... 163

Managing the Strangers Within Our Gates - Assimilation,

Transportation, Deportation, and Internment ........................................ 173

Excluding the Strangers Without ............................................................................ 181

7. The Rise of the Mosaic Metaphor............................................................................... 190

Canadian Identity as an Emergent Phenomenon.................................................. 191

The Canadian Mosaic as a Constrained Emergence Theory of Identity ....... 194

Design, Designers, and the Social Sciences ............................................................. 199 
WWII and the 'First Bureaucracy for Multiculturalism' .................................... 205

The Citizenship Machine ............................................................................................... 213

From Racial Assimilation to Cultural Integration................................................ 221

8. The New Idol - Multiculturalism as State Policy ........................................................... 229

The 'Liberalization' of Canadian Society ...............................................................229

From Monopoly to Duopoly - The B\&B Report........................................................ 231

Multiculturalism in a Bilingual Framework as Strategic Simulation of Assimilation to the Problematic Other...................................................237

Multiculturalism, Liberal Pluralism, and the Politics of Recognition ..............253

Multiculturalism - Modern or Postmodern? .............................................................267

The Mosaic as the Canadian National Thing ............................................................. 275

9. Conclusion ...........................................................................................................................283

The History of Canadian Diversity - Reprise ......................................................... 283

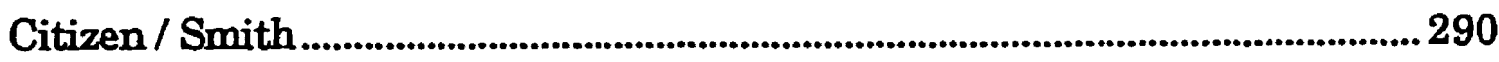

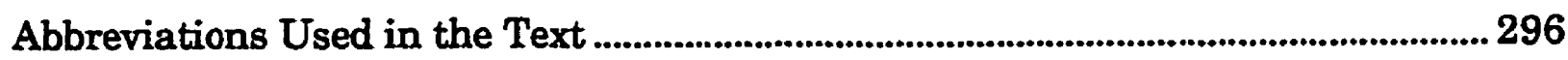

Bibliography ................................................................................................................................298 


\section{List of Figures}

Figure 1.1 - The problem? A full container ......................................................................................1

Figure 1.2 - The solution? The National Jewel .............................................................................2

Figure 3.1 - The Herodotan wheel of difference .......................................................................67

Figure 3.2 - The semiotic square. .......................................................................................................68

Figure 3.3 - The Herodotan wheel of squares .....................................................................70

Figure 3.4 - The hierarchized square of ancient Ionian Hellenism.....................................74

Figure 4.1 - Group identity in French colonial discourse (<Canada>).......................... 109

Figure 4.2 - Group identity in early British colonial discourse (<Canada>)............... 127

Figure 5.1 - Group identity in British Canada................................................................... 148

Figure 6.1 - Group identity in Canadian colonial discourse............................................... 154

Figure 6.2 - Group identity in Canada, 1870's - early 1900's ......................................... 158

Figure 6.3 - The mission as agent of rational-bureaucratic discipline........................ 176

Figure 7.1 - Group identity in Canada, post WWII ............................................................. 225

Figure 8.1 - Official identity in Canadian bilingualism and biculturalism................... 236

Figure 8.2 - Official recognition of identity in multiculturalism as state policy........ 266

Figure 8.3 - Multiple Origins in Canada, 1986 census...................................................... 272

Figure 9.1 - The Herodotan wheel of identity and difference ........................................... 288

Figure 9.2 - The Canadian wheel of identity and difference.............................................. 288

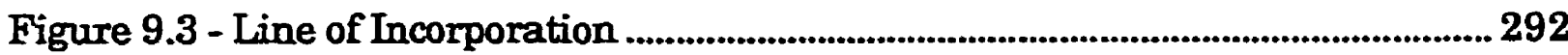





\section{Figure 1.2 - The solution? The National Jewel}

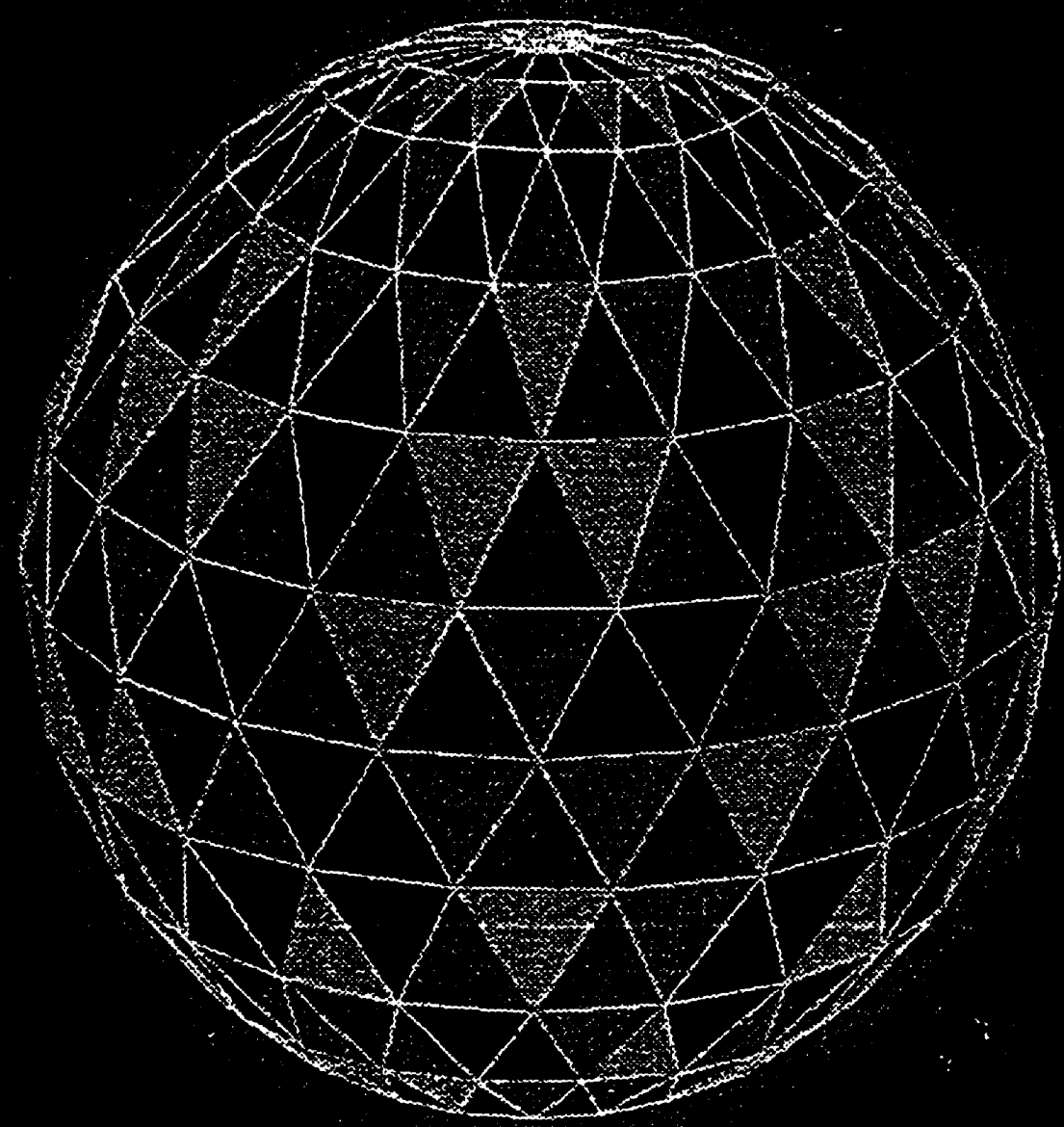

Canalin 


\section{Chapter 1}

\section{Introduction}

\section{The Problem of the Problem of Diversity}

Stated most succinctly -- and in a manner that will require elaboration - in this dissertation I attempt a revaluation of Canadian multiculturalism by way of a genealogical deconstruction of the problem of Canadian diversity. I do not argue 'for' or 'against' multiculturalism as a state policy or political-philosophical ideal, but set out to show how Canadian multiculturalism has emerged out of, and forms part of, an older and broader discourse on diversity that has its roots in a tradition of Western 'political anthropology' that can be traced back to Herodotus. The central chapters trace the continuities and ruptures in this tradition, as they appear in colonial and state policy, philosophical-theoretical analyses, and popular culture. Based on this evidence, I argue that while Canadian multiculturalism presents itself as a new solution to a problem of diversity, it is better seen as a creative reproduction of that problem which not only ensures its continued existence, but also its proliferation. By this I mean that each attempt to 'solve' the problem leads to an increase in the number of problematic subject positions and in the amount of rational-bureaucratic intervention in the daily lives of those who occupy these positions. In the sense that it marks a shift from coercive exclusion to seductive inclusion of problematic identities (see chapter 7), Canadian multiculturalism does provide evidence of a break with the modern mode of articulation of individuals, groups, and the state. Yet, even if it has taken on signs of a postmodern style, Canadian multiculturalism has not passed through the stage of modern nihilism inherent in the perpetuation of a total system of known, stable, identities that attempts to impose order upon hybrid and emergent forms. Canadian 
multiculturalism must therefore be seen as a technique of rational mastery which wills "itself [as] the sole context within which all that is other to it must attempt to be present" (Grant 1969:40). It is fulfilled nihilism (Nietzsche 1967b:9-39; Heidegger 1958:49; Vattimo 1991:19ff.) that cannot complete itself, because completion would require giving up on the project of Canadian unity which, from the beginning, has provided the conditions of existence for the problem of Canadian diversity.

Let me now try to clarify the resonance of certain key terms and assumptions in the passage above. There are, of course, many "dividing practices"1 operating upon the Canadian population to produce various kinds of "diversity, "but here I want to focus on differentiation according to what is known as "ethnocultural origin." This term is defined within state policy discourse as including "cultural, national, or racial origin of a person" (Multiculturalism: Building the Canadian Mosaic, Standing Committee on Multiculturalism 1987:87, hereafter cited as $M C B C M$ ). Inasmuch as culture, nation, and race are assumed to be conditioned by climate and geography - a holdover from the ancient Greek world upon which I shall elaborate in chapter 3 - Canadian ethnocultural diversity appears as an 'objective', 'natural' phenomenon which makes itself apparent in visible signs inscribed on certain bodies. "Diversity is a fact of life in this country," a government pamphlet declares (Multiculturalism: What is it Really About?, Ministry of State for Multiculturalism and Citizenship 1991:11, hereafter cited as MCWR). A newspaper photograph showing a White woman enjoying a tea party with a Chinese woman, an orthodox Jew and a Rastafarian is overlain with the headline: "Multiculturalism: Has diversity gone too far?" (Globe and Mail, Saturday March 15, 1997:D1). Social scientists have gotten in on the game as well, often adding to the confusion of terms: "Canada is a multiethnic nation with a variety of ethnic, racial, religious, and 
political identities. Some societies have more diverse populations than others; Canada is among the most polyethnic" (Driedger 1996:2).

With all of this semiotic activity, it is very difficult to spend even a short time in Canada without becoming acutely aware that Canadian diversity not only exists, but poses a serious problem. This problem, like the diversity that 'causes' it, must be constantly reproduced for, as Joseph Gusfield points out, "[h]uman problems do not spring up, full-blown and announced, into the consciousness of bystanders. Even to recognize a situation as painful requires a system for categorizing and defining events (Gusfield 1981:3). The public character of public problems must be created as well since, "all social problems do not necessarily become public ones" (5). The eligibility of a given social problem for attempts at public solution tends to be a matter of ongoing debate, especially in the current context of neoliberal attacks on the welfare state and the consequent pressure to 'privatize' both problems and their solutions. In general, though, once a problem has been successfully classified as within the public realm, the way has been cleared for the operation of government, for attempts to "structure the possible field of action of others" (Foucault 1982:221). Newspaper articles declare a crisis situation, Royal Commissions are struck, a ministry is created, legislation is drafted, buildings are erected and staffed, as the bodies and minds of concerned citizens are swept up in a whirl of rationalbureaucratic activity. Out of this chaos an emergent consensus forms: a crisis exists, but it is being addressed and all will soon be well again. The problem of the problem of diversity, then, is that the assumption of the existence of an objectively existing and problematic ethnocultural diversity covers over the work of differentiation itself. Because it is a discursive construct with no basis in an empirical reality - not a thing' of any sort at all -- Canadian diversity "does not exist." However, as a discursive formation with certain regularities, which I will identify later in this chapter, and which achieves certain power / knowledge effects, which I will identify in 
chapters 3 through 8, the field of Canadian diversity definitely does provide an environment which conditions the possibilities of life for those who are trying to be Canadian'.

While some suggest that the problem of Canadian diversity should not be given public status (Bissoondath 1994; Brotz 1980; Clifton \& Roberts 1982), this is to argue against a long history of attempts at governmental management of ethnocultural identities within the territory now claimed by the Canadian state. As I will show, from the arrival of the Europeans to the present day, the problem of Canadian diversity has always been public, in that it has always involved statesponsored attempts to define, know, and structure the possible actions a field of problematic Others (Savages, Québécois, Half-breeds, Immigrants) who have been distinguished from unproblematic Selves (French, British, British-Canadian, European) through a variety of means (civilization, humanity, race, culture, ethnicity, ethnocultural origin). ${ }^{2}$ Even more striking than this longevity is the tendency of each attempted solution to increase the size and complexity of the problem: for almost five hundred years, both the British and the French have been trying to 'civilize' the 'Savages'; for over two hundred years the British have not been able to eliminate or accommodate the French; over the past century, the list of problematic Others has been continually expanding as governments and corporations have sought to increase the size of the population and the economy via immigration. The public problem of Canadian diversity has a long history, and even the most cursory scan of the mass media and academic presses makes it clear that it shows no signs of being solved in the near future.

Yet, despite this history of rational-bureaucratic (governmental) multiplication and failure, multiculturalism policy documents produced by the Canadian state proudly declare that the problem of Canadian diversity has always already been solved, that multiculturalism has "been a fact of Canadian life for 
centuries," starting "when the first European settlers arrived to join the Aboriginal peoples in the northern half of a vast continent" (Multiculturalism ... being Canadian, Department of the Secretary of State 1987:3, hereafter cited as $M C B C$ ). In some documents, the history of Canadian diversity is extended back prior to the "joining", to times that literate, European minds see as prehistoric or primordial:

Cultural diversity characterized the earliest societies to be seen through the mists of our history. Aboriginal peoples speaking a diversity of Algonkian tongues were spread across the breadth of North America (MCBCM:13).

While this claim is hard to support if "multiculturalism" is taken to mean "the recognition of the cultural and racial diversity of Canada and of the equality of Canadians of all origins" (MCBC:3), it does make sense if it refers only to the "recognition of cultural and racial diversity." Here one needs to distinguish between three prevalent usages of 'multiculturalism': to describe (construct) a sociological fact of Canadian diversity; to prescribe a social ideal; and to describe and prescribe a government policy or act as a response to the fact and an implementation of the ideal (Angus 1997:139, Kallen 1982:51). By paying close attention to these resonances, one can see that the Canadian government is attempting to confound the descriptive and prescriptive senses of multiculturalism in order to provide its policy with an unearned history and reality. This effort has created a fourth meaning of multiculturalism, as an already achieved ideal, which suggests that the work prescribed has already been done, or is being done through the very process that created the problem in the first place, and now ensure its proliferation.

While I follow the policy documents in locating the emergence of the problem of Canadian diversity, or multiculturalism as fact, at the time of the arrival of the Europeans, I do not accept that multiculturalism as either act or social ideal - in any stage of realization - existed at this time. These came later, through the 
evolution of acts and ideals that did exist, but whose obviously violent and intolerant character makes it difficult to put them to service in the creation of a multiculturalist origin myth. I am speaking here of the methods of constructing and managing human difference that were brought by the Europeans in the 16th century, which involved marking out the civilized, human 'European' from the uncivilized, brutish 'Savage', who was then subjected to attempts at assimilation, displacement, and extermination. Over the years, this field has been evolving through innovations in colonialism, bureaucratic discipline, immigration policy, demography, social theory, and state policy- until it has been sufficiently transformed to allow multiculturalism as an already achieved social ideal to be projected back onto the history of Canadian diversity. This projection of a simulacrum of origin has allowed a 'solution of Canadian multiculturalism' to be represented as a natural, primordial, and already existing and successful response to a 'problem of Canadian diversity'.

Some clarification regarding methodological questions might also be in order. To restate the first sentence of this introduction, what I am attempting is a revaluation of Canadian multiculturalism by way of a genealogical deconstruction of the problem of Canadian diversity. The preceding discussion will hopefully have shown how the terms 'multiculturalism' and 'Canadian diversity' slide around on top of one another, and can therefore be used to achieve certain rhetorical effects. In "White Mythology: Metaphor in the text of Philosophy," Jacques Derrida suggests that the task of deconstruction is "to dismantle (déconstruire) the metaphysical and rhetorical structures which are at work in the text, not in order to reject or discard them, but to reinscribe them in another way." 3 This is what I am setting out to do with the 'text' of the 'problem of Canadian diversity'. The metaphysical and rhetorical structures that enable multiculturalism to be presented as an already 
achieved ideal will be dismantled, and reinscribed in a genealogy of the problem of Canadian diversity.

This brings me to the question of the relation of genealogy to history. In the spirit of Foucault's essay "Nietzsche, Genealogy, History," I claim that the Canadian discourse on diversity posits a history, that is, a linear narrative told from a place "outside of time" (Foucault 1985:76, 87). To counter this history, I will produce a genealogy, a search not for origins and "monotonous finality" (76), but for lines of descent, emergences, discontinuities. Foucault writes: "The search for descent is not the erecting of foundations: on the contrary, it disturbs what was previously considered immobile; it fragments what was thought unified; it shows the heterogeneity of what was imagined consistent with itself" (82). My approach takes genealogy as reinscription of historical texts, in a manner amenable to the task of deconstruction as set out by Derrida in the "White Mythology."

Finally, one might ask what is involved in a "revaluation." This term comes from Nietzsche, who held in The Will to Power that "radical" European nihilism "the conviction of an absolute untenability of existence when it comes to the highest values one recognizes" (1967b:9) - was the result of a state in which "the highest values devalue themselves" (9). In Nietzsche's time, these would include the Christian god, the European aristocracy, and all that he saw being swept away by an onrushing modernity. In using Nietzsche's term, I attach myself to the idea that the processes of European nihilism are still working themselves out, that there are many ways in which those who might consider themselves Canadian have reached a psychological state where "one has posited a totality, a systematization ... and a soul that longs to admire and revere has wallowed in the idea of some supreme form of domination and administration" (12). To the extent that Canadian multiculturalism represents one of these supreme forms of domination and administration, to the extent that it embodies exhausted values like nationalism, 
mass representative, state-oriented 'democracy', and the will to a perfect technique of designed subjectivities, escaping its grasp will require re-assessing these cherished values, touching what has been placed out of reach on a high altar. Of course, this heretical contact with sacred objects will provoke anger and misunderstanding. But, as Nietzsche put it, "We require, sometimes, new values" (4).

Some work that takes on the problem of Canadian diversity with an eye to revaluation has already been done, for example in the field of Canadian native studies. In his article on "The Image of the Indian," Robin Fisher notes many of the salient features of the Canadian discourse on diversity - without naming it as such, and without noting the larger and older connections - as it operated during the furtrade and settlement periods in British Columbia (Fisher 1988). Noel Dyck, in What is the Indian Problem?, challenges the assumptions that have led to generations of rational-bureaucratic "tutelage" disguised as a solution to the natural-biological problem of Indian difference (Dyck 1991). This approach can be applied to the study of the general problem of Canadian ethnocultural diversity, to both place the Indian problem within the broader context of the European discourse on diversity, and to show how this discourse has helped to create and maintain a series of other systems similar to the one Dyck analyzes.

For hints at how this task might be approached, we must turn to the growing, yet still marginalized, field of post-colonial studies, where the modern couplet essence / identity is being replaced with the postmodern problematic of construction / hybridity (Bhabha 1994:4-5; Hall 1987; Minh-ha 1991). This shift in the theorization of identity is not the result of some academic fad; it is a necessary response to the postmodern condition of diaspora, itself an effect of modern colonialism and the technologies of rapid mass transport (e.g. the ocean-going ship) that Europeans invented and applied with great effect around the world. Thus Stuart Hall: "What Ive thought of as dispersed and fragmented comes, paradoxically, to be the 
representative modern experience!" (1987:44). A focus on ethnocultural identity as a power / knowledge construct has been gaining momentum in the mainstream academy, as the insights of post-colonial theory are diffused. In a special issue of the journal October (\#61, 1992), Joan Scott criticized a report issued by the state of New York, entitled "One Nation, Many Peoples," by noting that the authors

naturalize identity, making it a matter of biology or history or culture, an inescapable trait that can matter more or less, but is inherently a part of one's being. The report assumes that people are discriminated against because they are already different when, in fact, I would argue, it is the other way around: difference and the salience of different identities are produced by discrimination, a process that establishes the superiority or the typicality or the universality of some in terms of the inferiority or atypicality or particularity of others (14-15).

By blaming the Others they construct for the existence of a problem of diversity, discourses of identity and unity -- such as Canadian multiculturalism -- disown and thereby mask their own power / knowledge effects. Scott goes on to suggest that "most discussions of multiculturalism avoid this kind of insight about the production of knowledge of identity and therefore undercut their most radical potential" (15). In the Canadian context, close attention to identity as a power / knowledge effect is best exemplified by the work of Himani Bannerji, who has repeatedly insisted that "colonialism is the context or entry point that allows us to begin exploring the social relations and cultural forms which characterize ... relations" between English Canada and its Others (1996:107). My goal is to delve into this context in detail, to show how the present of the problem of Canadian diversity has emerged out of its past, how it has survived and adapted, changed and remained the same.

As I will make use of the term 'hybridity' throughout this dissertation, I should point out how I will be using it, especially as its usage will resonate differently in different contexts. With regard to the Canadian Half-breed and Metis identities, I will be using the term as a description of what was then seen as a 'mixing of races' that 
produced new -- and generally 'inferior' - human types. 4 Of course, I hope that the reader will also be aware of the more current sense of hybridity as a semiotic process through which new identities are constructed. I should also point out that it sometimes seems as though hybridity is being presented as a sort of panacea by postcolonial theory. After noting that dispersal and fragmentation are "the representative modern experience," Stuart Halls goes on to wonder whether the "centering" of this "marginality" might be "the representative postmodern experience" (1987:44). On this theme Homi Bhabha suggests that the "wider significance of the postmodern condition" lies not in the philosophical deconstruction of Western metaphysics, but in "the awareness that the epistemological limits" of those ethnocentric ideas are also the enunciative boundaries of a range of other dissonant, even dissident, histories and voices - women, the colonized, minority groups, the bearers of policed sexualities" (Bhabha 1994:4-5). For Bhabha, the inbetween spaces of fixed identities "open up the possibility of a cultural hybridity that entertains difference without an assumed or imposed hierarchy" (4). While this "entertaining" of difference could be construed as an 'overcoming of European colonialism, I do not want to give the impression that post-colonial theory points the way toward a 'solution' to the problem of Canadian diversity through a 'recognition' or 'acceptance' of postmodern hybridity. As Bhabha notes, "the social articulation of difference ... is a complex, on-going negotiation that seeks to authorize cultural hybridities that emerge in moments of historical transformation" (2, emphasis added). States can, have, and always will, be able to authorize 'hybrid' identities by nominating them as 'pure', and then using the resulting category as a means of mass articulation with an administrated population. ${ }^{5}$

The remainder of this introduction will comprise a preliminary sketch of the ideas and claims that will be presented in the body of the dissertation, and a delimitation of the "field" of Canadian diversity. After a study of this field via the 
subfields of state policy, popular culture, and academic discussions, I will claim that it observes the following regularities: (1) Canadian diversity is seen as a sociological, natural-historical, objective fact, resulting from innate differences in human types based on race, culture, ethnicity, geography, and climate; (2) this diversity is thought to represent a public problem meriting state intervention, or rational-bureaucratic acts; (3) inasmuch as the fact is conflated with the acts, the problem of Canadian diversity is thought to contain its own solution, to be in the process of solving itself, of achieving its own ideal.

Chapter 2 sets out in greater detail my theoretical-methodological approach, and establishes the possibility of a genealogical investigation of the current Canadian field through an examination of its descent from an ancient Western discourse on diversity, which is intimately bound up with what I will call, following Deleuze and Guattari, 'state' forms of top-down organization or striation. Chapter 3 sets out the formal characteristics of the Western discourse on diversity through an examination of texts of Herodotus, Plato, and Aristotle. These characteristics -- the division of human individuals into groupable 'types', the arrangement of these types into a hierarchy, the naming of some types as presenting a 'problem', and the attempt to provide 'solutions' to the problem so constructed-- act as a metastructure which has reproduced itself throughout many changes in its form and content. In Plato and Aristotle, I argue, human types were differentiated according to the Great Chain of Being, unproblematic Greeks were opposed to problematic Barbarians, and the solution to the problem of Barbarian difference was to wage wars of destruction aimed at their exclusion and elimination. The Roman empire maintained the Barbarian as Other and perpetuated the Great Chain, but tended towards strategies of inclusion and integration in handling the problems it created for itself. Later, the Christians perfected the art of converting Pagans and Barbarians, semi-civilized Others lurking on the edges of what it perceived as the 'civilized world'. 
Also in chapter 3, I introduce and make use of Greimas' method of the "semiotic square," which is used throughout my argument to track the ways in which this ancient metastructure has reproduced itself, under different discursive conditions, up to the present day. My reasons for reaching back to the beginnings of Western civilization in analyzing Canadian multiculturalism are at least double. First, the degree of continuity is quite striking, once one becomes aware of it, and I believe that this continuity should be directly addressed by current policies and philosophies that seek to 'solve' the problem of Canadian diversity. Second, the age, depth, and subtle interconnections of this highly adaptable 'problem' suggest that its 'solution' will be no simple matter, not something a Royal Commission or a piece of legislation can hope to achieve with one blow, or even a series of blows. Indeed, the system has evolved precisely through turning such shocks to its advantage.

The task of chapters 4 through 8 is to show how Canadian multiculturalism as state policy is descended from these ancient forms, not in a line of simple repetition, but as a complex process of adaptation containing many discontinuities. In each discursive situation, through an examination of what I consider to be epitomal texts, I will look at the nature of the categories and the hierarchical order established, the problems constructed, and the solutions proposed and implemented. In chapter $4 \mathrm{I}$ discuss how the ancient Western discourse on diversity was adapted to the circumstances of European colonization of that portion of the New World that has come to be known as Canada. The ancient Greek methods of exclusion and 'war to the end' were creatively reproduced in the many -- yet always unsuccessful attempts of the colonial government of New France to displace and destroy the peoples of the Iroquois confederacy, and in the actually achieved British extermination of the Beothuk of what is now called Newfoundland. From the beginning of their colonial efforts, the French also attempted conversion and assimilation, methods which did not take hold in the early British colonial discourse. 
The British, however, made their own innovative contributions to the Canadian discourse on diversity, through their evolution of legal and rational-bureaucratic methods of distant microcontrol of the daily lives of both Selves and Others, as epitomized in the operation of the Hudson's Bay Company. With the conquest/ cession of New France, addressed in chapter 5, the British began to make use of the French methods of conversion and assimilation of the Native peoples and, after several failed attempts at transportation, extermination, and assimilation, began to try to integrate the French. With the addition of a 'European' Other, the system of diversity in British colonial Canada became more complex, the number of problematic subject positions increased, and the basis for construction of problematic difference began to shift from humanity and civilization to race and religion; the French were obviously 'people', but they were just as obviously not the same kind of 'people' as the British.

The rise of the Canadian nation-state forms the subject of chapter 6 , which documents how the British discourse on diversity was imitatively reproduced in a self-conscious quest to rise from the status of 'colony' to that of a 'nation' with colonies of its own. The Canadian invasion of the Red River region is taken as the archetype here, involving violent displacement of the existing population, seductive integration through the offer of 'province' status, followed by assimilation through massive inward movement of people who occupied higher positions on what had become a Great Chain of Race (White, Yellow, Black, Red). The acquisition of these apparently more 'desirable' person-types to colonize the newly minted province of Manitoba only exacerbated the problem it set out to solve, however, as it led to a proliferation of problematic subject-positions within the category of White itself. From a mere handful - French, Savage, Indian, Half-breed, Metis - the number of non-British types that posed a threat to canonical Canada increased to seventynine by 1903 (National Archives of Canada, Immigration Record Books, RG 26 
Series C.1 Vol. 26 Book 3). The Canadian state began a series of attempts at physical elimination of problematically different bodies, such as rejection of Immigrants based on racial criteria, exclusion via selective immigration policies, and ejection via individual deportation and group transportation. All of this was in keeping with the hegemony of an ideology of "Anglo-conformity", which held that all new Canadians' must be assimilated to a British-Canadian model. For those who could not be physically removed or assimilated, further coercive measures were adopted during the two World Wars, including disenfranchisement, internal displacement, transportation, surveillance, and internment.

In the 1920's, what I consider to be the key texts in the 20th century Canadian discourse on diversity appeared: Kate Foster's Our Canadian Mosaic (1926); and Robert England's The Central European Immigrant in Canada (1929). These texts, in their creative reproduction of earlier forms epitomized by J.S. Woodsworth's Strangers Within Our Gates (1907), established a set of generic characteristics that later came to dominate the field of Canadian thought, writing, and practice regarding the problem of diversity. The 'Mosaic' metaphor for Canadian society is one well-known example, but there are many others: the 'Flood' metaphor for incoming diversity; the tabular arrangement of racial groups vs. numbers arriving over some given time period; and the catalogue display of a variety of human types considered to be different from some unmentioned canonical type. Chapter 7 addresses these texts in detail, showing how they are descended from previous formulations of the problem of Canadian diversity, and how current government policy and many academic analyses are descended from them. Two critical shifts occurred during this period: a decline in Anglo-conformist, design theories of Canadian identity, in favour of what I refer to as a constrained emergence theory symbolized by the Mosaic metaphor; concomitant with this, a movement away from coercive assimilation and exclusion of races to seductive integration of 
cultures. This shift began to be officialized with the advent of World War II and the Nationalities Branch of the Department of National War Services, which provided the bureaucratic conditions necessary for the emergence of multiculturalism as state policy.

It has been argued that with its shift to an official policy of multiculturalism during the 1960's, the Canadian state finally began to solve the problem of diversity through granting "recognition" to non-canonical identities (Kymlicka 1995; Taylor 1992). Other commentators have seen this development as a 'dangerous' form of 'fragmentation' (Bibby 1990; Bissoondath 1994). However, from the perspective developed in chapter 8, Canadian multiculturalism appears as neither a generous gift of liberal democracy, nor a divisive practice threatening to destroy the enjoyment of Canadianness for all. Rather, it is the passive nihilistic fulfillment of an ethnocultural economy which takes as its raw material the 'objective contents' of Canadian diversity and hopes to produce out of it a simulacrum of Canadian unity. The reality of Canadian diversity is symbiotically dependent upon this will to unity without it, a diversity simply could not exist, and certainly could not be a problem. The rhetoric of multiculturalism says that Canada is attempting to become, not a nation-state, but a self-consciously multinational (civic) state, in which all nations can seek their enjoyment in possession of a national Thing (Zizek 1991:165). This Thing is universal, it is every Thing. But, as everything it is also nothing at all. This paradoxical object is tellingly represented in an image that I call the National Jewel: a disembodied Mosaic floating in an empty space, as seen on the cover of the government policy document Multiculturalism: being Canadian (Department of the Secretary of State 1987), reproduced here as Figure 1.2.

Guarding the Jewel is necessary because the discourse on Canadian diversity also contains, as its continually repressed Other, the possibility of abandoning the formation of designed, singular identities through mass Self-acceptance and Other- 
exclusion (culture), and orienting instead to an emergent and multiple (postcultural) experience of subjectivity. Staying within the discourse on Canadian diversity, we might refer to this possibility as one of 'open-ended integration', or a free emergence theory of identity. In the final chapter, I will present this possibility as a flight from the state-designed identities offered by the National Jewel. Precisely because of the 'failures' of British- and French-Canadian nationalisms, the constant threats from incompletely coded peoples, Canada is perhaps, after all, leading the way towards a future that will be shared by many other nation-states, and may, in its failure to achieve a universal mass identity, or even a universal mass of identities, inadvertently achieve its goal.

\section{The Field of Canadian Diversity}

My object in this study will be a discursive formation, or field, composed of several subfields: the discourse on Canadian diversity as observed in state policy, popular culture, and academic analyses. In the following sections I will provide specific criteria that can be used to delineate this field, and in Chapter 2 I will present a justification for proceeding in this manner. ${ }^{6}$ In its current configuration, the field of Canadian diversity is dominated by a single major player: the Canadian government. With all the means of modern coercion and postmodern coding at their disposal, legislators and bureaucrats have set out to bolster the reality of Canadian multiculturalism as fact and act, problem and solution, distopia and social ideal. The effects of this activity are a matter of current debate. Can tolerance be legislated? Is multiculturalism policy "working?" These are fair questions for philosophers, social scientists, and Canadians of all sorts, who have engaged them with much gusto. With regard to the question of multiculturalism policy "working" or not, one might say: of course it is, it is signification on a mass scale. A more important and interesting question would be to ask how it is working, what it is working to do. And 
we must not forget that the answers to these questions might be only accidentally related to any 'goals' or 'objectives' of the policy-makers, their constituents, and the philosophers and social scientists who claim to inform them.

As a first step in delineating the field of inquiry relevant here, it is necessary to say precisely what will be considered as part of a particularly Canadian discourse on diversity. For the purposes of this study, I take as being Canadian that discourse which emerges out of the British and French invasion of the northeastern portion of what is now known as North America, starting with the voyages of Cabot in 1497 and Cartier in 1534. This choice is not arbitrary for, as we will see, certain regularities can be observed in the attempts that have been made to impose a hegemonic striation upon this expanding geographic space, as well as in the selfidentifications and other-ascriptions of the bodies that have inhabited it. Obviously, the French colonizers of the seventeenth century did not think of themselves as Canadian, but they did send a "Governor of Canada" as early as 1540. Over the years the quality of being Canadian has been variously attributed to the Native inhabitants of New France, French Canadiens, British settlers only, British and French and people from western Europe but not Blacks or Asians, until, in the current situation, "everyone" who lives within the bounds of a certain territory is considered to be officially Canadian, or at least Canadianizable. Limiting the study to those geographical / semiotic / embodied spaces out of which what is currently known as Canada has emerged provides some sense of containment, a realm of structure within which the freedom of narrative might be exercised.

As mentioned in the introduction, I am aware that the semiotic and spatiotemporal complexity of this field, and of its relations to other fields, is vast. But here I will focus on only three subfields: colonial and contemporary government policies and practices; philosophical / social scientific analyses; and popular culture representations. As the prime agent of striation in the modern Eurocolonial domain, 
the state form is of crucial importance in analyzing the discourse on Canadian diversity as a technology of governance. Social science and philosophy are important because they have long been deployed to provide empirical data and moral justification for the activities of states. Finally, no state can exist without an articulation to one or more nations, that is, to groups of individuals who identify themselves as groups, and are willing to play the game of inclusion and exclusion, obedience and resistance. Within the history of Canadian diversity, activity in all of these fields has aided in the proliferation and differentiation of problematic human subjects, and each of them can be shown to observe similar rules in the construction of its objects, statements, and practices. In the following sections I will show in detail how these regularities are displayed, and how they work in relation to a broader field of Canadian diversity that structures and is structured by all of them. ${ }^{7}$

\section{Canadian Diversity in State Policy}

The contemporary form of the official discourse on Canadian diversity can be clearly discerned in policy documents produced by the Canadian government starting in the 1960's. Of particular importance is the Report of the Royal Commission on Bilingualism and Biculturalism (B\&B Report), which carried out its work from 1963 to 1967 . Almost immediately after the publication of the $B \& B$ Report and the passage of the Official Languages Act (1969), there was another flurry of activity in the world of policy-making, which focused on the management of what the Report called the "other ethnic groups." Multiculturalism: Building the Canadian Mosaic (MCBCM) was produced in June 1987, as a report of the Standing Committee on Multiculturalism. This document, which seems to have politicians and lobbyists as its intended audience, more clearly defined the goals and approaches of the policy of multiculturalism, and provided a basis for the Canadian Multiculturalism Act of 1988 . The other document of interest here is 
Multiculturalism ... being Canadian (MCBC), which describes itself as a "background paper" addressed to "all Canadians" (2). The purpose of this document was to 'spread the word' that multiculturalism was an official government policy and was being enshrined in a legal statute, and so it is best seen as a report of a policy rather than a policy report.

All three of these documents display similarities in the content they address and the ways in which this content is presented. Of central concern here is that all make reference to Canadian ethnocultural diversity as a public problem that needs a bureaucratic solution. The particulars of the construction of this problem in each of the documents reveal both a strong through-line associated with the problem of Canadian diversity, and the presence of certain definitions of the problem that appear to have been passed along from one generation of reports to the next. For example, all of the documents use the strategy of normalizing the problem of ethnocultural diversity by providing it with a natural/historical basis. This strategy can be seen at work in the table of contents of Volume IV of the B\&B Report, Chapter 1 of which is entitled "The Historical Background." The title presumably refers to the historical background of "Immigration", which immediately precedes it as the title of Part I. In a sub-section entitled "Early ethnic diversity", it is suggested that "the population of what is now Canada has always been ethnically diverse" (18). In order that the reader may know what an "ethnic diversity" is, succeeding subtitles make reference to the many "types of immigrants" that have come to Canada. These include "Early German Immigration", "The Dutch and Scandinavians", "Other Europeans", "Negro immigration" and "Asians on the West Coast", and so on. The arrival of these person-types is described in the B\&B Report with the help of a naturalistic metaphor of inundation that I call the Flood metaphor. On page 18 of Book IV, immigrants to Canada are depicted as part of a "flow" or "influx." On page 21, the metaphor is used more strongly, to liken the arrival of 
people to Canada to a "vast tide." Significantly, the flood metaphor is not used to describe the earlier arrival of British and French immigrants, balancing these naturally problematic Others with naturally unproblematic Selves.

The writers of $M C B C M$ drew heavily from the work of the $B \& B$ Report in their presentation of the problem of Canadian diversity, but also added some innovations of their own. The idea that Canadian diversity is a natural / historical object is deployed in Section 1.0, which is entitled "A Primordial Cultural Diversity." Here Canadian diversity is seen as originating "in the mists of our history" and as being "inevitably intensified" over time (13). This diversity "continued to grow" until it became a "massive flow." In the Executive Summary, Canadian diversity is placed on a firm geographical and economic foundation:

Regardless of where they [immigrants] came from ... depending on where they settled in Canada they developed differences and formed their own distinctive cultures in adapting to the particular geography and prevailing social and economic conditions of the different regions of the country where they made their homes (pages not numbered).

In the next paragraph, however, the economic and social connections are lost, leaving only the "natural" forces of "geography" as a cause:

Thus the French who settled in Acadia have evolved a distinctively different culture from those who settled in Quebec. Canada needs to come to terms with these many differences which will always prevail due to the very nature of its geography (emphasis added).

$M C B C$ also made good use of the historical approach, complete with the Aboriginal peoples connection, in its Chapter I "A Tradition of Diversity:"

Cultural and racial diversity have existed in Canada since long before the 16th century, when the first European settlers arrived to join the Aboriginal peoples in the northern half of a vast continent. Aboriginal society was multicultural as well as multilingual (3). 
All three of the documents suggest that Canadian diversity is a natural-historical phenomenon that has always existed, and will continue to exist in the future. The term multiculturalism is often used, in a descriptive mode, to denote this fact of diversity.

But Canadian multiculturalism is not just a fact - it is a problematic fact, a call to action. Each document, in its own way, suggests that the problem of Canadian diversity has reached crisis proportions, and that dire consequences will result if steps are not taken soon. In Book I of the B\&B Report, the Commission quotes its own preliminary report in order to reinforce the critical nature of the problem faced by the Canadian nation-state:

It was our conviction that ... "Canada was facing a national crisis, a time when decisions must be taken and developments must occur leading either to its break-up or to a new set of conditions for its future existence." This is still the situation (xvii).

Here the crisis is named as one involving an impending "break-up" of the Canadian nation-state. The writers of the report go on to assure their readers that they shall "examine various aspects of the crisis and shall propose some remedies" (xvii). These remedies involve changes in documents that will presumably lead to changes in institutions and practices. As can be seen from the table of contents of Book I of the report, such changes include "An Extension of Section 93 of the BNA Act", "A New Section 133 of the BNA Act", and a "Federal Official Languages Act." Thus the $B \& B$ Report, written for legislators and concentrating on the "British/French" problem, took on the task of suggesting how to modify certain words on certain pages so as to achieve the effect of preventing the Canadian nation-state from "breaking up."

Just as official bilingualism and biculturalism were the solutions proposed to prevent an imminent binary fission of the Canadian nation-state, multiculturalism 
appeared as the name for the bureaucratic work that sought to avoid a multiple fracture. From the "Executive Summary" of MCBC:

Since one third of the Canadian population is from minority ethnocultural communities, and this diversity continues to grow there is an obligation on the part of the Canadian Parliament and Government to respond.... Therefore, the Standing Committee ... submits various recommendations pertaining to a Multiculturalism Policy, Act, and Department.

Where the policy reports work on the fears of policy-makers by heightening the sense of crisis, the report of the policy gives the impression that the state has solved its problems, and now hopes that the people will do their part as well. The following passages from $M C B C$ display the complete cycle of problem creation, bureaucratic solution, and, finally, request for the adherence of all good citizens to the sorts of behaviour that have been legally codified and deemed appropriate. First, the problem:

Analysis of current population trends suggests that the country will have to rely on immigration, if it intends to maintain or increase its population. Moreover, most future immigrants are expected to come from non-European roots. This will mean that the size of Canada's racial minority communities, now roughly 1.9 million or seven percent of the population, will increase during the next several decades (25).

The state's role in providing a solution:

The government is confident that Canadians, their institutions and the country's existing communities will make the necessary adaptations in a spirit of generosity and understanding. Still, it recognizes that changes of any kind make some persons uneasy, so it accepts its responsibility to provide active leadership in fostering among all Citizens a heightened appreciation and understanding of multiculturalism (25).

And the citizen's role in conducting his or her life according to the words that the state has marked on pages: 
By maintaining Canadian citizenship values, by observing the provisions of an amended and strengthened Official Languages Act, and by following the principles and policies of multiculturalism, the government believes that Canada will always be a country where all groups can thrive and contribute.

Within the constraints imposed by the necessity of communicating effectively with their intended audiences, the policy reports and the report of the policy are commonly concerned with creating the problem of Canadian diversity and then solving this problem by way of rational-bureaucratic intervention. However, at the same time as the fact of multiculturalism (Canadian diversity) is seen as primordial, so is the act of multiculturalism as recognition and tolerance of diversity. If "aboriginal society was multicultural as well as multilingual", and if multiculturalism means both fact of problem and act of solution, does this not mean that the problem has also always been solved? Sometimes it seems that the policy documents would like this to be the case. $M C B C$ takes a step in this direction: "The Standing Committee believes that it is time to further the recognition of the multicultural reality of Canada by giving this reality its own legislative base" (18). This is obviously not much of a reality, if it can't stand unaided on its own two feet. Perhaps it is just too young? We can see the maturing of tautology into reality in the same document, a few paragraphs later:

[T]o say that multiculturalism is for all Canadians is to say that Canadians from the majority communities can also, and should also, participate in multiculturalism.... It recognizes that all Canadians have a cultural background which forms the essence of Canada's cultural diversity, that is multiculturalism (19).

In the report of the policy, the bumps in the language and thought process have been smoothed out, so that the text moves smoothly back and forth between fact and act to create a self-propelling system: "Having been a fact of Canadian life for centuries, multiculturalism has been official policy in Canada since 1971" (MCBC:3). 
Through a rhetorically compelling confusion between a non-existent history of harmonious coexistence and a package of toothless and mostly ignored legislation, the reader is led to believe that the Canadian government is on the high road to achieving unity within an ancient and problematic diversity. It is quite possible, of course, that this state-sponsored definition of the problem and its solution is merely a figment of the collective Canadian political-bureaucratic imagination. That is, one might want to know to what effect these moves in the general field of power have had in other subfields. It is to this question that we now must turn.

\section{Canadian Diversity in Popular Culture}

Since the stated goal of the policy documents is to further belief in and acceptance of the fact and act of multiculturalism, public opinion on these matters might give some indication of the degree of success of the Canadian government in gaining hegemony for its definition of the situation. Government-funded surveys and studies abound, which purport to show that multiculturalism is indeed "working." One of these was conducted in 1988, by Thompson Lightstone, and the findings were presented in a report by Optima Consultants. 2000 adults were asked a series of questions designed to elicit their "attitudes towards multiculturalism" (Optima 1988:1). 86\% of those surveyed "agreed" with the statement that "Canadians have come from just about every country in the world." $83 \%$ thought that "Canadians of all backgrounds have the freedom to maintain their cultures and languages," and 76\% felt that multiculturalism "makes Canada a better country to live in" (2). While its results might have been encouraging to bureaucrats in the Department of the Secretary of State, the survey suffers from a methodological problem: all of the questions are as positively slanted and highly leading as the examples given above.

This fact was not lost on the consultants from Optima, who suggested in the Conclusion that "it would be useful to repeat a more comprehensive range of 
questions to track public attitudes in a more definitive manner. These questions should cover both the 'hopeful' and 'apprehensive' aspects of public attitudes regarding multiculturalism" (12).

A similar study was conducted in 1991 by the Angus Reid Group. This study was much more extensive, involving both quantitative telephone survey research and focus groups. The questions in the telephone survey were not as obviously loaded to produce desired responses, although the section on "Credibility of Statements Concerning Multiculturalism" shows great similarity to the work done in 1988. The statement of highest credibility, weighing in at 95\%, was "You can be proud of being Canadian and proud of your ancestry at the same time." This was closely followed, at $94 \%$, by "Canadian citizenship is a two-way street ... it means everyone in Canada has both rights and responsibilities." The lowest rate of credibility achieved was still impressive, at 83\%, for "Multiculturalism is about equality for Canadians of all origins" (Angus Reid 1991:20).

Based on these findings, it would seem that all is well in the world of Canadian multiculturalism. However, a quick glance at what is going on in everyday life as constructed in the mass media shows that the situation is not so rosy. It seems that the confusion fostered by government policy has taken firm root - indeed, many see multiculturalism policy as part of the problem of Canadian diversity rather than a solution to it. A recent issue of the Vancouver Courier carried an article under the headline "Zulu woman condemns divisive, stigmatizing multiculturalism," with the subhead "Integration impossible" (November 27, 1996: 17). Here a "black South African" is quoted as saying that "multicultural idealism keeps Canada from being a united country." A month before this, the Globe and Mail ran the headline "Ottawa fails to sell multiculturalism: Report for Heritage Canada points to growing backlash against federal policy that aids ethnic groups" (October 18, 1996: A8). In both 
articles the theme is the same: allowing people to be different is dangerous, and threatens the existing social order.

In the Globe article, Hedy Fry, Secretary of State for Multiculturalism, took the blame for this failure of the act, admitting that "in the past we have not done a good enough job in getting the message out." Again, the curious necessity of "selling" a historical reality appears. Despite public acknowledgment of its failure, though, nothing much seems to be changing in the world of official multiculturalism. Witness the March 1996 edition of What's New in Multiculturalism, produced by Canadian Heritage and bearing the name of the Honourable Hedy Fry:

Since assuming the office of Secretary of State (Multiculturalism) ..., I have been meeting with Canadians from all walks of life and listening to their views on multiculturalism. Canada has been built by people of diverse backgrounds who together have created a unique country governed by respect for differences. As we face the challenges of a new millennium to improve on what we have built together, we will continue to be a role model to the world.

Nowhere in this press release is there any indication of what Canadians from all walks of life have been saying to the Secretary of State, but there is no doubt that her writers are well versed and able to pound the old platitudes without a twinge of mauvaise foi.

In addition to the occasional act of individual rebellion, there are also more organized and influential discourses of resistance to multiculturalism policy. These must be considered as they are a great aid in locating the (fluid) boundaries of the field, and because they bring out relevant speech that simply cannot be found anywhere else. It is important to note that these movements of resistance are in many cases themselves interventions in the field; that is to say, they accept the terms of the discourse, and are oriented primarily to admitting or excluding, improving or hampering, the trajectory of some given agent or group of agents. An example of an attempt to alter the configuration of the field would be the lobbying by 
organizations purporting to represent 'the other ethnic groups' that apparently helped to change the policy of 'bilingualism and biculturalism' into 'multiculturalism in a bilingual framework'. This sort of activity is ongoing, as various meta-groups jockey for position in the Canadian ethnocultural hierarchy, and it most certainly forms part of the field of Canadian diversity.

Examples of discourses that are more of a challenge to the existing economy can be found in the various sovereignty movements (Québécois, Metis, Native Nations, Western provinces) that seek to break the connection between the Canadian state, part of its current territory, and some of its nations. Again, while these discourses challenge the system of Canadian identity and diversity in its current form, they often seek to replace this system with a related one based on the same principle of ethnocultural capital. The working out of relations of power between those attached to Quebec's pur laine families and those who arrived before or after them shows this effect very well. These interventions will also be discussed, at least inasmuch as they appear within the federal field of power, which means, as much as they appear in the English language, in the context of British social, political, and legal institutions. I do not claim to comprehend, or even approach, the complexities of the various sovereignty movements within their own languages and contexts.

In summary, although there seems to be disagreement outside the halls of Ottawa on the value of the act of multiculturalism, there is almost complete acceptance of the fact of a problematic Canadian diversity. Thus, despite the handwringing and public confessions of failure, the Canadian government has made an important contribution to the tradition of diversity it so reveres, inasmuch as it has helped to perpetuate a belief that this diversity exists, poses a public problem, and requires an immediate and ongoing rational-bureaucratic response. 


\section{Canadian Diversity and the Academy}

As I have mentioned, social scientists have often been deployed by the state to produce demographic analyses, conduct surveys, and make recommendations regarding the problem of Canadian diversity, and have thereby made a great contribution to the hegemonic construction of what and how Canadian society is. Indeed, without sociology, there could be no sociological fact of diversity. As I will show in chapter 7, Canadian academics have also been involved at the highest levels of policy analysis and construction throughout the twentieth century. Starting with the work of Harold Innis and George Grant, professional social theorists and philosophers have engaged Canadian diversity as a social ideal, and entered into debates about what Canada should be. ${ }^{8}$ Thus the Canadian academic tradition, as sparse and barely self-supporting as it may be, has played an important role in the construction and management of the problem of Canadian diversity. However, to be included in the analytic field that is emerging in this chapter, it would be necessary for the academic discourse to display the same regularities as are found in state policy and popular culture. That is, we must see the fact of diversity being naturalized, historicized, and problematized, along with the assumption that state intervention can solve, and is already solving, this problem. In this section I will show that, despite its own lack of unity, these criteria are met by the dominant stream of the academic discourse on Canadian diversity.

The 'easiest' targets in the academic field are presented by texts that accept all of the criteria given above. This uncritical stance is most obvious in the case of scholars who are working directly for the state by helping to write policy documents and reports; but it also shows up in texts intended for consumption by other professionals. While these are rarely so naive or total in their reproduction of the discourse on Canadian diversity, most seem to accept several of the major axes, 
while taking issue with one or two of them. The aspect of the field that is most often left in place is the problematic natural-sociological fact of Canadian diversity. Oldtime demography is perhaps the greatest culprit here, with its focus on ethnicity as "an amalgam of objective factors ... that characterize the individual" (Hiller 1996:196; see also Halli et al 1990). In blithely setting out to quantify difference, demography has been a major contributor to the proliferation of ethnocultural subject-positions, as well as conjuring up further distinctions, such as those between visible and invisible minorities, single and multiple origin ethnicities, and so on. According to Elliot and Fleras, however, this tendency is on the wane: "[e]mphasis on objective features and cultural content has weakened in recent years, replaced to some extent by an interest in the subjective experiences and symbolic boundaries that define and encircle an ethnic group" (1992:134). While this may appear to be a step in the right direction, the subjectivist approach also leaves the system in place, as it does not bring into question the enabling constraints that make ethnocultural objectifications and subjectifications possible in the first place.

In evading this question, academic writing has contributed to the origin myth of Canadian multiculturalism as already-achieved ideal, through its construction of a history of diversity and tolerance marred only by occasional 'exceptional' events which, upon reflection, can be seen to have been rationally motivated and therefore 'understandable'. In his History of Canada, first published in 1887, William Kingsford referred to the expulsion of the Acadians as a "painful episode" that, "whatever its character, ... must be fully placed on the record" (502). In his account, the "ignorance" of the "primitive" and "illiterate" population of Acadia was played upon by unscrupulous Roman Catholic priests who opposed British interests. The Acadians also "precipitated the adoption of active measures against them" by sending an "insolently written" petition to the governor, who was then forced to do his duty without "an eye to sentiment" (505). Writing on the same topic in 1912, J. 
C. Hopkins also defended Governor Lawrence's actions on the ground of selfprotection from dangerous internal Others, and attempted to downplay its severity, offering up his own version of Governor Lawrence's "fairly reasonable explanation of his action" (Hopkins 1912:104). Hopkins provided the story with a happy ending, claiming that "as time passed on ... the Acadians were allowed to wander back to their old homes and to rebuild the altars of their sires, until, by the census of $1891 .$. there were more than a hundred thousand loyal, light-hearted and prosperous British subjects of Acadian descent" (104).

These texts are, of course, products of a previous era, and so might seem to be anachronistic. But the traditional version of Canadian history has also infiltrated much current academic work that is otherwise very critical and careful. Again, while few texts reproduce the official narrative entirely, many rationalize and displace the operation of the Canadian discourse on diversity by 'excusing' the Canadian state or the canonical peoples for their actions. Valerie Knowles, whose study of the history of Canadian immigration policy is thorough, concise, and very valuable in its attention to the repressed side of this history, also succumbs, on occasion, to the powerful desire to maintain at least a few fragments of the canon:
Shortly after the outbreak of the [First World] war the federal government took upon itself unprecedented authority with the passage of the draconian War Measures Act, designed to give Ottawa emergency powers to deal with real or apprehended war, invasion, or insurrection. Nowhere was the blanket character of the act revealed more clearly than in the provisions of clause 6 .... Before the war's end this provision was invoked in the internment of some 8,579 enemy aliens, a relatively small number however, when it is realized that over 80,000 such individuals had been registered. The insignificant number of enemy aliens incarcerated during the war in no way reflects, though, the depth of anti-alien sentiment felt by much of the Canadian population (Knowles 1997: 99 - 100, emphasis added).

Within the space of this passage, the internment of Enemy Aliens moves from a "draconian" act, to something involving a "relatively small," and then an 
"insignificant" number of people. The final return to a discussion of "anti-alien sentiment" sets up the Canadian state as somehow rising above the feelings of the masses, and casts its "limited" use of concentration camps as a sign of a high moral stance.

John Herd Thompson, setting out to discuss "Ethnic Minorities During Two World Wars," avoids falling for the justification for internment provided by the War Measures Act - "nightmares about enemy aliens were groundless," he declares (Thompson 1991:5) -- only to reproduce the economic emergency trope: "The Great Depression further exacerbated ethnic relations. Massive unemployment forced the Bennett government to shut off immigration in 1930 and it remained restricted thereafter (11, emphasis added)." Even without an emergency, fear and hatred can be justified for no particular reason except that the Other has been so impertinent as to exist. D.J. Hall, in a biography of Clifford Sifton, explains away Canadian nativism with a handy invocation of the flood metaphor, noting that "in a sense the hostility, though deeply regrettable, was understandable," due to "the rising tide of western settlement” (D.J. Hall 1981:262).

The most subtle work of the multiculturalist origin myth can be found in texts that follow Kingsford's History of Canada in attempting a public confession of Canada's less than glorious past. As an epitome of this genre, let us consider Cultures in Canada: Strength in Diversity (Buchignani \& Engel 1983), which appears to be aimed at high-school age children, and / or recent adult immigrants. ${ }^{9}$ This text very quickly sets up Canadian diversity as a problem that has already been solved:

As you study Cultures in Canada you will begin to understand how Canadians have met the challenge of living and working together. You will see examples of Canadians from varied backgrounds working side by side in harmony (4). 
But it is relatively sophisticated, in that it immediately attempts to cover for the covering it has put in place: "You will also find that we have not always respected the rights of our neighbours. Our history contains examples of our failure to live up to the ideal of treating one another as we ourselves would like to be treated" (4). Buchignani and Engel go on to note that the Beothuk "died out" (25), but provide a happy ending to the story by noting that "elsewhere in Canada, the experience of the Native people with the Europeans was different from that of the Beothuk. Instead of a culture becoming extinct, a new and distinct culture emerged" (26). In this way the text introduces the Métis, and even acknowledges their desire to be seen as a people, but glosses over their successive displacement, the theft of their land through the scrip system, and the necessity of sending in troops to make them into Canadians. Another happy ending is presented instead: "Riel asked that the Red River area be made a province, and that the Metis land, French language rights and religion be protected. Many of these terms were met. A new province, called Manitoba, was created in $1870^{\prime \prime}(49)$. Later, the text notes that the Acadians were transported by the British, and again a pleasant gloss is placed on the story in the final line of the section: "Although the British had uprooted them, the Acadians managed to preserve their way of life" (30). While it is significant that all of these stories are given happy endings, it is much more important to note that the text does not connect any of these events together, except to say that all of them are unfortunate exceptions to a general - yet historically unsupported - rule of harmonious coexistence. In this way, the representation of Canadian multiculturalism as an already-achieved ideal, which plays a crucial role in the state discourse, is reproduced by professional scholars in the name of public education.

The official history of Canadian diversity has of course been under fire for some time, beginning with a number of studies that were published in the late sixties and seventies: Ken Adachi's work on the Japanese, The Enemy That Never Was 
(1976), contributed to a movement for recognition of, and compensation for, their dispossession, internment, and displacement during the Second World War. Robin Winks' The Blacks in Canada (1971), Myrna Kostash's All of Baba's Children (1977), George Woodcock's The Doukhobors (1968) all contributed to the historical visibility of non-canonical peoples in Canada, and challenged the multicultural origin myth. Peter Ward made an explicit attempt, in White Canada Forever, to contest the "belief that the nation has evolved more or less harmoniously as a multicultural society" (Ward 1978:x). But this text focused on a single issue and group, i.e. antiOriental attitudes and policies that prevailed in British Columbia between the midnineteenth and mid-twentieth centuries. ${ }^{10}$ Other than the work of Donald Avery (1995; 1979) and Howard Palmer (1991; 1982a; 1973) there have been few attempts to draw out the commonalities and regularities both across the experiences of these groups and across time and no one has, to my knowledge, undertaken a genealogical study of the history of Canadian diversity in its broadest form.

In the realm of philosophy, much attention is being given to a theoreticalphilosophical discourse that accepts and reproduces Canadian multiculturalism as fact, act, and partially achieved ideal, and proposes that the ideal should be achieved more fully. The pre-eminent thinker here is Charles Taylor, whose essay Multiculturalism and the Politics of Recognition (1992) has gained influence as an expression of the current liberal-pluralist solution to the problem of Canadian diversity. Taylor's analysis is innovative in that he was one of the first post-war Canadian thinkers to place the problem of diversity in the larger context of the history of European social and political thought. It is typical, however, in that it accepts this diversity as natural and problematic. Taylor also does not escape the tendency to propose rational-bureaucratic solutions to the problems 'the others' create for 'us.' For example, he recommends as the best management strategy that 
"we not only let them [the others] survive, but acknowledge their worth" (Taylor 1992:64, italics in original). Invoking the trope of the already achieved ideal, Taylor feels that his updated version of "non-procedural" European liberalism, although not culturally neutral, is the best tool at hand for the job of managing diversity. Several other Canadian philosophers and theorists have joined in the debate, in an attempt to update modern liberal pluralism and enter it in the race for a solution to the postmodern problem of diversity, through an expansion of the realm of political rights, and an offer of the gifts of tolerance and recognition (e.g. Kymlicka 1995; Tully 1995).

The debate over the 'correct' form of rational-bureaucratic intervention that will solve the problem of diversity also appears in Canadian academic literature in the form of an "ideology critique" of multiculturalism as state policy. In this approach, multiculturalism as an achieved social ideal is confronted with an analysis of unequal relations of power between various racial and ethnic groups and found to be a "false" representation. The classic text here is The Vertical Mosaic, in which John Porter began to take apart Canadian multiculturalism before it had even been put together: "Segregation in social structure, to which the concept of the mosaic or multiculturalism must ultimately lead, can become an important aspect of social control by the charter group" (Porter 1965: 73-4). Karl Peter, writing after the official adoption of multiculturalism in a bilingual framework, called multiculturalism a "myth ... based on high-sounding liberal ideals, not on the empirical reality of Canadian society" (Peter 1981:65). Significantly, Peter ended this piece with a highsounding call to a "true multiculturalism" which would be "put into the service of revitalizing and reconstructing a Canada for the twenty-first century - a Canada that is built by all for the benefit of all" (66). Kogila Moodley very subtly and sharply attacked the "superficial nature" and "depoliticization" of Canadian multiculturalism policy (Moodley 1983:324), which "trivializes, neutralizes and absorbs social and 
economic inequalities" (326). She also made reference to a "true multiculturalism" which, in her case, "presupposes official multilingualism" (324). The 'multiculturalism as ideology' debate is still going strong into the nineties, with Laverne Lewycky trying to move beyond false consciousness and into a Mannheimian conception of ideology and utopia (Lewycky 1992). Inasmuch as Lewycky's approach does not posit a 'true' multiculturalism to hold up against its actually existing manifestation, it passes over from ideology critique and into the sort of relational discourse analysis that has been advocated by Jane Jenson (1993) and Greg Nielsen and John Jackson (1991). This is perhaps the most obvious point of departure for my own work, the thrust of which will be summarized and clarified in the final section of this chapter.

\section{Delimiting the Field}

Having made a cursory study of the field of Canadian diversity as it is displayed in state policy, popular culture, and academic discussions, it is now possible to claim that it observes the following regularities: (1) Canadian diversity is seen as a sociological, natural-historical, objective fact, resulting from innate differences in human types based on race, culture, ethnicity, geography, and climate;

(2) this diversity is thought to represent a public problem meriting state intervention, or rational-bureaucratic acts; (3) inasmuch as the fact of multiculturalism is conflated with the act, the problem of Canadian diversity is thought to contain its own solution, to be in the process of solving itself, achieving its own ideal. Where these three criteria are met in the context of a battle for articulation with disciplinary regimes associated with territories that have come, or might have come, under the sway of the Canadian state, I will hold that the speech / event / text in question can be included in the field of Canadian diversity. Stated most simply, my method will be to accept the claim, under proposition (1), that the 
tradition of Canadian diversity extends back to the arrival of the Europeans in North America, and use this to examine the assumption, given in proposition (3), that Canada has a tradition of liberal views, tolerance and respect for human rights that makes it specially suited to advance the cause of multiculturalist theory and practice through the acts enabled by proposition (2).

To provide a context for this approach, we must move towards the margins of the academic literature, arriving at those Canadian writers who have challenged the existence of multiculturalism as a sociological fact. Roman Onufrijchuk, in an insightful essay written in 1988, held that "[e]thnicity is already a construct -- an edifice. It is the product of history and discourse. This ethnicity emerges from the official discourse of Canadian federal multicultural policy” (Onufrijchuk 1988:3). Further steps have been taken by Evelyn I. Légaré, in a piece that adopts and maintains a relational distance to the discourse of Canadian multiculturalism, and shows how culture, like race before it, serves as a means of producing problematic Others:

Canadian discursive practices position culturally defined identities as exclusive categories. These categories are not defined using the rigid grammar of race or biology. Nevertheless, this discourse shares many similarities with nineteenth and early twentieth century constructions of race, in that 'culture' is invoked to signify ethnic identities as Other than the normatively defined Canadian identity (Légaré 1995:347).

Légare's work is also important in that it moves towards the deconstruction of the problematic character of Canadian diversity, placing the 'blame' not on the arrival of different person-types, but on Canadian nationalism. "Full inclusion within the nation demands 'sameness'," she notes. "Thus, difference is always problematic, even when it is recognized" (351).

The discourse on Canadian diversity has been most effectively challenged by Himani Bannerji. In her essay "On the Dark Side of the Nation: Politics of 
Multiculturalism and the 'State' of Canada" (1996), she suggests that multiculturalist ethnicities are "officially constructed identities" (105) arising out of individual and group acceptance of a "machinery of state that has us impaled against its spikes" (104). Rather than a happy history of harmonious coexistence, she sees a tradition in which "Europeans continue the same solidarity of ruling and repression, blended with competitive manipulations, that they practised from the dawn of their conquests and state formations" (107). With regard to the social ideal, she ironically notes that "some among us ['immigrants', 'ethnics', visible minorities'] even demanded the end of racist capitalism - and instead we got 'multiculturalism (105). Bannerji plainly rejects Canadian multiculturalism as natural-historical fact, rational-bureaucratic act, and social-philosophical ideal, choosing to locate its emergence in a history of difference "measured or constructed in terms of distance from civilizing European cultures” (117). In this identification of multiculturalism with a state Whiteness continuous with earlier colonial regimes, intersecting with race, class, and sex, she opens up the possibility of the genealogical deconstruction of the history of Canadian diversity.

While the basic approach Bannerji sketches in her article is close to what I set out to achieve in this dissertation, my focus will be both narrower and broader. Narrower, in the sense that I will focus on modes of differentiation based on humanity, civilization, race, culture, and ethnicity, and only peripherally engage the other axes. And broader, in that I would see race, sex, and class as categories that enable the rational-bureaucratic creation and multiplication of visible positions of Otherness that can be contrasted with an invisible Self. My theoretical approach, then, is ultimately an attempt to locate' the Canadian Self by careful attention to what it has perceived as its Other. This project is similar to that which has been undertaken by Tzvetan Todorov, in his attempt to delineate the problem of human diversity in French thought (1993), and in his case study of the application of the 
European discourse on diversity to the New World in The Conquest of America (1985). In the Conquest, Todorov says that his subject is "the discovery self makes of the other" (3). My task here is the same: to show how the Canadian Self first Discovered its Others, and continues to Discover them up to the present day.

\section{Terminological Issues}

In producing a revaluation of the problem of Canadian diversity, I will be obliged to make use of certain words and ideas that it would be better to leave behind. Among these I would include all terms that ascribe group membership to an individual based on some means of differentiation from other such groups, e.g. humanity, civilization, nation, ethnicity, culture, region, and so on. Some of these words have gained so much notoriety that approaching them brings on an intense struggle. Race is perhaps the best example, causing problems such as the following:

I have followed philosophical convention in italicizing reference to the concept of race and in placing between single quotation marks the word 'race' when mentioning (referring to) it (Goldberg 1993:ix).

In addition to creating a typographical nightmare, the problem is that there is no single "concept" (signified) to which the "word" (signifier) race "refers." Relationships between this signifier and signified, as in all semiosis, are worked out through perpetual negotiation, and thus it cannot be said that "the concept of race" exists at all, except as a fuzzy set within certain discursive constraints of space, time, and enunciation. A related difficulty is highlighted when one attempts to separate the 'unscientific'-everyday from the biological-expert resonances of the signifier 'race'. Here, the narrative of genetics is given a privilege that it does not deserve, and the ability of scientific intervention to multiply rather than delimit the resonance of a term is completely overlooked. Finally, if race is flagged more often than, say, 'civilization' or 'humanity', this is only because European ears are at present more 
sensitive to the atrocities of Nazism than to those of European colonialism. Acts carried out in the name of civilization and culture have caused at least as much death and despair as those deriving their motivation from race, and therefore deserve to be treated with equal caution.

How to handle these problems? The English language, in its everyday usage, provides a clue. Already, references to 'peoples' considered to be differentiable along various lines are capitalized, as in Canada ('nation', 'society', 'state'), Mongol ('race'), Jew ('religion', 'ethnicity', 'culture'), Maritime Provinces ('region' within 'Canada'). In current English usage, however, the bases for these differentiations are not marked, and this is what causes philosophers, semioticians, and social scientists so much grief. The simplest answer would be to flag not only the names of the particular groups that are supposed to provide the content of human diversity, but also the terms that enable their differentiation. The Canadian reader is likely to have only a little difficulty in coping with Race, as these days "everyone knows" that it is a construct. Reading Culture may not be quite so easy, though, and Region, with its attachments to 'solid ground' may be extremely difficult to set free from its discursive foundation. Also, once this process is set in motion, it is very difficult to stop. If culture is a construct, then so is language ... and so is every word ever uttered. Clearly it is not possible to mark each instance of the occurrence of a problematic or contested term in any text. And yet, certain words are so offensive -as a result of a spreading awareness of their lack of any concrete referent and of the power of words to consecrate horrible acts - that something must be done with them. Savage, a distinction based on a presumed lack of humanity and civilization, deserves the same sort of attention as French, which has been variously created out of presumed possession of superior civilizational, geographical, cultural, and racial attributes. I will capitalize Pagan and Barbarian for similar reasons, along with 
Discover, Conquer, Explore and their cognates and, in the context of Canadian immigration policy, Immigrant, Useful, Desirable, Visible, and Invisible.

This does not solve all of the problems, as it is very difficult to avoid constructs like 'the British' when referring to the speech and acts of certain individuals who apparently see themselves as representing or participating in a group with this name, and define this group in exclusion of certain individuals seen as comprising another, similarly delimited population category, such as 'the French'. In these cases, it would be best for the reader to keep in mind that 'the British' and 'the French' refer to spatio-temporally delimited discursive positions, and not to physical bodies, a transcendental Folk Spirit, or even to a 'gene pool'. Similar difficulties arise when using 'they' or 'them' to refer to such groups, as an 'us' is always implied. In these cases, I would hope that the reader will grant the possibility of taking a position that is Other to the system of Otherness in question, and treat 'them' and 'they' as 'mere' references to constructs that have already been marked as problematic. In the face of these difficulties, it seems that the best any writer can do is strike a balance; by avoiding a repetitive mass of highly qualified prose one leaves oneself open to being 'caught out. Similarly, references to the possibility of discerning human 'groups' or 'types', and any discussion of the 'problem', 'solution', 'recognition' or 'toleration' of the 'fact' of Canadian 'diversity', 'unity', or 'identity' are always to be treated with caution, as I will not continue to mark them, except when rhetorical considerations make it seem absolutely necessary to do so. Also in the interest of readability, all references to an unqualified 'multiculturalism' can be assumed to refer to 'Canadian multiculturalism', and where 'diversity' appears unqualified, please read 'ethnocultural diversity'.

Finally, I would like to point out that within the constraints of a racist, capitalist, patriarchal, anti-nature, mass state society, I do think that multiculturalism is preferable to fascism. I don't agree with the Canadian Reform 
Party, or certain American 'liberals', that questions of race, sex, and sexuality are, or should be, 'merely private' concerns; nor am I on the side of White Power, which would eradicate all forms of what it perceives as difference. I have no doubt that it is 'better' to be seductively integrated than coercively assimilated or exterminated, and I have great respect for those whose calling it is to risk their own destruction -emotional, financial, physical - in the name of ameliorating the often violent excesses of mass state societies. Obviously, wherever states exist, they must and will be resisted, tempered, revolutionized, and reformed. However, I also believe it is worth considering Canadian multiculturalism from a point of view that compares it not to the 'worst', but to the 'best' possible arrangements, which I take to be decentralized, non-hierarchical, participatory, non-exploitative, postcultural, postgender, appropriately scaled settlements that would be capable of defending themselves, both semiotically and physically, against the operation of state forms. Thus I shall leave it to others - and they are many - to fight and die for the question of who is or is not Canadian. My object is not to contribute to the discourse on Canadian unity and diversity, but to help dissipate it.

\section{Notes}

1 The term "dividing practices" comes from Michel Foucault, who has used it to characterize what he set out to study in the "second part" of his work, i.e. the period in which he investigated the differentiation of "the mad and the sane, the sick and the healthy, the criminals and the 'good boys"' (Foucault 1982:208).

2 I will use the term 'Self to refer to a group constructed as possessing propriety, normality, and validity, the existence of which does not pose a public problem of diversity. The term 'Other' will be used with reference to those groups constructed as 'not-Self, which are seen as improper and problematic by those who identify with the Self group, and against whom various actions may be taken to change or eliminate their presumed problematic qualities.

3 This translation comes from Spivak's Preface to of Grammatology (Derrida 1976:(xxv).

4 See (Young 1995:6-19) for an interesting and helpful discussion of modern European ideas regarding hybridity, fertility, and the differentiation of human types by way of species and race. 
5 Far be it from me, of course, to suggest that anyone who wants a hybrid identity articulated with a state form "should not" have it, or that it is "better' to be displaced, contained, or exterminated than it is to be incorporated as a hybrid or newly pure identity. I am simply pointing out that hybrid identities, like those that are supposed to be more 'stable', can be used in this way.

6 In my opinion the methodological justification should appear before the application of the method. It appears here only because it was a required revision in order to achieve a successful defense of the thesis. I apologize to the reader for any difficulties this might present, and strongly advise seeking out the work in published form, where the editorial constraints are less arbitrary.

7 See (Bourdieu 1977:72) for a discussion of the notion of the 'structured structuring structure'.

8 For an immanent critique of the contributions of Innis and Grant to the discourse of Canadian left-nationalism, and the implications of this discourse for the project of Canadian identity, see (Angus 1997).

9 Buchignani's involvement in this project strikes me as somewhat surprising, since in his other work he displays a critical distance from, and sometimes contempt for, the state policy discourse that is perpetuated by this text.

10 Curiously, Ward seems to be of the opinion that anti-Orientalism in B.C. stopped after the 1940's. 


\section{Chapter 2 \\ Theoretical-Methodological Concerns}

Genealogy, Complexity, and the State Form

Take the notion of tradition: it is intended to give a special temporal status to a group of phenomena that are both successive and identical (or at least similar); it makes it possible to rethink the dispersion of history in the form of the same; it allows a reduction of the difference proper to every beginning, in order to pursue without discontinuity the endless search for the origin....

- Michel Foucault, The Archaeology of Knowledge (1972:21).

As indicated in Chapter 1, my object in this study will be a discursive formation, or field, composed of several subfields: the discourse on Canadian diversity as observed in state policy, popular culture, and academic analyses. Before embarking on an analysis of the tradition of Canadian diversity, however, I would like to present a short discussion of Pierre Bourdieu's notion of "field" and some of his ideas on how to go about constructing an object of sociological study. Once one has an object, one might ask questions about how it has emerged, about lines of descent from previous forms to the present configuration. This is a genealogical question, to which the method adapted from Nietzsche by Michel Foucault is ideally suited. There are always problems with mix-and-match methodology, but there are also compelling reasons to make use of these approaches in a hybrid form. Bourdieu's work contains a theorization of social agency as an effect of the working out of relations of power within fields, but tends to focus on synchronic analysis. Foucault also noted how the power that creates subjects inevitably leads to resistance and counter-action, but concentrated on diachronic analysis of continuities and ruptures between successive modalities of a given discursive formation. United under the rubric of complexity 
theory, these approaches make it possible to consider both agents / subjects and fields / discursive formations as self-organizing systems that adapt to changes in their environment, and are continuously involved in relations of competition and cooperation at various levels of interaction. Thus, rather than simply asking how a given discursive formation "works," one can inquire into why it works so well -- how it has succeeded in perpetuating itself over time or, following Deleuze and Guattari, how it has managed to striate spaces, to make the world its own.

Bourdieu holds that the term 'field' does not name an analytic object, but rather is a "shorthand" for a mode of construction of analytic objects (Bourdieu 1992:228). A field has regularities and rules, which an investigator must identify; it is a "space," in both the physical and semiotic senses, the margins of which can be traced; and, finally, it is a space of play, of competition and co-operation involving objects, and over the boundaries of the field itself (97). Thus, rather than suggesting that the discourse on Canadian diversity is inscribed' into multiculturalism policy, and then 'written' onto Canadian bodies, I would hold that state policy, popular culture, and the bodies that are their subjects and objects, condition each other, in a complex, non-linear interaction that is never adequately captured in any theory of 'coding' or inscription'. "Those who dominate in a given field," Bourdieu writes, "are in a position to make it function to their advantage but they must always contend with the resistance, the claims, the contention, 'political' or otherwise, of the dominated" (Bourdieu, 1992:102). For Bourdieu, human history is precisely a history of struggles, and total institutions that attempt to eradicate all resistance can never achieve their goal.

Since I wish to investigate how the contemporary problem of Canadian diversity has emerged out of previous forms, it is necessary to establish a compatibility between the synchronic analysis of fields and the diachronic analysis of discursive formations, for which we must turn to the work of Michel Foucault. The 
most detailed exposition of Foucault's method can be found in The Archaeology of Knowledge (Foucault 1972). Here he presents his theory of discursive formations, as well as his thoughts on their study by way of "archaeology", a precursor to the genealogical method he developed later. In the section on "The Unities of Discourse", Foucault argues that belief in pre-existing forms of continuity - such as that claimed for the tradition of Canadian multiculturalism / diversity - must be suspended. The goal of the researcher is to seek out the rules which allow such claims of continuity to be made, to investigate what is unsaid and taken for granted by hegemonic narratives. Once this is done, Foucault suggests that "an entire field is set free. A vast field, but one that can be defined nonetheless" (26-27).

The term 'field' (champs) is used here in a way that suggests a similarity with Bourdieu's insistence that a field is an analytic construct created through certain methodological choices. Foucault goes on to provide some questions that can be asked of fields of discourse, or discursive formations, concerning the types of laws they obey, how they can be defined or limited, and what sorts of sub-groups they can give rise to. For instance, he suggests that a discursive formation can be discerned not in the objects to which it refers, but by the rules it uses to produce and transform objects. In the case of modern medicine, he also suggests that these rules are in evidence in groups of statements as well as in "perceptual descriptions, together with observations mediated through instruments, the procedures used in laboratory experiments, statistical calculations, epidemiological or demographic observations, institutional regulations, and therapeutic practice" (34). The rules are not hard and fast however; rather than determining action or existence, they "mark out the dispersion of the points of choice, and define prior to any option ... a field of strategic possibilities" (37). As with Bourdieu's notion of field, we are dealing with a system of rules that has conditioning effects on the possibilities of signification as well as material existence and action. Thus power, for Foucault, "includes strategies for self- 
development that both constrain -- through objectifying techniques - and enable through subjectifying techniques -- agency" (Lacombe 1996:334).

But Foucault makes a crucial distinction that helps to highlight a difference between his practice and Bourdieu's:

The question posed by language analysis of some discursive fact or other is always: according to what rules has a particular statement been made? The description of the events of discourse poses a quite different question: how is it that one particular statement appeared rather than another (27)?

Comparing Bourdieu's Distinction to Foucault's History of Sexuality, we see that where Bourdieu was interested in the study of the language of taste employed within various social strata in 1960's France, Foucault focused on the continuities and discontinuities displayed by the discourse of sexuality over a much longer period of time. For Foucault, discourse is language in motion, and it is discourse, not language, that is the object of genealogy. Genealogy also includes, or rather is, an ongoing critique of historical analysis: "It is necessary to master history so as to turn it to genealogical uses" (93). For Foucault, this involves three specific steps: genealogy is "parodic, directed against reality, and opposes the theme of history as reminiscence or recognition"; it is "dissociative, directed against identity, and opposes history given as continuity or representative of a tradition"; and finally, genealogy is "sacrificial, directed against truth, and opposes history as knowledge" (93). Where history is devoted to the serious business of getting at the truth, of providing a narrative that shows how 'we' got to 'here' from 'our' 'starting point', genealogy is a "concerted carnival" which acknowledges itself to be simultaneously using and abusing the historical tradition out of which it emerges.

Having itself emerged out of history, genealogy takes as its central focus the study of emergences in other discursive formations. Central to this effort is the distinction Foucault wishes to make between Nietzsche's use of several German 
words that have been translated into English as 'origin': Entstehung, Herkunft and Ursprung. By Foucault's reading, in "Nietzsche, Genealogy, History" (1985), Nietzsche began his study of morality as a quest for Ursprung, or ultimate, primal origin. Later, he came to understand the impossibility of this quest and began to favour, in The Genealogy of Morals, the construction of Herkunfthypothesen, fallible conjectures about descent rather than origin. The crucial difference between descent and origin is clarified in the notion of Entstehung, or emergence. 'Prior' to an origin, there is 'nothing' - the undifferentiated chaos of so many creation myths. Some 'external' force (a god's word, the voice of the people, a heroic act) must give order to this chaos and create a world. Prior to an emergence, however, there is 'something': again a chaos, but a chaos that, in and of itself, without help from any supreme being or 'external' force of any kind, gives rise to order, contains order within itself as an immanent and ongoing probability. ${ }^{1}$ Thus, behind every emergence there is a series of other emergences, trailing off into the distances of space and time, which leads Foucault to suggest (in a phrasing reminiscent of Lacan) that "the origin lies at a place of inevitable loss" (79).

Genealogy then, involves making hypotheses about continuity and discontinuity, about how symbolic orders and identities perpetually emerge from and submerge into the primal and ever-present chaos of being and becoming. In this sense, it can be considered as a 'complexity' theory of social historical formations and the subjectivities they enable. Some of the fundamental insights of complexity theory relevant to this discussion are: (i) complex systems are capable of displaying random, discontinuous behaviour; (ii) immanent in this "chaos" is the possibility of self-organization, i.e. the spontaneous development of structure / environment; (iii) agents work within environments, following simple rules and using strategies of both cooperation and competition to achieve certain goals; (iv) once a system has organized, it can tend to reproduce itself and the conditions of its own existence, thus 
modifying its environment and itself becoming an environment for the emergence of even greater complexity. Taken together, these insights amount to a revaluation of system and structure, chaos and order, that has led, in the physical sciences, to the possibility of approaching many phenomena that were previously seen as 'out of bounds' - e.g. in the analysis of turbulent flow, failure of materials, and population dynamics. (See Cambel 1993, Lewin 1992, Prigogine 1989, 1984 for introductory discussions of the use of complexity theories in the natural sciences.)

So far, critical social theory has made scant use of these new insights, although Lyotard devotes Section 13 of The Postmodern Condition to "Postmodern Science as the Search for Instabilities, " and Slavoj Zizek has toyed with an analogy between the Lacanian object (a) and the strange attractor ${ }^{2}$ (Zizek 1991:38). Anthony Wilden has grafted Gregory Bateson's notion of the dependent hierarchy onto Marxian ideology critique to come up with his own method of critical analysis of complex social phenomena (Wilden 1980;1981), and N. Katherine Hayles has taken the first steps in literary theory (Hayles 1990). Closer to my interests here, if we view societies as complex systems, as Zygmunt Bauman suggests in his essay "A Sociological Theory of Postmodernity" (Bauman 1992:187-204), both the "external" forces of "structure" or "discourse," and the "internal" forces of "agency" or "resistance," must be seen as formative of a field or landscape that is negotiated by an embodied, signifying subjectivity. This subjectivity is an ongoing memorymemorization-projection of many possible trajectories: an orbit that leads into one of the point attractors (stable states) of modern individual identity (worker, mother, musician, visible minority); or an endless, non-repeating path around some of the strange attractors (subject positions) that dominate the postmodern field of subjectivity (working Phillipina mother using music as a means of political activism). Social agents, as products and producers of discourse, are conditioned, but not 
determined, by fields of power, and they are able to 'use' hegemonic systems to achieve effects of resistance, reform, and -- occasionally - revolution.

To delve more deeply into genealogy as a complexity theory of history, it is necessary to investigate the revaluation of the analytic category of 'power' that occurs in Foucault's work. In "Two Lectures" (Foucault 1976) he says that "the course of study I have been following until now ... has been concerned with the how of power" (92, italics in original). Later, in "The Subject and Power" (1982) Foucault says that his purpose has not been to analyze power, but rather to "create a history of the different modes by which, in our culture, human beings are made subjects" (208). However, for Foucault the most important effect of power is precisely to create human subjects. Thus, in order to understand how discursive formations enable subjectivities, it is necessary to know how power operates. Foucault's polemic against "the repressive hypothesis" is of relevance here, especially as it is developed in the first volume of The History of Sexuality, where it is articulated to a positive statement of some of the central features of his own methodology. Here he argues that modern discursive formations have not been out to "repress" the objects and individuals that don't fit into their schemes, if by repression one means the attempt to cause an object to cease to exist or at least remain out of sight. Rather, Foucault says, the operation of modern power has caused a proliferation of non-canonical objects, subjects and practices, the purpose of which is to provide evidence and justification for a complementary proliferation of normalizing management and disciplinary techniques. With regard to the discourses of sexuality, Foucault claims that

the machinery of power that focused on this whole alien strain did not attempt to suppress it, but rather to give it an analytical, visible, and permanent reality... not the exclusion of these thousand aberrant sexualities, but the specification of each one of them (1978:44). 
For Foucault, the goal of modern discourses of power has been to create a series of management problems for which solutions must (obviously, urgently) be found. These solutions take the form of innumerable codifications of practice, daily regimens, compulsory exclusions and inclusions, and definitions of what is and isn't to be accepted as 'normal' behaviour. In the seventeenth and eighteenth centuries, Foucault says, a new form of power began to arise in Europe, which had to find ways to "gain access to the bodies of individuals, to their acts, attitudes, and modes of everyday behaviour" (1980:66-67). Thus, these various regimes have as their object, their focal point and final goal, the disciplining and conditioning of the human body itself. They provide the means by which structures of power come to permeate our bodies, allowing the operation of what Foucault has called "bio-power," which, I will argue, has evolved in the Canadian context as a specific form of governmentality or rational-bureaucratic domination. ${ }^{3}$

It is absolutely crucial to the operation of governmentality that its operations be carried out under the sign of the giving of gifts. "Power is the power to give gifts, and to choose when, how and how much to give and to whom. Power in an economy of excess is the power to manage the surplus" (Millot 1988:683). From a post-colonial perspective, Trinh T. Minh-ha has observed that "the compulsion to 'help' the needy whose needs one participates in creating and legislating ultimately leads to bombing people into the acceptance of gifts" (Minh-ha 1991:22). The most important gift one receives, of course, is the gift of being governed itself. To shed further light on what I mean in referring to gifts given by regimes of rational-bureaucratic domination, it may be useful to turn to the work of Gilles Deleuze and Felix Guattari, who have established a distinction between "state" and "nomadic" forms of social organization. In their Nomadology: The War Machine (1986), they include ancient empires, modern nation-states, and postmodern disciplinary regimes as state forms, and also cut 
across the boundary that traditionally separates the Western and Eastern traditions:

There is a unity of composition of all states, but states have neither the same development nor the same organization. In the Orient, the components are much more disconnected, disjointed, necessitating a great immutable Form to hold them together: "despotic formations" .... In the West, ... the interconnectedness of the components makes possible transformation of the state-form through revolution (Deleuze and Guattari 1986: 58 - 59).

One thing that all of these forms have in common is the task they set for themselves: to striate the space over which they reign. States hope to "capture flows of all kinds," to make order where there is chaos, convert outside into inside, or utilize the smooth outside spaces as a means of communication in the service of the inside (59). State forms build fences, gates, and fortresses, survey the land and develop systems of roads and highways. Whatever is outside and not part of the plan is to be brought in, reduced to the known, and thereby rendered manageable.

European civilization knows all too well what can happen when the war machine comes in off the steppes, sweeping away everything that matters: houses, walls, fields, property, lives, cultures. That China has fared no better is obvious in its monument to state insecurity, the Great Wall, the sedentary obstacle repeatedly breached and now a crumbling tourist attraction. State and nomadic forms are interdependent, each potentially giving rise to the other, each warding off the other, in an ongoing play of relations of power:

It is not in terms of independence, but of coexistence and competition in a perpetual field of interaction, that we must conceive of exteriority and interiority, war machines of metamorphosis and state apparatuses of identity, bands and kingdoms, megamachines and empires. The same field circumscribes its interiority in states, but describes its exteriority in what escapes states or stands against states (17). 
The desired - but never fully achieved - effect of operations in the field of power, then, is to striate or order physical, bodily, and semiotic spaces, and to protect these from external forces of disorder or smoothness. The bureaucratic and disciplinary apparatuses of the state have as their goal the striation of spaces, the provision of a designed context for everyday life. It is to these attempts that I am referring when I speak, throughout this text, of rational-bureaucratic action or domination.

While I will not be focusing directly on 'economic' issues, any analysis of modern and postmodern state forms cannot ignore the operation of capitalism, and so I will briefly sketch how I see these two machines working together. Deleuze and Guattari suggest that while capitalism needed the help of states in its battle with the towns, it has now become part of a worldwide system, helping to "realize" the capitalist "axiomatic" - "production for the market" (1987:436). In its international organization, capitalism makes use of states as apparatuses of capture, which then become part of a system that exceeds them. Most importantly for my task here is the work of the nation state, which has provided necessary linkages between embodied subjects in particular places -- the nation -- and a regime of rationalbureaucratic discipline bound up with a capitalist world system - the state. Again, as with the question of the relation of the subject to discourse, a position informed by complexity theory requires the examination of mutual relations of conditioning, with no clear lines of determination; yet, as seen in the recent triumphs of neoliberal globalization, it would appear that states need capital more than capital needs states, that the balance of power has shifted in favour of capital for the time being. In Canada, since the first days of New France and the Hudson's Bay Company, the imperatives of capital and rational-bureaucratic action have been so intimately related that they form an axis around which much of what is particularly Canadian revolves. 
A key point for my analysis is that attempts at state striation, in the name of capitalism, socialism, or whatever cause one can imagine, can never be fully successful, as there will always be someone, something, or somewhere left out, or emerging from within, that posits its own hegemony. That every boundary creates an interior which will be in tension with its outside is not a new idea. We can see it in: the Other (Lacan); the supplement (Derrida); the radical imaginary (Castoriadis); and in the more-than-life (Simmel), which challenges, restructures, and intrudes upon the instituted and causes it to have to work to maintain itself. This observation leads to a question: if all discourses of power multiply the subjects they attempt to objectively manipulate; if subjects always are capable of resistance; and if every boundary creates a sedentary interior which will be challenged by a nomadic exterior and vice versa, then the likelihood of a discourse of power ever actually solving $a$ problem it sets for itself is really quite low. What we would expect to see is a series of failed attempts, perpetually renewed efforts, which might have some efficacy, but will in the end only exacerbate the problems they are intended to solve, thereby creating a justification for further attempts at regulating everyday life.

Because rational-bureaucratic action can never solve the problems it sets for itself, it has a tendency to produce "disappointment regarding an alleged aim of becoming," and thus is susceptible to what Nietzsche has referred to as "fulfilled" nihilism, or "the recognition of the long waste of strength, the agony of the 'in vain', ... being ashamed in front of oneself, as if one had deceived oneself all too long" (1967b:12). The nihilism of the modern state form increases as its purview over territories and lives increases, until it reaches a point where "one has posited a totality, a systematization ... and a soul that longs to admire and revere has wallowed in the idea of some supreme form of domination and administration" (12). This theme was picked up by Heidegger, in The Question of Being:"Nihilism is fulfilled when it has seized all the component realities and appears everywhere, when nothing 
can assert itself any longer as an exception, in so far as it has become a normal

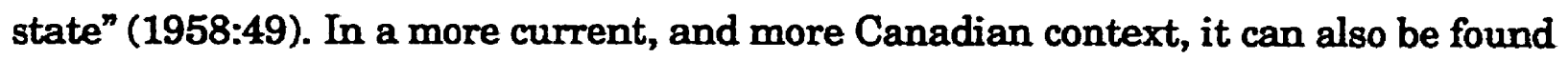
in the work of George Grant, who lamented the rise of the technique of rational mastery which wills "itself [as] the sole context within which all that is other to it must attempt to be present" (Grant 1969:40).

The state as a "normal state," as a "supreme form of domination and administration," has as its (impossible) limit the form of the apparatus, in which the state becomes "the New Idol," the bestower of all gifts, the entity to whom one turns for everything one thinks one wants or needs. This turning to the state is an effect of the operation of what Nietzsche called passive nihilism, as "decline and recession of the power of the spirit" (Nietzsche 1967b:17). The fulfillment of passive nihilism is not, however, its end. "With the fulfillment of nihilism only begins the final phase of nihilism" (Heidegger 1958:49, emphasis in original). During the final phase, the will which has brought the system to the zero point is no longer capable of producing effects, it cannot complete the project it has fulfilled. It distracts itself with "attempts to escape nihilism without revaluing our values so far: they produce the opposite, make the problem seem more acute" (Nietzsche 1967b:19). Problems are heaped upon solutions, the problems themselves are renamed, giving rise to more and different identities and positions, but preserving both the system itself and its inability to move on. So it goes for the problem of Canadian diversity which, as a particular instance of a self-organizing and evolving state form that has reached a stage of nihilistic fulfillment, the roots of which must be sought in the early years of what has become known as Western civilization.

\section{Notes}

1 For a comprehensive discussion of the revaluation of chaos, see $N$. Katherine Hayles (1990) Chaos Bound: Orderly Disorder in Contemporary Literature and Science.

2 In a phase space or, as Zizek seems to suggest, a semiotic field, there are locations that tend to be "occupied" by the system. These are called "point attractors": for 
example, a marble in a round bowl on the Earth will always end up sitting at the bottom. In semiotic terms, 'stable' everyday signs are point attractors, or points de capiton in Lacan's terminology. Strange attractors are infinite, non-repeating paths inhabiting a region of a phase space. Systems governed by strange attractors include most of those that linear science has failed to comprehend: weather, organic life (as information system), turbulent flow, human societies. Zizek can be read as suggesting that the quest for the lost object is an endless, non-repeating circulation around and about the object that will never achieve its goal.

3 In this dissertation the contributions of Michel Foucault and Pierre Bourdieu to the analysis of rational-bureaucratic domination figure most prominently, but there are of course other classical and contemporary theorists who have contributed to the development of this concept. Max Weber comes immediately to mind with his analysis of the characteristics of "bureaucratic authority" and "bureaucratic management" (Weber 1946:196). The notion of bureaucracy as a form of rational domination has been picked up by many others, notably by Jurgen Habermas in his Theory of Communicative Action (1989). After a close critique of Weber's theory of rationalization, Habermas offers his own theory of the colonization of the everyday "lifeworld" by a "system" of "purposive rational economic and administrative action" (2.154). An important cleavage in contemporary debates is that between the positions of Lyotard and Habermas, with the former offering little in the way of possibilities for what the latter refers to as the successful "completion" of the "project of modernity," i.e. for the possibility of a form of reason that could overcome rational-instrumental technique (c.f. Rorty 1985). 


\section{Chapter 3}

\section{European Antecedents to the Problem of Canadian Diversity}

Wherever and whenever in Europe or around the Mediterranean the collection and description of the manners and customs of mankind have assumed considerable volume, or when new and astonishing types of human behaviour have been called to the attention of Europeans, there and then the arresting problem of cultural diversity, or some one of its subordinate problems, has emerged - not only for the Hebrews, the Greeks, and the Romans, not only for the amateur anthropologists of the sixteenth and seventeenth centuries, but also for the moderns.

- Margaret Hodgen, Early Anthropology in the 16th and 17th Centuries (1964: 481).

\section{How Difference Changes, How it Remains the Same}

Staring into the mist. Straying into the mist. How far back must we go? Where and when did the problem of Canadian diversity emerge? The Canadian government claims that there is an origin to be found in a primordial diversity of preinvasion cultures, but I have suggested that whatever differences were 'present' prior to the arrival of the Europeans, they could not have signified within the Western discourse on diversity. If Canadian diversity did not exist until Europeans arrived to 'discover' it, the conditions of possibility for its emergence must be sought in the work of those who first took on the task of creating, defining, and ranking the European Self and its Others: Herodotus, Plato, Augustine, Linnaeus, and the travelers, scientists, and Colonizers who followed in their wake. Configured in a line of descent, these constitute what one might call the discourse of Western political anthropology, which establishes a hierarchical order among human beings of various types and uses this order to justify certain relations of power. I will argue that it is out of this discourse, and not out of 'the land' or 'the people' of the New World, that the problem of Canadian diversity has emerged. 
In recent years many layers of the sediment left by the operation of Western political anthropology have been excavated, and its effects in both the early European and current Eurocolonial contexts have been traced (Dickason 1984; Friedman 1981; Goldberg 1993; Hodgen 1964; Todorov 1993;1984). As the literature is large and growing exponentially, I do not propose to make an exhaustive study of it here. Instead, I will fashion a narrative that succinctly shows the nature and weight of the conceptual baggage that the European invaders brought with them to the New World in general, and Canada in particular. Between each turning point, I will discuss the nature of the categories and the hierarchical order established, the problems thereby created, and the solutions proposed. In constructing a genealogy of any discourse of power and mastery, it is necessary to listen to what those who represent the field of power have to say, what their plans are, and how they intend to implement them. But it is also important to see whether the plan ever was implemented, and if so what effects it had - they will perhaps have been different from what was 'intended', because of 'resistance' and 'interference' from agents both human and otherwise. In this sense, questions of 'fact' and intention' become relevant, not as indicators of 'what really happened', but as evidence of what certain people say happened. Sometimes, discrepancies between policy and practice, or between varying versions of history, are central to the evolution of the discursive formation. Thus, I will at times make comparisons between what was supposed to happen and what, according to some reporters, did happen, as represented within the relevant field, as an aid to understanding the character of certain shifts in the discourse. At no time, however, do I presume to possess or desire access to any internal state of mind' of any 'actor'.

Another issue that arises in the analysis of relations of power between Self and Other identities is the ways in which signs flow within fields of identity, and from one subfield to another. I will address these issues through the notions of 
assimilation and integration. In general, when I use these terms, I will be assuming the following definitions:

Group A assimilates person / group B, or $\mathrm{B}$ is assimilated by A:

$B$ takes on signs that mark A, and may or may not give up signs of its own particularity. In the limit case, $\mathrm{B}$ becomes $\mathrm{A}$, is indistinguishable from A. A will commonly be in a position of greater structural power (social, economic, political, cultural), and thus able to use both force and seduction to bring about the assimilation of $B$. B may attempt to resist the flow completely, or try to choose its form and / or content, in resistance to the will of $A$, in the case of coercion, or as a result of $B$ 's own will to integration, as a result of successful seduction.

A integrates B:

$\mathrm{B}$ is integrated by A:

A takes on signs of B's particularity. Generally, A is a relatively powerful group, or group of groups, so that while it acknowledges or reproduces some signs of the Other as Self signs, these are only the ones it chooses to acknowledge or reproduce. Again, B may attempt to resist the flow completely, or try to choose its form and / or content, in resistance to the will of $A$, in the case of coercion, or as a result of B's own will to integration, as a result of successful seduction.

The line between coercion and seduction, and therefore between 'resistance' and 'freedom', can only be drawn subjectively, in particular cases, and the drawing of such lines will give rise to statements of value, through which a given stance in relation to an attempt at / response to assimilation or integration would appear as 'rational', 'liberal', 'free', 'aesthetically (dis)pleasing', and so on. In one formation that I will analyze - Canadian multiculturalism as state policy, which is discussed in chapter 8 -- assimilation and integration have evolved specialized meanings, and a symbiotic relationship exists in which the terms have been richly 'confused' to achieve certain power-knowledge effects. Thus, when assimilation and / or integration are used within the discursive field being analyzed, their particular resonances within that field will be respected. 
Finally, I should point out that by invoking the notion of "relative power" above, I am trying to speak about the ability to achieve a hegemonic striation of spaces, bodies, and souls, as displayed in the articulation of a nation - race - culture with a state, polity, and territory, to form what appears within the Western tradition as a society. The net flow of signs enabled by a relatively successful striation tends to be from groups of greater structural power to those of lesser striative potential. I shall refer to this observation as the power law of sign flow. This is not to say that signs never flow in the opposite direction - they do -- and when this occurs, I would cite an instance of relatively successful resistance. However, close attention to the net flow of signs over time is of great use in unraveling the complex relations that exist between self-identified groups of people who wish to perpetuate their own style of life at the expense of other styles, and I will make use of it throughout the analysis.

\section{Herodotus, Father of Ethnography}

In her study of the historical construction of ethnocultural diversity in the tradition of anthropology, Margaret Hodgen ascribes priority to the work of the ancient Greek historian, Herodotus of Halicarnassus (Hodgen 1964:20-21). Here, she argues, the rules and categories according to which Western thinkers, missionaries, and colonizers would describe and judge Others were first laid down. Hodgen notes that Herodotus shows great rigour in choosing a set of categories of differentiation and applying them systematically to the peoples described in his Histories. "For each group," she suggests, "seven categories of cultural fact are given" (Hodgen 1964:23). These include the place of residence and climate, language, dress, food and the means of acquiring it, dwellings, modes of making or avoiding war, and prestige as judges. The final category might be better reckoned as involving internal and external political relations, and Hodgen leaves out the important category of religious rites, 
especially those involving burial, but it does seem that even in his briefest descriptions, Herodotus adhered quite closely to this formula.

Take, for example, his estimation of the Indians, whom he held to be the most Easterly of all Asians:

[T]hey will not take life in any form; they sow no seed, and have no houses and live on a vegetable diet.... All the Indian tribes I have mentioned copulate in the open like cattle; their skins are all of the same colour, much like the Ethiopians'. Their semen is not white like other peoples', but black like their own skins.... Their country is a long way from Persia towards the south, and they were never subject to Darius (III.98).

In this, and in dozens of other descriptions, we can discern what Herodotus considered to be the essential pieces of information that were needed in order to know the Other. To some extent, we can make out a particularly Greek set of interests, in the concern to trace lines of descent, to document abilities in war and statesmanship. But what is perhaps more interesting about Herodotus' categories is that they treat of what can be seen from a distance - a distance not only optical but cultural as well, the dis-stance of the one who observes but does not participate. And, even though he was full of disclaimers, he often relied upon hearsay for conclusions that would have required great intimacy, as in his report of the outrageous hue of Indian semen. Yet, even when Herodotus appears to be recounting what he himself has experienced, we are left with the impression that his subjects are objects, that he has observed them in passing with a collector's eye.

This tendency is most pronounced as the reader is brought further from the Greek World, into distant reaches of the East, West, and North. The Androphagi, or maneaters, are given only a few lines:

The Androphagi are the most savage of men, and have no notion of either law or justice. They are herdsmen without fixed dwellings; their 
dress is Scythian, their language peculiar to themselves, and they are the only people in this part of the world to eat human flesh (IV.105).

The Neurians are reduced even further. All we hear of them is that "it appears that these people practice magic; for there is a story current amongst the Scythians and the Greeks in Scythia that once a year every Neurian turns into a wolf for a few days, and then turns back into a man again" (IV.105). Herodotus quickly disclaims any belief in this tale, but tells it nonetheless. The same goes for the headless Blemmy, strap-foots, troglodytes, and the men who sleep for six months of the year. All of these peoples, real or imagined, are reduced to a single abhorrent characteristic, and thereby constitute a de facto category of their own: that of the monstrous semi-human being. At the margins of the known world, we find monsters of all sorts, mythic Amazons, amber, and gold. The terrible and the beautiful: indeed, anything but the everyday.

It is hard to argue that Herodotus was obsessed with tales of monsters, since the sections of the Histories devoted to them are quite few and far between. But, even when he was dealing with the relatively close and familiar, he was constantly operating in a mode of comparison between what he saw and heard and what he and his assumed readership - Greek men - would have considered normal. Implicitly and explicitly, he highlighted what he perceived as similarities and differences between the Greek way and all others. We can see this mode at work in the example cited above, where the members of the Indian tribe are said to avoid taking life in any form (unlike a Greek, who kills regularly for sport, riches, and glory); to sow no seed (unlike the Greek agriculturist); and to have no houses (unlike the Greek, who takes great pride in his oikos). In his attempts to spy the Other through the scope of the Self, Herodotus earned his place as the Father of Ethnography. But such comparisons cannot be achieved without a prior assumption, still with us in even the most postmodern of anthropological practices, which I will call the law of individual-group 
identification. This law lets the one stand for the many, and vice versa, and thereby allows the inquirer to know and describe that most useful of abstractions, 'the people'. Such an effect always begins at home, of course, for the first premise is that one's own people exists as a basis for comparison, that there is a set of practices and appearances that 'we' all share. Certainly it is tautologically true that, within human groups defined as such, some practices will be more common than others, more or less actively encouraged or discouraged, and it is this observation that gives rise to the notions of culture, race, society, and so on. Taken further, however, these premises are used to produce the always doubtful, and sometimes dangerous consequent that all who appear to be 'part' of some people will share certain very particular characteristics: rather like dog's heads or goat's feet, but less marvelous -or even positively valued - and therefore more difficult to detect in passing. ${ }^{1}$ Again, let us return to the Egyptians, "much the most learned of any nation of which I have had experience" (II.77). All of them? What of the slaves, prisoners, street hawkers, women stuck at home tending an infinity of dependent children and men? The Royal Scythians, according to Herodotus, "are the most warlike ... of their race" (IV.20), and the Issedonians, apart from eating their dead fathers, "appear to have a sound enough sense of the difference between right and wrong" (IV.27). This is a far cry from what was to come, of course, when individuals would be torn to pieces by dogs because of qualities supposed to be inherent in their people, but the modus operandi is the same.

The use of stereotypical, reductionist formulas to describe peoples and all individuals considered to be 'of those peoples was correlated in Herodotus, and in later formations of the European discourse on diversity, with a tendency to freeze these forms, to grant them a certain imperviousness to the ravages of time and change. Again, this is a regular feature of Herodotus' text that shows itself more clearly the further he ventures from home. The Egyptians at least had a history, 
though Herodotus didn't always agree with it. The more far-flung peoples, however, were granted their few attributes in perpetuity. A man-eater is a man-eater, always has been and always will be; Herodotus did not see cannibalism as a practice that might come and go, but as an essential characteristic.

While he saw each people as possessing an immutable nature, Herodotus was also very attentive to the existence of differences between peoples. One 'explanation' for the observed variance in human practice was provided by the influences of climate and geography, two powerful and unchanging forces that shaped the nature of the peoples in a given regime. Throughout the Histories, the land and its features figure prominently: "Not only is the Egyptian climate peculiar to that county, and the Nile different in its behaviour from other rivers elsewhere, but the Egyptians themselves in their manners and customs seem to have reversed the ordinary practices of mankind" (II.36). The Scythians, with their nomadic relation to a hostile land, have managed to preserve themselves better than anyone else, since none who try to conquer them can cope with either the environment or the people (IV.46). A theory of human nature based on geography, climate, and group membership fits in with the general plan of the Histories, inasmuch as the counter assumption, that the nature of a people is variable, would mean that Greeks could begin eating one another and forget the difference between right and wrong. The possibility of such drift had to be excluded from Herodotus' text, lest it tear open the fabric of Greek life that his narrative so subtly weaves.

The terms the Greeks used to define the sorts of difference they found in the non-Greek world are important, to illuminate their usage in context, and to give, in anticipation, some sense of the connotations their derivatives carry today. Ethnos appears to have had a broad usage, covering groups of beings of many sorts:

[W]e hear of ethnos etairon, a band of comrades, or ethnos laon, a host of men, in the lliad; of ethnos Achaion or Lukion, the tribe of Achaeans or 
Lycians, also in Homer, along with kluta ethnea nekron, glorious hosts of corpses / the dead, in the Odyssey; of ethnea melisson or ornithon, a swarm of bees or flock of birds, again in the liad; ethnos aneron or gunaikon, the race of men or women, in Pindar; and to Medikon ethnos, the Median people or nation, in Herodotus (Ostergard 1992:31).

Ethnos was also used in contrast to polis. Greeks lived in a polis, a city-state with an obvious physical centre and a particular set of institutions. Non-Greeks lived in various sorts of regional or village affiliations, and lacked Greek political institutions (Humphreys 1978:130-131). Those of an ethnos were commonly referred to by its name, or ethnikon, thus giving rise to the term ethnikos, commonly translated as 'heathen'. Genos was used by Herodotus to describe families or related groups within an ethnos, leading to the suggestion that "ethnos seems to be more suited to cultural than biological or kinship differences" (Ostergard 1992:32). In the ancient usage of ethnos and its variants, we can see the basis for later transformations into the use of ta ethne to describe all groups except Christians and Jews (A. Smith 1986:21), and the current situation in which 'ethnic' is used in everyday life to refer to any person or group other than those whom the speaker considers normal or dominant, and in Canadian multiculturalism policy discourse to refer to a people that does not, and should not, possess a polis (e.g. Kymlicka 1995:15).

Herodotan ethnography was a practical attempt to answer to the question: how are the Barbarians different from the Greeks? Based on the way he tried to answer this question, Herodotus can be placed within the greater Greek scheme of things, as a precursor to the development of the notion of the Great Chain of Being. In her book Centaurs and Amazons, Page duBois argues that, prior to Plato, the Greek mode of reasoning about Self and Other was by way of polarity and analogy. ${ }^{2}$ All Greeks were related in a network of likeness, set off in opposition to all Barbarians, who themselves were thought to share certain characteristics. To illustrate the analogy-polarity model, duBois uses the metaphor of a wheel. At its 
centre we find the network of Greek citizens -- human, civilized, rational, autonomous males - alike in their possession of these highly valued qualities. Radiating out from the Greek citizens were spokes of difference that defined an excluded periphery of animal, Barbarian, irrational and female types. All of these were related by their exclusion and by their lack of possession of the central qualities.

\section{Figure 3.1 - The Herodotan wheel of difference}
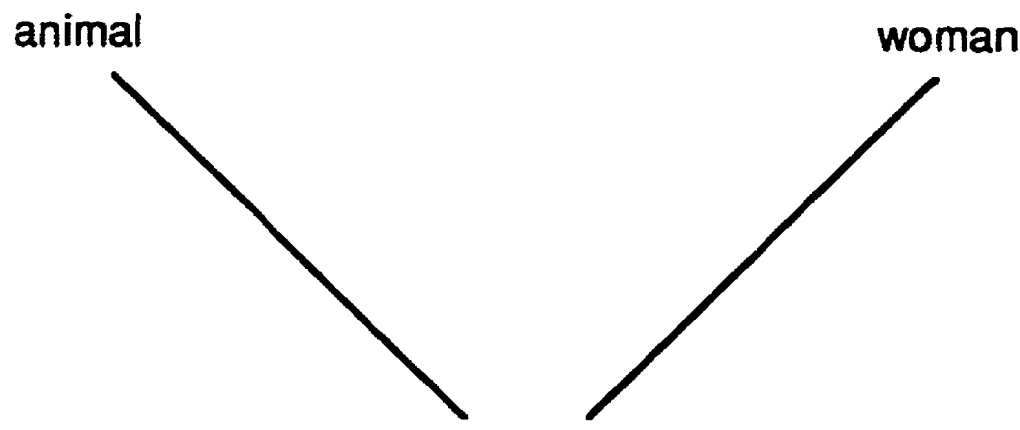

Greek citizen
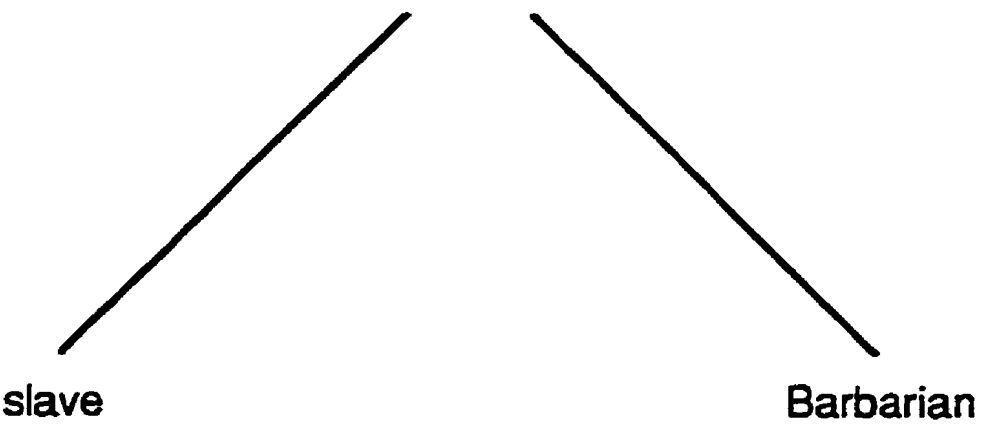

Greeks were those who possessed the good, and lacked the evil. Non-Greeks were their complement, so that one could write an equation of identity in which Greek is the negation of all that it excludes: Greek = not animal + not Barbarian + not woman + not slave-like. Of course, a positive equation could be written as well, following the traditional line of thought on nations and ethnicities as 'shared' agglomerations of positive attributes. ${ }^{3}$ But this approach tends to downplay very real and effective motivations and rationalizations for relations of power between the 
Self group and its Others; 'not sharing', i.e. being 'different' is a far less grievous sin than being a negation of all that 'we' stand for.

While the wheel metaphor is interesting and enlightening, it models only binary oppositions, and therefore does not fully capture the subtlety of the semantics of identity in Greek myth, which, as duBoìs has noted, contains many "fusions of oppositions" (105). What are we to make, for example, of the Centaur who, as both man and animal, undermines the firm opposition between these two terms? Or the Amazon, who confounds the male / female dichotomy in possessing a woman's body but a man's warlike temperament? A.J. Greimas' method of the "semiotic square" is a useful tool for analyzing systems of this sort, especially in the diagrammatic form given in Ronald Schleifer's A.J. Greimas and the Nature of Meaning (1987:25-33). Schleifer proposes a general representation of the square that can be rendered as follows:

Figure 3.2 - The semiotic square.

$\mathbf{S}$

positive term

negative term

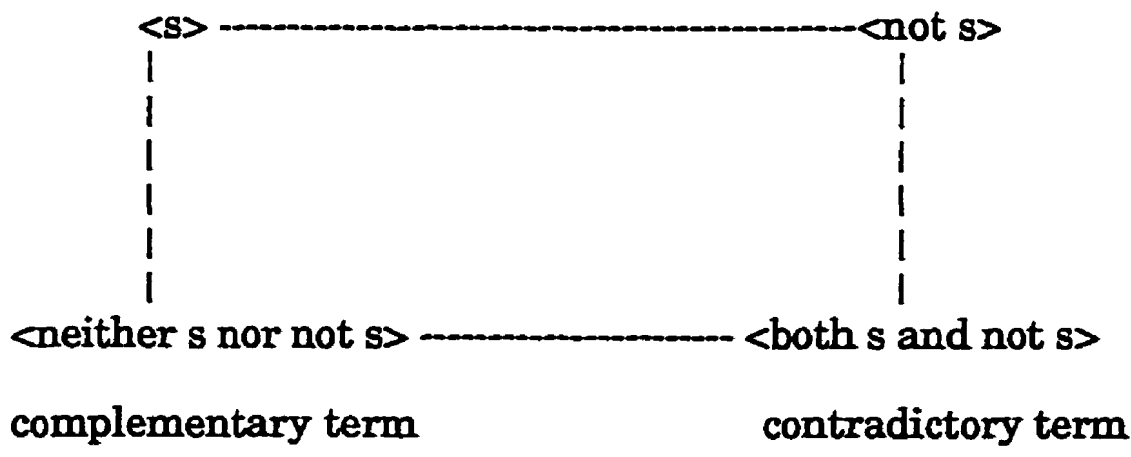

not S

The semiotic square is a formal method of exhausting the possibilities of signification inherent in a given concept or "semantic axis." $S$ above is a semantic axis, which 
sets up a binary opposition between two terms. Given a unit of meaning $<s>$, the square provides a means of generating terms that are contrary $\langle$ non s>, contradictory <both $s$ and non $s>$, and complementary $<$ either $s$ nor non $s>$ to $<s>$. The complementary term is of greatest interest, in that it admits of many possible interpretations. This term is inherently "synthetic", since it points to that which cannot be contained within the axis inscribed in the terms of the square, and may lead, in practice, to an overcoming of the binary opposition in question.

To generate particular squares, I use a method adapted from a "narratized" procedure that Schleifer attributes to Nancy Armstrong, which I present here along with an example that will help to clarify the process:

1) Choose a semantic axis $\langle S\rangle$, and think of the name of the dominant or hegemonic entity within it ( $\mathbf{S}=<$ gender in patriarchal societies $>, \mathrm{s}=$ $<\operatorname{man}>$ ).

2) Think of the name of that which lacks the qualities of, must not 'be', is the Other of $s$ (not $s=<$ woman $>$ ).

3) Think of the name of that which confuses the issue, which implies both the absence and presence of $s$ (both $s$ and not $s=<$ drag queen $>$, $<$ dyke $>$, which are not gendered identities).

4) Think of that which transcends the opposition between $s$ and not $s$ (neither $s$ nor not $s=$ individual in a degendered society of the future $>$ ).

In this all-too-familiar example, the contradictory term tends to undermine the static binary opposition that forms the basis for the square (see Butler 1990). The complementary term is difficult to imagine, or even name, since discursive practice has not yet made known its positive content. Yet it is always there, promising relief from, or at least a change in the form of, the system of binary opposition in question:

In actual practice ... it frequently turns out that we are able to articulate a given concept in only three of the four available positions; the final one, [the complementary term] remains a cipher or an enigma to the mind ... the missing term ... we may now identify as none other than the 'negation of a negation' familiar from dialectical philosophy. It 
is, indeed, because the negation of a negation is such a decisive leap ... that we so frequently come upon a system in the incomplete state (Fredric Jameson, cited in Schleifer 1987:29).

Extra subtlety and completeness can be added to duBois' analysis of the Herodotan wheel of difference if each of the spokes of the wheel is considered to be the semantic axis of a semiotic square, providing the full discursive resonance of each mode of opposition to the canonical Hellenistic identity, as follows:

Figure 3.3 - The Herodotan wheel of squares

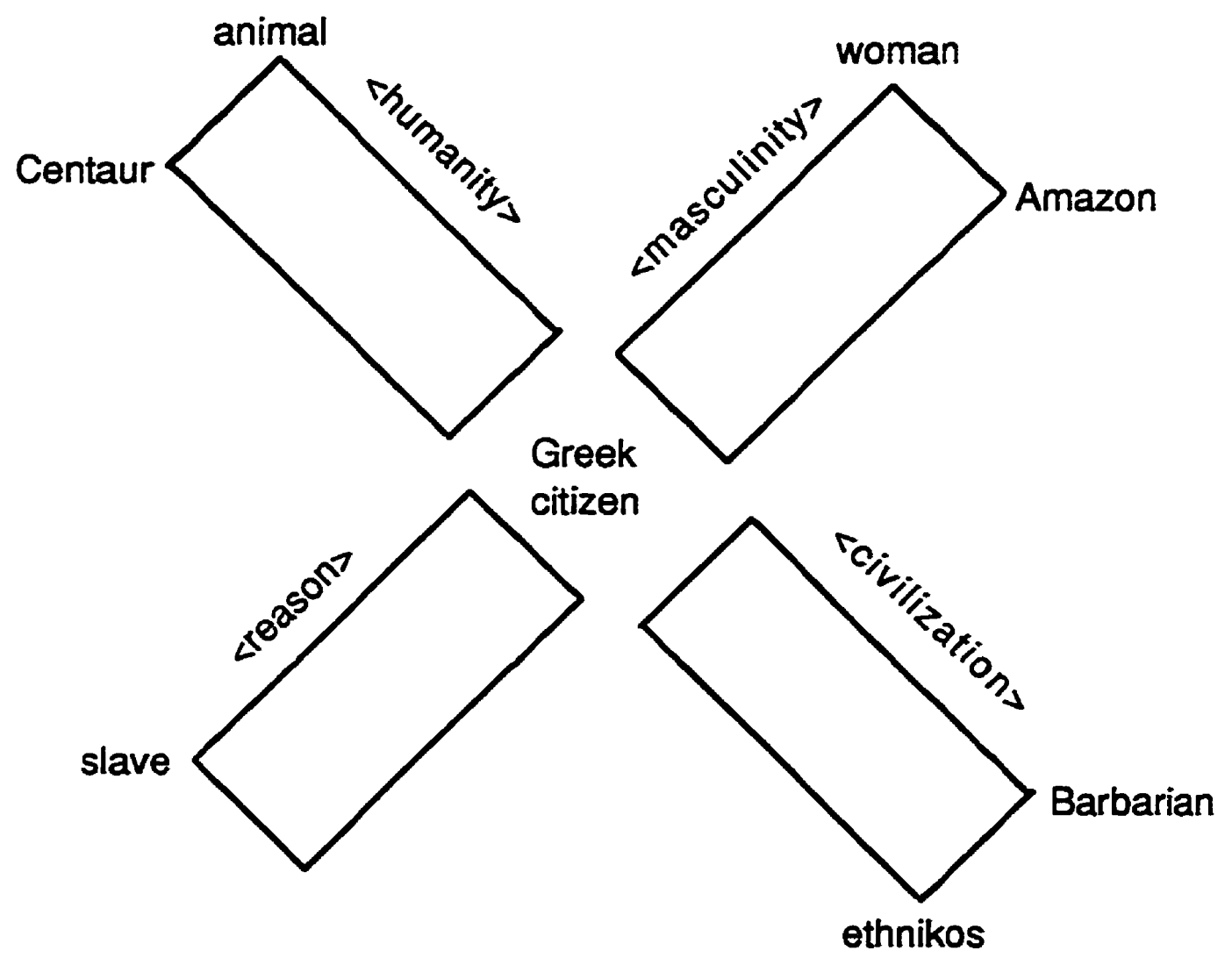

With this model, we can see some of the complexity inherent in human language, which goes far beyond a mere diacritics of meaning. A 'picture' of language in use, or discourse, emerges, which Jacques Lacan has referred to as a "chain" or "network" of signifiers (Lacan 1978:42-52). Any signifier, as a "quilting point" (point de capiton) 
could be placed in the middle of a wheel such as that pictured above, although some signifiers have more connections than others. Most importantly, some also have stronger connections to the field of power (the Big Other), and thus are more likely to produce effects that striate thoughts, bodies, and geographic spaces. The signifier 'Greek' must be seen as a particularly powerful striative force, signifying for over two millenia as $<$ Western civilization $>$ itself.

Returning to Herodotus, his method, as far as it is relevant to the European discourse on diversity, can be summarized as follows. A set of categories is constructed and used as a basis of evaluation and comparison of various peoples. These categories rely upon what can be seen from a distance, and provide information about what is supposed to be the 'nature' of a people, which is also presumed to be influenced by the land they occupy. In all cases, the Self people provides a basis for comparison, with signs of similarity to the Self usually counting as possession of a good, and signs of difference indicative of a lack or deficiency. The nature of a people is assumed to be displayed in all individuals who are of that people, so that to know one is to know all and vice versa. Finally, the further one gets from Self lands, the stranger the peoples one encounters, until at the edges of the world there are only marvels and monsters to which the normal categories of evaluation scarcely apply.

\section{Ancient Ionian Hellenism and the Destruction of the Inferior Other}

While he used the binary mode, Herodotus also explicitly referred to certain peoples as "the most barbarous," "the most knowledgeable" (outside of Greece), and so on, invoking a hierarchical comparison within the category of Barbarism. T.J. Haarhoff (1948:6-19) notes that the strong split between the Barbarian and the Greek arose with what he calls the "Ionian enlightenment" of the fifth and fourth centuries BC. In this discourse of identity and difference - which I will from now on 
refer to as 'ancient Ionian Hellenism' - one can observe hierarchical differentiation between terms, e.g. in placing all Greeks above Barbarians, as well as within a given term, as in the division of Greeks into various classes of males, followed by females and slaves. The hierarchization of the category of 'Greek' can be observed in Plato's description of his ideal polis:

While all of you in the city are brothers, we will say in our tale, yet God in fashioning those of you who are fitted to hold rule mingled gold in their generation, for which reason they are the most precious -- but in the helpers silver, and iron and brass in the farmers and other craftsmen (Republic 3.415a, cited in duBois 1991:133).

Significant in their absence from this discussion are the slaves, whose place in Plato's Republic is a matter of contention. ${ }^{4}$ I find compelling the position put forward by Page duBois, who suggests that "slavery's relationships of subordination and hierarchization" are archetypal to the differentiation of types at all levels in the Platonic scheme (1991:139). Unlike Plato, Aristotle made his position on the 'nature' of the slave quite clear. In the Politics, the slave was not even given the status of a degenerate human subject, but was classed as an object, a "tool," a "sort of living piece of property" (1253b23). Bracketing the question of whether certain philosophers thought their existence was 'justifiable' or not, the practice of slavery in Greek city-states and the existence of slavery as a political-philosophical category of inferior internal Other, clearly show that slaves were placed at the bottom of a hierarchical order of human types.

But the human categories were part of a larger order. A.O. Lovejoy, in The Great Chain of Being, suggests that Plato bequeathed to Western thought a "principle of plenitude," which he defines as

not only the thesis that the universe is a plenum formarum in which the range of conceivable diversity of kinds of living things is exhaustively exemplified, but also any other deductions from the 
assumption that no genuine potentiality of being can remain unfulfilled, that the extent and abundance of the creation must be as great as the possibility of existence and commensurate with the productive capacity of a 'perfect' and inexhaustible Source, and that the world is the better, the more things it contains (Lovejoy 1936:52).

To this notion Aristotle added a principle of "continuity," which is derivable from the principle of plenitude, and holds that there cannot be any 'gaps' between the beings of creation; if there were, then something possible would not have been realized, and the creator would have shown himself to be less than perfectly "good" (Lovejoy 1936:58). Thus evolved a conception of the universe as "composed of ... an infinite number of links ranging in hierarchical order from the meagerest kind of existents ... through every possible grade up to the ens perfectissum" (59).

Thinking again of the semiotic square of identity within ancient Ionian Hellenism, and continuing the quilt metaphor for semiosis, we can think of multileveled buttons, connected in a linear order by way of "sewing them through," the first sewn being highest, the last lowest, on the chain, and preserving within each term the hierarchy that exists within it. First the gods, in their order, followed by men, in theirs, and so on down the line. Thus, if the semantic axis is specified broadly enough, it is possible to collapse the spokes of the wheel into a single square, place the hierarchies inside their appropriate terms, and note that an implicit hierarchy exists with the occupants of the positive term highest, and those of the negative term lower down. In one sense, the occupants of the contradictory position are lowest on the hierarchy, as they lack what is required for identity; but they can be seen as excluded from the hierarchy for the same reason. In practice, one finds both situations, with absorption of the contradictory term proceeding by way of a progressive inclusion within the hierarchy, accompanied by a shift in the semantic axis. 
Figure 3.4 - The hierarchized square of ancient Ionian Hellenism

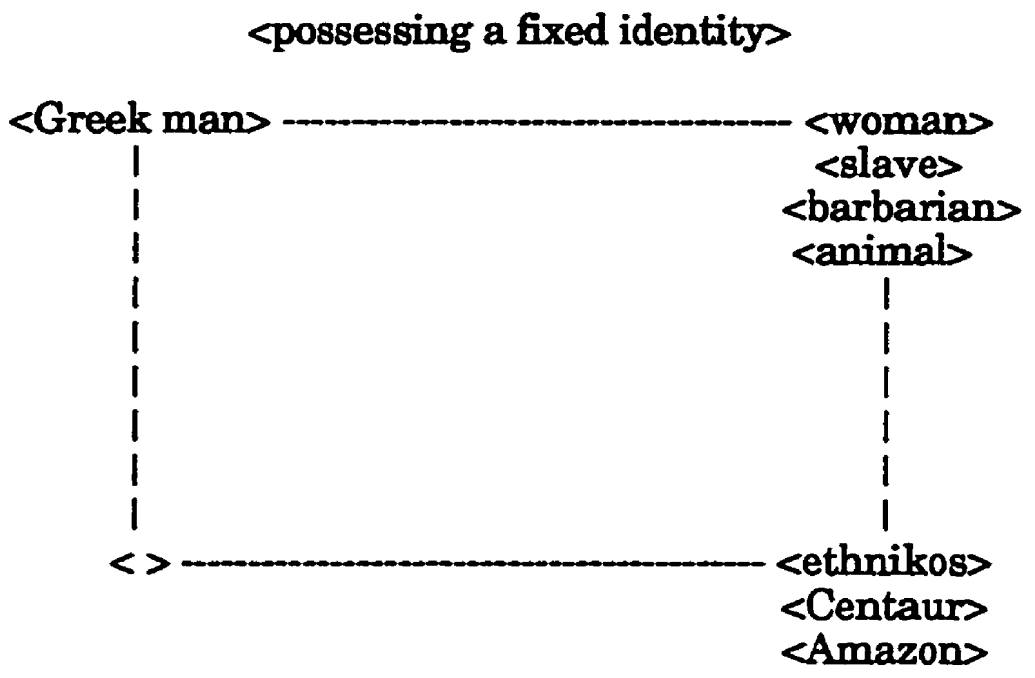

$<$ not possessing a fixed identity $>$

This is the model I will use in examining the evolution of Canadian identity, as it is the most concise and compact way to signify all of the models that co-exist, i.e. the line (binary opposition), the square (contradiction and complementarity), the wheel (analogy within opposition), and the ladder (hierarchy). This approach to the object of analysis might be likened to that taken by quantum physics in 'apprehending' objects that are sometimes considered as waves, sometimes as particles. That is, I don't feel that using a contradictory model is 'bad' analytic practice, but quite appropriate to a contradictory object.

I should also point out that in presenting material from the texts of Plato and Aristotle, I make no claim to be offering a definitive or final 'philosophical' reading, nor do I claim to be 'doing philosophy' at all. My aim, on the contrary, is to simply indicate how these texts might be seen as contributing to the European discourse on diversity, by pointing out how they construct and manage problematic human difference. Emma Dench has argued that "Herodotus makes panhellenic sentiments come to the fore against the background of the Persian wars," and that the idea of 
Greek supremacy gained momentum after that (1995:50). Following Lovejoy's (1936) reading of the relation between Plato and Aristotle on the hierarchical order of beings, Page duBois argues that a "new philosophical discourse" emerged in the fourth century BC." This discourse was "centred on questions of hierarchy, of mind over body, man over woman, "human" over foreigner, over slave.... The terms in which Plato articulated his problematic have defined Western philosophical discourse ever since" (1991:152). My reading is in line with this body of scholarship.

Such is the problem of diversity in ancient Ionian Hellenism; but what of its solutions? One important response to the problem of diversity was to avoid trying to solve it at all. Ignorance, in the sense of an active, willful desire not to know, was paramount, and helped to maintain its complement, xenophobia. This mode can be seen clearly in Herodotus, whose account of the Persians, while very detailed, contains enough spurious claims to make some commentators doubt whether he had any first-hand knowledge of his subjects at all (Georges 1994:51-58). Greek ignorance can also be seen in poetry, drama, and comedy, where Barbarian stereotypes were used extensively to both define the Greek Self and keep the nonGreek Others at an absurd, mocking distance (E. Hall 1989; Georges 1994; Long 1985)

When non-Greek others absolutely had to be recognized, they were sometimes dealt with by way of tactics resembling present-day assimilation or integration (Dench 1995:45-6). But the dominant active response was to attempt their elimination through destruction in battle or enslavement. In myth, the Centaurs and Amazons served as archetypal Others who were defeated and destroyed by Greek heroes (c.f. duBois 1991:49-77). In practice, the Greeks were constantly at war, both with each other and with non-Greeks. But there was an important distinction to be made between these two kinds of conflict. Plato has Socrates put it as follows: 
[W] hen Greek fights barbarian or barbarian Greek we shall say they are at war, and are natural enemies...; but when Greek fights Greek we shall say that they are naturally friends, but that Greece is torn by faction, and that the quarrel should be called 'civil strife' (Republic V.470).

Socrates goes on to expect that "brave and civilized" Greeks will "love their fellow Greeks, and think of Greece as their own land, in whose common religion they share." In victory, therefore, Greeks will not burn the land of Greeks, but only take a year's crop. Nor will they enslave the losers, the object of a fight being "to correct a friend rather than to enslave and destroy an enemy" (V.471). Thus Aristotle: "...[A]s the poets say, it is proper Greeks should rule non-Greeks, the implication being that nonGreek and slave are by nature identical" (Politics 1252a34). These statements indicate that, at the level of political discourse, there was a strong tendency to advocate the enslavement and destruction of problematic Others rather than their assimilation or integration.

Within ancient Ionian Hellenism, then, the methods of Herodotan ethnography were used to mark out the Greek Self from a range of Others. The notion of the Great Chain of Being placed these identities in a hierarchy, and political philosophy justified the ignorance and destruction of inferior beings by their superiors. As I will show, the idea of a ladder or chain of differentiated human types has persisted in Western thought up to the present day, and thus constitutes the most important contribution of ancient Ionian Hellenism to the Western discourse on diversity. The notion was passed down to through the middle ages to the late eighteenth century, where "most educated men were to accept without question ... the conception of the universe as a 'Great Chain of Being" (Lovejoy 1936:59). The following sections will show how Roman, medieval, and Renaissance thought drew upon Ionian Hellenism, creatively reproducing its categories and contents and ensuring the continuity of the Great Chain. 


\section{Incorporation of the Other in Roman Imperialism}

To the Greeks, the Romans were one among many Barbarian peoples; later, as they rose in influence, the Romans responded to this insult by adapting the Greek mode of Self / Other distinction, setting themselves up as Greeks and their Others as Barbarians. To the categories and contents of human diversity, the Romans brought little innovation. Pliny the Elder was one of the first miners of the ancient Greek vein, epitomizing and shuffling the words of Herodotus and his fellow Hellenes with a keen eye for tales of the monstrous and the wonderful. In all, he claimed to have consulted more than two thousand books and over one hundred authors in writing his Natural History, published in approximately $77 \mathrm{AD}$ (Preface, 17). The Great Chain of Being was taken over by neo-Platonism, and by this route passed from Greek to Roman and Christian thought (Lovejoy 1936:61 ff.). According to Plotinus, beneath God were the Celestials (daimones), and below them human beings, all of these three still partaking of the good. By becoming "evil and inferior" the soul produced "the animal nature" (Enneads VI.7.7), and proceeded on down to the vegetable and the mineral. Also important for later Western thought was the continuance of the idea that inequality and diversity were natural features of a divine order: "The question is not whether a thing is inferior to something else but whether in its own Kind it suffices to its own part; universal equality there cannot be ... the inequality is inevitable by the nature of things" (Enneads III.3.3).

In the area of responses and solutions to the problem of diversity, Roman Imperialism was much more creative. As a strategy of efficient management in the context of rapid expansion, violent invasion followed by toleration, assimilation and integration was favoured:

You, Roman, remember to govern

The peoples with power (these arts shall be yours), to establish 
The practice of peace, spare the conquered, and beat down the haughty (Virgil, Aeneid, 1962:6.860-863)

The case of the pacification of Britain, as related in Tacitus' Agricola (1954, circa $100 \mathrm{AD}$ ), provides a detailed account of developed Roman thought and action in such matters. The model Conqueror Agricola, when he comes on stage, alternates between the two methods of brute force and seduction. After several chapters of successful military exploits, he has succeeded in instilling fear into the many tribes, who have submitted to him. Now begins the real work of empire. The details are varied and interesting, and the conclusion so forceful, that I quote this section at length:

The following winter [after the campaigns] was spent on schemes of social betterment. Agricola had to deal with people living in isolation and ignorance, and therefore prone to fight; and his object was to accustom them to a life of peace and quiet by the provision of amenities. He therefore gave private encouragement and official assistance to the building of temples, public squares, and good houses.... And so the population was gradually led into the demoralizing temptations of arcades, baths, and sumptuous banquets. The unsuspecting Britons spoke of such novelties as 'civilization', when in fact they were only a feature of their enslavement (21).

Even local kings could be put to good use. Aulus Plautius, the first governor of Britain, knew what to do:

Certain domains were presented to King Cogidmnus, who maintained his unswerving loyalty right down to our own times - an example of the long-established Roman custom of employing even kings to make others slaves (14).

Within the discourse of Roman imperialism, unlike that of ancient Hellenism, Others, especially the upper strata, were actively encouraged to take on signs of Romanness, and it was even thought that these Others could, in time, become Roman. The process of assimilation used to achieve the pacification and 
enslavement of Others was, by the time of the Conquest of Britain, quite well developed and codified, so that it could form a central theme in what is obviously an idealized 'great man' narrative.

While assimilation was a vital component of its practice, it must be remembered that imperial Rome was willing to take on at least some signs of the external Others it encountered, as can be seen most obviously and famously in the polytheistic structure of Roman religion. As long as a sacrifice could be made to them, a Conquered people's gods could be set up alongside the ancient Roman deities:

We do not conceive of the gods as different among different peoples, nor as barbarian and Greek, nor as southern and northern; but just as sun and moon and sky and earth and sea are common to all men, but have different names among different peoples, so for that one Reason ... different honours and names have come into being among different peoples according to their customs (Plutarch, On Isis and Osiris 67.377, cited in Whittaker 1984:268).

Of course, not all gods were created equal, and there were fads and shifting hierarchies amongst those installed in the pantheon, with the Greek gods and those acquired in the early days of Roman expansion providing a sort of elite cadre (Wardman 1982:3). But the Romans were quite willing to extend their hegemony, and swell their pride, by taking on gods with the same glee as they took on new territories. With the world composed of an endless diversity of peoples, one could count on an equally endless supply of gods. The system was inherently open and unfinished, since it was "always possible for Rome to come into contact with the new gods of other societies who should be won over, or who may suit a Roman need" (3). Yet, through all of this change, the founding gods remained in place, rendering the system "both conservative and acquisitive" (3).

Certain others, however, were not extended the gifts of Roman tolerance - the case of the Jews comes to mind here. Philostratus was disgusted by their "unsocial existence," and felt that they had "nothing in common with other men, either food, or 
libations, or prayers, or sacrifices." This 'failure' to assimilate to Roman practices left Philostratus feeling that the Jews were "more remote in these respects from us than Susa or Bactria, and more alien than the Indians" (Vita Apoll. V.33, cited in L.A. Thompson 1989:128-9). Continued Jewish resistance culminated in the revolt of 66-70 $\mathrm{AD}$, and the destruction of Jerusalem. Along with the Jews, the early Christians soon became official internal Others, and were blamed for any misfortune that befell the empire. Thus, when Rome burned in $64 \mathrm{AD}$, "Nero fastened the guilt and inflicted the most exquisite tortures on a class hated for their abominations, called Christians by the populace.... Covered with the skins of beasts, they were torn by dogs and perished, or were nailed to crosses, or were doomed to the flames" (Tacitus, cited in Green 1996:16). Similar persecutions were carried out from time to time, until Valerian's edict of 258 that exposed all who were unwilling to accept Paganism to death (Green 1996:17-20). Certain forms of difference inside the empire were neither tolerated nor adopted, but violently repressed, by both physical and legal means.

Based on this cursory but, I hope, relatively uncontentious summary of the imperial Roman discourse on diversity, and again bracketing much particularity that can be constructed by way of historical and archaeological methods, the discourse of imperial Rome will be seen within my text as the epitome, within the Western tradition, of the strategy of incorporation of tamed Otherness. This could be done by way of both assimilation and integration, with limited tolerance granted as long as the Others being tolerated did not appear to be successfully resisting state striation by giving rise to, or perpetuating, local forms of organization. In cases where assimilation and / or integration did not seem to be proceeding as desired, violent repression by rational-legal methods and physical extermination were brought to bear upon the problematic population. 


\section{Early Christianity -- The Missionary Urge}

Through his prodigious effort at collecting facts, Pliny ensured that the lore of the Greeks was passed on, by way of Mela (De situ orbis) in the first century AD and Solinus (De mirabilibus mundi) in the third. According to Hodgen, Herodotus had described about fifty different peoples. "Five to eight hundred years later, Pliny, Solinus, and Mela referred to thirty-four of the same peoples, and in terms that are either identical with or very similar to those used by the Greek historian. Though forgotten in name, the author of the Histories was honoured in imitation" (Hodgen 1964:44). Along with Herodotus' monsters, late Roman and medieval Europe also inherited, and improved upon, Plato and Aristotle's hierarchy of being. Starting with St. Augustine a powerful new interlocutor in the European discourse on diversity was emerging - Christianity. In The City of God, Augustine devoted a very influential section to the question of whether the monstrous races spoken of by the Ancients were human or animal. As to the existence of such peoples, he was incredulous, but not entirely so; since there were monstrous individuals, why not monstrous races? At any rate, his answer to the question of the humanity of any 'real' monsters was guided by three principles from Christian theology: first, that whatever beings God has created have their purpose and place, and it is not for mortals to challenge the taste of the deity; second, that any rational, mortal being is human, regardless of its outward appearance; and third, that all human beings are descended from Adam. Out of these elements Augustine constructed a square circle of reason from which he could not extract himself, as seen in the final lines of the section:

I must therefore finish the discussion of this question with my tentative and cautious answer. The accounts of some of these races may be completely worthless; but if such peoples exist, then either they are not human; or, if human, they are descended from Adam (Augustine 1972 16.8). 
Of one thing, however, the early Catholic church was certain: that the Pagans and Aryan Christians constituted a serious threat to what remained of GraecoRoman civilization after the withdrawal of Constantine to the East, and especially after the sack of Rome in 410 . The Emperor Theodosius, who took the Roman throne in $379 \mathrm{AD}$, almost immediately enacted a "Decree against Heretics" designed to ensure that all Roman citizens would also be Roman Catholics:

It is our will that all the peoples who are ruled by the administration of Our Clemency shall practice that religion which the divine Peter the Apostle transmitted to the Romans .... We command that those persons who follow this rule shall embrace the name of Catholic Christians. The rest, however, whom we adjudge demented and insane, shall sustain the infamy of heretical dogmas, their meeting places shall not receive the name of churches, and they shall be smitten first by divine vengeance and secondly by the retribution of Our own initiative, which We shall assume in accordance with the divine judgement (Theodisian Code, XVI,1,2 (380), cited in Hillgrath 1969:45-6).

Later on, all Pagan worship was prohibited, with detailed penalties such as the loss of one's home for burning incense in it; finally, by 435 , Pagans became liable to the death penalty for the crime of observing their form of religious devotion (Hillgrath 1969:47-8).

Such was the internal mission that was to be carried out against Paganism, which proceeded by way of the violent enforcement of legal prohibitions. But the Roman Catholic church also saw itself as the bearer of civilization and Catholic Christianity to the lost lands of the West, as seen in the words of Pope Gregory II sending off St. Boniface to his task:

Knowing that some of the peoples in the parts of Germany that lie on the eastern bank of the Rhine have been led astray by the wiles of the devil and now serve idols under the guise of the Christian [Aryan] religion ... but like brute beasts are blind to their Creator, we have taken great care to send the bearer of these letters, our reverend brother and fellow-bishop Boniface, into these parts to enlighten them and preach the word of faith ... (Dec. 1, 722, cited in Halgrath 1969:133, emphasis added). 
Bishop Daniel of Winchester, in his advice to Boniface, suggested means by which he might "overcome with the least possible trouble the resistance of this barbarous people." The Bishop gave details of theological arguments he though would be successful in rooting out the "absurd opinions" and "disgusting rites and legends" that Boniface would encounter. Compared to the Christians, Herodotus appeared quite tolerant. But then Herodotus did not have the same kind of weighty task upon him. "For what does the baptizing of children ... signify if not the purification of each one from the uncleanness of the guilt of heathenism in which the entire human race was involved?" (Dec. 1, 722, cited in Halgrath 1969:135-6).

Prejudiced though they might be, the early Christian missionaries were not as credulous as their philosophers and cosmographers. Relying upon first-hand experience of the Barbarians who had taken over the western provinces of Rome, they were able to develop quite sophisticated and self-aware strategies for their conversion. The successful transformation of Constantine form a Roman Pagan to a zealous Christian was a move taken directly from the pages of the Agricola, and provided a model, by which the monks sought to enlist the existing secular powers to use "even kings to make others slaves." This worked with Clovis, King of the Franks, in around $500 \mathrm{AD}$, and with Recared, Visigoth ruler of Spain, in 589. Once converted themselves, these kings put the bureaucratic apparatus of their Empires to work on the task of converting the (now internal) peoples subject to them.

This was a very effective method of assimilation in cases where Aryan Christianity, and the means of mass coercion associated with it, already existed and could be used against both the remnants of Paganism and Aryan Christianity itself. A different game had to be played in England, however, where the Devil ruled supreme. When Pope Gregory sent monks there in 597, his instructions called for a strategy that was much more subtle and slow-moving: 
I have long been considering with myself about the case of the Angli; to wit, that the temples of idols in that nation should not be destroyed, but that the idols themselves that are in them should be. Let blessed water be prepared, and sprinkled in these temples, and altars constructed, and relics deposited, since, if these same temples are well built, it is needful that they should be transferred from the worship of idols to the service of the true God... (Pope Gregory the Great, Epistle XI, 56, cited in Halgrath 1969:114).

After this were to come more priests, and Bishops of the local "race and tongue." As we will see, a similar mode of nihilistic incorporation set the tone for the Jesuits who, almost one thousand years later, would adapt these methods in their adventures in the New World. In the early Christian era, then, I wish to highlight and carry forward into later discussions several key themes: the creative reproduction of the ancient Hellenistic discourse on diversity via the appropriation of the Great Chain of Being; the imitative reproduction of the Roman imperial use of state forms to repress and eliminate internal Others; and the creative reproduction and refinement of Roman imperial assimilation tactics into what must be counted as a 'new' strategy of selfconscious conversion of the Other into the Self.

\section{Renaissance Exploration and the New World Savage}

From Mela and Solinus, the torch of Herodotan ethnography was passed to Isidore's Etymologies in the seventh century, and thence to Bartholomew's De proprietatabus rerum in the thirteenth. Throughout this time, there seems to have been little change in the wide world at the expanding edges of Christendom; as far as one can tell from the European cosmographers, the same people and monsters lived in the same ways, in the same places, sporting the same odd characteristics, as they had always done. Undoubtedly this Iongevity should be attributed to the fact that many of these beings were living a life that was purely intertextual. Bartholomew, as soon as he felt the need to speak of lands beyond the European frontier, constantly fell back upon Isidore, Solinus, Pliny, and Herodotus. In India "ther ben hilles of golde 
and it is impossible to come therto for dragouns and gryffouns and for many manere men wondirliche yshape, as Ysider saith.... Therefor Plinius telleth wondres of myth and multitude of the Indies.... (Liber Quintus Decimus, Capitulum lxxv). Of Palestine: "As Erodatus seith, thise men ben allweye fals and gyleful and wyly, greuvous enemys to the kyngedome of Israel" (Liber Quintus Decimus, Capitulum cxiii).

At the same time as the theologians and cosmographers were debating the meaning of ancient ethnographic data, Europeans began to travel and report in greater numbers, thus bringing new information to challenge and supplement what had been handed down. Marco Polo was one of the most famous of these medieval trader-Explorers, who kept the Herodotan tradition alive. In almost every section of his Travels (1968), we are introduced to a new people, told how they are governed, if they are subject to anyone else, and whether they have "their own proper language." Then comes religion - usually they are idolaters - a few comments on customs and diet and, of course, commodities available for trade. Marco was a competent amateur ethnographer, and was even so incredulous as to deny the existence of certain marvels and debunk a myth or two.

In these qualities Polo was not unlike another great Explorer who set himself the task of achieving his own visit to the court of the great Khan. Fully versed in European history, geography, and ethnography, Cristobal Colón (Columbus) set out for the East by heading West, and became convinced that he had achieved his goal. Las Casas says of Columbus' reading of Native reports of Cuba: "he believed he understood that here put in ships of great tonnage belonging to the Grand Khan, and that the mainland was ten days sail distant" (cited in Todorov 1984:31). As Todorov points out, what Columbus "understood" was "simply a summary of the books of Marco Polo and Pierre d'Ailly' (Todorov 1984:31). For, although he never did meet the Khan, Columbus did encounter, or hear tell of, many of the other well-known marvels of the East. Cannibals abound in his narrative, and men with tails are to be found on 
at least one island (First Voyage of Columbus, Letter to Sanchez, in Major 1961:11). Amazons, women who "employ themselves in no labour suitable to their own sex", but "use bows and javelins" and wear "brass armour" are reported on another (15). As part of the proof of his theory of a pear-shaped world, he also reproduced the ancient connection between the south, black skins, and stupidity and laziness, and invoked the authority of Isidore, Pliny, Aristotle, and St. Augustine (Letter of the Third Voyage, in Major 1961:133-141). The voyages of Columbus marked an important bifurcation in the European discourse on diversity, as ideas from the Old world were applied to the New, and later Explorers were told what to expect on their own voyages.

Back in Europe, work continued apace on how to place the newly Discovered marvels. The old questions were asked, and the old answers given. Were the beings Columbus claimed to have met human? Dr. Chanca, who accompanied Columbus on his second voyage, said of the people he encountered: "they eat all the snakes and lizards, and spiders, and worms, that they find upon the ground; so that, to my fancy, their bestiality is greater than that of any beast upon the face of the earth" (Major 1961:66). Generally, though, the Savages of the New World were placed slightly higher, somewhere between beasts and men. The stories told of Barbarians far away to the east, over land, could quite easily be applied to those found to the west, over sea. Thus, in Muenster's Cosmographia (1544), Barbarians, Savages, and Monsters were lumped together as forms of the subhuman (Hodgen 1964:127-128).

The question of the humanity of the New World Savages was not easy to settle, however, as demonstrated by the inconclusive results of the 1550 debate between Las Casas and Sepulveda ${ }^{5}$. The argument here might be seen as one between medieval theology and ancient philosophy. Sepulveda based his position upon Aristotle, claiming that hierarchy was natural, so that the Savages, as inferior peoples, were born to serve the superior Europeans. "In wisdom, skill, virtue and 
humanity, these people are as inferior to the Spaniards as children are to adults and women to men; there is as great a difference between them as there is between savagery and forbearance, between violence and moderation, almost - I am inclined to say - as between monkeys and men" (Sepulveda, cited in Todorov 1984:153). Based on this reading, Sepulveda advocated a violent war of Conquest.

Unimpressed with the lack of forbearance and moderation shown by the Conquistadores, Las Casas argued that the peaceful conversion of the Savages was not only possible - that is, that the Savages were human, and had souls - but also desirable, since God had commanded that all men be brought into his flock. "Just as there is no natural difference in the creation of man, so there is no difference in the call to salvation of all men, Barbarous or wise, since God's grace can correct the minds of Barbarians, so that they have a reasonable understanding" (Las Casas, cited in Todorov 1984:162). Of course, neither of the disputants brought into question the Conquest itself: rather, they debated how it was to be carried out, by physical elimination or assimilation to Christian civilization.

An epitome of European notions about the Savage Other was given by Pierre D'Avity who, quite in keeping with the principle of plenitude, worked out a scale of five degrees of Barbarism in 1614. Each level on the scale was predicated upon a lack of some European quality, the most important of which was the possession of reason, which implied knowledge of religion and abstinence from cannibalism. Descending the scale of "brutality," one encountered, in Herodotan style, those who "sow not, nor have any tillage; those who go in nakedness; those without habitation, having no dwellings but caves and hollow trees; and those, the most brutish, deprived of government. For some being altogether barbarous, live without lawes or a commander, either in peace or warre" (D'Avity, cited in Hodgen 1964:201. c.f. Dickason 1984:66-7). At this point, soon after the first voyages to the New World, the Savages were seen by some Europeans as beasts, by some as monsters, and by 
yet others as human; but, even when granted the gift of humanity, they were allocated an inferior status. This assumption was inherent in Las Casa's position, and shows up in the quote above: as they stood, the Savages did not have reason, wisdom, and so on -- but Europeans could teach them. And so they would, as European colonialism took hold throughout the New World, and fast-paced Discovery and looting gave way to more sedentary rhythms of domination

\section{From Prehistory to History - A Summary of European Contributions to the Problem of Canadian Diversity}

Let us recall the question presented in the introduction, and which has informed the analysis presented in this chapter: if it is true that there is a primordial tradition of diversity out of which Canadian multiculturalism has emerged, what are the relationships between the current system and that tradition? How are they the same and different, what rules and regularities do they share, what are the lines of descent from the older forms to the new? I would suggest that ancient philosophers and statesmen, medieval theologians and missionaries, and renaissance travelers and Conquerors, all contributed to the construction and maintenance of a highly adaptable system, a sort of toolkit, ideally suited to the task of Self / Other differentiation and management. From Herodotus came the basic method of marking out visible differences between peoples, assigning to each people a set of timeless characteristics assumed to be representative of all who were 'part' of that people. Herodotus also supplied the rhetorical device of implicitly basing all comparisons on the assumption of a superior people, that of the one making the comparisons, while covering this over with a gloss of detached interest and even occasional praise for certain characteristics of the Others. Plato and Aristotle made explicit what was implicit in Herodotus, by providing the rudiments of a hierarchical gradation of all beings, placing the Self group at the top, just under the gods, and also providing 
justification for the particularly Greek responses of ignorance, xenophobia, and destruction. Roman civilization took on the fundamentals of the Barbarian typology and the hierarchy of beings, but tended towards strategies of assimilation, integration, and state repression in its handling of the problems it created for itself. Medieval Christianity expanded upon the ancient system of differentiation, providing justification for it in scripture, and also pioneered new methods in its successful conversion of all of Europe. Through the early Christian and medieval theologians there was a clear line of descent from Herodotus to the fifteenth and sixteenth century Explorers who, steeped in the European discourse on diversity, quite 'naturally' applied the Old definitions and methods in the New World.

At one point in Early Anthropology, Hodgen marvels: "One of the problems for the historian of European ideas is to account for the backwardness of ethnological thought despite sustained contact with non-Europeans" (80). Is this problem really so hard to solve? A "backwardness" appears only if one gives priority to certain scientific narratives, which themselves reproduce many aspects of the tradition they are supposed to transcend. In backward times and places, as in more forward ones, the means by which the Other is separated from the Self allow her to be objectified, dehumanized, and thereby put to work. The European discourse on diversity, if it is indeed an 'error', has been, and still is, a very useful and productive one. It is absolutely crucial to remember, though, that 'the Europeans' do not exist as a timeless entity with assignable group characteristics given by some 'nature', any more than the Blemmy or the Acephales. In the Canadian case, this is true both in the sense that 'Europe' is a name for an idealization of an Old World, and because people, ideas, and practices associated with that World have been coming to Canada with varying intentions and effects, more or less continuously over the past five hundred years. Whatever continuities there might be between a discourse on diversity that can be correlated with the signifier 'European', and one that might be 
designated 'Canadian', the successive waves in which it has broken on the shores of the New World have introduced discontinuities, as have the relatively separate developments of local formations. Thus the 'baggage' with which 'Europeans' might arrive cannot be given any essential or timeless qualities. At best, we can simply observe, in particular cases at particular times, how people (mis)informed by ancient ideas from the Old World reacted when they encountered Savages and Barbarians once again in the New. In this chapter, I have tried to give some indication of what I consider to have been the contents of the Eurocolonial sea-chest. In the next, I will show how this store was deposited, unpacked, and put to use.

\section{Notes}

1 I am not claiming here that individuals do not identify with races, nations and cultures, nor am I suggesting that 'guesses' that one might make about the attributes of an individual based on 'visible' signs are necessarily wrong. I am, however, claiming that these guesses may be wrong, and that there is no necessary or conclusive link between other-ascribed group characteristics and individual identifications or personality traits. I am also taking this stance because I believe that attempting to guess is at best an imposition, at worst the beginning of a round of violence; and, finally, I believe that whatever predictive power these otherascriptions might have had is dwindling, in contexts like those of 1990's Canada, as multiple rather than single 'origin' individuals become the norm.

2 The extent to which Plato marked a change may be a contentious claim, but I mention it only out of respect for duBois' argument. It is not a central issue for my analysis, since, as will become apparent, what matters for me is the presence, and not the origin, of polarity, analogy, and contradiction within a hierarchical system.

3 Anthony Smith might serve as an exemplar of this approach: according to him, "ethrie (ethnic communities) may ... be defined as named human populations with shared ancestry myths, histories and cultures, having an association with a specific territory and a sense of solidarity" (Smith 1986:32).

4 See Gregory Vlastos' comments on slavery in Plato's utopia in "Does Slavery Exist in Plato's Republic?" (Vlastos 1981:140-146).

5 Debate and practice on the European frontier proceeded as though uninformed by the orders of several Popes. Paul III, for example, declared in 1537 that the savages were not to be treated as "dumb brutes created for our service” but "as truly men ... capable of understanding the Catholic faith" (Papal Bull Sublimus Deus Sic Dilexit, 1537, cited in Dickason 1984:32). 


\section{Chapter 4 \\ Two Canadian Solutions to the Problem of Diversity}

Spanish civilization crushed the Indian; English civilization scorned and neglected him; French civilization embraced and cherished him.

-- Francis Parkman, The Jesuits in North America (1915:131)

One of the greatest difficulties in constructing a history of Canadian diversity lies in the fact that 'Canada', as a European outpost in the northeastern section of the continent now known as North America, has come to exist many times. Norse, Portuguese, Spanish, British, and French adventurers visited the coast, planted their crosses, and crushed, scorned, or embraced their Others at various places and times. Most of these attempts at colonization led to nothing, though, and this makes the genealogical task a little easier. Only the work done by the British and French has remained to create particularly Canadian problems and solutions, and it is from these two colonial and national traditions that Canadian strategies for defining and managing problematic difference have emerged. The overall purpose of this chapter, then, is to show precisely how the French and British colonial discourses creatively reproduced their European antecedents in a new context, giving rise to the nascent forms of what would become known as the problem of Canadian diversity.

In this chapter I also set out to achieve three more specific goals. First, to produce a semiotic square of the system of identity that prevailed in each of the British and French colonial discourses, showing the positions created, how they were differentiated, and their place in a hierarchical order. With regard to this question, it has been clearly shown that the European Explorers were steeped in the Herodotan tradition of geography and cosmography (see Dickason 1984:5-25; Friedman 
1981:197-207). John Cabot, like Columbus, was seeking a sea route to the court of the Great Khan when he bumped into what he thought was northeast Asia in 1497. On his second voyage he planned to hug the coastline to the south, sure that he would find the island of Cipangu, which Marco Polo had reported as the source of "all the spices in the world, and all the precious stones" (Letter of Raimondo de Soncino to the Duke of Milan, cited in Biggar 1911:20). Jacques Cartier, in relating the story of his first voyage in 1534 , claimed to have conclusively proven that the world was round by sailing westward to Asia (Cartier's account of his Second Voyage, cited in Cook 1993:36). Unlike Cabot, Cartier spent a fair amount of time on rivers and dry land, and so was able to tell some tales when he returned home. He was not surprised to find the place populated by les sauvages ${ }^{1}$, nor was he taken aback by reports of people with no anus, a single leg, and "other marvels too long to relate" (Cook 1993:82). These Explorers found, because they expected to find, monsters and Barbarians, gold and silver, spices and degenerate potentates; the Imaginary West, confused as it was with the Imaginary East, was in a sense fully mapped out before any European ever saw it.

The second aim of this chapter is to provide an account of how European methods of managing problematic diversity were adapted and transformed by the French and the British for use in the New World, and how new methods also emerged. During this period, the defining binary distinction was between the European Self and the Savage / Indian Other. In tracking the evolution of this deceptively simple system, I will make use of a device used in Canadian Native studies, whereby the history of European-Native interaction is divided into three phases. First, the contact phase, during which "the French explored, traded, and attempted to leave their permanent mark on the place. The Indians happily bartered but rejected the white men's presumption at erecting ... signpost[s]" (Miller 1989:3-4). The next was 
the fur-trade era, in which the Natives were possessed of their own economies and polities, and thus of a strong measure of self-sufficiency and power. Here the Natives and newcomers are thought to have coexisted on relatively equal or co-operative terms, although the Europeans, or more precisely the French, were working hard to assimilate the Savage Other, and both the French and the British had recourse to extermination. Here I am referring to attempts to totally eradicate signs of the Other through killing all who are considered members of the problematic group. This term plays on the distinction between massacre societies and sacrifice societies made in Todorov's Conquest of America, (1984:143), where the Spanish and Aztecs are respectively cast in these roles. From extant documents it is clear that the French were in horror of Native methods of individual torture; with time, Native peoples came to have the same fearful respect for the European ability to remove the possibilities of existence for entire nations. The relative success of massacre over sacrifice tactics led to a third phase, which has seen massive expansion of European striation of the continent, and has been one of "tutelage", or "unilaterally imposed administration of one party by the other" (Dyck 1991:6). I will look at the construction of the Native Other in each of these phases, and will also point out some additional features of each, and of the relations between them. In addition to noting some relatively well-known European methods used during this period, I will also point out what I see as the most innovative and important contributions, from the point of view of the problem of Canadian diversity in its larger context. From the French came what I will refer to as strategic simulation of assimilation to the Other; from the British, the discourse on Canadian diversity received great refinements in forms of distant microcontrol of everyday life in the forts of the Hudson's Bay Company, that anticipate the environment of the postmodern Canadian citizen . 
Finally, I will pay attention to the role played by 'hybrid' identities, i.e. the coureurs-de-bois, 'Half-breed', and Metis', which were deeply feared and repressed by both the British and the French state organizations. Because of this repression, the terms Half-breed and Metis are highly charged. As with the term 'Savage', 'Halfbreed' will be always capitalized, to show that it is being used within a certain discourse and that I am aware of its use as a negative other-ascription. In the late 1800's, Half-breed was used within official and popular discourses in English to refer to both English- and French-speaking people assumed to be of 'mixed' European and Native parentage. Over the past few years, there has been an effort on the part of Metis organizations to replace Half-breed with Metis, but some of those who see themselves as English rather than French hybrids are currently trying to reclaim the term Half-breed as a positive self-identification. These identities, I will argue in chapter 9, can be seen as the semiotic ancestors of today's 'multiple origins', and therefore provide clues as to how the much-lamented lack' of Canadian unity and identity might be understood.

\section{The First Others of the New World}

Although the British came first, the French stayed first, and so they shall be given priority. And the first of the French, the Explorer Jacques Cartier, shall be seen as having established the nascent forms that would be developed later by specialists devoted to the task of Conquest. Cartier's extensive journals make it clear that he had sufficient contact with Savage 'Canadians' and 'Hochelagans' to comment on many aspects of what would now be called their 'culture'. Taking in order D'Avity's degrees of Barbarism - presented at the end of the previous chapter - we can see how Cartier's first impressions of the New World Savages were formed, and how they changed with further contact. 
With regard to D'Avity's primary markers of civilization, reason and religion, Cartier's opinion might seem ambiguous to a late 20th century reader. In the account of the First Voyage there are rov comments on these topics. By the time he returned, though, Cartier was equipped with kidnapped interpreters, and was able to investigate these vital questions. Sometimes, it seems that he saw neither attribute, advising his king that the people of the New World lived "without the knowledge of God and without the use of Reason" (Cartier's Commission for his Third Voyage, Cook 1993:135). In the same passage, however, he is reported as describing the Savages as "well endowed in mind and understanding" (135). "This people has no belief in God that amounts to anything;" he wrote after his second journey, but then continued the sentence: "for they believe in a god they call Cudouagny" (Cook 1993:68). Did they have a god or not? The apparent ambiguity can be reconciled if we remember that, for Cartier, there was only one religion that "amounted to anything," and that was Christianity.

Cartier also commented several times upon the Savage's lax conduct regarding agriculture. He was impressed by the natural abundance of the New World, which included "as good hemp as that of France, which comes up without sowing or tilling it" (51). Likewise the vines "so loaded with grapes that it seemed they could only have been planted by husbandmen; but because they are never looked after nor pruned, the grapes are not so sweet nor so large as our own" (57). Later on, in Hochelaga, Cartier found "that the land began to be cultivated. It was fine land, covered with large fields covered with the corn of the country" (61). But, even once he knew that the people of the New World were capable of agriculture, Cartier was not impressed with the effort they put into it. "They are by no means a labourious people and work the soil with short bits of wood about half a sword in length" (69). 
On the subject of clothing, there is also much to be learned from Cartier's narratives. During the first voyage, he used its lack as part of the justification for his conclusion that some people he met near the mouth of the Gaspé "may well be called savage ... for they go quite naked, except for a small skin, with which they cover their privy parts and for a few old skins which they throw over their shoulders" (24). In his description of the Hochelagans, Cartier noted that "the greater portion of them go almost stark naked" (62). The same went for the Canadians, who "would come to our ships every day across the ice and snow, the majority of them almost stark naked" (70). That Cartier saw this form of clothing as a lack of something normal was made explicit later on, when he noted the various animals that inhabited the region. "The people wear the skins of these animals for want of other apparel ${ }^{n}(74$, emphasis added).

Habitation also figured prominently in Cartier's records of his voyages. The people he met at Chaleur went "from place to place maintaining themselves" (22), while those at the Gaspe had "no other dwelling but their canoes, which they turn upside down and sleep on the ground underneath" (25). On the way to Hochelaga, Cartier noticed "a large number of houses along the banks of the river" (57). In the village itself, the Europeans found fifty houses, the contents and use of which were described in such detail that it leads one to wonder if Cartier were not pining for his own beloved boards. Altogether, Cartier saw Hochelaga as the most civilized locale in the New World, and treated of it in unusual detail:

This whole people gives itself to manual labour and to fishing merely to obtain the necessities of life; for they place no value upon the goods of this world, both because they are unacquainted with them and because they do not move from home and are not nomads like those of Canada and of the Saguenay, notwithstanding that the Canadians and some eight or nine other peoples along this river are subjects of theirs (61-62). 
Much can be made of this passage. First, it shows that Cartier was sufficiently familiar with, and open to, New World Savagery to begin to assign degrees of difference within it. It attributes to the Hochelagans several Christian virtues; a sedentary life, hard work, self-negation, other-worldliness and, of course, the ability and right to dominate less civilized and hard-working peoples. The Hochelagans did not appear to Cartier to have a polis; but he thought they might be possessed of some sort of empire, the next best thing, and certainly an indication that they were not, like other Savages, altogether barbarous and "deprived of government."

For Cartier, then, the peoples of the New World were of varying degrees of civilization, with most being quite Barbarous but some having achieved, if on a small scale, the level of empire-building. As to their humanity, Cartier seems to have been ambivalent. The Canadians he found to be "more indifferent to the cold than beasts" (70). Regarding those who some commentators think were Beothuck of Newfoundland, Cartier commented: "there are people on this coast whose bodies are fairly well formed, but they are wild and savage folk ${ }^{n}(10)$. Not monsters, he seemed to be saying, but certainly not Europeans either. The most compelling evidence of Cartier's opinion on this matter can be seen in his immediate and ongoing conviction that he had found fertile ground for the cultivation of souls. During the first voyage, though he had shown no signs of knowing anything about their religious beliefs, Cartier twice stated his opinion that the people he had found would be easy to convert to Catholicism (22-23). Obviously, Cartier followed his Church in believing that the Savages were convertible, that is, that they were human, and therefore had souls that could be saved.

In both the form and content of his narrative, Cartier worked closely within the genre of Herodotan ethnography and the categories of the European discourse on diversity. But this reproduction was creative, in that it produced ambiguity and 
contradiction as Cartier worked to reconcile the Monsters of the cosmographies and the Pagans of the Saints with the obviously human people he encountered. While European philosophers could easily provide a list of Barbaric qualities, the man in the field found it difficult to fit those who were supposed to be Barbarians into the slots provided. Thus, during the phase of first contact, the New World Savage began quite quickly to be transformed from an unknown, semi-monstrous, external other to an ambiguously human, potentially Useful Other on the margins of an advancing civilization. In this shift, the French discourse on diversity began to diverge from the ancient European system and, although it reproduced many of the Old World definitions and practices, it also started to develop its own particularity.

\section{Conversion and Extermination. The Cases of the Huron and the Iroquois}

The French claimed the right to not only Explore, but also to Colonize the New World according to the ancient Roman civil law of vacuum domicilium, which allowed one to take possession of 'empty' or 'vacant' land (Dickason 1984:131; Jaenen 1991:24). This interpretation, which came to be known as the doctrine of terra nullius, was commonly used in royal letters patent, which gave Explorers the right to take possession of lands "uninhabited and not possessed or ruled by any other Christian princes" (e.g. Roberval's Commission in Cook 1993:144). Of course, the 'emptiness' of a given piece of land was judged according to European standards, that is, it was said to be 'inhabited' only where the Europeans saw signs of agriculture, government, reason and religion, and so on. The problems posed by the fact that the New World was not truly 'empty' were acknowledged early on, and were 'solved' by Mare Lescarbot with the help of Christian theology:

The earth pertaining then, by divine right to the children of God, there is here no question of applying the law and policy of nations, by which it 
would not be permissible to claim the territory of another. This being so, we must possess it and preserve its natural inhabitants, and plant therein with determination the name of Jesus Christ and of France... (Lescarbot 1907:1.17, emphasis added).

From their first attempts at Colonization, marked by the third voyage of Cartier and the first of Roberval, the French, at least in their official documents, eschewed the ruthless Spanish quest for riches in deference to higher goals:

His majesty [Francis] ... is not afraid to engage in new expense, to establish the Christian Religion in a country of Savages at the other end of the world from France, and where he was well aware that there were no gold or silver mines nor any other gain to be hoped for, other than the winning over of an infinite number of souls to God... (List of Men and Effects for Canada, in preparation for Cartier's third voyage, Cook 1993:126).

This course appears to have been followed with the Huron nation, which I will treat as an epitomal application of 'soft' methods of preservation, conversion and civilization. But, as we will see in the case of the peoples of the Iroquois confederacy - some of whom are still at war with the Canadian state today - the French, beginning with Samuel de Champlain, also made use of the 'harder' strategies of physical elimination through displacement, containment, and extermination.

The task of initiating a flow of signs of French civilization to the bodies and souls of the New World was taken up by the Jesuits, who arrived in 1625 . In the Relations, narratives sent back to France from spiritual labourers in Canada, Jesuit views on the people they encountered, the tasks they set out to achieve, and the methods they used, are quite self-consciously and explicitly put forward, making these texts very useful in discerning how they constructed and managed the problem of human difference. As epitomes of their type, that is, as bearers and innovators of theories and methods developed over a thousand years of Christian missionary work, 
I have followed the canon and chosen Father Jean de Brébeuf, who arrived with the first party, and Father Paul le Jeune, who came soon after.

Le Jeune's relation of 1632 sets to rest any doubt that the Jesuits were selfconsciously applying lessons learned in the past to new their task. After giving his views on the "wholly barbarous" dress, intelligence, and social mores of the Savages, and describing some of the tortures to which the Iroquois subjected their prisoners, le Jeune explicitly linked the Savages of New France to those of Old Europe:

Let no one be astonished at these acts of barbarism. Before the faith was received in Germany, Spain, or England, those nations were not more civilized. Mind is not lacking among the Savages of Canada, but education and instruction. They are already tired of their miseries and stretch out their hands to us for help (Relations: 5.32-33).

While the Jesuits used the common term Savage (Sauvage) in their descriptions of the people of the New World, one also notices the addition of the new (old) terms Pagan (Payenne) and Barbarian (Barbare). This change marked an important shift in perception, in that it tied the problem of New World diversity directly to ancient Europe. There was nothing like an abrupt transition, of course, but with the Jesuits the unknown, beast-like Savage one might only hope to save began to be transformed into a type that European civilization had already successfully assimilated many times. "If we go outside our cabin, Heaven is open to us ... so that we can say our prayers in full liberty before the noble Oratory that saint Francois Xavier loved better than any other" (10.107). For le Jeune, and the many Jesuits who came after him, Canadians were exactly what northwestern Europeans had been one thousand years before: Barbarians begging to be given the gifts of Christianity and civilization borne by selfless priests.

Just as the early Christians had allowed Pagans to maintain their altars, the Jesuits were compelled to accept from their flock behaviours that would never have 
gone over back home in Europe. Indeed, Brebeuf's 1637 Instructions for the Fathers of our Society who shall be sent to the Hurons concerned itself mainly with the "hardships, annoyances and perils" of the mission:

Leaving a highly civilized community, you fall into the hands of barbarous people who care but little for your Philosophy or your Theology. All the fine qualities which might make you loved and respected in France are like pearls trampled under the feet of swine, or rather mules, which utterly despise you when they see that you are not as good pack animals as they are (Relations: 12.123).

Annoyances aside, the Instructions for the Fathers was deeply structured by the conviction that, before the Barbarian could be expected to take on European signs, the European must display signs of the Barbarian. "To conciliate the Savages, you must be careful never to make them wait for you in embarking" (Relations: 12.117). "You should try to eat their sagamite or salmagundi in the way they prepare it, although it may be dirty, half-cooked, and very tasteless. As to the numerous other things which may be unpleasant, they must be endured for the love of God, without saying anything or appearing to notice them" (12.117). In his mission to the Huron nation, which is often considered the epitomal case of 'peaceful' conversion, Brébeuf followed his own rules, stepping very carefully around the civilizational minefields he encountered, and even backing down, for the time being, on confrontations with the Devil. "Generally speaking they praise and approve the Christian Religion, and blame their wicked customs; but when will they leave them off entirely?" (Relations: 10.25).

Brébeufs fears were well founded. But other forces would come to his aid, altering the balance of power so that the Huron would be reduced to such conditions of extremity that they had no choice but to try to accept what the Jesuits offered. In 1648 the Iroquois, who were known for assimilating those they Conquered, began a 
series of attacks on Huron villages that gave every appearance of constituting a Spanish-style war of extermination. The Jesuits retreated first to Sainte-Marie, the last redoubt of Christianity in Huron country, but the position was untenable, and so it was resolved that the missionaries would follow their flock, and "flee with the fleeing" (33.203) to the island of St. Joseph. Once a mission had been set up, things went from bad to worse. There was not enough food laid in, so that by winter the Jesuits were "compelled to behold dying skeletons eking out a miserable life, feeding even on the excrements and refuse of nature" (Relations: 35.89 ). There was not much to sustain the life of the Huron, but the priests managed to survive, and counted themselves lucky to obtain, after so much effort, a bountiful harvest of souls:

[T]hat nothing might be lacking in the miseries of an afflicted people, all the days and nights of Winter were but nights of horror, passed in constant fear and expectation of a hostile party of Iroquois, of whom tidings had been received; these (it was said) were to come to us to sweep this Island, and to exterminate, with us, the remnants of a nation drawing to its end. Here is an aspect of the matter calamitous indeed; but it was in the midst of these desolations that God was pleased to bring forth, from their deepest misfortunes, the well-being of this people. Their hearts had become so tractable to the faith that we effected in them, by a single word, more than we had ever been able to accomplish in entire years (35.91).

Just as they were assured of the eventual 'peaceful' conversion of the Huron, Champlain and le Jeune were convinced of the necessity of forcefully subjugating the Iroquois confederacy, which operated in its own best interests, resisted the flow of French signs, and was possessed of sufficient military might to operate as an equal power. In the summer of 1609, Champlain had participated in a Huron raid on the Iroquois, where he and his firearms met with much success; the year after that 
found him again at war. In these 'battles', Champlain showed no mercy, apparently not bothered by the fact that he had guns, and his enemies didn't:

The Iroquois were much astonished that two men should have been killed so quickly [by gunfire], although they were provided with shields made of cotton thread woven together with wood, which were proof against their arrows. This frightened them greatly.... [S]eeing their chiefs dead, they lost courage and took to flight ..., whither I pursued them, and laid low still more of them (2.99-100).

During another such encounter Champlain halted the slaughter when he saw that some fellow Europeans were about to join in; he wanted them to "have their share of this pleasure" (2.132). The simple joy of sacrifice should not be seen as Champlain's main motivation, however. Twenty years after the founding of Quebec, he continued to blame his problems on the Iroquois confederacy, and had come to the conclusion that it was time to "engage in [a] legitimate war, in which, by destroying those peoples, we should make the land and the rivers free for our commercen (6.314). The Iroquois had been developed into bearers of intolerable difference, Absolute Others who could not be assimilated, with whom one could not stand to integrate, and who must therefore be physically eliminated. In this way Champlain moved beyond ritual sacrifice and began to see himself as fighting a very Spanish war of extermination, which grew in its intensity as the perceived need for the secure passage of furs increased.

Later French governors followed Champlain in blaming their problems on the Iroquois. Jean Talon, known in the history books as the "Great Intendant," was instructed by Jean-Baptiste Colbert, Louis XIV's favourite minister, to begin a systematic program of physical elimination of the Iroquois in order to allow the consolidation and expansion of French control: 
The Iroquois ... having prevented the country being more peopled than it is at present, and by their surprisals and unexpected forays always keeping the country in check, the King has resolved, with a view of applying a suitable remedy thereto, to carry war even to their firesides in order totally to exterminate them (Instructions to M. Talon, March 27, 1665, PD-NYCD:25, emphasis added).

The Intendant displayed his greatness in trying to carry out the instructions of his king. Although the campaign of extermination was unsuccessful in achieving its ultimate goal - the Iroquois soon learned to elude large contingents of armed Frenchmen - it did allow European striation of the land to proceed apace: "It is fine to see new settlements on each side of the St. Lawrence for a distance of eighty leagues ... The fear of aggression no longer prevents our farmers from encroaching on the forest and harvesting all kinds of grain" (Le Mercier, Relation of 1668, cited in Chapais 1964:48). This successful "encroachment on the forest" was also, of course, encroachment upon the traditional lands of various Native peoples, more and more of whom found themselves in the position of the Huron, i.e. without the means of subsistence and - for the moment - reduced to dependence upon handouts from the French. Now that the haughty had been beaten down, the conquered could be spared ${ }^{2}$ - and further managed by the use of 'softer' methods of conversion and civilization. By 1668 there were Jesuits amongst all of the five Iroquois nations, ministering to both Iroquois and French and Huron captives (Chapais 1964:94-5, Relations: 49.103-117). In 1703, the Jesuit historian Joseph Jouvency was able to report that "there are numbered in this formerly solitary and unexplored country more than thirty very prosperous and well-equipped missions of our society" (Mealing 1963:115). 


\section{The Coureurs de Bois as a Repressed Hybrid Identity}

If the missionaries were having some success in initiating a net flow of signs to the Savage Other, there were other products of the meeting of French and Native peoples who did not fit in so well with the Royal plan. Despite constant state intervention to prevent inverse sign flow, French individuals assimilated to Native ways of life, as best seen in the example of the coureurs de bois. Good European colonists were supposed to stay in one place, till the land, and reproduce the categories of peasant, petty bourgeois, seigneur, and so on. Those who chose instead to live a semi-nomadic life and take on the ways of the Native peoples posed an ongoing problem to the Jesuits, proper French visitors, and above all to the colonial administration. Themes of wanton alcoholism, interracial sex, and idleness were central to the evidence produced by Father Etienne de Carheil, in his relation of 1702 regarding the state of the mission at Michillimackinack, a centre for the activities of the coureurs de bois (Relations: $65.190 \mathrm{ff}$.). Trading in furs at such remote outposts, he argued,

serves but to depopulate the country of all its young men; to reduce the number of people in the houses; to deprive wives of their husbands, fathers and mothers of the aid of their children, and sisters of that of their brothers; ... it accustoms them [the young men] not to work, but to lose all taste for work, and to live in Continual idleness; it renders them incapable of learning any trade, and thereby makes them Useless to themselves, to their families, and to the entire country... (Relations: 65.219).

Seeing the combined forces of the traders and the military commanders arrayed against him, the Jesuit argued that the fur trade should be limited to Montreal, and the young men kept at home, along the St. Lawrence (65.220 ff.). 
The Baron de Lahontan was also unimpressed by what he saw of these young men, even when they were among the more civilized habitants:

You would be amaz'd if you saw how lewd these Pedlers are when they return [from trading expeditions]; .... the Batchelors act just as our East-India-men, and Pirates are wont to do; for they lavish, eat, drink, and play all away as long as the Goods hold out; and when they are gone, they e'en sell their embroidery, their Lace, and their Cloaths. This done, they are forc'd to go upon a new Voyage for Subsistance (Lahontan 1940:20-21).

The comparison of the coureurs de bois to pirates seems to have been a common rhetorical trope of the late seventeenth century, as seen in Talon's complaints below, which also shows some of the many attempts to legislate the 'illegitimate' traders out of existence:

[P]roclaiming the intention of the King, I caused orders to be issued that the volunteers (whom on my return, I found in very great numbers, living, in reality, like banditi) should be excluded from the [Indian] trade and hunting; they are excluded by the law also from the honours of the Church, and from the Communities if they do not marry fifteen days after the arrival of the ships from France. (Talon to the King, Sept. 10, 1670: PD-NYCD:65).

Frontenac, who governed New France after Talon, shared his predecessor's fear and disdain, and also tried, with the help of Colbert, to use state power against them. $\mathrm{He}$ thought it was crucial to the peace of the country to prevent "the disorders of the Coureurs de bois, who will finally become, if care be not taken, like the banditti of Naples and the Buccaneers of Saint Domingo... Their insolence ... extends even to the formation of leagues, and to the distribution of notices of rendezvous..." (Frontenac to Colbert, Nov. 2 1672, PD-NYCD:91).

Such attempts failed, of course. French state power was never able to overcome these nomadic forms, and so they formed an important, though mostly 
ignored, undercurrent within mainstream historical accounts. They are of special interest with regard to the continuous efforts of the French colonial government and every state form seeking to control the shifting territory known as Canada - to suppress any spontaneously emergent forms that might have resulted from the European invasions. What the state absolutely forbids is that any group might begin to striate its own space according to its own rules, to form leagues and set up meetings. Like the Iroquois Confederacy, the coureurs de bois were relatively successful competitors for organized control of geographical space, especially as they were seen to be taking on the socio-political forms of the Native peoples, which were fundamentally nomadic -- in the sense discussed in chapter 2 - and therefore appeared as a challenge to sedentary society. Again, the Jesuit opinion is quite informative:

\begin{abstract}
The Savages ... imagine that they ought by right of birth, to enjoy the liberty of Wild ass colts, rendering no homage to any one whomsoever, except when they like. They have reproached me a hundred times because we fear our Captains, while they laugh at and make sport of theirs. All the authority of their chief is in his tongue's end; for he is powerful in so far as he is eloquent; and, even if he kills himself talking and haranguing, he will not be obeyed unless he pleases the Savages (Relations: 6.243).
\end{abstract}

As representative of a nomadic, i.e. emergent, local, decentralized, and nonauthoritarian mode of organization, the coureurs de bois constituted the first repressed semi-internal Other in the history of Canadian diversity. These hybrids, eventually driven out of the Great Lakes region by the decline of the fur trade and the incursions of American settlers (Peterson 1985), form one line of descent to the Metis of the nineteenth and twentieth centuries, who have yet to be fully recognized as either Canadians or as a sovereign people in their own right, and therefore still occupy a liminal and contradictory position within the discourse on Canadian 
diversity (Adams 1995;1989). More importantly, however, their treatment shows the extent to which Canadian state organizations have been deeply fearful of emergent, hybrid forms, and have been on an endless quest for Canadian unity, i.e., for a single hegemonic striation of as much space as possibie by the largest possible rational-bureaucratic apparatus.

\section{The System of Difference in French Colonial Discourse}

It is not so hard to penetrate the mists that hide Canada's primordial multiculturalism - the documents are there, at least from the French point of view, and they allow us to construct a semiotic square (see chapter 3 ) of those who could be considered <subjects of New Frances. The positive term here was obviously $<$ French $>$, the negative term - the name of the Other - was <Sauvage>, and the basis for the distinction was given by the possession or lack of <civilization $>$ and $<$ Christianity $>$. Within the negative term, there was a hierarchy, differentiated by degree of assimilation to the French, ranging from the Huron on down to the less assimilated Native nations. The contradictory position was taken up by the <coureur de bois $>$, who displayed the qualities of both $\langle$ French $\rangle$ and $\langle$ Sauvage $\rangle$, and therefore threatened to undermine the system of binary opposition. In the sense that they were cast as roving bandits, these were not proper subjects of the French King; inasmuch as they were not seen as possessing a right to a group identity of their own, they were prevented from organizing as a distinct society. What was neither $<$ French> nor <assimilated Sauvage> and had the potential to bring this system crashing down? The troublesome <Iroquois Confederation>, the external Enemy who had to be exterminated. 
Figure 4.1 - Group identity in French colonial discourse (<Canada $>$ )

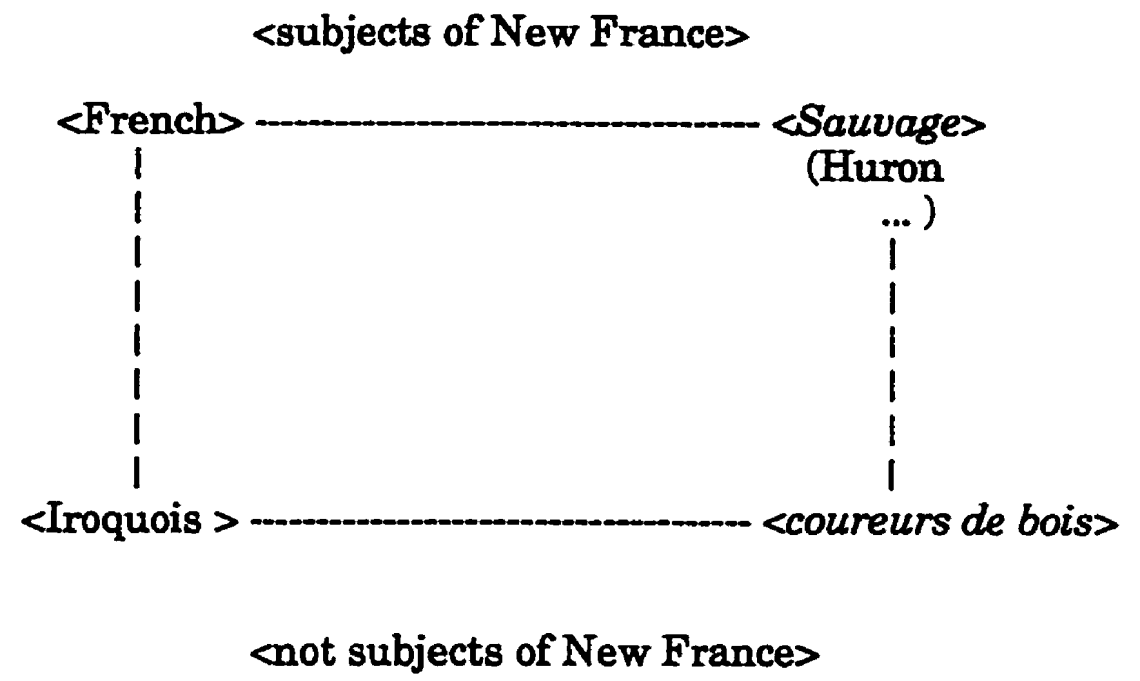

As in the ancient Greek case, it should be noted that within this square there was another implicit hierarchy, which had the Self group at its apex, traveled through the primary Others, then down to the contradictory position, vis: French, Sauvage (Huron ... ), coureurs de bois, Iroquois.

When we part the mists and look at the relations that existed under this system of primordial multiculturalism, what we see is not "harmonious coexistence," but a number of groups struggling to the death for hegemony. What we also see in this 'origin' is the Europeans pulling on their history to achieve as much as possible given their inferior position according to the power law of sign flow. The most important strategy they adopted was to appear to give in the short term to win in the long term. This form of strategic simulation of assimilation to the Other was perhaps the greatest innovation of the French in the New World, and would be put to good use as the history of Canadian diversity played itself out. For, despite ongoing resistance and mutual assimilation and integration, it is obvious that the net flow of signs was not equal. Very few Québécois now live in open-roofed longhouses and speak 
Algonquin tongues, but many Algonquin-speakers live in bungalows and speak French ... or more likely, English. Mohawk warriors are dragged into Quebec courts, but do not have the right to subject Canadian and Québecois armed forces and pulice to their own forms of justice. The allies of the French did not fare much better than their enemies. The Huron and Iroquois can be seen as archetypal cases of French/ Native contact in the New World, inasmuch as they show that being friend or foe to the King only made a difference in the means the French used to attain their goals; in all cases, the end was the same.

Thus we might summarize the French handling of the problem of Canadian diversity during the time of the establishment of New France as follows: for 'friends', that is those who did not fight to the death to maintain their style of life, there would be seduction, displacement, denomadification and containment, leading to a state of dependency conducive to civilization and conversion. For 'enemies', a war of extermination would be carried out to strip the competing society of its demographic, social, and political power, and reduce them to the state accepted 'voluntarily' by the 'friends'. Of course, neither of these solutions could be implemented just as the French would like, and so they were also forced to assimilate to and integrate their Others to whatever extent was necessary to guarantee the survival of their project. Thus was one "joining" of the "Europeans" and the "Aboriginal peoples" accomplished; thus began one branch of the history of Canadian diversity, that of the French colonial discourse, which creatively reproduced its European antecedents. But before we emerge from the mists, there is another tradition that must be unveiled, that inaugurated by the British with their many attempts at the still unfinished business of Conquering and colonizing not only the Natives, as first Other in the New World, but also the French, who were themselves soon to feel the sting of 
Conquest - as those who adhere to the British story would have it - or Cession, as their own descendants would prefer.

\section{How Canada Became British}

In the previous sections I have presented the French colonial discourse as one of the "two Canadian solutions to the problem of diversity" to which I refer in the title of this chapter. In the immediately preceding section, I have outlined how the French colonial discourse adapted an Old European system of constructing and managing diversity to the conditions of a New World, and tried to point out some of its more interesting innovations. In the following sections, I will address the second "Canadian solution," as it is found in the early British colonial discourse. Again, I will discuss the means used by the British to distinguish themselves from the people they encountered, but as there is little difference here from the French system, I will treat this issue in only a cursory fashion. The use of the methods of displacement and extermination against the Beothuk of Newfoundland will be noted, but more attention will be paid to the strategy of ignorance of the Other that contributed to the demise of this group. The Hudson Bay fur trade will be presented as an example of British adoption of the French method of integrating the Other in a capitalist economy, but again the emphasis will be placed on an innovation - that of distant microcontrol of everyday life. As in the French case, even this concerted attempt to lock bodies into systems of state striation could not succeed in achieving the stage of 'apparatus'. British fur-traders took Native women as wives, increasing their capital (in Bourdieu's sense) in the local branch of the colonial economy, giving rise once again to what was perceived by the British as a surplus, hybrid population of Halfbreeds. I see this combination of ignorance and failed attempts at microcontrol as being eminently Canadian in its basic outlines, as I will show in the chapters on post- 
confederation formations (6-8). This is what makes the early British colonial discourse important for the history of Canadian diversity, and this is one important sense in which I hope the allusive title to this section might be read. In the remainder of the section I will present some general comments on British 'theory' regarding the means of differentiation and methods of management appropriate to New World "planting," before turning in the succeeding sections to a discussion of two instances of the application of this model.

When comparing the British to the French system, one finds that similar questions were asked, and similar answers were provided, regarding the humanity, civilization, and convertibility of the peoples of the New World. Sir George Peckham's 1583 True Report of the late discoveries ... of the Newfound Landes argued that the New World Savages, lacking government and agriculture (Quinn 1979:3.54) and going about naked (3.54), could only benefit from the riches about to be bestowed upon them:

[T]hose Countries are at this day inhabited with Savages who have no knowledg of God. Is it not therefore (I say) to be lamented that, that these poore Pagans, so long living in ignoraunce and Idolatry, and in sorte, thirsting after christianitie, ... that fewe or none can be found which wil ... apply themselves to the relieving of the miserable and wretched estate of these sillie soules? (3.41)

If they could be persuaded to give this precious gift, Peckham suggested, the English people would join the proud company of ancient biblical heroes - and contemporary Spaniards - in taking on a task "as well pleasing to almightie God, as profitable to men ... as lawfull as it seemed honourable" (3.41).

Peckham was aware of the possibility that the Savages, in their ignorance, would not appreciate the kindness being shown them, and might resist being lifted to the level of European civilization. Drawing a page from Virgil's exhortation of the 
Romans to imperial glory, he advised that if persuasion proved to be necessary, peaceful means were to be preferred, such as informing the Savages that the English had come to bestow gifts and do no harm, offering beneficial trade and protection from their enemies (3.44). This was, however, only one method of "planting" available to England as a Christian European power.

[1] $f$ after these good and fair meanes used, the Savages nevertheles will not be heerewithall satisfied, but barbarously wyll goe about to practise violence either in repelling the Christians from theyr Portes and safe Landinges or in withstanding them afterwardes to enjoye the rights for which both painfully and lawfully they have adventured themselves thether. Then in such a case I holde it no breache of equitye for the Christians to defende themselves, to pursue revenge with force, and to doo whatsoever is necessary for the attayning of theyr safety: For it is allowable by all Lawes in such distresses, to resist violence with violence (3.44-45).

This circle of retribution - which does not address the question of what one might call the 'first violent act' - - was taken up and advocated by both the younger and elder Hakluyt (see Quinn 1979:3.61 ff.), and soon became quite firmly established as the correct method of dealing with the problem of diversity in the New World. ${ }^{3}$ Thus, at least in the official-intellectual discourse, the British took up a policy very similar to the French. They were to offer kindness to their inferiors, whom they would elevate if possible; but, if the gift were declined, they were quite willing to make every attempt to lay them low.

\section{Ignorance and Extermination in the New Founde Landes}

The 'disappearance' of the Native people of Newfoundland has been much discussed, elevated to the status of a myth; a "vanished race" that "passed out of existence as mysteriously as they entered thereupon," still in a condition of "primitive ignorance and barbarity" (Howley 1974:62). Did the Beothuck just 
vanish? Some claim they were displaced and exterminated to make way for British settlement and exploitation, aided by the silent complicity of the British discourse on diversity and various levels of government (Kelly 1974; Mairshall 1996; Rowe 1977). Then there are those who deny that the Beothuck were exterminated at all, or if they were, that this was not the fault of the British settlers and government, or if it was, that they did not do it 'on purpose' (Upton 1992). Space limitations make it impossible for me to produce the volume of 'proof that might be necessary to convince certain readers of the position I take on this issue, which is that the Beothuck did not just 'disappear'. However, for my purposes, the question of intention' re the 'extermination' of the Beothuck need not be resolved, for what is important is the treatment of the Beothuck as problematic Others -- to be destroyed or 'helped', but certainly not to be left in peaceful occupation of their island. One point upon which the various commentators seem to agree is that a people that existed before British colonization ceased to exist soon after. This 'historical fact' is relevant to the problem of Canadian diversity, and so forms part of the field I am analyzing.

Compared to the French, the British Explorers have left relatively little in the way of documentation, and certainly nothing like the detailed 'ethnographic' studies provided by Cartier and Champlain. Edward Hayes, who was on the second voyage of Sir Humphrey Gilbert in 1583, provided an account of the flora, fauna, and mineral wealth of the New World, which runs to more than ten thousand words. But there is scant mention of the human inhabitants, other than to hammer home that they are "barbarous" (4.24), "pagans" (4.24), "poore infidels captived by the devill, tyrannizing in most woonderfull and dreadfull maner over their bodies and soules" (4.24) - none of which seems to be based on actual encounters, or even observations, and hence gives the appearance of a simple restatement of established prejudice. Hayes admits that "in the South parts we found no inhabitants, which by all likelihood have 
abandoned those coastes, the same being so much frequented by Christians," and gives no evidence of having seen or met anyone in the North (4.33). The New World Savage was, for the British, very much an absent, mysterious quantity.

From 1610 on, various public and private efforts at colonization led to a slow growth in the British presence in Newfoundland, as well as that of the other European nations fishing off the coast. Between them, by the middle of the sixteenth century, the Europeans had taken over most of the shore of the island, where the means of subsistence were most plentiful, driving the Beothuck inland (Marshall 1996:22). In the early seventeenth century, Lord Falkland recommended further displacement and containment in his instructions to "the well affected planters in new fownde lande:"

first of all I wishe them to plante in the most extreme parte of the land northwestwarde ... to keepe the natives out from the maine land ...; which being Carefullie donne \& observed, they will have the better parte of 2/3 parte of land of the bignes of Ireland to themselves (Lord Falkland's Instructions to his Settlers, in Cell 1982:244).

From this time forward, the British slowly but surely progressed around, and then penetrated into, the whole of the island, leaving nowhere for the Beothuck to live. By 1760, when primary sources again began to appear, Sir Joseph Banks' report showed that a century and a half of coexistence had done little to bring the Beothuck out of the realm of fantasy: "Of the Indians that inhabit the interior parts of Newfoundland, I have as yet been able to learn very little about them. They are supposed to be the original inhabitants of the country" (Banks' Journal, cited in Howley 1974:28).

Falkland's missive suggests that the displacement of the Beothuck was not entirely random and unplanned, but for at least one British leader, and in keeping with British 'theory' on this issue as presented above, part of a conscious strategy. 
Neither were the more direct forms of destruction that went along with it entirely 'accidental'. Explicitly planned missions of extermination equivalent to the repeated forays by the French into Iroquois territory were also undertaken by the British settlers, usually justified by a claim of retribution for the loss of material to the Beothuck. The historical literature abounds with such tales, with various commentators taking positions regarding their veracity. Even the most doubtful of historians, however, tends to grant credence to the evidence collected by Captain G.C. Pulling, which appears in a transcription of his 1792 report on the state of Native - settler relations in Newfoundland (Marshall 1989). In 1790, a Mr. Harry Miller told Pulling that he had "sent eight of his men ... in pursuit of some Indians who had the preceding summer taken away some of his Salmon-netts - Traps \& many other things than \& at different times before" (123). Despite the fact that Miller could not have known who was stealing his equipment, and that even if it had been Beothuck, his men could not have known if any people they found were those who had stolen the gear, they set out "fully resolved to kill everyone we saw both Big \& small to be revenged on them for killing Thomas Rowsell the summer before" (123). A classic use of the law of individual - group identification: anyone who looks like 'them' must be 'them'; the one stands for the many and the many for the one, justifying the random slaughter of the Other.

Various governors of the colony issued proclamations apparently intended to stop the killing. The first and most succinct came out in 1769 , and is worth citing at length as an epitome of the confluence and conflict between the official-intellectual discourse of the centre of the British Empire, and actual practices on the periphery:

Whereas it has been represented to the King, that the subjects residing in the said Island of Newfoundland, instead of cultivating such a friendly intercourse with the savages inhabiting that island as might be for their mutual benefit and advantage, do treat the said savages with the 
greatest inhumanity, and frequently destroy them without the least provocation or remorse. In order, therefore, to put a stop to such inhuman barbarity, and that the perpetrators of such atrocious crimes may be brought to due punishment, it is His Majesty's royal will and pleasure, that I do express his abhorrence of such inhuman barbarity, and I do strictly enjoin and require all His Majesty's subjects to live in amity and brotherly kindness with the native savages of the said island of Newfoundland (Proclamation issued by His Excellency Capt. the Hon. John Byron in 1769, cited in Howley 1974:45).

This proclamation was reissued in 1775 and 1776, and a similar edict was put forth by John Holloway in 1807. Even with repetition, the high sounding words had no effect, as magistrates regularly turned a blind eye to the killing of Beothuck by settlers, and no one was ever brought to England for trial as required by the proclamations. I cannot suggest that this systematic inaction occurred 'on purpose', of course - but I can argue that issuing proclamations one expects will be ignored is an extremely useful tool of state formations, as it allows a high-sounding legal gloss to be placed on (in)actions which would be seen as reprehensible within one's own system of morality if admitted openly and thereby exposed to the vicissitudes of analysis.

Of course, there were British 'men in the field' who were not content to stand idly behind a legal-rhetorical screen for physical extermination. At a 1793 Parliamentary Inquiry, John Reeves asked if it were not time that something should be "done for these Indians .... [1]s it not incumbent upon us to use the means in our power to impart to them the rights of religion and civil society?" (Howley 1974:55). Cartwright and Bland recommended, perhaps taking a page from stories of the French experience, that a reserve be put aside for the Beothuck. In 1804, however, William Cull reported in a letter to the governor that, contrary to the opinions of the gentlemen back in England, "the people do not hold with civilizing the Indians as they think they will kill more than they did before" (cited in Rowe 1974:50). As late as 
1827, after 217 years of colonial coexistence, the British were still in a first-contact stage, sending out explorers to acquire information on the mysterious, uncivilized Savages' manners and customs, and trying to establish friendly relations with them. Were they human? Did they deserve protection? Such questions had not yet been decided when they became moot, for one thing the various commentators do agree upon is that by 1829 , the last Beothuck known to Europeans was dead. The last word on this subject will be drawn from the 1837 Report of the Select Committee of the Parliament of the United Kingdom on Aborigines (British Settlements):

On our first visit to that country the natives were seen in every part of the coast. We occupied the stations where they used to hunt and fish, thus reducing them to want, while we took no trouble to indemnify them, so that doubtless many of them perished by famine; we also treated them with hostility and cruelty, and many were slain by our own people as well as by the Micmac Indians, who were allowed to harass them....

Under our treatment they continued rapidly to diminish.... In the colony of Newfoundland it may therefore be stated that we have exterminated the natives (cited in Bartlett 1990:7, emphasis added).

Thus the Beothuck entered, passed through, and disappeared from European history as a "mysterious" people of whose qualities the newcomers remained ignorant. This apparent ignorance has a positive value as a tool in the management of problematic human diversity, as a person who might not exist, or more precisely is not known in the sense of being assigned a set of typical characteristics, is equivalent to a non-person. This fortuitous situation could not last forever, though. As is apparent in the above quotes, from Peckham to the Select Committee on Aborigines, the term 'Indian' slowly began to replace 'Savage' in reference to the Native people of Newfoundland. Within the British discourse, the category of Savage, drawn from the cosmographies and histories, was dominant during Exploration and first contact stages, when extremely little was known about the peoples of the New 
World. 'Indian', a term derived from the widespread and long-lasting European conviction that the New World was in fact a piece of the Old, can be seen as a postcontact term ascribing an increasing measure of particularity to these peoples. The appearance of this term in the Newfoundland context should not be attributed to increased contact between the local settlers and the Beothuck, however, as there is little evidence that this occurred. Rather, it is likely that the term drifted in from Hudson Bay, where, as we will see, the Savages were fairly quickly constructed as Useful Others. There was no agreement made to shift the discourse, and the change did not happen fully, quickly, or without contradiction. But, as we have seen in the language of those presenting themselves as Native 'advocates' in Newfoundland, and as we will see in the discussion of Hudson's Bay Company sources, the term Indian began to replace Savage throughout the eighteenth century in the British colonial discourse, and the increase in its usage was accompanied by a decline in the use of, or at least official ignorance of the unofficial use of, the method of physical extermination.

\section{Microcontrol and Hybridity - The Hudson's Bay Company and the British} Fur Trade

The Hudson's Bay Company was, it is true, a keen trader, as the motto "Pro Pelle Cutem" - "skin for skin" - clearly implies. With this no fault can be found, the more that its methods were nearly all honourable British methods. It never forgot the flag that floated over it.

- George Bryce, in The Remarkable History of the Hudson's Bay Company.

In the Hudson Bay region, where they came with the express purpose of establishing themselves in the fur trade, the British immediately perceived the 
Native peoples as Indians -- Useful external Others - rather than Savages. They learned everything they needed to know about working with Indians from Radisson and Groseilliers, two notorious French coureurs de bois (Instructions to Captain William Stannard... in Nute 1935:419-20). It seems that the backers of the company 'knew', at some level, that they would have been unable to gather a single fur if they had relied upon the "honourable British methods" of ignorance, displacement and extermination used by the quickly bankrupted Newfoundland Company. Without admitting it, indeed likely without any conscious awareness of having done so, the British fur traders assimilated with New World practices evolved by the French and Native peoples, and ultimately gained, at least for the stockholders of the Hudson's Bay Company, immense profits from doing so.

The British at Hudson Bay also made some original contributions to the methodological arsenal of the discourse on Canadian diversity. One of these was a 'legal', 'contractual' means of taking land from Native peoples, as described in the 1680 Instructions to Governor Nixon:

In the severall places where you are or shall settle, you [should] contrive to make compact wth. the Capns. or chiefs of the resepective Rivers \& places, whereby it might be understood by them that you had purchased both the lands \& rivers of them, and that they had transferred the absolute propriety to you, or at least the only freedome of trade, And that you should cause them to do some act wch. by the Religion or Custome of their Country should be thought most sacred \& obliging to them for the confirmation of such Agreements (HBRSS 11:9).

The Company was later to claim that these instructions were consistent with the actions of Zachariah Gillam in 1668, when he "Discovered a river in the botome of the sd. Bay ... where he met with the Native Indians \& haveing made a league of Friendship wth. the Capt. of the said River \& firmly purchased both the river it selfe 
\& the Landes there aboute, he gave it the Name of Rupert River" (Answer of Sir James Hayes to a letter from Labarre, 1683, HBRSS 11:70). As in the case of the Newfoundland proclamations, the key to this process is the difficulty of making it "understood" to people who did not share European notions about 'ownership' and 'title' that they had signed away the right to occupy 'their' land. Those whose values and interests lie with the British interpretation will see a high-minded attempt at "fair play." Those who do not will see yet another creative use of the strategy of ignorance to achieve ends that would, if one were to apply the principles of British justice to Indians, be unconscionable. Whatever its moral status, the utility of this strategy has continued down to the adjudication of present day land claims where, according to Thomas Berger:

it [is] difficult to convince lawyers and judges that the Native peoples of Canada possess rights based on the indisputable fact that they occupied vast areas ... before the Europeans colonized it. They had their own institutions, their own laws. But of this lawyers and judges remained unaware (Berger 1991:150, italics added).

Another contribution of the Hudson's Bay Company was its development of methods of bureaucratic micro-control of the daily lives of its "Servants" and "Home Indians." This approach was made easier by the Company's charter, which granted it possession of all the lands whose rivers emptied into the Bay, gave it sole right to trade therein, allowed it to make and enforce laws, and even to "make peace or Warre with any Prince or People whatsoever that are not Christians" (Newman 1985:1.329). As E.E. Rich has pointed out, “[t]he whole Charter was, in fact, a magnificent grant of rights and privileges, not a specification of duties" (Rich 1958:1.56). From its inception, the members of the Company Council wanted to know every detail of every action of every one who set foot in what amounted to its own kingdom (HBRSS:5.7). Once the trade was up and running, they did not relent in 
their attention to detail, requiring from each factor "Journalls of what hat been done in the respective factories $\&$ of all occurrances that have happened to them in the yeare past that we may know how they \& those under them have emploied their time" (HBRSS:11.73). A 1738 letter from Prince of Wales fort, written in response to queries and concerns from London, has the men in the field answering 53 different questions, many of which seem to have been absurd in their quibbling, e.g.:

10th The large quantity of copper rivets we principally find useful in mending of kettles.

11th We have examined the state of provisions in the account book 1737 and we find it must be an oversight for the pork stand charged thus ... the beef thus ... so likewise the butter thus...

(HBRSS:25.243).

Item 11 goes on to give details of where each cut of beef and firkin of butter has gone, and ends by declaring the company's employees blameless in any misallocation of food. The Company kept this up for several hundred years, thereby amassing an immense pile of incredibly detailed documentation of its activities - or, at least, an official representation thereof. It is often thought that the globalization of capital requires a certain electronic infrastructure to be in place; but the British showed, 300 years ago, that exploitation for the profit of distant capitalists was possible using only the ship, the letter, and the musket.

The many rules and regulations regarding trade and contact with the Native peoples are of particular interest. It is obvious that, at least insofar as they could be caused to yield up land and bring down furs, the Native peoples of the Hudson's Bay area, unlike the Beothuck of Newfoundland, were from the beginning seen by the British as potentially Useful Others. The Company's Instructions to Thomas Draper, issued in 1680, insisted that he "use the greatest circumspection" in his dealings with 
the "Northern Indians," and that he "deal justly with them, and let no body offer them any ill usage to provoke their revenge" (HBRSS 11:14, italics in original). This difference in point of view can also be seen in the replacement of the term 'Savages', which predominated in the Northwest exploration narratives (Quinn 1979: chap. 3, cited above) with the term 'Indians' in the instructions, correspondence, and reports of the Hudson's Bay Company and its associates. This transformation occurred much more quickly, abruptly, and completely than it did in Newfoundland, and could reflect a stronger sense of intimacy and Usefulness being associated with the people to whom the labels were being applied.

While the Indians were seen as Useful Others by the British, they were Useful external Others, definitely to be kept outside, both literally and figuratively. During trading, one person at a time was allowed to come up to a window, there to strike his bargain and yield his place to the next. No Native people were to be allowed in the storehouse, nor were they welcome on the ships (HBRSS:25.128,268). Private trade was repeatedly forbidden, and to discourage "debauchery," the Council did "absolutely prohibite ... women to be entertained or admitted into our Forts or houses under the penallty of the forfeiture of their wages" (75). Finally, at the conclusion of their trade, those Indians not of the Home Guard' were encouraged to migrate back inland, "the less opertuney will be given to our serveants for private Trade or debauchery with them" (HBRSS 11:76).

But colonial capitalist rational-legal domination, as effective as it might be, can never be perfect or total. Despite the official regulations, there was constant unofficial contact between the Servants of the Company and the Native peoples, for the exchange of pelts and bodily pleasures. At both Moose Fort and Eastmain, the masters took Indian wives, and their children became important players in the fur trade (Francis \& Morantz 1983:90). Jennifer Brown claims that "it is possible to 
document at least fifteen instances of Hudson's Bay men ... taking Indian women as

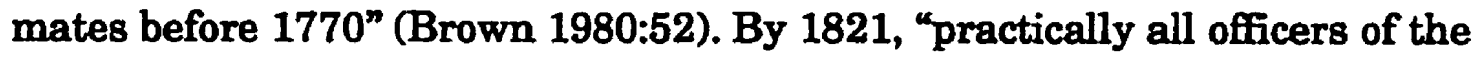
Hudson's Bay and Northwest Companies, and many lower-ranked employees as well, were allied with women born in the Indian country" (Brown 1980:51). These alliances gave rise to a considerable, but widely scattered, Half-breed population which, along with retired White traders, was not seen as assimilable by either Canada or Great Britain, and was therefore cast as a surplus, problematic group:

It comes to be a serious consideration how these people are to be disposed of. It is both dangerous and expensive to support a numerous population of this description in an uneducated and savage condition, and it would be impolitic and inexpedient to encourage and allow them to collect together in different parts of the country, where they could not be under proper superintendence. The establishment of clergymen and schools at the Red River Settlement, where means of instruction will be afforded them, and where they will be under a regular police and government, by the establishment of Magistrates ... points out the proper mode of disposing of this numerous class of persons ( $H B C$ Committee to Gov. Simpson, March 8, 1822, cited in McLean 1987:49, emphasis added).

Once again, difference -- now only partially Savage, but that was enough -- was to be collected, contained, and subjected to the salutary effects of European law and religion. Rather than solving the problem, however, this method of "disposition" of problematic hybrid bodies only set the stage for their later displacement as the lands controlled by the Hudson's Bay Company were bought - or invaded, or welcomed into Confederation, as one will have it - by the Canadians

\section{The Early Colonial History of Canadian Diversity}

By way of their operations up to the end of the seventeenth century, the British and French ensured, between them, that the methods of both the Greeks and the Romans were preserved and brought to bear upon the construction and 
management of the problem of diversity in the New World. Fabulous, semi-human Others, often right out of the cosmographies and histories, were 'discovered', and dealt with by means of the interlocking systems of xenophobia - ignorance extermination, and exploitation - knowledge production - assimilation. The European discourse on diversity was thus transplanted and reproduced; but this was a creative reproduction in a new context, which gave rise to novel forms. The French colonial experience contributed the notion that the existing peoples were to be taken on as wards, helped, changed, elevated, and also developed methods to carry out this task. This practice of tutelage, which can be seen as compatible with the modern European idea of educating the masses, was something that did not occur to Greeks and Romans, nor to medieval Europeans. In those systems, it was quite fine, if not preferable, to leave the people in ignorance, so as to render them more easy to govern. The French brought modern ideas about individual development to the New World, and showed how they could be used as a tool of exploitation and domination.

In the early colonial era, the particularity of the British contribution does not yet show up, except in nascent form. But already, in futile proclamations regarding the Beothuck of Newfoundland, and the land purchases' around Hudson's Bay, we can discern the outlines of what would become the most important and enduring British contribution to the Canadian discourse on diversity: the adoption of a mode of legalized domination and disenfranchisement that allowed all manner of dishonest and inhuman practices to be used, but always with a gloss of high civilization and due process. The strength, usefulness, and longevity of this contribution can be seen in the particularly Canadian propensity for state-sponsored sinning - e.g. by invoking the War Measures Act - followed by an attempt at gaining absolution through public confession at a commission of inquiry. The British, through the offices of the Hudson's Bay Company, also showed that distant, centralized control of a vast tract 
of land could be implemented with a rather startling degree of success given the technologies at hand. When it came time for Canada to graduate from colony to country, the methods of distant micro-management pioneered by the London Committee were not forgotten by thcse who took it upon themselves to do the same sort of thing from their base in Ottawa.

But the greatest gift given by Europe to the Canadian discourse on diversity came from both the English and the French, in the form of a binary system of SelfOther distinction that both allowed the immediate work to be done, and has also proven to be amenable to infinite multiplication and permutation as the problem of Canadian diversity has evolved. The early British-colonial square of <Group Identity $>$ was similar to the French, except that $<$ British $>$ occupied the position of $<$ French $>$ as the dominant identity, and the distinction between Savages who would assimilate and those who would not was now marked through the use of a different name: Savage for the Useless external Native Other, and Indian for the somewhat Useful marginal Other. Noting that the British and the French were locked in a battle to drive each other off the continent, we can see that they took on a mutually complementary relationship, where each threatened the very possibility of existence of the other's system of identification. Thus the French belong with the Savages, as neither British nor Indian, and not possessing British subjectivity. As what would become known as the Half-breed did not yet possess any kind of official recognition, I will leave the contradictory term blank. 
Figure 4.2 - Group identity in early British colonial discourse (<Canada>)

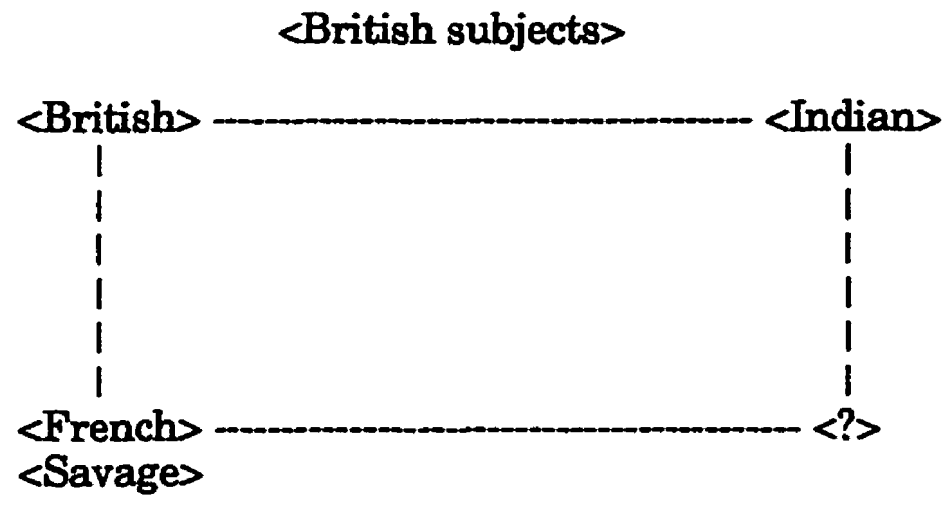

«ot British subjects>

Through their mutual complementarity, the French and British came to be intimately connected as Imaginary Others to each Other, lurking just beyond the forest, one river or trading post away, or across the ocean in the Old World; never fully present, but never quite forgotten either (Je me souviens / What do they want from us?).

\section{Notes}

1 Throughout this section, I will use the term 'Savage' only as it pertains to a discursive category appropriate to the European discourse on diversity as it was brought to the 'New World'. I do not believe that there is, or ever was, a referent for this term, and do not intend it to apply to any person or peoples who live, or have lived, in what is now known within the dominant British-Canadian culture as North America'.

2 An allusion to the quote from Virgil in chapter 2.

3 Chapter 4 of Quinn's New American World (1979), an excellent compendium of primary sources, provides countless examples in dozens of thinkers and Explorers. 


\title{
Chapter 5
}

\section{Integration and Administration in British North America}

\author{
Open your eyes, Canadians, to your own interests.... We exhort you \\ eagerly to have recourse to a people, free, honest, and generous.... For if \\ you do not profit by this advice, you must expect the most rigorous \\ treatment....
}

Proclamation by. G. Murray to the people of Quebec, 1759, (cited in Nish 1966:5).

The status of the French as the antagonistic equals of the British, outlined at the end of the previous chapter, was - and still is - far from stable. In fact, the dualcomplementary system of what are now known as the Two Founding Races began to shift at the turn of the eighteenth century, when the ascending British empire first glanced covetously, then stared unashamedly, at the prospect of taking as its own the whole of North America. Now, according to the terms of European colonial discourse, the benefits of Colonization must not accrue only to the Conquerors; the Conquered must also be constructed as somehow being 'raised' by the destruction of their way of life and the removal of their autonomy. In his Outline of a project to capture Quebec and Placentia (circa 1700), the Baron de Lahontan cunningly suggested that what the British had to offer to the French was exactly what the British and French had been offering to the Savages: the gift of a superior civilization:

What makes me believe that the English will attain the end of this enterprise [the capture of Quebec] easily is the mildness of the English government, which the inhabitants of Canada would hope to experience, for finally I heard them speak a great deal of it when Sir William Phipps came there, and they had hoped that he could have succeeded, thus ensuring them liberty of conscience. There are not two hundred families 
in Canada who could not wish with all their hearts to be under English rule... (Lahontan 1940:41).

Thus, the French in Canada were set apart as inferior and in desperate need of gifts that might improve their lot -- they were granted the possibility of a New World identity as Others to the British Self. This, in its most compact form, is the source of the sting of Conquest; to be shifted from Self in one's own system to Other in an Other's, to go from position to negation, to be managed as a problem rather than managing problems oneself.

As I show in the following section, the Conquest / Cession of New France was no simple matter. While the French army and bureaucratic infrastructure could be eliminated through brute force, the people - as seen in the failed attempt to transport the Acadians -- posed a much more difficult problem. This was especially true in the St. Lawrence region, where the logistical problems of a transportation effort would have been overwhelming. After several failed attempts at assimilation, the British finally gave in and allowed the French to preserve and maintain signs of their problematic difference, making them the first group to be granted the gift of what is now known, within multiculturalism policy, as integration. A similar shift in management style can be perceived in the British handling of 'the Indian problem'. Displacement - and the concomitant loss of the means of subsistence - now functioned as an indirect means of physical elimination, and the bodies that remained were collected together, made sedentary, and put under a regime of rational-bureaucratic tutelage that not only persists, but has been steadily increasing its size and scope, up to the present day. This passage from methods of physical elimination to preservation and integration, I will argue, has become a Canadian archetype, providing a trajectory through the identity-space of Canadian diversity 
that would be followed by each new group created through the ongoing proliferation of the problem of Canadian diversity.

\section{The Conquest / Cession of New France}

Although much is made of the fall of Quebec, the Conquest / Cession of New France began in 1710 with the capture of Port Royal, after which time the British were able to stake a lasting claim to the much-disputed territory of Acadia. As I noted in chapter 1, the British attempts to solve the problem posed by the Acadians comprise another of those "unfortunate" occurrences in Canadian history which, as with the handling of the Beothuck, are covered with an ornamental sheen by the official history of already achieved multiculturalism. Again, historians dispute the details. Rather than try to remove a 'mask' to expose a 'truth', though, I will focus, as I did with the Beothuck, on how the history has been put in place, and what its existence might mean for the problem of Canadian diversity. In particular, I will focus on the way in which the British seemed to flail about, grasping tools in the kit of human diversity management only to drop them again, and thereby failed utterly to 'solve' the problem of Acadian diversity in any definitive way. This, I would suggest, is the source of any historical embarrassment; not that ignoble methods were used, but that all methods, noble or otherwise, so obviously failed to achieve their goal in the face of Acadian resistance.

The guns hardly had time to cool before the first - and most radical - solution to the problem of Acadian diversity was proposed:

All French must be deported outside the country, save those who adopt Protestantism. ... [1t would be most advantageous for the Crown that this measure be effected with all possible speed and that they be replaced with Protestant families from England or Ireland (Council of Victors, October 14, 1710, cited in Arsenault 1966:73). 
Like the Beothuck and Iroquois before them, the Acadians were clearly in the way'. But they could not be displaced and exterminated, because their European connections meant that they had to be seen as both civilized and human. Thus the Council of victors quickly and intuitively found another way to justify treating the French as objects rather than subjects: they were found to be problematic Others on the basis of a lack of Protestant religion. A method well-suited to this sort of partial Otherness seemed to be transportation, which could appear as a 'soft' or 'humane' means of physical elimination. This strategy, especially when coupled with a subsequent cleansing by way of importation of Desirable Selves -- "Protestant families from England or Ireland" - appeared admirably suited to the task of remaking the human landscape to suit the new regime of group identity.

But, after some thought, it became apparent that even transportation might have ill effects on British interests, as the French of 'Nova Scotia', once added to those already at Cape Breton, would be "of the greatest danger and damage to all the British Colony's as well as the universal trade of Great Britain" (Letter from Colonel Vetch to the Lords of Trade, Nov. 24 1714, Akins 1972:18). The British then began to hope that assimilation would solve the Acadian problem: "tho' we may not expect much benefit from them, yet their children in process of time may be brought to our constitution" (Lt. Gov.. Caulfield to Board of Trade and Plantations, Nov. 1715, in Akins 1972:9). Indeed, the gift of toleration - the necessary counterbalance while waiting for assimilation to have its effects - had been bestowed upon the Acadians in Article XIV the Treaty of Utrecht of 1713 . Those who wished to leave were given a year in which to do so:

[b]ut those who are willing to remain here, and to be subjects to the Kingdom of Great Britain, are to enjoy the free exercise of their religion according to the usage of the Church of Rome as far as the laws of Great Britain do allow the same (Akins 1972:14-5). 
Selves, of course, do not need to be tolerated - no special provisions need to be made for them, they are not even noticed. It is only when one is in the presence of what appears to be intolerable difference that tolerance becomes necessary and, in many cases, manifests itself as a gloss on hidden resentments. This the Acadians seem to have understood all too well, complaining often to the King about their treatment over the next several decades, as a battle of Oaths of Loyalty, trade in corn, and religious dogma played itself out. The British continued to try to hammer them into submission rather than neutrality, claiming that "they have remained upon their possessions in contempt of the Government, waiting the opportunity of a rupture between the two Crowns to re-establish their former Government, and in the mean time are daily in secret, inciting the Indians to robbery and murder, to the destruction of trade and hindrance of settling the country" (Gov. Phillips to Lord Carteret, circa 1720, in Akins 1972:19). For their part, the Acadians continued to complain that they had "preserved the purest sentiments of fidelity to our invincible monarch" and had not been treated fairly in return (Letter of the inhabitants of Acadie to Mr. St. Ovide, May 6 1720, in Akins 1972:25).

Royal tolerance proved to be short-lived, and more drastic measures were soon sought. Of course, the ground had to be prepared, by way of much handwringing over the intractability of the Undesirable bodies. Governor Lawrence was one of the most vocal in proclaiming the lack of efficacy of kind treatment, basing his opinion, in the anthropological style, upon first hand experience and intimate contact with the Other:

[The Acadians] have long been the object of my most serious attention, which, with the frequent experience I have had of them in the course of my duty, has enabled me to form an opinion of them and their circumstances that I shall now take the liberty to lay fully before your Lordships, together with such measures as appear to me to be the most practicable and effectual for putting a stop to the many 
inconveniences we have long laboured under from their obstinacy, treachery, partiality to their own Countrymen, and their ingratitude for the favor, indulgence and protection they have at all times so undeservedly received from His Majesty's government (Lawrence to Lords of Trade, August 1 1754, in Akins 1972:213).

The ethnographic style of intimate, first-hand knowledge displayed in Lawrence's text is important, as it shows how the Acadians, who were obviously 'human' and at least relatively 'civilized', came to be increasingly differentiated from the British as a separate 'people'. Later historians, such as Francis Parkman, have clumsily painted this over, by claiming that the problem with the Acadians was that they were of a different race (e.g. Parkman in Griffiths 1969:41, Brebner in Griffiths 1969:92) - but there is no evidence that this innovation in human differentiation had infiltrated the official British discourse of the time. Governor Hopson could not tolerate the Acadians because they were "so ignorant and so bigoted a people" (Hopson to Lords of Trade, July 1753, in Akins 1972:199); the Lords of Trade wrote of the lack of an Oath as "an Obstacle to the Industry and Quiet of these People", and did not object to "sending proper Persons amongst these People, to endeavour to quiet them" (Lords of Trade to Gov. Lawrence, March 4 1754, in Akins 1972:207); Cotterell, acting Provincial Secretary, felt that it was "both unsafe \& unprecedented to trust our cause in the Hands of people of their Persuasion" (Cotterell to Capt. Scott April 12 1754, in Akins 1972:208). The construction of the Acadians as an intractable Other, a 'people' that could not be exterminated, assimilated, or tolerated, culminated in official acceptance of the strategy recommended by Lawrence, which was the same as that of the Council of Victors in 1710: "it would be much better, if they refuse the Oaths, that they were away" (Akins 1972:213).

The results of this forcible removal are now on record in English Canada, thanks to books like the History of the Acadians (Arsenault 1957). It is commonly 
accepted that the Acadians were rounded up by British soldiers, and in the confusion "women were loaded onto ships other than the ones which carried their husbands, and children became orphans forever at the very point of embarkation" (1957:143). Not in the realm of 'common knowledge' - and certainly excluded from the multiculturalist history of Acadia - is the story of Lawrence's campaign of destruction of the countryside, hoping to starve out those who had escaped being loaded onto the ships. "Six hundred and eighty-six houses, eleven mills and two churches were set on fire in the two parishes of Grand-Pré and Rivère aux Canards alone" (147). Many Acadians, however, had friends and relatives amongst the Native inhabitants of the region, and so were able to flee into the woods:

Governor Lawrence decided to get rid of them by putting a bounty on scalps. In a proclamation dated May 14, 1756, he guaranteed 30 pounds for the scalp of every male Indian over 16, and 25 pounds for scalps of younger males or for any female or child brought back alive. A number of English soldiers, however, confused Indian and Acadian scalps. They had the legal excuse that officially all Acadians had been deported from Nova Scotia (162-3).

Those who weren't burned to death, starved, or scalped faced a fate not much better on the heavily overloaded and poorly provisioned ships that Lawrence sent out from Acadia to the British colonies to the South. Six ships destined for South Carolina were forced to land in Boston, where it was discovered that they did not have adequate supplies to reach their destination. The people were kept in Massachusetts, "bound by contract to English masters," and prevented from leaving the colony to look for lost relatives without first obtaining a pass (152). "Virginia flatly refused to receive the 1200 Acadians deported there. They were detained for some time at Williamsburg, where an epidemic broke out, killing of hundreds of them" (156). In Georgia, the British North American view of the Acadians was made most 
explicit, as they were "put to work on the plantations with the Negro slaves" (157). What was supposed to have been a relatively 'soft' transportation led, once again, to enslavement and extermination, justified by the problematic Otherness of a people who professed the wrong religion, spoke the wrong language, and thereby forfeited what would otherwise have been a claim to full humanity. The handling of the problem of Acadian diversity already showed the futility of rational-bureaucratic management of problematic human Others, as it cycled through military conquest, failed assimilation, and failed tolerance, to settle upon physical elimination and extermination via transportation.

With the capitulation of Quebec, the British were faced with a problem similar to the one they had brought upon themselves in Acadia. The Fourth Article of the Definitive Treaty of Peace (1763) is interesting in that it set up the same situation as that which ended so disastrously in Acadia, by allowing that "the French inhabitants ... may retire with all safety and freedom wherever they shall think proper ... and bring away their effects... the term limited for this emigration shall be fixed to the space of eighteen months" (Maseres 1772:85). Always resourceful, the British had not relied entirely upon this one method of managing problematic diversity. A form of religious tolerance was granted, in both the 1760 Articles of Capitulation (Nos. XXVII - XXXV, in Maseres 1772:77-78), and in the Fourth Article of the Definitive Treaty of Peace (84-85). The British king also thought it wise to give the gift of British laws and political institutions, by way of the famous Royal Proclamation of 1763. The goal of this policy was to bring about "the absorption of the French nation by the English, which in matters of language, patriotism, law and religion is evidently what is most desirable and could perhaps be realized in one or two generations" (Maseres, cited in Bergeron 1975:49). Thus, once again, the gifts of religious tolerance and 
liberal political institutions were bestowed as stop-gap measures intended to encourage assimilation in the long run.

As is well known, this policy also failed to achieve its goal, and so the British found themselves forced, after so many failed attempts at physical elimination and assimilation, to take on signs of Frenchness. By way of the Quebec Act of 1774 , the British officially "established" hated French Popery in Quebec, allowing that "the Clergy of the said Church may hold, receive, and enjoy, their accustomed Dues and Rights" (RSC 1985 Appendix II, No. 2, Article V). A new oath was designed for Roman Catholics to take, so that they could become civil servants without becoming Protestants (Art. VII). The British also conceded that their laws might not be the best for everyone everywhere all the time, by decreeing that "in all matters of Controversy, relative to Property and Civil Rights, Resort shall be had to the Laws of Canada" (Art. VIII). Of course, the King reserved the right to provide support for the Protestant clergy and the "Encouragement of the Protestant Religion" (Art. VI), and British criminal law would stay in place (Art. XI). This was the first attempt at officially integrating a problematic 'Canadian' population that could not be eliminated or assimilated, and set a precedent that would be followed, over the next two centuries, by each new group in an expanding ethnocultural economy.

\section{The Emergence of the Two Founding Races}

The Quebec Act was passed and put into effect, but it was not long before the American revolution brought several thousand British Toyalists' to the Province, thus exacerbating the rather paradoxical problem of British diversity in a British colony. These new Canadians had just fled from thirteen colonies that were becoming far too un-British for their liking; what a surprise to find themselves surrounded by Frenchness in their place of refuge! Like the English merchants who arrived to 
exploit New France after its Conquest / Cession by arms, the American Immigrants had high expectations from their new home; precisely, they expected to assimilate it, rather than have it assimilate them. Certainly this sort of hehaviour would not have been tolerated if it had been displayed by any other 'minority group'. But these got a sympathetic hearing from the Lieutenant Governor of the time:

A principal object for the consideration of the Legislature is the arrival in this Province of numbers of Englishmen or the descendants of Englishmen who must abhor their being subjected to an authority they have been unacquainted with, and to men whose language \& customs they are as yet strangers to. Provision by Law should be made to conciliate these people, and if possible prevent complaint by anticipating their grievances (Hamilton to Sydney, April 1785, in $D R C H C: 1.527)$.

Conciliation of the British-American Immigrants came in the form of the Constitutional Act of 1791. Canada was split into two large pieces, with one (Upper) space for those who identified with Britishness, one (Lower) for those who preferred Frenchness. In its Preamble, the Constitutional Act noted that the Quebec Act had been found "in many Respects inapplicable to the present Conditions and Circumstances" of the Province (DRCHC:1.696), and was therefore to be repealed. Of course, the Quebec Act was itself supposed to have been a solution to the problems created by the Royal Proclamation of 1763, which was intended to solve the problems of military rule. Thus began the dance of antagonism between the British and French which persists to the present day. In its first thirty years, Canada had already gone through four constitutions with no more progress being made than confining the English and French to their own separate territories.

This did not work either, of course, as was clearly shown by the violent rebellions, in both Canadas, of 1837-39. The fact that physical force had been necessary to keep down their supposedly loyal colonial subjects attracted the 
attention of the British Parliament, which sent out Lord Durham to report on the state of affairs there. As a "High Commissioner," Durham took it upon himself to bring about a quick, yet final, solution to a crisis situation, using language that is all too familiar to Canadians who have seen dozens of such commissions come and go. "Every day during which a final and stable settlement is delayed, the condition of the Colonies becomes worse, the minds of men more exasperated, and the success of any scheme of adjustment more precarious" (Durham's Report, in Lucas 1912:2.10). To fulfill his mandate, Durham provided yet another definition, and proposal for the solution, of the problem of Canadian diversity. In the Introduction to his report, he noted that his opinions on the Canadas had changed upon crossing the Atlantic. The common wisdom in England, which held that the problems were caused by inappropriate design and implementation of political institutions, was off the mark:

I expected to find a contest between a government and two nations warring in the bosom of a single state: I found a struggle not of principles, but of races; and I perceived that it would be idle to attempt any amelioration of laws or institutions until we could first succeed in terminating the deadly animosity that now separates the inhabitants of Lower Canada into the hostile divisions of French and English (2.16).

Thus the notion of racial difference lodged itself in official Canadian political discourse, playing the explanatory and causal role that had previously been allocated to the concepts of nation and people.

The idea that the French and English might be of different races did not, of course, come from nowhere. Scholars differ as to precisely when the term 'race' was first used with the connotations it has today, but by the end of the eighteenth century, the word was becoming current in Europe. Petty used it as early as 1677, and Francois Bernier in 1684 (Todorov 1993:99). Theo Goldberg has argued that "the concept of race enters European social consciousness more or less explicitly in the 
fifteenth century" (Goldberg 1993:21, italics added), while duBois is of the opinion that the concept did not come into play until the late 1700's (duBois 1991:92, Note 1). Whatever its origin and development in the various European languages and intellectual communities, there is little doubt that differentiation by race was on the rise, adding natural-historical credibility to the Great Chain of Being. Thus Durham was able to use race as a means of assuring himself, and his audience, that there was a scientific-transcendental 'cause' for the problem of Canadian diversity in the 'fact' of racial divisions. Thus armed, the possibility that French hatred for the English had something to do with a history of being treated as an inferior and problematic Others in need of gifts of Britishness did not have to enter into the High Commissioner's text. It was all in the bodies, the 'blood' -- it was natural. Since Durham's report sits at a nexus of racial, rational-bureaucratic, and imperial-colonial discourses that have had profound effects on the history of Canadian diversity, I will devote some time to showing how it epitomizes the discursive conditions that enabled the emergence of the antagonism between the British and French as one between two 'Canadian races'.

After claiming that "our happy immunity from any feelings of national hostility renders it difficult for us to comprehend the intensity of the hatred which the difference of language, of laws, and of manners creates" (1.17), Durham went on to present what he considered to be the generic characteristics of Canadian racial diversity. The French population, descended as it was from the despotic regime of New France, he described as "a race of men habituated to the incessant labour of a rude and unskilled agriculture, and habitually fond of social enjoyments ... they made little advance beyond the first progress in comfort, which the bounty of the soil absolutely forced upon them; that under the same institutions they remained the same uninstructed, inactive, unprogressive people" (2.28). Here, we might note, 
Durham's description ascribed to the French inhabitants of Lower Canada several qualities of Savagery and Barbarism. Indeed, he claimed that "the continued negligence of the British Government left the mass of the people without any of the institutions which would have elevated them in freedom and civilization, that would have assimilated their character and habits, in the easiest and best way, to those of the empire of which they became a part" (2.30-31).

Durham's description of the English race was much more kind. "Among these people [the French], the progress of emigration has of late years introduced an English population, exhibiting the characteristics with which we are familiar, as those of the most enterprising of every class of our countrymen" (2.34). These entrepreneurs, by their very nature, "drove out of all of the more profitable kinds of industry their inert and careless competitors of the French race" (2.35). According to Durham, the same thing happened with farming. "The English farmer carried with him the experience and habits of the most improved agriculture in the world.... He often took the very farm which the Canadian settler had abandoned, and, by superior management, made that a source of profit which had only impoverished his predecessor" (2.36). In "every branch of industry" the English race flourished, due to its "superior energy, skill, and capital" (2.36). Durham went on to devote many further pages of his report to the problems created by differences in language, religion, and so on, before concluding his discussion by stating that "the superior political and practical intelligence of the English cannot be, for a moment, disputed" (2.46). Certainly not by an Englishman like Durham, who for all of his lack of understanding of "feelings of national hostility," blithely reproduced the salient features of English prejudice, leaving no doubt that the 'differences' between the two races amounted to a hierarchy, in which the British race occupied the dominant position. 
Durham's estimation of the two races of Canada displays all of the characteristics of what Tzvetan Todorov has referred to as the five central "propositions" of "racialist doctrine" (1993:91 - 6). The first of these is belief in the existence of races, i.e. in the affirmation that "there are human groupings whose members possess common physical characteristics," which may be "proven" by physical measurements and observations, as in craniology. The second is "continuity between physical type and character," or the idea that "physical differences determine cultural differences" (92). Todorov's third proposition is a version of what I have referred to as the law of individual - group identification, in which it is assumed that "the behaviour of the individual depends, to a very large extent, on the raciocultural (or 'ethnic') group to which he or she belongs" (93). Fourth is the assumption of a hierarchical ordering of the races, and last is what Todorov calls a "knowledgebased politics," based on the idea that there is a "need to embark upon a political course that brings the world into harmony with the description provided" within the hierarchical ordering (94).

If Durham was relatively original in giving the problem of Canadian diversity a basis in race, he was not so innovative regarding the political course needed to achieve racial harmony. He was afraid to allow further integration of the French, or even to reconvene the Assembly of Lower Canada, which had been once again 'prorogued': “In the present state of feeling among the French population, I cannot doubt that any power which they might possess would be used against the policy and very existence of any form of British government" (Lucas 1912:2.306-7). Thus he conceived the idea that "tranquillity can only be restored by subjecting the Province to the vigorous rule of an English majority; and that the only efficacious government would be that formed by a legislative union" (2.307). What was "efficacious" was, as 
always, determined by the power-law of sign flow, now adapted to parliamentary rather than physical warfare. Durham did the numbers:

If the population of Upper Canada is rightly estimated at 400,000 , the English inhabitants of Lower Canada at 150,000, and the French at 450,000, the union of the two Provinces would not only give a clear English majority, but one which would be increased every year by the influence of English immigration; and I have little doubt that the French, when once placed, by the legitimate course of events and the working of natural causes, in a minority, would abandon their vain hopes of nationality (2.307).

Durham felt that re-unification under more pleasant demographic circumstances than those which obtained in 1791 would lead to French assimilation and would "at once decisively settle the question of races" (2.309).

Despite objections from both Upper and Lower Canada, the British centre accepted Durham's recommendation of re-unification. With uncharacteristic dispatch the Union Act was passed, creating the Province of Canada and, it was hoped once again, solving forever the problem of Canadian diversity. We now know this to have been overly optimistic; being placed in a minority and having their language rights revoked did not diminish the national aspirations of French Quebec by any means - rather than solving the problem, re-unification just shifted and intensified it. The British desire to take and hold 'Canada', however 'Canada' might be defined, has proven to be a source of endless problems and solutions, countless states of crisis, along with an infinity of commissions, legislation, and constitutional reform that have each time been trumpeted as the End of the Problem, and have always failed at providing any sort of solution at all. The enactment of this desire, I would suggest, created that aspect of the problem-solution set of Canadian diversity which displays itself today as an insoluble antagonism between Two Founding Races. Already, by 1841 , the full gamut of Old and New World strategies for the 
management of problematic internal Others had been attempted with the French and found lacking. No new ideas seemed to be forthcoming; history, as is its wont, was beginning to repeat itself.

\section{Rational-Bureaucratic Tutelage - The Indian Problem Under British Rule}

Established in small communities under the Jesuits and Recollets, acting as allies in war and the fur trade, and having proven themselves, under Pontiac, to be capable of successfully resisting the expansion of European civilization into their traditional lands, the Native peoples of the St. Lawrence region - unlike the Beothuck of Newfoundland - could not be ignored by the new British regime. However, while they were definitely seen by the British, the Native peoples of Canada were not seen as equals. To the British mind, the Indians were even more incapable of appreciating the subtleties of parliamentary democracy and capitalist entrepreneurship than the French. Thus they were to be protected from some forms of European depredation, as prescribed in the Royal Proclamation of 1763, which set aside a large 'reserve' for the use of the Indians, who were to occupy spaces outside of the realm of European civilization and function as semi-Useful external Others, according to the Hudson's Bay model, under the legislated care of the King (RSC 1985 Appendix, No. 1).

But the protections offered by the British King and his bureaucratic apparatus turned out to be as ineffective as the edicts against killing Beothuk in Newfoundland, since the Proclamation also provided a legal means by which Native people could continue to be exploited and displaced:

[T] at any Time any of the Said Indians should be inclined to dispose of the said Lands, the same shall be Purchased only for Us, in our Name, at some public Meeting or Assembly of the said Indians, to be held for 
that purpose by the Governor Or Commander in Chief of our Colony respectively within which they shall lie (128).

That master of the interlocking colonial system of law, politics, and capital accumulation, the famous Governor Simcoe, was able to carry out an expansion of the boundaries of the Euro-Canadian ecumene that was "orderly and fully consistent with the dictates of the Proclamation" (Henderson 1980:8). Thus the Native nations were driven further into what at first seemed to be a hinterland of infinite expanse, "as settlement of the country advanced, and the land was required for new occupants, or the predatory and revengeful habits of the Indians rendered their removal desirable" (Report on the Affairs of the Indians in Canada, 1845 [Bagot Report]:5).

The results of this expansion are well known and documented (Berger 1991; Cardinal 1969; Cumming \& Mickenburg 1972; Henderson 1980; Leslie and Maguire 1978; Waubageshig 1970). With the rise of European self-sufficiency, the declining importance of the fur trade, and relative peace with the United States, the Native peoples on the margins of an expanding Canada were no longer needed in their traditional roles, and thus were progressively transformed from relatively Useful semi-external Others into a large, Useless, and problematic, internal population:

You came as wind blown across the great Lake. The wind wafted you to our shores. We received you - we planted you - we nursed you. We protected you till you became a mighty tree that spread thro our Hunting Land. With its branches you now lash us (Mississauga Chief to William Graves, circa 1820, in D.B. Smith 1989:43).

British colonial policy shifted again, to allow for the conversion, civilization, and eventual assimilation of those Native nations that had been reduced to a state of relative submission. In 1775, a "Plan for the Future Management of Indian Affairs" divided British North America into two districts, each with a Superintendent 
of Indian Affairs and a number of deputies. The Superintendents were granted sole power to purchase lands, apply British civil and criminal laws, and appoint Indian leaders (DRCHC:1.428). To contrcl the body, one must also control the soul. As the Society for the Propagation of the Gospel was chased out of the United States by the American revolution, it began to do this sacred work in the Canadas. In 1782, a missionary was sent to Six Nations at Niagara, and in 1784 to the Mohawk at Kingston. From 1820 to 1830 the reports and recommendations came thick and fast, as French experiments from the 1600 's were repeated by the British: houses were built; missionaries and agricultural tools were sent out; and six Indian boys were placed in a school in Lower Canada. (Bagot Report:7). However, none of this activity had the desired effect, so that in 1836, Sir Francis Head declared that the "attempt to make farmers of the Red men has been generally speaking a complete failure" (Parliamentary Papers 1839:125, cited in Bagot Report:11).

But this did not stop the rational-bureaucratic machine -- it only spurred it on to further action. A flurry of legislation followed the Bagot Report, beginning with the "Act for the better protection of the Lands and Property of the Indians in Lower Canada" (Statutes of the Province of Canada: 13 \& 14 Victoria Cap. 41-42, 1850, and the "Act for the Protection of the Indians in Upper Canada" in the same year (SPC: 13 and 14 Victoria, c. 74). The Protection legislation, designed to keep the Indian Others in their assigned places as internal Others, was soon followed by a complementary Civilization Act, which was supposed to make them less problematic. The 1857 "Act to encourage the gradual civilization of the Indian Tribes" - like the 1969 White Paper - sought to "encourage the progress of civilization among the Indian tribes ... and the gradual removal of all legal distinctions between them and Her Majesty's Canadian Subjects" (SPC: 20 Victoria, Cap. 26, Preamble). As the writers of the Bagot report noted, the expansion of the Canadas 
left the Native peoples in "a state of tutelage, which although devised for their protection and benefit, has in the event proved very detrimental to their interests" (6).

Thus was the first bureaucratic machine for microcontrol of Indian lives instituted; a hybrid of British rational-legal authoritarianism and French paternalism, it survives to this day as the model of interaction between European and Native societies. In commenting upon this system, Noel Dyck has described it as "coercive tutelage," or "a form of restraint or care exercised by one party over another as well as the condition of being subjected to such protection or guardianship" (Dyck 1991:24). He has also noted how the history of "the Indian problem" has seen "both active and passive modes of resistance," which have "served to validate the assumptions that underpin institutionalized tutelage. Indians' refusal to respect the authority of their tutors has been interpreted as a further sign of their confusion and inability to know what is best for them" (27). This justifies a further round of action. I would see this system of tutelage as an instance of what I have described, in chapter 2, as a self-reproducing problem-solution set based on proliferating rational-bureaucratic action. Just as the possibilities of handling the French had already been exhausted by the middle of the nineteenth century, the Indian problem was similarly set in its groove and showing signs of desperate, imitative reproduction.

To summarize this section, as Canada became British, the discursive position of the Savage - uncivilized, Useless, external, monstrous Other -- gave way to that of the Indian under tutelage - the semi-wild, Useless, internal, inferior but definitely human Other. This period saw a shift from past methods of ignorance and physical elimination by extermination to softer forms of physical elimination, involving orderly, legal displacement. When the limits of displacement were reached, the Indian 
was then acknowledged to be 'inside', and subjected to various forms of rationalbureaucratic management and control, for purposes of elimination of signs of difference via assimilation. In this way the British adopted methods pioneered by the French, and added a gloss of "due process" to make it all seem quite proper and legal. The British also used Canada to further develop their eariy experience with the micro-management of distant lands and peoples via the Hudson's Bay Company. Out of this confluence of early French and British methods of managing human diversity, there emerged a particularly Canadian form of paternalistic rational-legal

domination - through integration and administration - that has come to define, more than any other characteristic, the Canadian Way.

\section{Group Identity in British Canada}

In this chapter I have shown how, from the eighteenth century on, the British reorganized their systems of human differentiation and management to adjust to the problems of diversity created by their expanding empire. It was no longer a question, as in the early colonial era, of dealing with - or ignoring - semi-human, semi-civilized, semi-Useful external Others; the Others were now internal as well as external, Civilized as well as Savage, and very obviously existing and present. Thus, with the rise of British control over the territories that would become known as Canada, there was a compensating shift in the discourse of identity, to make way for the Second Others of the New World: the Canadiens. Just as the French in New France were shifted from the position of external Others to internal Selves, the contained Savage became the Indian and moved from the complementary position to the contrary. In the territories exploited by the Hudson's Bay Company, the emergence of British Native Half-breeds added to the problem of contradiction attributed to the French 
hybrids. The particular shifts that occurred as Canada became British can be inscribed on the square of <group identity> in British Canada as follows:

Figure 5.1 - Group identity in British Canada

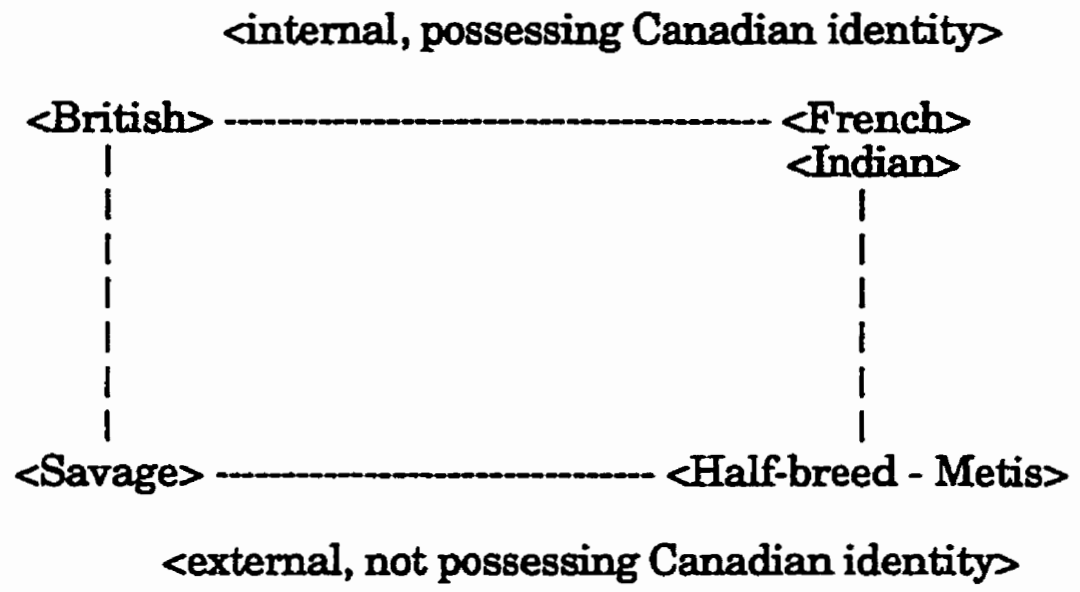

Despite these efforts, the British were not able to solve the problems they had set for themselves, and fell into a stupor of imitative reproduction that lingers to the present day. But this 'failure' was, paradoxically, also a success, as it ensured that the problem of Canadian diversity would multiply, that those who declared the necessity of ever more intrusive methods of population management could provide a justification for their manipulations and practices of distant domination. The British failure to solve the problem of Canadian diversity ensured that the discourse itself would live on, as an adaptive, self-reproducing, public problem-solution set, to Conquer new regions of space, time, and individual-group identity. For, just as the French were brought inside and put under tutelage, so were the Indians, and so, with the passage of time, would be all who allowed themselves to be called Canadians. 


\title{
Chapter 6
}

\section{The Canadian Nation and the Immigrant Other}

\begin{abstract}
The virgin soil, the primeval forest, and the teeming seas and lakes and rivers all possess undeveloped riches. Man alone is apparently the missing quantity, and his energy, industry and capital are the required elements in developing this young, but sturdy Dominion into the Greater Britain of the West - the worthy scion of the grand old Motherland across the seas, whose pride is in the colonial gems which adorn the imperial diadem, of which Canada is one of the brightest and most valued jewels.
\end{abstract}

The New West, (Canadian Historical Publishing Co. 1888:Preface).

This chapter tracks the emergence of 'Canada' proper, that is, the rationalbureaucratic apparatus which, from its base within the British colonies, extended its regime of striation until it had achieved (relatively) effective control over half the continent. As I will show in the immediately following section on the Canadian invasion of the Red River region, the methods of creating and managing the problematic diversity of a Roman-style 'empire' were self-consciously taken up by the Canadians from both the ancient European discourse on diversity and its New World adaptations by the British and French. Once they had secured their control, the Canadians began trying to import Self bodies to re-populate the region. But this plan, like all before it, came off miserably, and only succeeding in creating the greatest proliferation ever seen in the problem of Canadian diversity, through the emergence of literally dozens of categories of Immigrant Other.

This profusion of new identities quickly overwhelmed the system of classification the Canadians had inherited from the British, which could neither differentiate between various types of Immigrant, nor adequately separate the Immigrants from proper Canadians. In response, there emerged the Great Chain of Race, a creative confluence of Herodotan ethnography, European natural history, 
and North American social gospel / science, which I will present as it was epitomized in the work of J.S. Woodsworth. Along with this new means of classifying human diversity, there arose new solutions. After toying with transportation and assimilation, the Canadians became more creative, making use of the unique characteristics of the Immigrant - her qualities of having come from afar and of being in transition - to evolve the new methods of deportation, disenfranchisement, and internment for those Immigrants who had already arrived. For those yet to come, immigration laws were used to try to ensure the exclusion of individuals identified with groups considered 'Undesirable' in Canada. In this way, the Canadian state creatively responded to the expanded problem of diversity it posed for itself through its desire - perpetually unattained - for unity, identity, and the status of Great Nation.

\section{Clearing the 'Empty' West}

The origin myth of Canadian Confederation suggests that Canada was founded by an agreement between four provinces, which were "joined" by other groups and individuals later on. 1 This myth has been challenged by writers such as Howard Adams (1995) and Himani Bannerji (1996), who argue, respectively, that 'Aboriginal' and 'Immigrant' are colonized identities within the purview of the Canadian state. It is interesting to note that certain contemporaries of the 'Fathers of Confederation' were in agreement with what has now become a 'radical' stance. Canadian Rev. A. M. Dawson, in a lecture delivered to the Mechanics' Institute of Ottawa in 1864, declared that "every people, when they have reached a certain degree of power and renown, ought to aim at possessing colonial dependencies" (Dawson 1870:45). William Norris echoed this sentiment and invoked both ancient and modern European antecedents as a guide for the future of Canada: 
Every known nation at present in being ... has at first been a colony.... In ancient history, the nation the most famous in war, in oratory and art... was Greece. That this nation was once a colony, it is not necessary to prove. The same may be said of Rome ... but the precedent which ... more particularly concerns the inhabitants of this country, is that of England -- the motherland.... At first the attempt to colonize the Island was made from Rome, and it is more than probable that the Romans laid the foundations of those great institutions which have since been the means of England's greatness (Norris 1875:27-8.

Driven by visions of the glory of empire, those who identified with the new Dominion invoked the European dictum of terra nullius to construct the territory they desired as empty, unstriated, and therefore fair game. Henry Hind, sent out on an "Assiniboine and Saskatchewan Exploring Expedition" by the Province of Canada in 1858, reported on the "vast unpeopled wastes -- often beautiful and rich, often desolate and barren -- of the great North-West" (Hind 1859:1). The New West, a procolonization pamphlet published in Winnipeg in 1888, described the Northwest as containing "countless thousands of leagues of territory on which the foot of man has never trod, lying tenantless and silent" (Canadian Historical Publishing Co. 1888:Preface).

Finding "empty" land, however, was only half the battle. According to E.G. Wakefield's influential pronouncements on British colonial policy, "the elements of colonization ... are waste land and the removal of people [i.e. Europeans, to fill the empty land]" (Wakefield 1929:30). In an 1876 Report, the Commander of the Canadian Militia showed that he had read up on his colonial theory:

The appointment of magistrates, and encouragement of missionary labour are questions also becoming prominent in the dawning development of that noble territory, not long ago only known to the wild Indians of the mountain, the forest, and the prairie, to the dissipated, nomadic half-breed, and to the hardy trapper, but now silently and patiently awaiting the approach of the immense wave of human life which must shortly overrun the fair and productive soil of those remote and beautiful solitudes (Report of Major Selby Smyth, cited in Canada 1876:131). 
While these dreams of striating an apparently empty space were quite in keeping with building an empire on the Roman-British model, there were some difficulties to be overcome. Here Smyth and Dawson's vision of an empty land awaiting "human" settlement are telling, for as Smyth's own text notes, this space was already the home of a number of Native nations, Metis settlements, Hudson's Bay Company forts and, of course, the Red River colony. This was not an exceptional case, in Canada or elsewhere. It seems that everywhere the Europeans went, the "waste" lands turned out to be occupied. There was, therefore, an element missing from Wakefield's formula for colonization: before the "waste" lands could be populated, they had to be de-populated, i.e., their emptiness had to be constructed in colonial practice so as to correspond to colonial theory. The proven way to do this was to remove from the existing bodies their possession of full human subjectivity by setting them up as Others to the colonizer's Self.

In the case of the Canadians and the Indians of the Northwest, the means of differentiation, and a method appropriate to it, were already at hand in the form of the myth of the doomed Savage:

The policy of peace and protection towards the Indians has proved a wise one. It has cost far less than the aggressive policy of the United States towards the tribes within their boundaries.... For the sake of our own interests, if not from pity for a race destined apparently to extinction, we should deal with these Indian tribes kindly, and let them pass from the world unstained by the shedding of English blood. (Charles Marshall, The Canadian Dominion, cited in Canada 1876:117, 130, emphasis added).

While there were proven methods in place for dealing with the Indians, the difficulties presented by the people of the Red River settlement posed a problem as yet unsolved by any colonial power. Emitting contradictory signs of all of the identities within the system of human difference the Canadians inherited from the British (see the previous chapter), the settlement was too Savage to be tolerated and too European 
to be destroyed. In the report of an 1857 expedition, the writers were overjoyed to Discover "attractive and substantial" Christian churches, as well as a church and school where "the congregation appeared to be exclusively Indian; in their behaviour they were most decorous and attentive" (Canada 1858:332). But they also felt compelled tc give their impressions of the 'darker' side:

On two Sundays during my stay, at the time when Divine service was being celebrated in all the churches of the settlement, the heathen Indians held their dog feasts and medicine dances on the open plain. [T] he evil spirit was invoked, the conjurer's arts used to inspire his savage spectators with awe ... (333-4).

How could the local Christians stand it? To the Canadians, this could only be due to the impure blood that flowed through their veins:

These hardy and fearless children of the prairie [the Half-breeds] constitute a race ... endowed with remarkable qualities.... It is, however, much to be regretted that ... many of them are fast subsiding into the primitive Indian state; naturally improvident, and perhaps indolent, they prefer the wild life of the prairies to the tamer duties of a settled home; this is the character of the majority, and belongs more to those of French descent than of Scotch or English origin (353).

This passage shows the full scope and force of the Canadian adaptation of the British colonial discourse on diversity. Both the British and French Half-breeds were set apart as a separate race, and were simultaneously held to be inferior in humanity and civilization, with the French Half-breed appearing as even more inhuman and uncivilized than the British. Lowest of all on the Great Chain of Race were the unassimilated people of the Native nations who, being in the way of the Canadians, seemed to have 'regressed' from the days of the HBC and, once again, were being named as Savages. Except for the addition of "Canadian" to the tail end of "British" and "French," the semiotic square and hierarchical ordering of Canadian group identity was taken over directly from the British colonial regime. 
Figure 6.1 - Group identity in Canadian colonial discourse

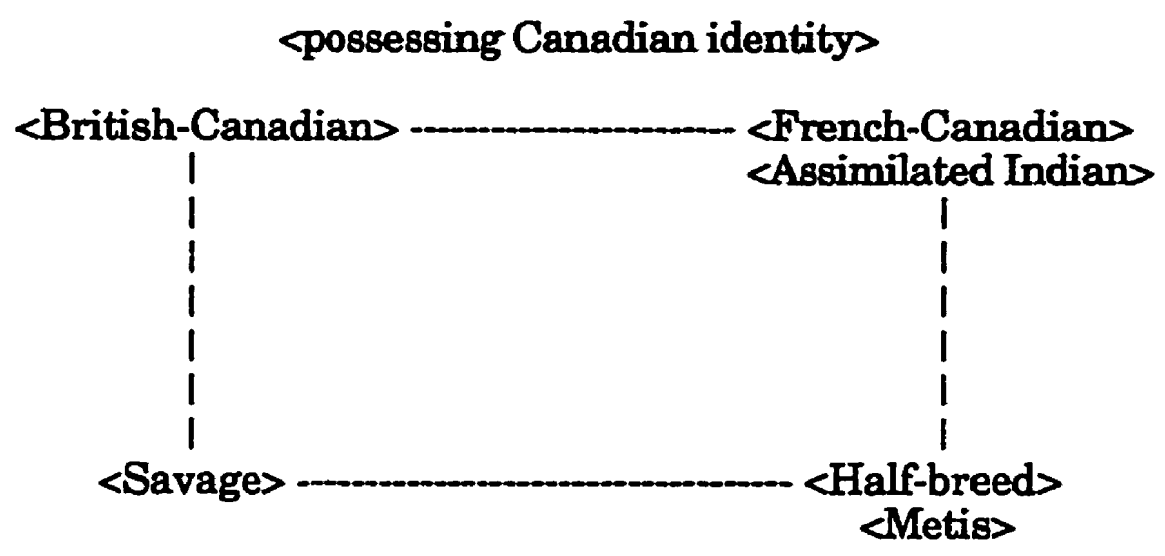

<not possessing Canadian identity>

The 1857 Report made use of the hierarchy implicit in the separation of these groups in assuring its readers that the sorry state of the settlement was not the fault of the land. The few Full-breed Europeans who were there had managed to produce all the signs necessary for a Canadian to feel at home: "Mr. Gowler, Mr. Gladieux, Mr. Flett, the McKays, and several others that might be named ... farm with industry and economy" (360). All that was needed, then, was to move out the hybrids so the pure stock could move in. There was a problem, however. In the interval between the transfer of control over their lives from the Hudson's Bay Company to the Dominion of Canada, the people of the Red River settlement had set up their own government. Like the Iroquois confederacy and the coureurs de bois before them, they were striating their own space, and appeared to have at their disposal the means of defending that space against violent intrusion, as they had shown in preventing the Canadian-appointed Governor from entering the area. They also had the means of expressing themselves in a style that showed fluency with the civilized humanist discourse that was being used to justify their displacement for lack of civilization and humanity: 
Whereas, it is admitted by all men, as a fundamental principle, that the public authority commands the obedience and respect of its subjects. It is also admitted, that a people when it has no Government, is free to adopt one form of Government, in preference to another, to give or to refuse allegiance to that which is proposed ....

[W]e refuse to recognize the authority of Canada, which pretends to have a right to coerce us ...

(Declaration of the People of Rupert's Land and the North-West, Dec. 8 1869 , in CNW:904-906).

Casting this resistance to invasion as a 'rebellion', the Canadians sent in troops as soon as they could. They also incorporated many of the demands of the Red River Provisional Government into the Manitoba Act of 1870 (33 Vic. c. 3), which attached a hopefully tamed new province to the Dominion. Manitoba was presented to the Metis as a guarantee of their rights and lands and was supposed to "extinguish" Half-breed title (Article 31). But, like the Indian reserves under the 1857 Civilization Act, the Half-breed Homeland was designed to self-destruct. This time the method was not enfranchisement, but the scrip system, through which Halfbreed adults and children were issued certificates that could be redeemed in land or money. Individual and institutional capitalists from Canada were quick to grasp this opportunity to put their capital to work by buying up scrip certificates at discount prices. According to Donald McLean, a Metis historian, "the chartered banks were the largest dealers in scrip throughout the Northwest territories, purchasing about $60 \%$ of all scrip sold (McLean 1987:108). Research done by the Metis and NonStatus Indians of Saskatchewan has shown that "90 per cent of scrip certificates ended up in the hands of bankers, lawyers and merchants, bought at prices ranging from 25 to 33 per cent of face value" (cited in Purich 1988:116-7). Dispossessed of their land by the Canadians, many of the Metis of the Red River region moved further North and West, hoping to escape the strange machinations that the gifts of civilization and representative government had brought to them. 
As the existing people of Manitoba were cleared out or contained, Canada was able to begin importing Anglo-Saxons, following the plan of "a conquest and military rule, until a Canadian immigration can outvote the present inhabitants" (Taylor to Fish, April 27 1870, in Stanley 1961:132). John A. Macdonald felt that "these impulsive Metis have got spoilt by the émeute [uprising] and must be kept down by a strong hand until they are swamped by the influx of settlers" (Macdonald to John Rose, February 23, 1870, cited in McLean 1987:105). And so they soon were. The 1870 census of Manitoba showed that the population of 11,963 was divided into 9840 "Half-breeds" and 558 "Christian Indians," as opposed to 1565 "Whites" (Abstract Statement of Census, SPHC 1871 No. 20:92). Fifteen years later the situation looked quite different. The total population counted by the $1885-86$ census had risen to 108,640, and the 'blood' ratios were radically altered (StatsCan 1887:7). The province was bigger now, and Indians and Half-breeds were counted whenever they could be found, but even so there were only 7985 people who claimed to be Half-breeds, and 5575 who were counted as Indians, for a total of 13,560 non-White bodies. The White population, however, had increased dramatically, to about 84,000 , or eighty percent of the population.

Ironically, the displacement of the people of the 'empty' Northwest, while it achieved a short term goal, had the long-term effect of exacerbating the problem of Canadian diversity. The initial invasion of 1870 , and subsequent attempts at legislating away the Half-breeds and Indians caused a series of displacements that led to further violent confrontations in 1885 , which in their turn have left a legacy of disputes to this day. There was, and continues to be, much debate over the means by which the displacement of the Metis and Indians was carried out. Was it moral? More importantly for Canadians who share the New World obsession with the bottom line, was it legal? Will the government have to dole out more blankets, pouches of tobacco, tractors, and now, millions of dollars in cash? These questions linger, but are of 
greater importance at the end of the twentieth century than they were at the end of the nineteenth, when it appeared that colonial practice had finally caught up to colonial theory. Moving steadily outward from their base in Manitoba, the Canadians quickly cleared out or contained the Half-breeds and Indians, so that by the 1890's all of the Northwest was "awaiting only the advent of the Anglo-Saxon race to be transformed into a prosperous and thriving country" (Canadian Historical Publishing Co. 1888:Preface).

\section{An Explosion of Racial Subject Positions}

Unfortunately for the ambitious new nation, filling the Northwest with the Anglo-Saxon race proved to be even more difficult than clearing it of Savages and Half-breeds. It was obvious from the beginning that this task would require many more Canadians than presently existed and were willing to leave central Canada, and so the politicians and businessmen in Ottawa looked to immigration to help make up the difference. To this end, two pieces of legislation were put in place: the Immigration Act of 1869 (32-33 Vic. c. 10); and the Dominion Lands Act of 1872 (35 Vic. c. 23). The purpose of the Immigration Act, as gleaned from its explicit inclusions and exclusions, was to open Canada to healthy, wealthy, Anglo-Saxon bodies. ${ }^{2}$ In order to provide places for these bodies, the Dominion Lands Act required that those parts of Manitoba and the Northwest Territories which were not currently being used by Anglo-Saxons be carved up into squares - agriculturally striated - and offered up to chosen Immigrants for free, provided they made certain "improvements" to the land within three years (Section 33). Under the direction of the Department of the Interior, which replaced the Hudson's Bay Company as the apparatus of distant microcontrol in what was now the Canadian Northwest, these two acts set up the legal means by which colonization by proper British-Canadian types could proceed. 
In the 1870's, the ships' manifests used to record statistics on Immigrants had only 4 categories of "Nationality": English, Scotch, Irish, and Foreigners (NAC RG 76 Series C.1 Books 16-24). These forms reflected the British-Canadian hope for Immigrants from the Old Country, and the lack of any perceived need to differentiate between those few who might come from elsewhere. That hope was quickly dashed however, as ships began arriving with 400 out of 500 passengers listed as Foreigners, mostly with names like Pedersen, Larsen, and Andersen. The people in the field tried to make up for the lack of an officially supplied category by sometimes writing in "Scandinavian" as a "Nationality." In the 1880's, the "Nationality" categories were (irregularly) expanded to include English, Irish, Scotch, American citizens, Germans, Scandinavians, French and Belgians, Mennonites, Icelanders, and Other Countries (NAC RG 26 Series C1 Vol. 25 Book 2). These immigration numbers are notoriously 'unreliable'.3 For my purposes, though, both the gathering of immigration statistics and the objections to their empirical 'validity' are part of the same game, and show the importance of numerical tabulations to the creation of an entirely new subject position - that of the Immigrant, the non-British, non-French, non-Indian internal Other.

Figure 6.2 - Group identity in Canada, 1870's - early 1900's <possessing Canadian identity>

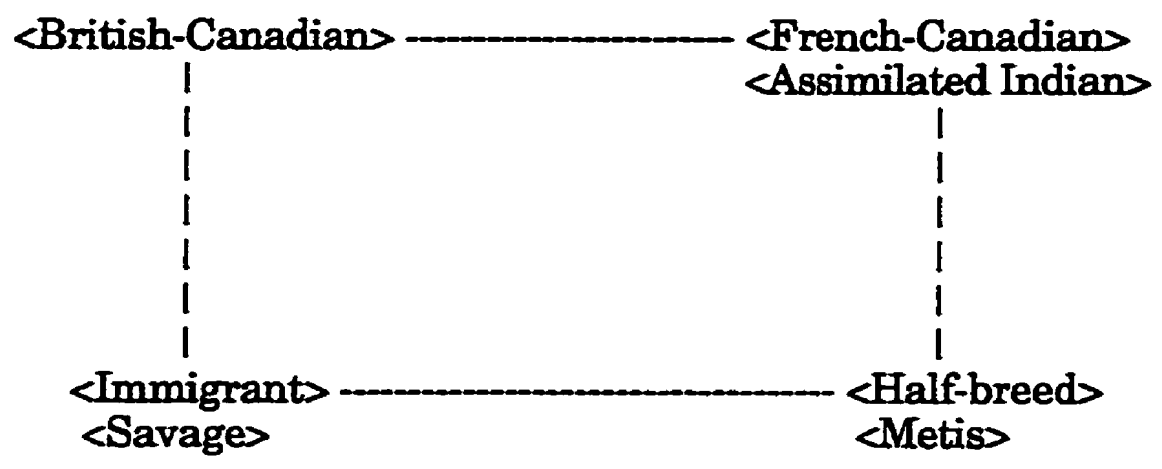

<not possessing Canadian identity 
In 1896, Clifford Sifton took over the Department of the Interior, after having promised in his election campaign to overhaul the system and correct these problems. But his regime also failed to secure a sufficient supply of Desirable bodies, claiming that while "the British immigrant is by far the more desirable ... the difficulty is, that in Great Britain ... there is only about one million people all told, who are engaged in agricultural pursuits.... It is therefore necessary to look to other countries" (JHC 1900 v. 35, App. 1:308). From this point on, the official line was that anyone who could till the land could be a Canadian: "Our desire is to promote the immigration of farmers and farm labourers. We have not been disposed to exclude foreigners of any nationality who seemed likely to become successful agriculturalists" (Sifton to Laurier, 1901, in Knowles 1997:62). While it is true that the Anglo-only policy was largely abandoned, Canada was not really accepting "any nationality." Sifton's policy was clearly oriented to finding agriculturalists who were, if not Anglo-Saxon, at least European, and therefore second best. ${ }^{4}$ Another innovation of Sifton's regime was the easing of regulations regarding block settlement of Immigrants. There were, in 1896, 36 such settlements, comprising over 37,000 people, mostly German and Russian Mennonites, along with some Eastern Europeans (SPHC 1897 No. 13:124-5). Sifton's department altered the established policy by allowing more and larger settlements of Doukhobors attempting to escape Old World religious persecution in the New, and by admitting 'Galicians' - a catch-all category for anyone appearing to be from eastern Europe attempting a similar improvement in their material well-being.

While the Department of the Interior tried to present these policy changes as improvements, the people of Canada were quick to notice that although the new Immigrants might be 'Europeans', they were Europeans of an incorrect type. Yet another attempt to solve the problem of Canadian diversity had only served to exacerbate it, as was immediately apparent in the House of Commons. As soon as 
Sifton's Deputy Minister, James Smart, had revealed that his Ministry was "looking to other countries" than Great Britain, the Select Committee on Immigration turned to a discussion of the "comparative value" of immigration from these "other countries." From this discussion, a clear picture of the hierarchical arrangement of the category of Immigrant emerges. American settlers were classified "next to the British settlers - if not equal or in some instances superior" (JHC 1900 v. 35, App. 1:309); Germans were seen as quite Desirable, although difficult to acquire. Belgium was considered to be too small, and the Swedes seemed to prefer the United States. Russia was possessed of a great stock of "desirable classes" but, like Germans, they were hard to come by.

The discussion then turned to the Doukhobors, who were the only people besides nihilists and anarchists - with whom the Russian government was willing to part. Where the Committee had been content to listen quietly to the Deputy Minister's exposition of the previous groups, the questions began to fly. Five hundred Doukhobors had come to Canada. Where were they now? Was it true that they were leaving for the United States? Next, and even more problematic, came the Galicians, lumped in with the Doukhobors as fast-breeding Undesirables:

Q. Do the Doukhobors and Galicians have large families?

A. I think so, yes....

Q. I have a statement from a party in the locality where the Doukhobors are that where they have settled the land has gone down in value, as Canadians do not like to settle there but sell out and leave. Do you know anything of that?

A. ... It may be so, I won't say ( $J H C 1900$ v. 35, App. 1:319-320).

Both in and out of Parliament, the dawning understanding that they would fail to realize the fantasy of Anglo-Saxon purity incited fear, rage and civil disobedience in British-Canadians, which was acted out upon those whom they saw as invading Others. In the Prairies, it was the Doukhobors and Galicians who took most of the blows. Under the title "Misfit Immigration," the Calgary Herald took on Sifton and 
Smart directly, calling the recent report of the Select Standing Committee "one of the most amusing books of the season, as funny as Three Men in a Boat and as pathetic as Dodo:"

What is this country coming to? Doukhobors pouring in by thousands on the eastern slope, Galicians swarming over the central portions, and rats taking possession of Dawson City, one would imagine that Canada has become a veritable dumping ground for the refuse of civilization (Calgary Herald Feb. 1, 1899).

Although Canadian nativism has not been well studied, Howard Palmer's Patterns of Prejudice: A History of Nativism in Alberta (Palmer 1982) deals in depth with these, and other, nativist reactions in Alberta and provides references to further sources.

In British Columbia, which Canada acquired in 1871, Canadian nativism took the form of a particularly virulent anti-Asian sentiment. All of the rhetorical stops were pulled out in the attack on the Chinese, as seen in an address to the 1902 Royal Commission on Chinese and Japanese Immigration. C. Wilson, presenting on behalf of the Province of British Columbia, invoked a litany of all the modes of differentiation available to him, constructing a stupid, inhuman, uncivilized Other:

The foundation of all social order is based upon a vigorous and intelligent people and the state cannot long endure whose foundation rests not upon those of its own race and kind, but upon a race not only alien in so far as their birth is concerned, but of a different type of humanity and civilization ... who do not assimilate with us, who would not if they could, and who could not if they would... (Evidence of C. Wilson, SPHC 1902 No. 54:282).

Several thousand petitioners for Oriental exclusion announced their devotion to the high principles of British-Canadian nationalism, declaring that "it is in the interests of the Empire that the Pacific province of the Dominion should be occupied by a large and thoroughly British population rather than by one in which the number of aliens would form a large proportion" (279). To show that they were serious, the Canadians 
of British Columbia took it upon themselves to solve the problem of Asian Otherness by a series of attacks on people and property, culminating in the famous riot of 1907.5.

Canadian nativism was not, however, a purely English-Canadian phenomenon. French nationalism was as strong as ever, and its adherents also had their concerns about the racial content of the Northwest. Henri Bourassa, for example, accepted the empty land thesis, and the basic tenets of Canadian expansionism. But his imaginary Northwest differed in one very important respect from that of British Canada:

[W] hen they [the fathers of confederation] considered ... those virgin lands when they threw open to civilization those immense territories which had theretofore been only the domain of the Indian and the buffalo, what was the idea which dominated their minds? It was to introduce there an idea that would include both nationalities, to introduce an idea that would bring together the French and the English; it was to create there a British colony, but also and Anglo-French alliance that would endure for all time (DHC March 28, 1905:8588).

While the British might not have been winning the demographic battle in the Northwest, they were not losing it as badly as the French. Already, Bourassa had noted that the pattern of immigration was again making it possible to use 'democracy' to further marginalize the French in Canada:

The Solicitor General, I was sorry to hear, made an argument this afternoon that because the French Canadians are less numerous in the Northwest than the Germans, or the Scandinavians, or the Doukhobors, there is no reason to grant us the official use of the French language (DHC March 28, 1905:8588).

Despite having different ideas about what they had founded, there was a rather unusual level of agreement between the Two Founding Races that incoming Otherness was a threat to their existence. Each race felt its hold on its Homeland declining, and the Northwest, rather than becoming British and / or French, was once 
again refusing to follow design parameters and giving rise to all manner of emergent forms. To French-Canadian nationalism, this meant an intensification of the minority status of French language and culture outside Quebec, and another reason to fear the loss of an existing, but always threatened, identity. For English Canada the situation was a little different; rather than worrying about protecting an identity, there was a fear of never achieving one. Through its failure to acquire pre-striated Self bodies through immigration, and its 'success' in escalating the number of types of Immigrant Other to 79 by 1903 (NAC RG 26 Series C1 Vol. 26 Book 3), English Canada dealt itself a wound that continues to fester to this day.

\section{Restoring Order - J.S. Woodsworth and the Great Chain of Race}

What was to be done? A 'flood' of lectures, articles, and books poured out into the symbolic realm, hoping to counter the imaginary flow of incoming Otherness the problem of Canadian diversity had come into its own. "Canada is today the Mecca of the world's emigration," R.G. MacBeth declared:

and those who are coming are by no means immigrants like ... the early settlers in the Province of Ontario, or the Maritime Provinces or the Red River country, who took no rest till they had erected churches and schools and colleges.... For the most part those who have been coming in recent years are of inferior races and lower civilizations (MacBeth 1912:20-21).

R.G. Macpherson, Liberal M.P. for Vancouver, agreed with MacBeth, and pushed the proud lineage of Canada's Foundational Stock back to ancient Rome:

The men who built up this country, who hewed homes out of the forest, were men of first class, A1 stock, and the responsibility they left us is great. The sentiment expressed in the proud phrase, Civis Romanus sum, becomes the citizen of Canada as well as it became the citizen of Rome. A race of men who cannot appreciate our mode of life, our mode of education, all that goes to make up Canadian citizenship, are not fit immigrants of this country (cited in Ward 1978:84). 
"These indeed are perilous times," intoned Arthur Hawkes in The Birthright (1919). "Those who suppose that dangers can be overcome by prophesying smooth things concerning them will find no lullabies here. If we daren't be frank we had better be dead" (xvii).

One of the first, and most famous, to sound the alarm was J.S. Woodsworth, in his very popular Strangers Within Our Gates (1972a [1909]). I have chosen to treat this text in detail as it displays a fascinating - and influential - confluence of discursive forms: in this text, Herodotan ethnography is revived and applied to the study of Immigrants as internal Others; European racialism, with its hierarchy of White, Yellow, Black, and Red finds a permanent home in Canada; 6 North American social science, with its charts, graphs, tables, and diagrams, is brought to bear to reproduce and highlight the objective-natural quality of the problem of Canadian diversity; and the discourses of socialism and the social gospel provide the text with a strong bias towards the use of the institutions of the state and civil society to try to solve the objective-natural-scientific problem of Immigrant diversity. Woodsworth's text is also interesting in that it is a compendium of the work of a number of writers, brought in to give their opinions on various issues and immigrant groups. It is thus very much a cross-section of "informed opinion" at the time. In the interest of maintaining a focus on the problem of Canadian diversity, rather than on Woodsworth's place within history, I should point out that it is not my intention to challenge the view, expressed by Marilyn Barber in the introduction to the 1972 edition of the book, that Woodsworth possessed "an inquiring mind with a deep interest in people and their welfare" (viii). Rather, I hope to show that Woodsworth, like his less inquiring and compassionate contemporaries, was reproducing and heightening the problem of Canadian diversity in his attempts to define and solve it through rational-bureaucratic means. 
Woodsworth's goal, as stated in the Preface, was to "introduce the motley crowd of immigrants to our Canadian people and to bring before our young people some of the problems of population with which we must deal in the very near future" (9). Much of the book is devoted to a discussion of the relevant characteristics of this amorphous heap of problematic Others, taking on both the method of Herodotan ethnography and its obsession with the seven categories of cultural fact: place of residence and climate, language, dress, food, dwellings, religion, and political organization. The categories were updated where necessary, but there can be little doubt that, as the problem of Canadian diversity expanded in size and scope, the ancient methods of cataloguing diversity were revived and put to productive use.

'Country of Origin' - with the usual confusion of races and places - provides the main structure for the presentation of subjects in Strangers Within Our Gates, standing in quite easily for place of residence when the Others are inside rather than out. In its presumed influence upon bodies originating in a particular place, climate plays its ancient role: "taken all in all there is no class of immigrants that are as certain of making their way in the Canadian West as the people of the peninsula of Scandinavia, "Woodsworth proclaims. "Accustomed to the rigours of a northern climate ... they will be certain of success in this pioneer country" (77). Linguistic attributes are also frequently invoked in the descriptions of human types that adorn the pages of Strangers Within Our Gates. Four pages (92 -96) are devoted to a table giving the "linguistic differences and affinities" of the European races. J.C. Speer, Woodsworth's correspondent in "Chinatown," found it "pleasing to hear words of our own tongue" from the "little strangers" - children - he met there. "One is reminded that some of them are as much Canadian as are we of Anglo-Saxon speech" (145). Speer found further evidence of strangeness in the Chinese mode of dress: "the Chinese ladies wear no head covering, but seem to find their chief pleasure in the most elaborate toilet" (146). Food choice serves a similar function and, as in the 
ancient and medieval cosmographies, sometimes veers into the fantastic. "They [the Chinese] are by no means vegetarians, as so many people believe, but they can live on rice exclusively when it is necessary to do 80 " (147). This is a feat surely worthy of the Apple-Sniffers and Lotus-Eaters of yore.

The religious and political propensities of Woodsworth's Others also merit frequent comment. The arrangements adapted by the Mormon communities are given a great deal of attention, since Woodsworth feared that the "octopus of Mormonism" was reaching out from Salt Lake City to grasp hold of Canada (66). After enumerating the many heresies of the Mormons, Woodsworth declares that "these doctrines are obviously inconsistent with the teaching of Christianity," and can only lead to "the end of all free government" (71). In the allusion to ignorance of the value of a hat, in the assumption that English words are the only Canadian words, that rice is not a Canadian food, that the principles of British liberalism and European self-determination are the only valid form of political organization, we see the value of the Herodotan trope of implicit comparison with a standard assumed to be shared with the reader, but not with the object, of the text. Neither Woodsworth nor Speer were expecting their words to be read by a Chinese woman or a Mormon Bishop, but intended them only for a hidden, Invisible Self group to which they assumed themselves to belong.

Without doubt, Woodsworth was reproducing ancient prejudices. But his reproduction was creative, as it introduced, recovered, or popularized certain metaphors, theories and methods that have had a profound influence on the twentieth century discourse on Canadian diversity. For example, he and his colleagues helped the ancient system adapt to a modern world motivated increasingly by, or shall we say obsessed with, the achievements of science. Following the lead of government bureaucrats, and preparing the ground for the later contributions of professional ethnic demographers, Strangers Within Our Gates 
makes copious use of tables showing the numbers of people arriving in Canada, arranged according to "birthplace", "race", and "nationality," thereby providing 'concrete' evidence of the existence of the problem of Canadian diversity. To help convince the reader that the problem is getting worse, the tables are placed in chronological order, so that even the most doubtful can see the distressing trends: no Bulgarians at all arrived in 1900, but each year after that the numbers steadily increase: 1, 7, 14, 2, 71, 896, 1802 (23). "Figures talk" (17), the sociologist declares, then abruptly backs off from his own empiricism: "[i]f only we could read into these figures their real meaning!" (22).

While it might have been hard to read the "real" meaning of social-scientific tabulations, it was relatively easy to use them to magnify the Immigrant problem until it took on the proportions of a crisis. For this purpose, Woodsworth made copious use of the Flood metaphor for incoming diversity. This trope, which I discussed in chapter 1 , aids in the construction of incoming Others as a natural disaster creating a crisis situation. It is invoked repeatedly by Woodsworth and the other contributors, providing a sort of basso continuo that underlies and sustains the rhetoric of the text. It first appears in Sparling's introduction, as quoted at the start of this section, with a reference to "the incoming tides of immigrants." Then, in the introductory section "Immigration -- a world problem" (attributed to WHELPLEY (sic)) the Flood metaphor is applied to immigration from "the remote and little known regions of northern, eastern, and southern Europe:"

Like a mighty stream, it finds its source in a hundred rivulets. The huts of the mountains and hovels of the plains are the springs which feed; the fecundity of the races of the Old World the inexhaustible source (13). 7

At the end of the second chapter the Flood metaphor is again invoked, to put to an end any doubt that We are facing a problem of great importance: "We have entered a 
new era in our history. The immigrants are upon us! For good or ill, the great tide is turning our way, and is destined to continue to pour in upon us" (29).

While charts and tables can help to support the idea of an impending natural disaster caused by the arrival of an amorphous mass of human person-types, they are also useful in establishing the possibility of organizing this mass according to certain assignable characteristics. The categories of classification can act as a series of dikes, keeping the Flood at bay; or perhaps, better yet, as channels, directing the flow into productive tasks, such as the construction of known and manageable identities. For, once the identities and differences have been worked out, the 'tide' does not seem so amorphous and frightening: it can be seen to contain 439 Chinese, 1200 Ruthenians, 4 Quakers, and so on, ad infinitum, until every last shred of difference has been accounted for.

We have, of course, encountered this will to exhaustive naming before - in the principle of plenitude that accompanies the Great Chain of Being. It, like Herodotan ethnography, re-appeared in Canada at the start of the twentieth century, taking a form I refer to as the Great Chain of Race, structuring thought, action, and even the table of contents of Woodsworth's book. Reading its chapters one descends the Chain from pinnacle to base, following the contours given by the European natural philosophers and racialists. With the second edition of his Systema Naturae (1740), Linnaeus included humanity in his scheme, under the classifications Europaeus albus, Americanus rubescens, Asiaticus fuscus, and Africanus niger: White, Red, Yellow, and Black. These colours were put into an explicit hierarchy of humanity and civilization by LeBon, vis: White, Yellow, Black, Red (see Todorov 1993:107 ff.). Again, Woodsworth was not doing something entirely unheard of in Canada. The order he presented followed that given in the reports of the Department of the Interior from 1896 on. But he was innovative in his ability to lay out the entire structure and justify its arrangement, with the sort of meticulous attention to 
completeness and detail that one would expect from a modern social scientist following in the footsteps of medieval natural historians and ancient Greek philosophers.

The discussion begins with "Immigrants from Great Britain", who are the most Desirable type for Woodsworth's vision - which he assumes is shared with his reader - of a White Anglo Saxon Protestant Canada. The British are "among our best citizens" since they bring with them "more of our own blood," and can "assist us to maintain in Canada our British traditions and to mould the incoming armies of foreigners into loyal British subjects" (46). Next on Woodsworth's scale, and in keeping with the official government line, are Immigrants from the United States. "Desirable settlers? Yes" (65). These are followed closely by the Scandinavians -"they easily assimilate with the Anglo-Saxon peoples and readily intermarry" (76). Next come the Germans, who are "among our best immigrants" (84). "Even those who detest foreigners make an exception of Germans, whom they classify as 'white people like ourselves" (84). Woodsworth places "The French" fifth on his scale of White Desirability, and even then allocates only a single page to his discussion. "Up to the present time the French immigrants have formed no large colonies, "he declares, seeming to forget the entire history and even the simple existence of Quebec (90).

The descent down the Great Chain of Race takes the reader to Southeastern Europe, where "we enter what is to most of us a terra incognita" (92). Again, one can note the assumption that the reader - one of 'us' - is not a Southern European. Here Woodsworth stumbles, almost falls off the structure he is working so hard to complete:

We plunge into an apparently inextricable tangle of nations, races, languages, and religions. On what principle are we to adopt a working classification - geographical situation, political allegiances, national 
ties, racial characteristics, linguistic affinities, religious beliefs, social distinctions, or some group of these? (92).

If it encounters difficulties outside of northwestern Europe, social science fails utterly when it is applied to the Yellow portion of the Great Chain of Race. At this point a long description of "Chinatown", attributed to the Rev. J.C. Speer, is inserted into the text, in which the many strange differences of "The Chinese" are enumerated. They are "clumsy men" who play "outlandish fiddles" (148), make use of "ill-smelling punk-sticks" (150) and have "peculiar" funeral customs (151). Turning to the 'Hindu', Woodsworth declares that 'they are very slow, and do not seem capable of hard, continuous exertion. Their diet is light, and physically, they are not adapted to the rigorous climate of Canada" (154). This litany of tragic differences leads to an inevitable conclusion: unlike even the most southerly or easterly of Europeans, "[t]he Orientals cannot be assimilated" (155).

Proceeding down the Chain, Woodsworth arrived at the Black and Red in a chapter entitled "The Negro and the Indian." Short though it is, this chapter is quite interesting for both its explicit statements and inadvertent admissions:

Neither the Negro nor the Indian are immigrants, and yet they are so entirely different from the ordinary white population that some mention of them is necessary if we would understand the complexity of our problems. We group them merely because both stand out entirely by themselves (158, emphasis added).

The Invisible Selves - the "ordinary white population" - are named explicitly, in terms of their Invisible Colour, against which the Blacks and the Indians "stand out" for the writer and assumed readers of the text. For his description of the "unmanly" and "undemocratic" traits of the Negro, Woodsworth cites an American 'expert', 8 then finishes his discussion by saying that "we may be thankful that we have no 'Negro problem' in Canada" (158). Quite true. While the semi-Whites and Yellows in Canada were despised as Useless internal Others, the Blacks fared even worse - so 
low on the scale of Desirability that, despite the fact that there were Black slaves in Champlain's Quebec and a continuous, but tenuous presence ever since, this 'type' had been so successfully prevented from obtaining a place in the history of Canadian diversity that it could not even become part of the problem. ${ }^{9}$

With regard to the Indians, whom he described as "grossly pagan ... half civilized ... debauched," Woodsworth had little to say, other than to cite the necessity of providing them with the gifts of Christianity and civilization (160). Woodsworth's attempt to consider the problems of the Indian and the Immigrant together was important, though, in that he was forced into it by his desire for a complete description of the Great Chain of Race. The Indian was not an Immigrant, but still he was part of the problem of Canadian diversity, and thus had to be included in any enumeration of its content.

In codifying, clarifying, and completing the Great Chain of Race, in recovering useful ancient, medieval, and early Canadian colonial forms, and in providing these with a sound basis in New World social-scientific observation and commentary, J.S. Woodsworth and the contributors to his text made an outstanding contribution to the construction of the problem of Canadian diversity. But this was not all. Woodsworth also turned his attention to the need for solutions, bringing to bear the same literary vigour and social-scientific attention to detail. The Flood metaphor was crucial here, as it reinforced the idea that the incoming Others were not human subjects but natural objects, and made it possible to consider state policy intervention as providing a 'tap' to control their 'flow'. Yet, as the previous ten years had shown, even the Canadian state was being overwhelmed: "Government policy may to a small extent quicken or direct the flow, but great economic laws rather than Government policy are responsible for the rise of the tide" (29). With the help of the Flood metaphor, the diversity that threatened Canada was simultaneously objectified, 
problematized, publicized, and rendered insoluble. For what could be done in the face of a natural disaster arising from intractable economic laws?

Despite his lack of faith in government policy, Woodsworth had no intention of being swept away in the Stream. He had a plan, but first he had to dismiss a competing paradigm that will be familiar to late twentieth-century readers as a latent form of multiculturalism:

There is an unfounded optimism that confidently asserts that all this mingling of the races is in the highest interest of our country. We get the strength of the North, the beauty of the South, and the wisdom of the East; such is the line of thought often presented in after-dinner speeches (182).

Anticipating the theory of complex systems, Woodsworth perceived that "the newer nations are in a state of unstable equilibrium" (182), poised on the edge of order and chaos, ready to give rise to new forms. Fearing these emergent forms because they were unpredictable, he presented his own design plan for enabling a "higher type" to be developed:

English and Russians, French and Germans, Austrians and Italians, Japanese and Hindus - a mixed multitude, they are being dumped into Canada by a kind of endless chain. They sort themselves out after a fashion, and each seeks to find a corner somewhere. But how shall we weld this heterogeneous mass into one people? That is our problem (167).

In constructing an unavoidable and unsolvable dilemma in this way, Woodsworth provided the canonical formulation of the problem of Canadian diversity in the twentieth century as a problem of a perpetual lack of unity caused by the presence of a disordered chaos of non-canonical Others. To help Canada achieve its destiny, Woodsworth advocated a two-pronged attack: assimilation to an Anglo-Canadian model for those Others already within - the mass that needed welding - and 
exclusion for those who could not be expected to "assist us to maintain in Canada our British traditions" (46) -- the flow that required direction away from Canada:

We, in Canada, have certain more or less clearly defined ideals of national well-being. These ideals must never be lost sight of. Non-ideal elements there must be, but they should be capable of assimilation. Essentially non-assimilable elements are clearly detrimental to our highest national development, and hence should be vigorously excluded (202).

I will discuss each of these solutions, and others adopted by the Canadian state but not advocated by Woodsworth, in the following two sections.

\section{Managing the Strangers Within Our Gates - Assimilation, Transportation, Deportation, and Internment}

Dealing with internal Others was nothing new to those who took it upon themselves to construct a British Canada, as they had been struggling for centuries to displace, contain, exterminate, and assimilate the Savages, French, Indians, and Half-breeds. Out of these methods, only assimilation was applied to the Immigrant Other, in what I will describe below as passive and active modes. But, try as they might, early twentieth-century Canadians could not assimilate their Others as fully or completely as they (the Canadians) might desire. So, while the Canadian federal government continued to leave most of the work to the provinces, via their compulsory education systems, and the churches via their missions and settlement houses, it also began to take seriously its responsibility for "directing the flow" of Undesirable Immigrants. Because these identities occupied a low position on the Great Chain of Race, bodies associated with them could be treated like objects and moved about with impunity. This, when combined with their lack of full BritishCanadian subjectivity ('naturalization'), provided some appealing options: deportation of individuals, and mass deportation, or transportation of groups; the 
Immigrant's 'ack' of full citizen status also enabled disenfranchisement and internment. With these methods of physical elimination of Undesirable Immigrants, the Canadian government began to subject bodies that were not seen as conforming to the English-Canadian model to various forms of rational-bureaucratic discipline.

It was not uncommon for British-Canadians of the early twentieth century to assume that Southeastern Europeans, as members of the White race, would simply 'be assimilated', in the passive tense. An example of this can be seen in the response of Deputy Minister James Smart, when questioned by a member of the Select Standing Committee on Immigration and Colonization:

Q. Are the habits of the Doukhobors like those of the Mennonites, who want to make everything themselves?

A. Yes, largely the Doukhobors are the same. They make their own shovels, spades, boots, clothing and all that; many of them are blacksmiths....

Q. They will get over that in time?

A. I have no doubt that after rubbing against Canadians, they will change their habits (JHC 1900 v. 35, App. 1:314).

The Canadian government had always been against "assisting" immigrants too much, so that, when questioned by the same committee, a later Superintendent of Immigration was forced to admit that he knew very little about the bodies that his department attracted, processed, and deposited "on the land:"

Q. I understand you follow the immigrant on his arrival in Canada by one of your agents all the way through to his destination in the Northwest?

A. No.

Q. You know nothing about them after they arrive?

A. After they land in Canada, we know they are ticketed to a certain point by the railway.

Q. Do you find out where they are going, whether they are going to

friends in the Northwest, or simply going without any connection?

A. No.

(JHC:1906 v. 41 App. 2:476). 
Being dumped into the prairies to rub up against Canadians did not seem to be enough to transform Immigrants into British-Canadians, and so there was a growing feeling that more active measures had to be adopted. Again, Woodsworth was a leader. As a follower of the social gospel, linking the salvation of the individual to the salvation of society, 10 Woodsworth was of the opinion that "special attention should be drawn to the necessity of mission work in our cities" (Woodsworth 1972a:256). He himself had put in his time "where the white harvest standeth," at the All Peoples' Mission in Winnipeg, as Chair and Superintendent of its operations. In his more methods-oriented volume, My Neighbour, published in 1911, he spelled out in great detail how the task of assimilation was to be carried out. As indicated by its name, his mission really did attempt to be all things to all people, including among its 21 "Departments" Kindergarten, boys' and girls' social and educational classes and clubs, gymnasiums and baths, libraries, night schools, concerts and lectures, Sunday meetings, monetary relief, religious services, and hospital and home visits (Woodsworth 1972b:210-216). Reminiscent of the colonial fort, the mission was an outpost of civilization in a wilderness of Barbarism which, in a telling metaphor, acted like a "focusing glass" to direct rays of assimilative energy onto the homes of Immigrant families (183). 
Figure 6.3 - The mission as agent of rational-bureaucratic discipline.

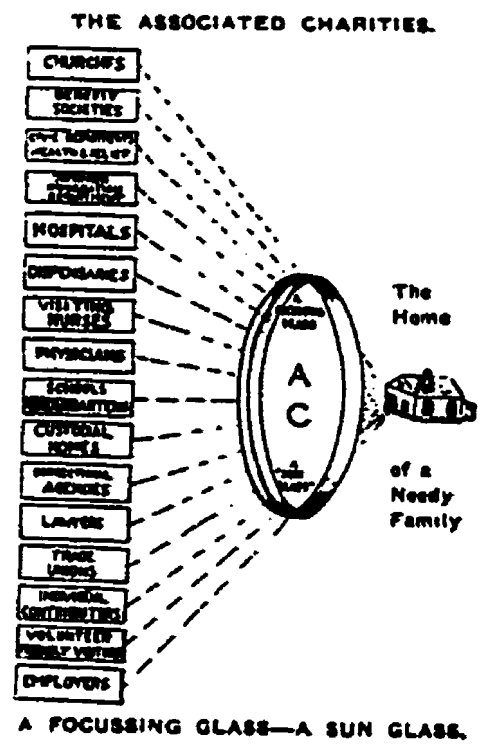

In The Education of the New Canadian: A Treatise on Canada's Greatest

Educational Problem, J.T.M. Anderson also came out against the theory of passive assimilation:

There seems to be a too prevalent idea that each and every male and female new-comer may, irrespective of age, and after being subjected to some more or less indefinable process, which we call 'assimilation', enter the ranks of full-fledged Canadian citizenship (Anderson 1919:7).

Citing Woodsworth, whom he presented as "one of the best Canadian authorities on the subject of racial assimilation" (29), Anderson was concerned that the new Immigrants would never become "true Canadian citizens, imbued with the highest Anglo-Saxon ideals" (8). An Inspector of Schools in Saskatchewan, he tended to favour compulsory education in British language and culture, conducted by proper British teachers only. 'The unqualified, half-Canadianized, 'foreign' teacher cannot properly inculcate those ideas so essential in laying the foundation of true citizenship 
in Canada" (37). Taken up in the right hands, though, miracles could be worked with even the sort of inferior material that was landing on Canadian shores, as Anderson allows an unidentified pioneer of assimilation to relate:

I was the first teacher in this little prairie school, in the midst of a foreign settlement in which were represented half a dozen foreign nationalities - Swedish, Hungarian, German, Ruthenian, Polish, and Slovak. My feeling of aversion soon wore off, and I became intensely interested in teaching these children English. In a few days they were making use of English sentences, executing commands and playing games. At the same time filthy clothing was being discarded and the little girls began to appear in cleaner dresses. The boys soon made free use of towels, soap, and combs, and instead of the large 'chunks' of bread wrapped in filthy rags, there soon appeared neatly parceled lunches, with the bread carefully sliced. Thus the work went merrily on! (36)

Painting a scene reminiscent of the first visits of Canadian bureaucrats to the Northwest, Anderson goes on to tell of a place, "within a few miles" of this school, run by "unqualified teachers," where "except for a barely noticeable ability to speak a little English, nothing has been accomplished" (38). Like the Savage before him, the Immigrant was desperately yearning for the gift of Britishness so close at hand: "the cry of the foreign child for better schooling must be heard and answered" (121). Again like the Savage, the Foreign child was to be taken from the care of his parents for his own good, and any local attempts at the striation of space forcibly overcome. Anderson had high praise for how "sensibly and fearlessly" the Alberta authorities dealt with difficulties arising in "foreign" districts, by swooping in and appointing school boards where they were not happy with the policies adopted by those who had been democratically and legally elected (99-100). Certainly, if anyone had chosen to fight harder, there would have been yet another rebellion in the Northwest, as distant microcontrol was once again imposed in an attempt to force people's lives to conform with a distant ideal of British Canadian identity. 
Such was the treatment of the Strangers within the gates of fortress Canada. But what about those who threatened from without? Frank Oliver, who took over control of the 'tap' from Clifford Sifton in 1906, began what was to become a centurylong attempt to classify, manage, and solve the problem of Canadian diversity. His first action was to present a bill to give the government new discursive and legislative powers over Foreign bodies, both incoming and existing:

This Act is designed to enable the Department of Immigration to deal with undesirable immigrants -- that is the sole purpose, as I understand it. We provide certain definitions, which will give us necessary authority over the people it is desired to reach (DHC June 13, 1906:5201).

Oliver referred to the 1906 Immigration Act as a "weapon of defense," which included sections allowing the Minister, or the Governor in Council, to deport, exclude, and probibit from landing, various "classes" without consulting the legislative or executive branches of the Canadian government (The Immigration Act of 1906, $6 \mathrm{Ed}$. VII, c. 19).

While it was only with this act that the legal means were set in place to deport people from Canada, it seems that the practice had been going on illegally for quite some time. ${ }^{11}$ In his 1877 Report to the Select Standing Committee on Immigration and Colonization, the Secretary of the Department of Agriculture, which was then in charge of immigration, let it be known that his department had a "rule" about these things:

The rule of the Department is that immigrants who have not been over one year in the country, are, in some measure, under the care of the Department; and if it has been found, after they have come to the country, that, from illness or bodily infirmity, they have been unable to get their living, they have been sent back, as the simplest and cheapest mode of dealing with them (SPHC 1877 App. 6:40). 
From 67 in 1903, the number of deported Immigrants increased to 137 in 1906, after which it doubled every year until it reached a high of 1748 in 1909 (Urquhart 1965:A342-347). During this time, total immigration decreased, from 211,000 to 173,000 , so it seems that Oliver had provided a weapon that was quickly put to good use.

There was also within the Canadian tradition a more radical, en masse form of deportation, which had been used to shuffle various Native peoples about within the Dominion as it expanded, and had also informed the less successful British handling of the problem of the Acadians. Despite its mixed results, the Canadian government also tried transportation as a method of dealing with some of those Immigrants who apparently could not be welded into the Canadian mass. In 1908, shortly after the anti-Asian riot in Vancouver, there was an attempt to send "some hundreds of unemployed Hindoos now in B.C. to West Indies as indentured immigrants" (NAC RG 7 File 507, Reel C220:84). Observers were sent out, but when they reported back that the Honduras was swampy and infested with mosquitoes, the idea was rejected at a meeting organized by the Khalsa Diwan society (Singh 1994:42-43), and the scheme was abandoned. Again, transportation had proven itself to be a less than adequate means of solving the problem of human diversity.

With the beginning of the First World War, Canadian fear and anger also came out under the cover of protecting the Homeland from "enemy aliens." In what looked like a single stroke, "immigrants of German or Austro-Hungarian nationality" - who had previously occupied a high position on the scale of Desirability - became Others to be tracked and managed. Any individual who was associated with these nowdreaded nationalities became a potential Enemy, and was required to take an oath "in consideration of ... exemption from detention," and "to report to such official and upon such terms as the Canadian authorities may from time to time prescribe" (Proclamation of August 15, 1914, Section 4, Canada Gazette vol. 48:617). Anyone 
who refused to submit to Canadian racial discipline could be "arrested and detained" (Section 1) and, if "the officer or authority making the arrest was not satisfied" with their pledges of allegiance, they could be interned (Section 5). These provisions were expanded to cover Canadian citizens by the Wartime Elections Act, which revoked the franchise for "naturalized enemy aliens," except those who were serving in the Canadian armed forces (7-8 Geo. V. c. 39 s. 154). Regardless of one's citizenship, beliefs, or personal history, having as one's "mother tongue ... the language of an enemy country" was enough to make one an official Enemy.

On November 6, 1914, an "Internment Operations" branch - rather ironically attached to the Department of Justice -- was created by Order in Council, to be headed by W.D. Otter (PC 301). Over the 6 years of its mandate, the Internment Operations branch processed 8,579 people, identified in Otter's 1920 report as consisting of 6,954 "Austro-Hungarians, covering Croats, Ruthenians, Slovaks, and Chzecks," 2,009 “Germans," 205 "Turks," 99 "Bulgarians," and 312 "Miscellaneous" (Report on Internment Operations, 1921, reprinted in Gregorovich 1983:74-94,79). Of these, Otter states that "not more than 3,138 could be correctly classed as prisoners of war," (79). He suspected that "the tendency of municipalities to 'unload' their indigent was the cause of the confinement of not a few" (80). Not only their indigent, perhaps, but their Others, defined as indigent, then redefined as Enemy Aliens? Thus did deportation, transportation, and internment function: as methods of physical elimination of problematic bodies that provided modern equivalents to colonial extermination, displacement, and containment. Just as the extermination of Savages was justified on the basis of their lack of humanity and civilization, the treatment of human Immigrants as inhuman objects was predicated upon their lack of "suitability" for the honour of being considered Canadian. 


\section{Excluding the Strangers Without}

Deportation, transportation, and internment, however, were of minor importance compared to the efforts made by the Canadian government to regulate the flow of incoming Otherness by means of individual and group exclusion of bodies that were still outside. Section 30 of the Immigration Act of 1906 provided the legal basis for wielding this weapon:

The Governor in Council may, by proclamation or order, whenever he considers it necessary or expedient, prohibit the landing in Canada of any specified class of immigrants, of which due notice shall be given to the transportation companies (6 Ed. VII, c. 19).

As with the new rules regarding deportation, the courts and elected representatives could be bypassed, enabling decisions to be made by a small group behind closed doors. The use of the term "class" is also important, as it was empty of specific content and therefore provided a wide-open category under which any group of people could be excluded for any reason. That Frank Oliver was aware of this potential is apparent in his answer when questioned on the relevant section in the House of Commons:

[T]here has been an immigration of gypsies lately and it is thought that such people are not desirable under any circumstances although they are physically and mentally fit, and that it would be quite proper to take power to say: You cannot come in (DHC June 13, 1906:5253).

Applicable without explanation or reason, without public knowledge or the potential for criticism, exclusion by 'class' was a perfect weapon of defense in the war on incoming Otherness.

Like deportation, exclusion was in fact practiced prior to 1906. It had been possible since 1869 to prohibit the entrance of those seen as medically or psychologically unfit, and the Chinese had long had the honour of being the first race 
to be excluded from Canada via a separate piece of legislation (Chinese Immigration Act of $1885,48-49$ Vic. c. 71). But formal, explicit racial exclusion was not commonly practiced, either before the 1906 Act or after, as the Canadian government chose to do its work in roundabout ways. The "continuous journey" legislation, which led to the Komogata Maru incident ${ }^{12}$, is one famous example of the preference for implicit rather than explicit racial discrimination. This tradition of claiming to be open and tolerant while actually being closed and afraid can also be seen in Frank Oliver's presentation of the 1910 Immigration Act as a triumph of egalitarianism:

The intention of the Bill, and the policy of the government, is that all immigration shall be treated on exactly the same footing, on the same basis, according to their merits, irrespective of their race or religion (DHC: March 21, 1910:5505).

An odd claim, since Section 38 of the Act restated the continuous journey restriction, and also allowed the Governor in Council to "prohibit for a stated period, or permanently, the landing in Canada ... of immigrants belonging to any race deemed unsuited to the climate or requirements of Canada, or of immigrants of any specified class, occupation, or character" (Section 38c, emphasis added). Perhaps what the Minister meant was that everyone would be classed as Desirable or not based on the same set of racial principles?

Canadian exclusionism reached its mature form with the 1919 Act to amend the Immigration Act. Section 3, which dealt with the "prohibited classes," was revised, and the number of problematic classes extended from 9 to 20 (9-10 Geo. V.c. 25). Of greater importance, though, was the broader latitude given to the Governor in Council for prohibiting the landing of:

immigrants of any specified class or occupation, by reason of any economic, industrial or other condition temporarily existing in Canada or because such immigrants are deemed unsuitable having regard to the climatic, industrial, social, educational, labour, or other conditions or 
requirements of Canada or because such immigrants are deemed undesirable owing to their peculiar customs, habits, modes of life and methods of holding property, and because of their probable inability to become readily assimilated or to assume the duties and responsibilities of Canadian citizenship within a reasonable time after their entry (Section 13).

During the second reading of this bill, J.A. Calder, the Minister for Immigration and Colonization, spelled out its aim quite clearly. Although he held it to be "self-evident" that Canada had to increase its population -- to increase the tax base, size of markets, and other reasons of capitalist exploitation summed up in the catch phrase "people and production" (DHC April 29, 1919:1868) -- he was concerned that the population thus acquired be of the correct type:

[F]or some years to come ... our policy should be directed along two lines, first, towards increasing our agricultural population; second, towards providing, under the existing law ... for the exclusion of certain classes of people who cannot be readily absorbed into our population at the present time (DHC April 29, 1919:1876).

Eager to make use of his new powers, Calder allowed himself an orgy of expiatory exclusion, which began only three days after the Act to Amend the Immigration Act received royal assent. PC 1202, issued on June 9, 1919, allowed Asians to be barred from B.C. - and thereby from Canada - by prohibiting the landing of "any immigrant of the following classes or occupations, viz., skilled and unskilled labourn at its ports (SC 1919, v. 1 Prefix to Statutes: ix).13 PC 1203, passed on the same day, prohibited "immigrants who are alien enemies or who or who have been alien enemies during the war." Next to go down were the Doukhobors, Mennonites and Hutterites, for whom it seemed that the final lines of Section 13 had been explicitly written. PC 1204 of June 9, 1919, excluded them for their "peculiar customs, habits, modes of life and methods of holding property, and because of their probable inability to become readily assimilated or to assume the duties and 
responsibilities of Canadian citizenship within a reasonable time after their entry" (x). To the extent that was possible for a British-modeled political system, the Canadian government was finally able to give free reign to its desire to punish the Others whom it had long blamed for ruining its National Dream. At the same time, Calder achieved his goal of increasing the flow of incoming Selfhood. In 1918, 5,396 of 41,845 , or $13 \%$, of immigration to Canada was from Great Britain. The next year, the total had almost tripled, to 107,698 , with $54 \%$ from the Mother Country, and $39 \%$ from the United States, leaving only 7\% in the Other class, most of whom were French (B\&B Report Book:4.238 ff.). For having achieved what the Canadian government had been striving for since 1867 , Calder should definitely be elevated to the status of Great Man.

The Canadian government continued to add restrictions and prohibitions until the number of Undesirable categories vastly exceeded the Desirables, rendering it easier to specify which classes were admissible rather than those that were prohibited. This technique was used in an Order in Council of 1923, which limited entry to only a few classes: agriculturists with the means to begin farming, farm labourers with reasonable assurance of employment; female domestic servants with reasonable assurance of employment; wives and children of residents able to support them; U.S. citizens with means to maintain themselves until they could find employment; British subjects with means except, of course, those who were Asian; persons who could satisfy the Minister that their labour was required; and finally, other relatives, not under eighteen, and not Asian (PC 183, 1923). The Chinese Immigration Act of 1923 took this same approach, and showed how the specification of Desirables could be used to totally exclude Undesirables without giving the appearance of having done so. For, while the title of the act seemed to indicate that its purpose was to allow Chinese immigration, its effect was to shut it down entirely, by limiting entry to diplomats, returning children of Chinese descent, and merchants 
and students coming to Canada on a temporary basis (13-14 Geo. V. c. 38 s. 5). By denying entry to persons "of Chinese origin or descent other than the classes mentioned" (s. 7), the Act was spectacularly effective; over the next 20 years, a total of 8 Chinese are recorded as having emigrated to Canada (B\&B Report:4.238 ff.). In their close attention to economic conditions, the focus on classes of employment as a means of implementing an exclusionary policy, and the specification of Desirables rather than Undesirables, these proclamations and Acts established the forms followed by current Canadian immigration legislation.

The strategy of exclusion reached its zenith with the Great Depression, which provided the justification for a total prohibition of all Undesirable Others. In 1931, the landing in Canada of all classes and occupations was prohibited, with five exceptions: British subjects with means to maintain themselves; U.S. citizens with means; wives and children of citizens; agriculturalists with means; and fiancées who could be supported (PC 695, March 21, 1931). The sections allowing Americans and unspecified agriculturalists were further qualified by a proviso that these could not settle in a province "which signified its disapproval of these sections." Thus, the only way to get into Canada in 1931 was to be a non-Asian, relatively well-off British subject or American, or to marry your way past the border guards. And if you were already in, it was a good idea to stay off the dole. In 1929, 444 people were expelled from Canada for showing a likelihood of becoming a public charge -- that is, for being suddenly Useless to Canadian capitalists. In 1930 this number increased to 2,106, doubled again in 1931 to 4,084, and rose to a high of 5,217 in 1932, a year when total immigration was only 20,591. By the 1930's, the immigration 'tap' had been shut off, and to a great extent the 'flow' of Otherness had been reversed. Canadian nativism especially in its English variant, which hoped for the French to be excluded as well as everyone else - had found its expression in a restrictive immigration policy which made it very clear that Canada was, and would remain, British. 
Two central themes emerge from this chapter. First, the prevalence of a design theory of identity that required strict conformity to an Anglo-Canadian model. Associated with this was a dependence upon coercive methods of removal and exclusion of those who were not seen as capable of conforming to the specified design parameters. In this stage of the history of Canadian diversity there thus appeared one important part of the late twentieth century policy of multiculturalism - a desire for unity and identity achieved through rational-bureaucratic action which was presented as 'fair' and 'non-discriminatory'. Yet, physical force was systematically invoked by excluding, containing, and deporting, at one time or another, virtually every 'class' of person who did not appear to be a healthy, wealthy, British-Canadian. Those whose bodies could not be eliminated were politically disempowered, through the removal of their ability to vote. This was all done under a covering rhetoric of open, fair, liberal democratic ideals, with every abuse justified by claiming that some crisis or another made it sadly necessary: wars, depressions, strikes, political activity, all served this purpose admirably, and in each case it seemed to be possible to claim that this was only an emergency measure, a deviation from the regular practice of an otherwise peaceful and friendly nation. Such was Canada's commitment to treating "all immigration" on "exactly the same footing, ... according to their merits, irrespective of their race or religion" (Frank Oliver, DHC: March 21, 1910:5505).

I would suggest that the Immigrant was blamed for the failures of the Two Founding Races to realize their respective National Dreams and, like the Jew and Christian in ancient Rome, served as a scapegoat whenever a plague fell upon the nation. The formulation of the problem of Canadian diversity in the early twentieth century, with its focus on the difficulties of racial assimilation, gives some clues as to 
precisely why and how the Immigrant was at fault. His greatest sin, it would appear, was first to behave like the British and French and attempt to striate his own bodies and spaces according to his own models; but worse than this, the unassimilable Other appeared to be succeeding where the British and French were failing, in being possessed of distinctive characteristics, in being part of an ongoing and lively culture which could give rise to strange churches, evil-smelling punk sticks, and outlandish clothing. Obsessively marked out as distinct from canonical Canadian society, the Immigrants of the early twentieth century, like the Savages and Indians before them, appeared to have precisely what those who would administer and assimilate them lacked - an identity. This was, I suggest, simply too much to bear. The BritishCanadians, as the occupants of the highest rung in the Canadian Great Chain of Race, knew all about 'swamping out' existing peoples by overcoming them numerically. They had done this across what was now the whole of Canada, with the glaring exception of Quebec, where it seemed that the French could never be outnumbered. Something had to be done if the nation were not to be broken into ten or a hundred Quebecs, a sea of Red Rivers, a cosmopolitan chaos in which Britishness itself might be at risk from the forces of unconstrained racial and civilizational mixing and cultural emergence.

\section{Notes}

1 The BNA Act begins: "Whereas the Provinces of Canada, Nova Scotia, and New Brunswick have expressed their Desire to be federally united into One Dominion under the Crown of the United Kingdom of Great Britain ..." (RSC 1970 Appendix 9:257, emphasis added). From their earliest attempts to wrest control of the Northwest away from the Hudson's Bay Company, the Canadians represented themselves as the bearers of a gift of unity and civilization. For example, they petitioned the British government to "unite Rupert's Land and the North-Western territory with this Dominion, and to grant to the Parliament of Canada authority to legislate for their future welfare and good government" (RSC 1970 Appendix 9:264). It is now commonplace to read that Manitoba "entered confederation" (MCBCM:15) or that "Riel 
asked that the Red River area be made a province..." (Buchignani \& Engel 1983:49). I would also refer the reader to the discussion of what I call "Our History" in chapter 6.

2 Section 1 provided for immigration offices only in London "and elsewhere in the United Kingdom," and also "on the Continent of Europe." Not all were welcome, however. Masters of ships arriving at Canadian ports were required to report on any passengers who were "lunatic, idiotic, deaf or dumb, blind or infirm, stating also whether they are accompanied by relatives able to support them" (Sect. 9.1). "Pauper immigrants" were also prohibited from landing (Section 16), and the established practice of using medical quarantine stations to filter out diseased bodies was continued (Section 1).

3 Throughout the 1880's, the writers of the Statistical Yearbook of Canada cautioned that it was only possible "to form a general idea of the numbers that yearly settle in each province," due to much unofficial travel across the American border, B.C. not distinguishing between visitors and settlers, and so on (CSY 1888:66). In the twentieth century, the Canadian classic seems to be (Ryder 1955).

4 In 1899, during Sifton's tenure, the Canadian government sent out 886,000 maps and pamphlets. These were printed in "Bohemian, German, Swedish, French and English, Danish, the Scandinavian language, Icelandic and Hungarian," and sent to Great Britain, the European continent, and the United States (JHC 1900 v. 35, App. 1:349).

5 See (Ward 1978:53-76) for a full discussion of the riot and the events leading up to and following it.

6 This statement anticipates and foreshadows evidence that will be presented in chapter 8.

7. That "northern eastern and southern Europe" were seen as "remote and little known" regions also serves to highlight the arbitrary character of the assignation of problematic difference. Individuals whose genetic stock derives from these regions are now cast much more often as 'invisible selves' than 'visible others'.

8 "In Africa the people are unstable, indifferent to suffering, and easily aroused to ferocity by the sight of blood or under great fear. They exhibit certain qualities which are associated with their descendants in this country, namely aversion to silence and solitude, love of rhythm, excitability, and lack of reserve. All travelers speak of their impulsiveness, strong sexual passion, and lack of will power.... The very qualities of intelligence and manliness which are essential for citizenship in a democracy were systematically expunged from the negro race through two hundred years of slavery" (158).

9 For more on the Black as unmentionable, excluded Other in Canadian history, see James Walker's A History of the Blacks in Canada. Walker suggests that the exclusion of the Black experience from Canadian history might have something to do with the fact that it challenges the belief that British-Canada has only been home to freed American slaves, having never owned any of its own. "But from the early nineteenth century," Walker writes, "there was never a time when blacks were not held as slaves in Canada. Slavery is thus a very real part of our history, yet the fact that slavery ever existed here has been one of our best-kept historical secrets" (Walker 1980:19). 
10 For more on the Canadian social gospel movement, whose relation to immigration and assimilation has yet to be fully explored, see (Allen 1971; Antonides 1985; Fraser 1988).

11 Other parts of Lowe's evidence are cited by Barbara Roberts, who encountered it in the Immigration archives, at p. 5 of her book Whence They Came: Deportation from Canada 1900 - 1935. She offers up many insightful comments on the role and function of deportation in Canada over this period.

12 For further description and comment on the Komogata Maru incident, see (Ward 1978:87-3; Ferguson 1975).

13 The intent of this Order, and those like it, was confirmed by J.A. Calder in the House of Commons. "[A]n order in Council is in existence prohibiting the entry of skilled and unskilled labour from Asia; at least skilled and unskilled labour is not permitted to enter our British Columbia ports, which means that, in so far as this class is concerned, we are excluding it" (DHC April 29, 1919:1874) 


\section{Chapter 7}

\section{The Rise of the Mosaic Metaphor}

In the previous chapter I showed how early twentieth century Canada was dominated by racial intolerance and nativist demands for assimilation or exclusion of bodies that could not be accommodated within what I called a design theory of Canadian identity as Anglo-conformity. But there was another line of thought extant at the time - which I will describe in this chapter as a free emergence theory of Canadian identity -- where it was assumed that a 'proper' and 'high' Canadian identity would emerge on its own, out of an unconstrained mixing of 'racial qualities'. I will also discuss the evolution of a constrained emergence theory that combined elements of both the design and free emergence lines, and was the ancestor of multiculturalism as state policy after 1971 . The reason I make this design / emergence distinction is to highlight the theme of emergence and hybridity vs. design and singular identity which permeates the Canadian discourse on diversity. It also provides a means of linking up late twentieth century theory and practice of multiculturalism with its predecessors, which is a necessary task that, as far as I know, has not been adequately carried out. In the remainder of the chapter, I address the changing role of the Canadian state as it became intimately involved in the production of appropriately integrated subjects who would perform according to a simulation model of an ideal 'Canadian citizen'. In summary, this chapter shows how state-sponsored seductive integration of cultural signs slowly replaced coercive assimilation of racialized bodies by civil society as the preferred solution to the problem of Canadian diversity over the course of the twentieth century. 


\section{Canadian Identity as an Emergent Phenomenon}

As J.S. Woodsworth had noted in 1909 , some concerned citizens around him were suggesting in "after-dinner speeches" that assimilation to the British-Canadian model would not be the way of the future, but that "the mingling of the races" was "in the highest interest of our country" (Woodsworth 1972a:182). Professor Maurice Hutton, addressing the Empire Club in 1904, had argued that "all great civilizations are created by a blend ... when one people of one type meets another people of quite a different type and by force of circumstances are compelled to ... add their joint civilizations together" ("The Canadian National Character," in Clark 1904:68). As a model for this process, Hutton invoked the ancient Greek experience, and spoke in the first person to one of its pre-eminent philosophers:

Your own civilization of Greece, Plato... was produced by a sturdy northern people coming down like a wolf upon the southern fold of a very ancient and rich civilization ... and these produced the many-sided, susceptible, marvelous genius of the Ionian Greek (68-69).

Hutton had big plans for the Canadian hybrid, which he expected would possess the qualities of the philosopher-king, the occupant of the highest rung on the Platonic Great Chain of Being:

Plato, in his picture of an ideal state, asks himself this question - How am I going to combine the manly qualities which build up an empire, enterprise and self-reliance and high spirit and aggression, with the other qualities more gentle but more efficient in maintaining an empire, perhaps, when built?

... We are going to say to him, Plato, it is possible that in the Island of Atlantis you will find a people known as Canadians ... fitted ... for realizing this ideal character $(68)$.

In The Foreigner, a popular novel published in 1909, Ralph Connor presented a similarly stirring and hopeful vision of the future Canadian: 
In Western Canada there is to be seen to-day that most fascinating of all human phenomena, the making of a nation. Out of breeds diverse in traditions, in ideals, in speech, and in manner of life, Saxon and Slav, Teuton and Celt and Gaul, one people is being made. The blood strains of great races will mingle in the blood of a race greater than the greatest of them all (1909:Preface).

Unlike Woodsworth, who argued for the use of agents of socialization to convert Foreign Others into Anglo-Saxon Selves, Connor and Hutton imagined that the Canadian type would eventually emerge on its own. They understood that the characteristics of this identity, as the result of a process of fusion and mixing, were essentially unknowable, but they were certain that it would be of the highest type. In that they placed no limits on the mingling of races, and entrusted their future to superior 'blood stocks', I refer to their vision as a free emergence theory of Canadian identity.

This vision did not catch on with early-twentieth-century British Canadians, perhaps because it sounded too much like the all-American ideology of the "melting pot." However, an even more marginal - but homegrown - alternative, to both designed assimilation and free emergence, was also being advocated in Canadian public life:

The day will come in Canada when each nationality, while preserving its own peculiar characteristics, brought up in the broad, strong, national life of Canada, ... will combine to form the grandest race that the continent of North America or the world has yet produced (Lieut.- Col. Sam Hughes, DHC 1902:3026-7).

The key innovation here is the suggestion that "each nationality" will "preserve its own characteristics," but only within "the broad, strong, national life of Canada." The possibility that a total eradication of difference might not be attainable was already implicit in Woodsworth's metaphor of "welding" together a series of "elements," or fundamental, indivisible units, but this entailment was suppressed in his text. 
Hughes was willing to follow it through, to the point that he arrived at what might appear to be a logical contradiction in his claim that some kind of singular form "the grandest race ... yet produced" -- would emerge out of a "combination" of a diversity of preserved characteristics. ${ }^{1}$ Like Hutton and Connor, Hughes hoped for the emergence of a single race, and he also expected that an essentially unknowable result would, by some necessity, be the best possible. But, in allowing for the contradictory existence of a diversity within this unity, and in setting limits to the realm of particularity, Hughes prefigured, without using the name, the integrationist approach that Canada would eventually adopt.

Charles McCullough, a founder of the Canadian Club, also weighed in on this theme. "Let us be broad Canadians," he argued, "as broad as from sea to sea ... and from the south to the north; but in all our breadth let us endeavour to conserve the national spirit, but build up Canada in every possible way" "Canadian Clubs and Canadian Problems," address to the Empire Club, in Hopkins 1911:220). McCullogh further pursued the theme of unity within diversity by noting that the Canadian Clubs had as their mandate the "promoting of unity among ourselves" and the development of an ideal of "toleration and respect" between the French and English (222). This could be extended, he thought, to the other races as well:

In building up the walls of Jerusalem everyone of the children of Israel enclosed their city with unusual strength of wall - the duty devolved upon them to build, and every man did his part. So, in Canada, it is by every one doing his part, men of diverse views, men of different races, men who have no knowledge of the liberty we enjoy in this Canada of ours, but who have come here to share in our privileges (222).

Thus he added the idea that if problematic diversity were to be preserved rather than eradicated, it would be necessary for canonical Ganadians to tolerate the resulting signs of Otherness. 
These 'theorists' of Canadian identity did not yet have a name for their approach, nor did they share a common metaphor. But there were observable regularities in an emerging discourse that held to what I will call the constrained emergence theory of Canadian identity. An (incomplete) characterization of this approach as I have described it so far would note its assumption that $a$ unity of higher types will emerge through the preservation and tolerance of limited forms of difference. As I have noted, this was a marginal view in early twentieth century Canada. But greater hegemony for the idea of seeking unity within diversity would come in time, as the Mosaic metaphor for Canadian society made its first tentative appearance on the scene, and constrained emergence theory was further refined.

\section{The Canadian Mosaic as a Constrained Emergence Theory of Identity}

The story of the Mosaic began, not with a self-conscious attempt to provide a name for a particularly Canadian form of nation-building, but with a passing reference in a traveller's journal. The following passage, which is perhaps the first published invocation of the Mosaic metaphor for Canadian society ${ }^{2}$, is taken from Victoria Hayward's Romantic Canada (1922). It was prompted by her encounter with the Canadian prairies, and occurred in the context of a discussion of the many "New Canadians" who were to be found there:

The New Canadians, representing many lands and widely separated sections of Old Europe, have contributed to the Prairie Provinces a variety in the way of Church architecture. Cupolas and domes distinctly Eastern, almost Turkish, startle one above the tops of Manitoba maples or the bush of the river banks. These architectural figures of the landscape, apart altogether from their religious significance, are centres where, crossing the threshold on Sundays, one has an opportunity of hearing Swedish music or the rich, deep chanting of the Russian responses; and of viewing at close hand the artistry that goes to make up the interior appointments of these churches transplanted from the East to the West.... It is indeed a mosaic of vast dimensions and great breadth, essayed of the Prairie (187). 
Here one can discern the operation of the tradition of Herodotan ethnography, in producing signs of Otherness from architecture, musical taste, mode of worship and, of course, language and country of origin. The encounter with these Alien signs in a familiar pastoral setting among the Manitoba maples "startles" the visitor whose senses are not accustomed to the assault. The diversity is there, it is multifaceted and real; and yet, it is a foreign figure set against a local ground.

A daunting profusion of differences, both natural and human, to be sure. But, for Victoria Hayward, Canadian diversity was not a problem - rather, it represented a positive and prefious opportunity for a roving spirit with a collector's gleam in her eye. In the introduction to the text, E.J. O'Brien applauded Hayward and her photographer companion, Edith Watson, for their loving attention to what made Canada particularly, and proudly, Canadian:

Those who know and love the by-ways of Canada have frequently encountered Miss Watson and Miss Hayward in the pursuit of a selfimposed task. Hardly a task we should call it, but a delight, to record with the camera and the pen those unique and beautiful racial traditions which have survived in Canada and flourished, which the passion for conformity to a provincial process of standardization has crushed in the United States.... That wise tolerance and appreciative catholicity which is not always found in a new land has preserved old loveliness here (iv).

O'Brien's introduction reinforced the articulation of Mosaic and race found in the form and content of the main text, with its reference to the "beautiful racial traditions" that "flourish" in Canada. It also noted the necessity of "tolerance" in the presence of problematic difference.

It seems fitting that this celebration of Romantic Canada, like so much else that is Canadian, was a gift from two Americans. No matter: the Canadians were quick to make use of a good thing, as can be seen from Kate Foster's publication, in 1926, of Our Canadian Mosaic. Foster followed Woodsworth's lead with her Section I, 
"Immigration and Statistics," which contains the requisite tables, and with Section II, "At Our Gates," which establishes the Tide of Immigrants as a bona-fide national problem. She deviates from his line, however, in trying to make a distinction between "assimilation" and "amalgamation:"

In many minds the term "assimilation" is confused with amalgamation. Does the former necessarily imply inter-marriage - the fusion of races? Is not assimilation rather the incorporating into our national life of all peoples within our borders for their common well being? Is it not the working together side by side for the common advancement, each race contributing something of value and so slowly but surely evolving a new people enriched by the diversity of its origin? (135, emphasis added).

What Foster calls "amalgamation" would presumably be what assimilation is not, i.e. a free emergence "fusion of races," which she rejects. But neither is assimilation, in Foster's text, a name for a design theory of identity. Assimilation is, for her, a process of "incorporating ... peoples" that she expects will leave room for the "evolving" of "a new people." The characteristics of this new people will be unknown, to the extent that they will be left to "evolve"; but, to the extent that they will result from a process of incorporation" into our national life, they will not be entirely unknown. Thus, what Foster advocates appears, once the terms are sorted out, as a version of constrained emergence theory.

In an attempt to give a concrete form to her ideas, Foster became the first writer to invoke the Mosaic metaphor in the context of a discussion of Canadian immigration policy and nation-building. In justifying this choice, she wrote of the Mosaic's "capacity to endure," a quality "essential in nation-building" (141). Equally important was the ability of the Mosaic to order and unify the Flood of chaotic diversity: "In nation-building all manner of materials are required," for the task involves the "fitting together of many generally small pieces ... to form a pattern" (141). Even "the humblest cube" was to be incorporated into the Mosaic, for it had a part to play in the overall design (142). Thus, every person was to be assigned a set of 
typical characteristics, and every set of characteristics was to be included in the Mosaic. But, while Foster advised that the variety of types should be brought together into a single (Canadian) pattern, it was equally important that they be kept separate, "no one tesserae encroaching in the very smallest degree upon another" (142). Thus did the Mosaic display in its form the abstract notions of equality, diversity, and unity in diversity.

Foster went on to note that in Mosaic-building, "as in other art, design is of paramount importance" (141). "A principle of order must prevail in every ornamental composition - otherwise the pattern is spoiled and there will be disturbing patches" (142). A design of course implies a designer and, in the spirit of Woodsworth's dedication to racial taxonomy, Foster was quick to point out that the designer "must know his material or fail:"

The most glaring mistakes that have been made in the course of erecting our national structure have been due to ignorance in regard to its constituent parts.... Just as the use of pictorial and figure subjects demands comprehensive historical knowledge ... so the use of human 'tiles' demands that we native-born Canadians make it our business to know something of the background of our fellow workers (143).

Foster expected that there would be great difficulties facing anyone "who attempts to classify the human elements that must be fitted into our intricate Canadian pattern" (141). But, like Woodsworth, this did not prevent her from making an effort. Section III of Our Canadian Mosaic provided "A Near View of Our New Canadians" where, following the conventions of Herodotan ethnography, the various types and their characters were brought into relief. But mere knowledge was not enough. Well aware of the tendency of internal Others to create difficulties for the realization of the Canadian National Dream, Foster insisted that the designer must "render the object which he produces useful... It matters not how beautiful the object is to be, it must first be formed as though it were a mere work of utility; and after it has been 
carefully created with this end in view it may then be rendered as beautiful as you please (141-2, emphasis in original). For the designer of the Canadian Mosaic, the program was clear: first, know the other, then render him useful; later, use him to put a layer of attractive ornamentation on your creation.

Foster also spoke about the "cement" used to hold together the pieces of the Mosaic, which for her could be nothing other than "good will and friendliness born of natural respect and confidence between all peoples within our borders" (143) - that is, tolerance of the differences displayed in the preserved human tiles. Here, however, the limits to the realm of emergence in early twentieth century Canada became clear: the only way to "natural respect" was to ensure that everyone had more or less the same nature:

We can surely learn a lesson from our great neighbour to the South for there is such a thing as a country being swamped by unemployable and undesirable immigrants. Thus Limited Selective Immigration is Canada's great need today. Prospective immigrants should be selected preferably from British stock or from among the more readily assimilable peoples of Europe (11).

For all of her talk about Mosaics and "evolving a new people", Foster was, in her policy recommendations, unable to take a step beyond the tried and true tradition of Anglo-conformity and exclusionary immigration policy.

To aid in the "evolution" of a British Canada, and following her previous suggestions about knowledge and utility, she suggested increased intervention in the daily lives of "the foreign born," in the form of a "Dominion-wide system of educating the aliens in Canada for citizenship" (128). As in the policy suggestions of the Canadian design theorists, the Immigrant Others were to be subjected to a system of tutelage and surveillance oriented to correcting their problematic difference. "Isolation is the greatest wrong to the Foreign-Born. They should not be left to themselves" (128). Thus early twentieth century constrained emergence theory 
shared with its ancient and colonial antecedents the characteristic orientation to improvement of the lot of a sorry, inferior Other who was seen to be begging for the gift of recognition from those in possession of a superior civilization. The Immigrant was to be lifted out of the muck, polished up, and cemented into a place of honour on the magnificent Canadian Mosaic.

\section{Design, Designers, and the Social Sciences}

After Woodsworth and Foster's first steps, the theory and practice of Canadianization through rational-bureaucratic intervention would be further refined and professionalized, with the help of the emerging disciplines of anthropology, sociology, and psychology. An important figure in this transformation was Robert England, whose Central European Immigrant in Canada (1929) drew on experience in the field to produce a general theory of Immigrant assimilation. The introduction set up England as a "representative of the voice of fifty experienced nation-builders who were encouraged to go forth into the outlying parts of rural Saskatchewan as apostles of the highest type of Canadian citizenship" (England 1929:x). Having put in his time in the Saskatchewan educational 'wilderness', England continued the social gospel tradition that had by this time taken firm root in the Canadian psyche. But he also attended the Collège Libre des Sciences Sociales in Paris, and so was able to bring a profusion of social sciences to bear upon the problem of Canadian diversity. In this way he invoked two new categories of differentiation, culture and ethnicity. England also began to more closely define the realms of constraint and emergence in the constrained emergence theory of Canadian identity, and refine the method of assimilation, arguing that it must be seductive rather than coercive in nature.

In his first chapter, entitled "The Problem," England made the customary display of tables and invoked the Flood metaphor, ritualistically creating a difficulty of "national concern" (3-4). He was worried that "our British ideals" would "go into a 
melting pot rather different from that which we have perhaps too superficially imagined" (8). For, competing with these ideals were others equally desirous of perpetuating themselves. Freezing his subjects in a Herodotan frame, England claimed that he encountered in Saskatchewan "districts where the customs, habits, social and economic background of the people belong not only to another land but to another century. There has been the question of the education of a medieval people" (9). In his descriptions, England implicitly put to work many of the classic, medieval, and modern means of differentiating the Other: ability to function in a democratic polis and to use the language of the observer; intelligence; mode of dwelling, literacy, and of course the ubiquitous climate theory: "The severe winter conditions which are a tonic to more Northern races must have confined in many a sod cabin in Northern Saskatchewan much home-sickness and regretful longing" (77).

But England, as a social scientist, also helped to push the frontier of the Canadian discourse on diversity into a new realm: that of culture. In one of its first appearances in a semi-official Canadian setting, culture leaned on the established authority of history, language and race as axes of problematic difference: "The linguistic problem ... emerges ... as the most urgent. Closely linked with it is the culture problem, which to some extent rests on historical development and racial differentiation as well as language distinctions (60)." Culture also had a certain scientific cachet borrowed from the discipline of anthropology: "Anthropologists are beginning to discover how cultural influences reach down to our most deep-seated emotional tendencies. The whole machinery of logical thought may be affected by the type of culture (161)." Culture, it seemed, was so important that if one were to be abruptly deprived of its support "serious psychological" problems could result and, as in the South Sea Islands, "races" could "die out" (162) from the effects of coercive assimilation. 
Under pressure from exponents of the new science, the Canadian government had added several anthropologists to the staff of the Geological Survey of Canada, whose job it was to conduct research on the "aborigines of Canada" and thus bring the equivalent to the tools of sociology to bear upon "those members of the human species as have been supposed, rightly or wrongly, to come nearest the state in which we may imagine primitive man to have lived" (Sapir 1912:62). Although still of dubious civilization and modernity, the Native peoples of Canada had been granted cultures of their own. As both Foster and Woodsworth had pointed out, one must know the Other in order to create and constrain her, and anthropologists were the specialists at this sort of knowledge production.

The new discourse of Mendelian genetics was also invoked in England's text, as a means to 'prove' the impossibility, or at the least the improbability, of the notion that a superior type of order would necessarily emerge out of a chaos of races:

When the question of the amalgamation of racial stocks comes to be studied in the light of biology and anthropology, it is probable the results will not justify facile optimism as to the merging of characteristics. In accordance with Mendelian law dominant racial characteristics will be found to persist, Mediterranean will not become Nordic, nor Nordic Alpine (England 1929:65).

If the free emergence thesis was scientifically insupportable, and if coercive assimilation could cause mental illness and death, then what was Canada to do? Following Hughes and the "evolutionary" undercurrent in Foster, and making use of yet another new category of differentiation - ethnicity - England proposed a strategy that involved the preservation and tolerance of difference, plus evolution / training to find "common denominators" between the various "elements" of Canadian society: "The modern world is more sympathetic to the idea of ethnic individuality. We are beginning to realize that a primitive people has a right to preserve its own cultural background whether aesthetic or not" (163). The category of ethnicity will be 
discussed further, in the context of its rise to dominance in the 1960's. For now, it should suffice to note that England's usage contained the seeds of a later 'confusion' or 'richness' in the use of the term, in that it would seem that while Other groups - in this case "primitive people" -- have ethnicity, anthropologists of the Self group do not. This was in keeping with ancient Greek and early Christian usage (see chapter 3), and tended to be the sense of the term when England was writing. In the latter part of the century, this sense was retained mainly in popular discussions, while those who considered themselves to be more 'scientific' began to point out that everyone had an ethnicity, that is, a race and a culture, also objectively delineated.

At any rate, in anthropology's paternal relation to the cultures of Primitive peoples, England had invoked and expanded upon another key idea of constrained emergence theories of identity: not only must problematic Others be allowed to preserve signs of difference, non-problematic Selves must be trained to tolerate these signs. It was not enjoyable, it offended the "aesthetic" sense, but it was necessary. And, perhaps not too difficult, given the history of Canadian diversity:

The British Empire has been fortunate in having administrators in colonial and mandated territories imbued with sufficient sympathy to realize that the type of social life to which a race has accustomed itself must be touched with care.... Idea, customs, "taboos," which seem to us totally illogical and incomprehensible, are logically sound and completely comprehensible given the background, the mentality, and all the premises upon which the whole social structure is based (163).

What forms of difference were to be tolerated by Canadians, according to England? First of all, he thought it unwise to "expect or require" Immigrants "to surrender anything that might be helpful to unity and progress" (184-5). The Immigrants would also be permitted to hang on to certain aspects of their particularity which, while they might not directly contribute to the greatness of the Dominion, would not pose a challenge to the canon of British-Canadian liberal-democratic capitalism. "[W]e need not care whether the peasant woman, for example, keeps or discards her head dress, 
unless it indicates adherence to a general scheme of custom and institution alien to the spirit of Canadian progress" (185). In general, England thought that "older Canadians should welcome variety of custom" (185).

While variation in customs was seen to be acceptable - as long as they were of no social or political consequence -- no tolerance was possible with regard to the crucial issue of language:

To understand and sympathize we must speak a common language, share a common opportunity fitted to our capacity, and thrill to common memories of mutual service rendered, of pain endured, of story, legend, tradition, and song (185).

England suggested that "out of these [commonalities] will come inevitably similarities of custom and habit, a certain standardization of logical processes in thought, and even, perhaps a similar response to emotional appeal" (185). The common language would, of course, be English. Anyone who was not "Englishspeaking" was an Other, including the French, whom England unceremoniously lumped in with types generally considered to be far lower on the Great Chain of Race in his enumeration of thirty-one "non-English" rural districts in Saskatchewan: wable II shows that District No. 8 was Hungarian; No. 16 Mennonite; No. 5 German, Norwegian, and Anglo-Saxon; No. 6 Ukrainian-German; No 30 Doukhobor; No. 2 French" (69). For England, language was the great assimilator. ${ }^{3}$ If the Immigrants could be seduced into speaking English, they would eventually become British, and the problem of Canadian diversity would be solved.

Here, in the realm of intolerance, England was cautious to avoid the mistakes made by other Colonizers. Citing W.H. Rivers, he noted that "the only way in which the culture of an immigrant people can be carried about the world is in a psychological form, in the form of sentiments, beliefs and ideas" (161). If cultures had 
an immaterial basis, then those who sought to manage them would have to take this into account:

Fundamentally, the problem must be regarded to some extent as a psychological one and this, in turn, means that the institution which deals with the moulding of minds and wills must be operated efficiently, and the newer citizens must be shown especially how worth-while it is to make the institution ... theirs (185).

Thus, instead of a policy of coercive total assimilation, England argued for a subtler form that was partial and seductive:

We cannot compel people to accept our standards, our customs or our ways. The work of assimilation must not be a work of putting into bondage. It must be a task of emancipation. It must be a challenge and a call to wider perspectives, saner ideals, better habits and customs ... (165-6).

In this way, he hoped that a "bond of national unity" could be forged (168), warning that "we must incorporate the races who have come to us into one people: otherwise our Dominion from sea to sea will perish in strife and anarchy" (173, emphasis in original).

Again, we see the fear of conflict and disorder that permeates the Canadian discourse on diversity, along with the equally ubiquitous dream of a perfectly striated space of social order that closes the Canadian ecumene, stretching between two 'smooth' seas. In his plan to achieve this ideal, England adhered to the constrained emergence theory of Canadian identity, placing in the realm of preservationtoleration-emergence what he calls "custom," and in the realm of constraint any social, political, or economic forms that he felt would threaten British-Canadian liberal-democratic capitalism. To convert these constrained and preserved Others into free Selves England relied upon linguistic assimilation, which he assumed to be a powerful seductive force that could be harnessed to the task of producing an English- 
Canadian unity and identity. This continuation of the English-Canadian dream of Dominion, coupled with the assumption of the assimilative power of language, shows that the willingness to leave some differences in place and tolerate them was a selfconscious move in a long-term game. Even though it had failed miserably in both Acadia and Quebec, strategic simulation of toleration of the Other was being offered up once again as the solution to the problem of Canadian diversity. Blithely unaware of its own history, the English-Canadian tradition marched on, professing sympathy and liberal views and offering up the gifts of freedom and civilization, all in the name of gaining a much-coveted, but ever-elusive, national unity and identity. As yet, however, the Canadian state had not committed itself to this task, and continued to remain aloof. This would change with the Second World War, when relatively tolerable, somewhat Canadian Selves were once again transformed into monstrous Enemy Others whose mere presence constituted a national crisis.

\section{WWII and the 'First Bureaucracy for Multiculturalism'}

In this section I set out to show how the constrained emergence theory of Canadian identity was introduced to, and taken up by, the Canadian state as a solution to a problem of wartime Immigrant diversity. The transfer of socialscientific knowledge to official policy came by way of two key figures: Tracy Philipps, whose intense lobbying helped to create the Nationalities Branch of the Department of National War Services; and Watson Kirkconnell, who tried to limit the realm of emergence to the mixing of European "nations," and whose writing established the generic characteristics of the state-sponsored, academically-produced pamphlets which are now ubiquitous. Through the efforts of Philipps, Kirkconnell, and other academic experts, the Canadian state began to take upon itself the role of "policing culture" (Bauman 1992:8), and it is in this sense that the Nationalities Branch, the 
form of which was maintained after the end of the war, can be considered as the "first bureaucracy for multiculturalism" (Dreisziger 1988).

The Canadian government began its assault on the new Enemy Aliens with the tried and true methods of bodily discipline. The War Measures Act, left over from 1914, was again invoked, and used to issue the Defence of Canada Regulations (Canada 1939). As in the First World War, one did not need to actually do anything to become an Enemy Alien; it was enough that one had lived in an occupied country, or that the Minister of Justice "satisfied" himself that one might, in the future, act "in any manner prejudicial to the public safety or the safety of the state" (Canada 1939:29, s. 21). Such persons could be registered, detained, arrested, and interned, with no requirement for what is known as 'due process' within the tradition of Western liberalism.4 ${ }^{4}$ While some people were disciplined for their former place of residence or supposed political beliefs, 5 others were deprived of their Canadian identity because of what appeared to the Canadian government as their 'racial origin'. Many whose origin the government identified as German or Italian were arrested and interned for having been so identified, and a large proportion of the interned Communists were classified / self-identified as Ukrainian or Jewish (J.H. Thompson 1991:11-14). Perhaps the most famous WWII internment was that of the Japanese, which also involved an effort in displacement and transportation the likes of which had not been seen in Canada since $1713 .^{6}$

Although it depended heavily upon ancient and modern methods of discipline during the war, the Canadian government also took its first, tentative steps toward the adoption of a new, postmodern form. Following England, J.F. MacNeill of the Department of Justice wanted to abandon the use of "repressive police measures" in dealing with the Immigrant problem, and advocated a shift to "well written articles published in their own language ... printed and distributed free of charge" (cited in Dreisziger 1988:5). Tracy Philipps, a widely traveled, multilingual diplomat and spy, 
was thinking along similar lines. Early in 1941, Philipps wrote a report on a tour he had made of the Immigrant heartland of the Western provinces, and addressed the means of attaining two goals:
A. Immediate Aim. To win the war. B. Ultimate aim. Unity of the Canadian nation. (NAC RG 26 Vol. 1 File 22-2 Vol. 1, Short Extract, Report Submitted on 16th January to the Associate Minister:1).

\begin{abstract}
Arguing against the strategy of "attack" on the "foreign element"7 that had been used so far (Section VI-1), Philipps proposed a method of seduction much more "convenient to Nature:"
\end{abstract}

One gives the subject access to the sun. It illuminates, it enlightens and heals. One unearths their misapprehensions and their grievances. One treats these simultaneously and sympathetically.... This second process calls for far more patience. It is slower but surer.... The subjects spontaneously begin to detach themselves from their ancient backgrounds.... They are caught up into Canadianism of which at last they can be helped to feel themselves the co-creators (VI-2).

To "catch up" the problematic continental Europeans, Philipps advocated a focused propaganda effort, arguing, after Woodsworth and Foster, that "each national group has to be treated on its own peculiarities" (VI-3):

The first hook-up has... to be not between the divergent unCanadianized groups themselves. Each community needs to feel itself separately and directly linked to the country's permanent government (VI-4).

On the level of tactics, Philipps advocated the Roman-Jesuit technique of "employing even kings to make others slaves," and seducing the Others into assimilation without their conscious awareness of what was taking place:

[O]ur first task is to work through the willing and already assimilated elements within each national group and of the same vocational class. Through them we can close up to other and older-Canadian contacts, 
until the new Canadians are insensibly merged into the main lifecurrent of the nation (VI-4, emphasis added).

As a complement to this effort, Philipps also suggested that the government seek to "diminish Canadian disunity by interpreting sympathetically the less understood European Canadians to audiences of older Canadian stock" (VI-1). Like England, Philipps was assuming that the problem of European diversity could be officially addressed not only by removing signs of Otherness from European bodies, but also by trying to render these signs less offensive to those whom they offended. Thus, for the first time, the Canadian government was to subject solid BritishCanadian Selves to racial-cultural discipline, just as though they were Savage, Indian, French, or Immigrant Others. As an end-goal, Philipps visualized a constrained-emergent Mosaic-like object, created through "a process of building-in of a richly diversified human material into a very distinctive British-American edifice, identical with neither but drawing the best from both" (IX-2).

Throughout 1941 Philipps continued to argue for the creation of a bureaucracy that would carry out this work, until finally, in December, he was hired as European Advisor to the Director of the Bureau of Public Information of the Department of National War Services, along with Professor George Simpson, who was to act as Senior Advisor (PC 103, 104, December 3, 1941). This was an informal arrangement that seems to have served a mainly propagandistic function, the style of which can be seen in the pamphlet Canadians All: A Primer of Canadian National Unity. According to the Foreword, "[i]n this booklet, the authoritative pen of Prof. Watson Kirkconnell tells the story of the peoples of Canada, and points to a road for us to follow towards permanent unification of all our groups into one strong, resolute nation" (Kirkconnell 1941). Here, for the first time, academic authority and state power were brought together to produce seductive literature for mass consumption, 
with the goal - once again - of "permanently" solving the problem of Canadian diversity.

In the first few pages, Kirkconnell follows Woodsworth's lead in laying out immigration and population statistics to prove the existence of "the varied ingredients that history has poured into the huge mixing-bowl of Canada's national life" in which, stealing a line from Foster, he declares that "no one element predominates" (7). The "mixing-bowl" metaphor suggests that Kirkconnell adhered to a free emergence theory of Canadian identity. This tendency can also be observed in his claim that "we are all minorities, but all Canadians, entering, each with his own capacities, into the richness of the national amalgam" (7). To justify this egalitarian rhetoric, and to counteract possible "Nazi underground warfare," Kirkconnell tries to discard the notion of race, calling it "one of the most dangerous errors that can delude the human brain" (8), and declaring that "there is no such thing as a French race, an Italian race, an Anglo-Saxon race, or a German race.... We are all mixtures" (11). Mixtures of what, one might ask? It turned out that "to the scientist" - the Linnean natural scientist -- there were in Europe "three main subspecies of the human race, namely (i) the tall, fair-haired, long-skulled Nordic, (ii) the short, dark, long-skulled Mediterranean, and (iii) the stocky, broad-headed Alpine type" (8). Kirkconnell claims that "every nation in Europe has been a mixture of these types," and thus concludes that "none of our national groups from Europe is really alien to the rest of us" (11).8

This equality effect can also be seen in the form and content of the minicatalogue of human types that takes up the last half of the pamphlet. Here the focus is on the "contributions to Canada" made by various groups. Equality is apparent in the fact that this section is arranged alphabetically, rather than in order of the Great Chain of Race as it was in Woodsworth's text. The tone is decidedly more generous than Woodsworth's as well. The Indians and Eskimos are credited with having "built up an extensive and typical American civilization" and with "teaching 
the French and the Anglo-Saxons the arts of travel and survival in a vast new land (37). Indeed, if he mentions a group at all, Kirkconnell has nothing unpleasant to say about it, as he notes in his memoirs: "I gave Oscar Cohen and the Canadian Jewish Congress a chance to vet my section on the contribution of the Jewish-Canadians. My one plea was that he should not try to inflate my text, since, in my effort to be generous to the Jews, I had given them more inches than any other group in Canada, including the French, the English, or the Scots" (Kirkconnell 1967:273). These are signs that his pamphlet, of which 300,000 copies were distributed, was produced not to aid bureaucratic action, nor to edify academic colleagues, but for mass consumption by Canadians both problematic and canonical.

While he tried to set up a rhetoric of equality, a close reading of his text shows that Kirkconnell was not a free emergence theorist, but an advocate of a Canadian identity that would emerge only out of the White section of the Great Chain of Race, with these races renamed as nations. He writes, for example, that we "should be careful never to assume that our fellow-Canadians, of any origin, are by nature unworthy of our sympathy, respect, and good will (11, emphasis added). But this occurs in a paragraph which has as its topic "our national groups from Europe." In the discussion of races as "mixtures," he clearly states that "none of our national groups from Europe is really alien to the rest of us" (11, emphasis added). Later, he suggests that "all of us, of every origin, must resolutely repudiate" hatreds brought to Canada from abroad. Again, however, the only hatreds mentioned are those brought by "our citizens from Europe" (12). Nowhere were non-Europeans explicitly excluded from Kirkconnell's "multi-national state" (12), but everywhere there operates the assumption that the "us" and "we" that will contribute to the emergence of a Canadian identity are exclusively European. With its high rhetoric of equality masking a racialist limitation on the allowable parameters of emergence for a Canadian identity, Canadians All established the generic characteristics of the 
mass distribution pamphlets that would be produced by the Canadian state for the next 50 years, and which are still being pumped out by the hundreds of thousands.

This propaganda effort was given a more formal footing in 1942, with the creation, under Ministerial authority, of the Nationalities Branch of the Department of National War Services. Also at this time, the Advisory Committee on Cooperation in Canadian Citizenship (ACCCC) was formed, to bring academic and other expert advice to bear upon the problem of the European Other. Its work, in the face of administrative and personal difficulties, is presented in glowing terms in Robert England's memoirs:

Despite [some] handicaps, the committee and the branch continued to function, issuing a weekly release as to the use made of the Canadian topics in the foreign-language press, keeping liaison with the Red Cross, auxiliary services, the National War Finance Committee, and various friendship councils and community councils throughout the country, initiating helpful newspaper stories, and working actively with the various ethnic groups throughout the country (England 1980:137).

A similar resume can be found in the pamphlets and speeches of Watson Kirkconnell, one of which was quoted at length in the House of Commons (DHC April 27, 1944:2417).

The records of the Nationalities Branch and the papers of Tracy Philipps in the National Archives corroborate these claims, but also add a little more to the story. The Editorial Section of the Nationalities Branch, under Vladimir Kaye, did indeed contribute to the foreign language presses; but it spent much more time monitoring them, with the help of Kaye, who was multilingual (NAC RG 26 Series B1 Vols. 3-4, Files 33-C-1 to 33-C-Z). Not only were Foreign presses watched, Foreign groups and individuals were tracked as well, and information exchanged with the police. In May of 1942, Tracy Philipps sent a report on "Communist Activity, Organization, and Plans” to Mervyn Black of the RCMP, and requested information on certain Slavic organizations and individuals. Black responded by naming several 
people as members of the Communist party, and also provided his opinion on the links between communism and Elements of Canada's Foreign population:

An amalgamation of Slavic organizations took place in Hamilton during April and while there were included in this so-called United Slavic Organizations of Hamilton some church organizations, the Communist controlled language groups were overwhelmingly predominant. The ostensible object of the conference held in Hamilton was, of course, for aid to the Red Cross (M. Black to T. Philipps, June 22, 1942, NAC RG 30 E350 Vol. 1 File 8).

A similar exchange of correspondence, marked "Secret. ${ }_{2}$ took place in November of 1942 , in which all of the directors of the United Slavic Organizations of Hamilton were provided with a communist or ethnic nationalist connection. "It seems quite obvious," the Assistant Director of Criminal Investigation for the RCMP concluded, "that the Communists exercise considerable influence, if not control, in the Organization" (K. Duncan to T. Philipps, November 23, 1942, NAC RG 30 E350 Vol. 1 File 8). This was how the Nationalities Branch "liased" and "worked actively" with "various ethnic groups throughout the country" - it subjected those Enemy Aliens who were not in internment camps to surveillance and secret manipulation, in an attempt to assuage the Canadian government's fear of the Red Menace.

Yet, despite its many activities -- and perhaps because most of them were kept secret - this early bureaucracy for the management of problematic Otherness atrophied, and was faced with dissolution at the end of the war which had provided its raison d'être. Following what was quickly becoming a great Canadian tradition of using academic expertise to construct and justify the existence of the problem of Canadian diversity, Robert England was brought in as a sociological hired gun to help reorganize the Nationalities Branch. His report made no new contributions or innovations to the discourse on Canadian diversity, but was important in that it recommended that the efforts of the Nationalities Branch be continued during the peace: 
It was probable that we had before us at that time two or three more years of war succeeded by years of political adjustment in Europe, which would disturb many of our peoples of European origin. It was a measure of national wisdom to attach them closely to Canadian ideals and aspirations in the interest of their own peace of mind and the future welfare of their children. In view of this situation, I recommended the permanent establishment of a Citizenship Division... (England 1980:141).

A difficult debate ensued in the House of Commons (DHC April 27, 1944:2396 ff.), with various members citing pamphlets, invoking the Mosaic, and telling their personal stories of immigration. A Mr. Pouliot desperately pleaded for the Minister to "get back to normalcy by removing this item from the estimates" (2405), but there was a new normalcy on the horizon, and the item was passed. The Nationalities Branch - renamed as the Citizenship Division - was not only saved, its budget was more than doubled, so that it could carry on its dual mission of public friendship and secret surveillance, even though the National Emergency that had justified its creation would soon pass into history. Recalling this period in his memoirs, Robert England remembers that he had been asked "facetiously" how he was getting on in the "twilight zone" of the National War Services department. "I was not quick enough to reply," England writes, "to the slightly pejorative term, by saying that I was midwife in the twilight sleep to the birth of a federal agency that would outlast the World War II defense agencies, and that the concept of citizenship was as vital to the survival of Canada as the Polymer Corporation or research into the splitting of the atom" (England 1980:143). Plastics, atomic fission, and multiculturalism: harbingers of the coming postmodern age.

\section{The Citizenship Machine}

Having arrived at the safe resting place of the end of the Second World War, we might pause and consider the state of the problem of Canadian diversity at this crucial juncture. Rough-and-tumble, coercive, total assimilation of European Others 
was giving way to a more subtle form, in which the preservation of certain signs of Otherness was seen as permissible, perhaps even Desirable. The Canadian government was taking upon itself the task of not only training Others to be Selves, but of training Selves to accept the signs of Otherness that were being preserved. This strategy was adopted with the goal of helping problematic European Others feel like their nation was becoming an official state nation, and thus constituted a simulation of the Selves assimilating to the Others. This was a strategic simulation, however, because the long-term goal was still assimilation of the Others by the Selves, the moment of preservation playing the role of "ancient soil" brought along with the "plant" to the "new world," where it would eventually be knocked off (England 1929:187).

With the rise of the first bureaucracy for multiculturalism, the Canadian state began to expand its purview outside of the concentration camps set up in times of "national emergencies," to attempt increasing, everyday microcontrol of the lives of both canonical Selves and problematic Others. While I would not want to downplay the sufferings of those who have been held in concentration camps, both in Canada and elsewhere, there is a sense in which this form was being extended to cover those who, due to semiotic, financial, and physical limitations, could not be constructed as Enemy Aliens and interned. Rather than constraining the bodies of some of those who inhabited its territories, the Canadian government began to try to constrain the minds of all. This was the task allocated to the postwar Citizenship Branch which, as I will show in this section, progressively extended its domain from the management of European Immigrants to include Indians and then canonical Canadians, becoming what I will refer to as a citizenship machine. In this way the state emerged as the entity that would solve the problem of Canadian diversity once and for all, by providing a basis for unity that had otherwise been lacking. 
One crucial aspect of the postwar problem of diversity was set in place in 1947, when the Canadian government announced that its new immigration policy would be "based on the conviction that Canada needs population," and would involve "productive immigration measures." In putting forth this "new" policy, W.L Mackenzie King relied on some old arguments:

[T] a world of shrinking distances and international insecurity, we cannot ignore the danger that lies in a small population attempting to hold so great a heritage as ours.... A larger population will help to develop our resources. By providing a larger number of consumers... it will reduce the present dependence of Canada on the export of primary products (W.L. Mackenzie King, DHC May 1, 1947:2645).9

Past experience had shown that the procurement of Foreign producers and consumers usually led to trouble. But the Prime Minister hoped to avoid such problems by way of proper rational planning:

The fear has been expressed that immigration would lead to a reduction in the standard of living. This need not be the case. If immigration is properly planned, the result will be the reverse.... The essential thing is that immigrants be selected with care, and that their numbers be adjusted to the absorptive capacity of the country (2645).

This planning and adjustment had as its goal the expansion of the size of the managed population available to the Canadian state and its capitalist economy, while preserving the state's articulation with that population through excluding Immigrants - e.g. the "oriental" - who would "change" its "fundamental composition" (2846).

This new immigration policy of course required a new bureaucracy. King gave the Department of the Secretary of State, which had long been responsible for the registration of Canadian citizens, control of the Citizenship Branch, which was supposed to create them. The role of the Branch, as proposed by the ACCCC, was essentially propagandistic: to "create among Canadians of French and British origin 
a better understanding of Canadians of recent European origin, and to foster among the latter a wider knowledge and appreciation of the best traditions of Canadian life" (Dept. of the Sec. of State 1949:78). In carrying out its mission of peacetime propaganda, the Branch encouraged the provinces, which were responsible for education, to set up citizenship training classes. Seven of the ten provinces had done so by 1949, producing 17,000 new Canadians (Dept. of the Sec. of State 1949:78). The task that had been formerly entrusted to the rubbing of shoulders and Christians on internal missions was now being taken up by the Canadian state at both the federal and provincial levels.

To complement its new official policy for the production of citizens, Canada also required a new official history. This was provided by a booklet entitled Our History, 10,000 copies of which were produced for use in citizenship classes. Here the Canadian government presented what was supposed to be "a factual account of Canadian history under the general headings of Discovery and Exploration, Settlement, and Political Development" (Canada. Dept. of Citizenship and Immigration. Canadian Citizenship Branch. 1961:79). It is worth seeing what was included in and excluded from Our History, as this pamphlet was periodically revised and reprinted up until its last edition in 1967, and the sanitized narrative it presented is still being recited as 'fact' to anyone who can be forced or seduced into listening to it. ${ }^{10}$

The English colony at Newfoundland is included in Our History, but the Beothuk are not (26). The Acadian transportation is given a few lines, and some attention paid to the "hardships" that were endured. But the events are treated as a sad necessity, the fault for which is laid at the door of its victims: "Their refusal to swear allegiance to the British crown brought disaster upon them." (27). In the section on "Settlement," the expansion of Upper Canada under Simcoe is related, but no mention made of the people Simcoe had to push out of his way to implement what 
is referred to as his "ambitious immigration policy" (30). The discussion of further Canadian expansion to the West is justified according to the ancient European doctrine of terra nullius, as "the west was still practically empty. Its limitless plains were not well known even to fur traders who had established their isolated posts on Hudson Bay" (32). New Immigrants would have been especially happy to hear about the wonderful experience of the Doukhobors in Canada:

The group consisted of 7,400 persons who had fled from religious persecution in the Russian Crimea and who sought sanctuary in the New World. The Canadian government guaranteed them religious freedom, exemption from military service, and gave them a large tract of land on which to settle (78).

Again, there is no doubt about the facts' as given. What was not mentioned is that these promises were never kept, and that the Doukhobors have been excluded, ridiculed, persecuted, disenfranchised, interned, and jailed ever since setting foot on Canadian soil.

But the Sons of Freedom should have felt honoured to be included in the short list of peoples and religions that merited attention as having made contributions to Our History: British, French, Scottish, German, Americans, Mennonites, Irish, French Canadians, Icelanders, Mormons, Doukhobors, Ukrainians. The Chinese, Japanese, Negroes, and Hindus were totally excluded, perhaps because there was simply no way to put an appropriate spin on the relevant "facts." No mention was made of the Indians, Half-breeds, Metis, or Inuit, as separate groups that had made a "contribution" to Canada. In the sense that the development of this genre has always been towards greater inclusiveness, Our History was actually somewhat behind Canadians All, to which it owed a great debt for its literary-bureaucratic existence as a mass-consumption pamphlet. It was innovative within its genre, however, in its presentation of the 'facts' of Canadian history in such a way that only the 'good facts' were mentioned in most cases, and if the 'bad' came out at all, they 
were accompanied by a justification, as a sort of epistemological chaperone. Rogue facts have a way of tripping up even the most poised and well-balanced of narratives, and the task of the Information Division of the Canadian Citizenship Branch was to ensure that those relevant to Our History were kept in good order.

Meanwhile, the bureaucrats were playing a fast-paced game of musical chairs. The Citizenship Branch was transferred to the newly created Department of Citizenship and Immigration. Louis St. Laurent, the new prime minister, gave the Branch the old task of "bring[ing] to full citizenship as many as possible of those who immigrate to this country ... as quickly as could reasonably be expected" (DHC November 26, 1949:2285). Once the government had decided that responsibility for citizenship and immigration should be consolidated, "it was considered that the minister responsible for this department should, in addition, be given the responsibility for the Indian Affairs Branch" (Louis St. Laurent, DHC November 26, 1949:2285). This shift in bureaucratic responsibility deserves some comment. While attention had been focused on the Immigrant throughout the first half of the twentieth century, official interest in the Indian problem had picked up in 1946, with the formation of a Special Joint Parliamentary committee to examine the operation of the Indian Act and recommend changes. Why the sudden resurgence of interest in the Indian Other? John A. Glen, whose ministry of Mines and Resources had governmental responsibility for the management of Indians, expressed it in clear, numerical terms. The Indians - who would not assimilate and who were supposed to be dying out - were not only continuing to live, but thriving, with a population "of 128,000 , increasing at the rate of 1,500 a year" (DHC May 13, 1946:1447). The size of the Indian problem, which was taken to be proportional to the size of the unassimilated Indian population, was therefore seen as increasing at an alarming rate. 
The debate regarding the establishment of the Indian Act committee shows that the Indian was still being viewed as an inferior internal Other to be protected and given the gift of civilization. John Glen, again, at greater length:

It would appear that we have reached a stage in our development as a nation when economic conditions will force us to do one of two things: (1) purchase at public expense the additional lands and additional hunting and trapping rights for an Indian population of 128,000, increasing at the rate of 1,500 a year; or, (2) decide on an educational and welfare programme that will fit and equip the Indian to enter into competition with the white man not only in hunting and trapping but in agriculture and in the industrial life of the nation. While I have no desire to indulge in over-simplification ... I fell that we have here the crux of what is usually referred to as the Indian problem (DHC May 13, 1946:1447).

While this definition of the Indian problem and its possible solutions was indeed accurate, and centuries old, Glen also showed his awareness of recent developments in the history of Canadian diversity when he cast the Indian problem in the same terms as the problem of the Immigrant, and opted for the same sort of solution:

The educational and welfare programme to which I have referred cannot, in the nature of things, accomplish much overnight. Nor should it be aimed at making the Indian into a white man. The Indian, as I see it, should retain and develop many of his native characteristics, and should ultimately assume the full rights and responsibilities of democratic citizenship (1447).

Like the European Immigrant, the Indian was not to be totally assimilated, but would be allowed to preserve "many of" his characteristics; that is, those which the canonical Canadian people and their state found to be non-problematic. From now on, he would be citizenized rather than civilized.

St. Laurent was following this line in his attempt to bring all of those who were seen as not quite Canadian together under the same bureaucratic roof. This, it was hoped, would bring together the people themselves, united in their articulation with the state apparatus as official Others. When pressed on the creation of yet another 
ministry, St. Laurent replied that "the object in all these activities is to make Canadian citizens of those who come here as immigrants, and to make Canadian citizens of as many as possible of the descendants of the original inhabitants of this country" (DHC December 2, 1949:2596, emphasis added). Still plagued with an excess of Undesirable internal Others who would not go away, and facing a new 'flood' of incoming Others because of insecurity over the size of Canada's population and its status as a capitalist power, St. Laurent envisioned the new Canadian Citizenship Branch as a machine for the production of citizens out of raw human resources. Following the model of modern capitalist industry, he hoped that this machine would provide as many of its objects as possible, as quickly as possible.

The Department of Citizenship and Immigration came into existence on January 18, 1950, and issued its first report in 1951. Frank Foulds, the director of the Canadian Citizenship Branch, described its mandate as follows:

The functions of the Canadian Citizenship Branch are to promote unity among all racial groups; to awaken in every Canadian, regardless of race or creed, a deep conviction of the worth of the individual and the principles of democracy; and to encourage a greater consciousness among our people of the achievements of the Canadian nation and the fact that all Canadians actively share in these achievements (Department of Citizenship and Immigration [DC\&I 1951a:9).

Foulds had a vision of expanding the mandate of his branch beyond European Immigrants and Indians, to cover "all racial groups" and "every Canadian." Its scope was thus not merely widened, it was made open-ended. Everyone, regardless of their "race or creed," became potentially subject to Citizenship discipline; everyone became part of the problem of Canadian diversity. Of course, everyone could also become part of the solution, if only they would occupy the position of citizen offered by the various levels of the Canadian state, which took on a role similar to that played by Apollo and Artemis for the ancient Greeks in representing "the hope of 
intervention from above, for dei ex machina to re-order and clarify difference" (duBois 1991:119).

\section{From Racial Assimilation to Cultural Integration}

The question remained, however, as to how order would be restored and Canadian unity achieved. While still under the Secretary of State, the front-line workers and policy-makers at the Branch seemed to know that "assimilation" was not a good term to use for what they hoped to do to "newcomers," but they did not yet have anything to use in its place. With the move to their own Department, however, they found their word - integration:

The varied activities of the Canadian Citizenship Branch in the interests of a more closely integrated Canadian population were carried out with good success (DC\&I 1951a:7).

The officers of the Liaison Division continued to facilitate the integration of new residents of Canada by assisting them to take their place in established Canadian organizations and institutions (9, emphases added).

While the 1950 Citizenship Branch report was crucial in its official adoption of the strategy of integration, the report for 1951 also marked an important shift in the discourse on Canadian diversity: the fall of the category of race. Even before the war, the use of race in Nazi propaganda had rendered the term suspect. Once news of the death camps was being widely broadcast, and the horrible results of the fascist combination of racialism with capitalist (ir)rationalism became apparent, very few people wanted to read, write, speak, or hear the word. The Canadian Citizenship Branch followed this trend by altering its statement of purpose. Whereas it had previously been out to promote unity among "all racial groups," it now took as its mandate the promotion of unity "among the various ethnic elements in Canada" (DC\&I 1951a:9). Other than this change of term, the rest of the sentence remained 
the same, as did the format and content of the report. Race was out. Ethnicity was in.

Even the technicians of the Canadian census, who had hung on to race for decades despite public opposition, now gave it up. In the 1951 census, "Origin” - with no qualifier - was said to refer to "the cultural group, sometimes erroneously called 'racial' group, from which the person was descended." Enumerators were told to "first attempt to establish a person's origin by asking the language spoken by the person (if he is an immigrant), or by his paternal ancestor when he first came to this continent." If that failed, they were to start providing possible answers which, interestingly enough, had been racial distinctions ten years before, by asking "Is your origin in the male line English, Scottish, Ukrainian, Jewish...." Finally, if all else failed, "if a person states that, because of mixed ancestry, he really does not know what to reply to the question on origin," the census-taker was authorized to commit a sad but necessary act: "you will mark the oval Unknown" (Canada. Dominion Bureau of Statistics 1951: Question 17).

The last bastion of race was to be found in the Immigration Branch, which was under the same Minister as Citizenship, but was a little behind the times, in that it continued to issue statistical tables under titles like "Racial Origin of Immigrants by Nationality" until 1954 (DC\&I 1954:32-33, Table 3). The next year, quite without fanfare, "Nationality" was replaced by "Country of Citizenship," and "Racial Origin" gave way to "Ethnic Origin," to produce an otherwise identical table under the title "Ethnic Origin of Immigrants by Citizenship" (DC\&I 1955:32-33, Table 5). As if by magic, 46 racial designations, from Albanian to Ukrainian, became ethnicities.

The decline of racialism was not merely a Canadian phenomenon, but occurred throughout the Western world. Theo Goldberg has noted that "since World War II ... the cultural conception of race has tended to eclipse all others. It has 
become paradigmatic" (Goldberg 1993:71). Tzvetan Todorov marked the same historical endpoint in claiming that "the period of classical racialism seems definitely behind us, in the wake of the widespread condemnation of Nazi Germany's policies toward Jews; thus, we can establish its chronological limits with a precision that is unusual in the history of ideas: from 1749 (Buffon) to 1945 (Hitler) (Todorov 1993:157). Todorov points out that, while the term race might have fallen from favour, the work that it enabled would continue:

The term 'race', having already outlived its usefulness, will be replaced by the much more appropriate term 'culture'; declarations of superiority and inferiority, the residue of the attachment to the universalist framework, will be set aside in favour of a glorification of difference (a difference that is not valorized in itself). What will remain unchanged, on the other hand, is the rigidity of determinism (cultural rather than physical, now) and the discontinuity of humanity, compartmentalized into cultures... (Todorov 1993:156-7).

As we have seen in chapter 5 , the first proposition of what Todorov calls "classical" racialism is affirmation of the existence of races. This flexible proposition is vital to the survival of the Western discourse on human diversity, because race can easily be replaced by any means of differentiation of human types without disrupting the other axes of the discourse. Indeed, race itself was a replacement for civilization and humanity in a prior formation, and so could quite easily give way to culture, while preserving the other axes of the discourse: the continuity between physical-cultural type and character; the action of the group on the individual; hierarchical ordering of the differentiated types; knowledge-based politics or, as I would put it, the prescription of a program to bring everyday life into line with the symbolic universe created by the discourse of differentiation. In the case of the problem of Canadian diversity, the project of Canadian unity took this role under racialism, and kept it as culturalism began its rise in the period after World War II. 
But culture, it seems, was not able to replace race without some help from ethnicity, which helped to provide the needed causal link between the physical body and the personality. The 1950 report, even though it spoke of unifying races, also noted the existence of "voluntary organizations ... referred to as ethnic groups," which were "clubs, societies, and other organizations built around the memory of the countries from which the members or their families came" (DC\&I 1951a:10). The report also used the term "ethnic group" in a broader sense, noting that "the many ethnic groups have established numerous organizations to satisfy the needs and problems peculiar to their own groups" (11). The next year, ethnicity was elevated to a central position, with the first function of the Citizenship Branch being to "promote unity among the various ethnic elements in Canada" (1951b:9). In its 1952 report, the Branch provided a definition of ethnic groups as "various non-English or nonFrench-speaking organizations of Canada" (1952:12). Presumably, since a separate section of that same report dealt with the Indians, they did not constitute an ethnic group. Ethnic groups were thus neither British nor French nor Indian, but were Canadian to the extent that they had assimilated and acquired, like the British and French before them, a hyphen. The semiotic square of Canadian identity that had been emerging over the postwar period can now be set out as a means of showing how Canadians were distinguished from non-Canadians by way of the categories of culture and ethnicity. 
Figure 7.1 - Group identity in Canada, post WWII

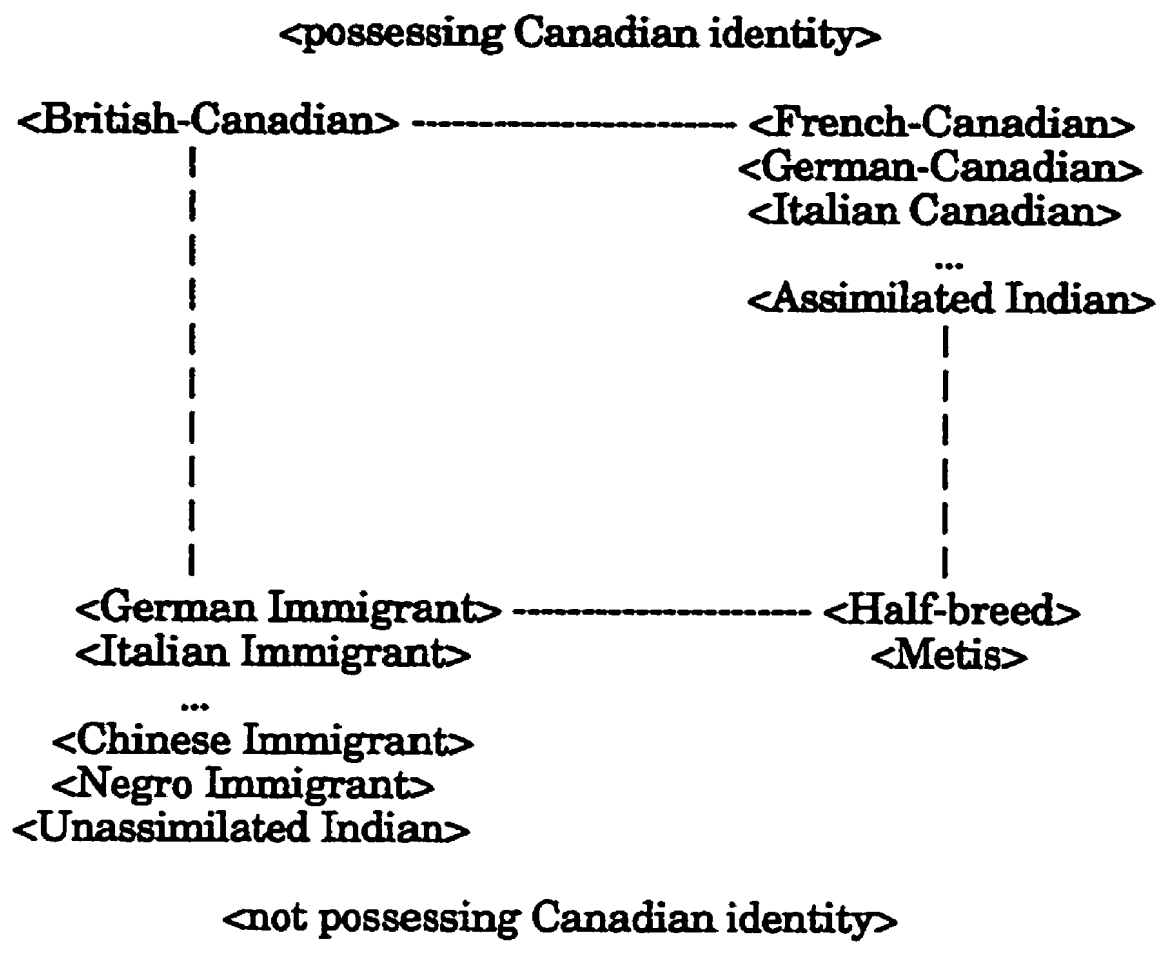

The representation of the hierarchies above is not intended to be complete nor, by the principle of plenitude (see chapter 3), could it ever be complete. I have, however, tried to capture the central features of the discourse on Canadian identity and diversity at this time. The hierarchy in the <Immigrant $>$ term was arranged according to the Great Chain of Race, and there was a 'bar' above which a group had to be placed before it could be considered for transformation into a Self group. After the second World War, this bar was placed just below the White portion of the Chain - itself a shifting boundary - and thus excluded the Yellow, Black, and for all practical purposes, the Red. Continental Europeans could, however, be brought over to the Self side, where they would be fitted into an appropriate place in the hierarchy within that position, which also reproduced the Great Chain of Race. This, indeed, was precisely the function of the Citizenship machine: to transform <Immigrant Xs> 
not possessing Canadian identity, but potentially Useful to Canadian society, into <X-Canadians> who could be seen, to some limited extent, as Selves.

By 1956, the Citizenship Branch was able to issue a clear and concise statement on The Integration of Immigrants in Canada, in which the shift away from racial assimilation, began early in the 20th century, finally achieved explicit articulation as a government policy based on a history of respect and fair dealings:

Canada's policy towards immigrants is naturally a reflection of the political and cultural pattern of our society. It is a society built on the ideas of individual worth and cultural difference.... The pressure of one dominant group to assimilate, that is, to absorb others is therefore impracticable as a general theory. The assimilation which does occur, is gradual and cannot be forced (DC\&I 1956:1).

Immediately after mentioning the "assimilation which does occur," which is gradual and not forced, the report moved on to a discussion of integration:

Integration, however, is used in Canada to express a theory which combines unity and diversity. The unity is sought in common principles of political philosophy and in participation in common citizenship. The diversity is maintained by reciprocal appreciation of diverse cultural contributions (1).

In addition to explicitly formulating and justifying the shift from racial assimilation to ethnic / cultural integration of Immigrant Others, this report also ventured onto new ground. Buried within the manuscript, and occurring only once, was a reference to "the multicultural structure of the Canadian population" (5). The acts had been described, and the fact was now named. Although most of the work was still being done by patriotic volunteer organizations and the provinces, the postwar era saw increasing intervention of the Canadian state in providing solutions to the problem of Canadian diversity, primarily by taking on the task of what it now called 'integration' of citizens. This effort to reach out from the concentration camps and into the everyday lives of both canonical Selves and problematic Others provided 
the basis for the following half-century of efforts at designing and instantiating a simulation model of the proper Canadian citizen, and thus contributed directly to the emergence of multiculturalism as state policy.

\section{Notes}

1 This is only a logical contradiction, however, if one takes both terms to exist on the same level, as being of the same logical type. Certainly a unity can, and often does, emerge out of a diversity as a distinct, but interconnected, logical type at a different level. See (Wilden 1980) for this distinction in general, and (Angus 1997: 138-140,144) for its application in the particular context of a national unity emerging out of an ethnocultural diversity.

2. J.M. Gibbon appears to have been the first to ascribe this priority to Hayward's usage, in the preface to his Our Canadian Mosaic (Gibbon, 1938:viii - ix).

3 Later in the twentieth century, both the Canadian state and some Canadian philosophers of multiculturalism would challenge the assumption of a strong link between language and culture. These issues will be discussed in the chapter on multiculturalism as state policy. I should point out now, however, that the question of the 'objective' ability of language to assimilate Others is not what is of importance to my analysis. Rather, I only claim that England hoped that linguistic assimilation was possible, and that it played a role of constraint in his theory of seductive assimilation.

4 Even the much-vaunted separation of the courts and the police disappeared in 1940 , when PC 2363 (June 4, 1940) redefined "Justice of the Peace" to include "a police magistrate," and "every commissioned officer of the Royal Canadian Mounted Police." This allowed them to issue their own search warrants, and thereby bypass even the minimal protection that the courts offer against the arbitrary exercise of their authority.

5 Alderman Jake Penner of Winnipeg was one of those interned. Joseph Zuken, who was present for Penner's appeal, says that it was dismissed "without any evidence produced against him" (Repka 1982:15). How could a duly elected representative of the People be an Enemy Alien? He was an anti-fascist communist, one of several hundred rounded up and interned during the war. Dangerous Patriots (Repka 1982), gives a number of first-hand accounts from Second World War political internees, most of whom were feared as Communists.

6 See Ken Adachi's (1976) The Enemy that Never Was for a critique of the Japanese internment.

7 In constructive diplomacy as in bone ailments, there are two main methods. The first method is the most spectacular, prompt, and popular. It is the equivalent of a surgical intervention. It often requires other operations to follow. It is rapid, drastic and aggressive. One attacks the foreign element which has entered the body politic. In the realm of diplomacy it takes the form of threat and direct action. It is a regrettable wartime technique extended to the realm of the civilian" (Section VI-1).

8 Kirkconnell's readers need not have felt too badly about their lingering habits of Racial thought, however, as the author himself, or at very least his editor, was guilty 
of committing "the most dangerous error that can delude the human brain" many times in the same pamphlet. On the bottom of page 19, there is a photograph of what appears to me, trained in discourse of difference emerging out of the $1960^{\prime} \mathrm{s}$, as a group of White men eating. Underneath the photograph is the caption: "The lumber camps have long been the meeting ground of the races." Similar "errors" are made on page 47, and on page 21, where the title "Racial Origins" heads a list including "French Canadians," "German Canadians," and many others that Kirkconnell had explicitly -- and rather mockingly -- declared not to be races.

9 This announcement was also a continuation of another Canadian tradition, that of bypassing Parliament in setting immigration 'levels' and 'sources'. PC 2071 of May $281946 \mathrm{had}$ created the category of "sponsored" immigration, which was to allow Canadians to bring in relatives from continental Europe who had been displaced by the war. Under this order, postwar immigration had already increased from 12,000 in 1944 to 64,000 in 1947. PC 1734 of May 1, 1947 extended the "terms of admissibility" of the already admissible classes of British and Americans and also, for the first time, openly welcomed "persons who are suitable for employment in the primary industries" (cited in $D H C$ May 1, 1947:2645).

${ }^{10}$ See, for example, "A Look at Canada," produced by the Integration Branch of the Department of Citizenship and Immigration (1996) as a study guide for citizenship exams. $M C B C$ is another good example, as noted in the Introduction, but pretty much any government pamphlet on immigration, citizenship, or naturalization will do. 


\section{Chapter 8 \\ The New Idol - Multiculturalism as State Policy}

There are still peoples and herds somewhere, but not with us, my brothers: here there are states.... It would like to range heroes and honourable men about it, this new idol.... It will give you everything if you worship it, this new idol: thus it buys for itself the lustre of your virtues and the glance of your proud eyes.

-- Nietzsche, "Of the New Idol" (1969:75-6)

\section{The 'Liberalization' of Canadian Society}

Given the hegemony of British language, culture, and social and political institutions, English Canada before the 1960's was, for most purposes, a monocultural, monolingual, single-nation state, and made no apologies for being so. "Canada is perfectly within her rights in selecting the persons whom we regard as desirable future citizens, "W.L. Mackenzie King declared in 1947. "It is not a 'fundamental human right' of any alien to enter Canada. It is a privilege" (DHC May 1, 1947:2646). With its citizenship bureaucracy, the Canadian state had acknowledged the existence of non-canonical Canadian identities, but, as their WWII surveillance, internment and transportation shows, these official Others were not seen as possessing full subjectivity and rights of citizenship. By the 1960's, Canadian society began to be "liberalized," following an international trend towards American-style individual "human rights" that was spearheaded by the United Nations. Canada eagerly signed on to the various declarations and proclamations, and produced its own Bill of Rights (8-9 Elizabeth II c. 44 1960).

In federal language and culture policy, there have been three main components to this 'reform': official bilingualism and biculturalism, which was supposed to give the Québecois nation an official state identity, and thereby 
transform it from an Other to a Self position; the policy of multiculturalism in a bilingual framework, which carried out the same transformation on the Other Ethnic Groups in a slightly different way, by offering official recognition of possession of identity, finally, the Indians, Inuit and Metis were brought into official language and culture policy as 'the Aboriginal peoples', and were granted their own set of rights. In this chapter I will evaluate each of these areas of current state policy, with an eye to whether or not they represent a "break with the past" (Canada. Dept. of Indian Affairs and Northern Development 1969:5). I will also address multiculturalism as a theory of liberal pluralism, the leading advocates of which have been Charles Taylor and Will Kymlicka. My aim is to test the claim, advanced in both the state policy and liberal-theoretical discourses, that multiculturalism represents an 'overcoming' of, or at least an 'improvement' upon, the history of Canadian diversity. In both cases I will rely upon the genealogy I have presented in the previous chapters to show that multiculturalism as state policy and liberal theory reproduces the basic characteristics of the Canadian discourse on diversity, namely, the differentiation and problematization of a target human population which is then to be subjected to forms of rational-bureaucratic discipline in the name of solving the problem so created. I will argue that while Canadian multiculturalism as state policy does show signs of taking on a 'postmodern liberal' style, it does not represent an overcoming of the history of Canadian diversity. Rather, it creatively reproduces this history by carrying out a shift from control of difference to control of différance, and from simulation of unity to simulation of multiplicity. The extension of 'rights', and 'equality' to an increasing number of mass-designed identities has not led to 'freedom', but to further penetration of state forms into the daily lives of Canadians, through the progressive officialization of both Self and Other identities. 


\section{From Monopoly to Duopoly - The B\&B Report}

Mr. Blackmore: Canada was explored, settled, and developed by two great races, two of the greatest races in the world; the French and the British people. Have these races no rights? Have their fathers no rights to see their children well provided for in this land they strove to gain for them? Have their children no rights to be well born into an environment in which they can succeed and be happy? We might sum the matter up in this simple question: Has Canada no right to remain British?

Mr. Michaud: To remain Canadian.

Mr. Blackmore: That is very well put. I thank the hon. member. I say, has Canada no right to remain British Canadian?

Mr. Laurendeau: Put "Canadian" on the record.

Mr. Blackmore: We have finally arrived at the word which pleases everybody. Has Canada no right to remain Canadian?

(DHC August 28, 1946:5514, cited in Palmer 1973:285).

Before it thought about connecting itself to what it saw as a multiplicity of cultures and ethnic groups within its territories, the Canadian first tried to solidify and clarify its articulation with the Two Founding Races. In theory, Canada had been a two-nation state since 1774, when the right to maintain certain aspects of their social, legal, and religious particularity was granted to the French of Quebec. While this was undoubtedly a gift from the British, who occupied a superior position at the time, the deal struck at the time of Confederation implied that the two peoples were coming together as equals, to form, in the words of Adelard Godbout, "the headstones of the entire edifice” of Canada (Dept. of National War Services 1940:13). That English-Canadian nationalists had never really seen Confederation as a meeting of equals is apparent in the obstinate equation of Britishness with Canadianness in the quote that opens this section, in the policy of encouraging immigration from the British Isles, and in attempts to assimilate / integrate non-British Immigrants to the English-speaking society. Whatever the BNA Act might say, or however it might 
have been interpreted, the Canadian state had always lived, worked, and most importantly dreamed in English.

In 1963, acknowledging yet again that it had a French problem, the federal government appointed a Royal Commission to find a solution. The Commissioners soon found themselves, like Lord Durham, "driven to the conclusion that Canada, without being fully conscious of the fact, is passing through the greatest crisis in its history" (Royal Commission on Bilingualism and Biculturalism 1965:13).1 Their mandate was to "report upon the existing state of bilingualism and biculturalism in Canada and to recommend what steps should be taken to develop the Canadian Confederation on the basis of an equal partnership between the two Founding races ..." (1). Curiously, race had resurfaced as a means of distinguishing between the two Founding groups, making the Preliminary Report of the Royal Commission on Bilingualism and Biculturalism sound even more like the Durham Report. But the nature of the problem of Canadian diversity had expanded considerably since the visit by the Lord and his entourage, and so the Commission was also instructed to take into account "the contribution made by the other ethnic groups to the cultural enrichment of Canada, and the measures that should be taken to safeguard that contribution" (151).

Alerted to potential problems caused by distinguishing between "founding races" and "ethnic groups" during preliminary hearings, the Commission tried to crawl out from under the heavy terminological load that had been placed upon it:

This wording, particularly the use in the English text of the word 'race', has been a source of misunderstanding. Should it be taken to mean that the two 'races' or two 'peoples' will receive special treatment at the expense of the "other ethnic groups"? Some understood it this way... (xxii).

The Commissioners, however, understood their terms of reference in a different way: 
In our view the reference to the two 'founding races' or 'peoples who founded Confederation' is an allusion to the undisputed role played by Canadians of French and British origin in 1867, and long before Confederation. The word 'race' is used in an older meaning as referring to a national group, and carries no biological significance (xxi).

This argument is very odd, in that it was not the biological connotation that was causing the objections, but the perpetuation of differential relations of power within the discourse on Canadian diversity. It makes sense, however, in that the Commission was following the general postwar trend of simply renaming racial distinctions as cultural, national, or ethnic, and continuing on with its work.

While it accepted the necessity of struggling with the Founding races and the Other ethnic groups, the B\&B Commission managed to lighten its load by shedding the Native peoples of Canada: "We should point out here that the Commission will not examine the question of the Indians and the Eskimos. Our terms of reference contain no allusion to Canada's native populations. (xxvi)." This act of exclusion highlights a subtle, but important difference between the status of the Native peoples and the Europeans within the regime of bilingualism and biculturalism. The Other Ethnic Groups were seen as potentially making "contributions" to the "cultural enrichment" of Canada, but the Native peoples were to enjoy their "preserved" cultures in solitude. For, while the Canadian state was becoming able to consider the possibility of giving off more signs of the French race, and perhaps even displaying a touch of Ukrainian ethnicity, it could not imagine itself, under any circumstances, going Native. Indeed, despite its relative sophistication in textual construction, the Commission managed to unwittingly invoke the settlement and expansion phases of the Canadian discourse on diversity as a means of setting up a solidarity between the Other Ethnic Groups and the Two Founding Races:

When they [the Other Ethnic Groups] arrived, their essential concern was to continue the work of carrying civilization into the thinly 
populated areas. By settling the country they helped to lay the basis for Canada's cultural growth (xoxv, emphasis added).

On one side, we have the Civilized Europeans, possessed of cultures and civilizations that can be shared. On the other, the Indian, Uncivilized and, although possessed of a culture, not one of the sort that could be shared with Europeans.

In its attempt to ward off the idea that the Canadian state was offering "special treatment" to the Two Founding Races, the Commission was deep in contradiction, since it held at the same time that "[]]anguage is the most evident expression of a culture, the one which most readily distinguishes cultural groups even for the most superficial observer" (xxx). If this is the case, a culture which was allowed to striate a space with its language would have a greater likelihood of achieving and maintaining hegemony than one that did not. Certainly, as I have shown in chapters 6 and 7, English Canada had always operated under this assumption, and there was nothing in the policy of bilingualism and biculturalism to indicate that this was changing. Indeed, at the close of its discussion of the links between language and culture, the Commission concluded that "the vitality of the language is a necessary condition for the complete preservation of a culture" (xxvii), and that "the life of the two Founding cultures implies in principle the life of the two languages" (xxxviii).

After several years of research, consultations, and hearings, the Royal Commission issued a lengthy report and a series of recommendations. Access to bilingual education was to be guaranteed, and a Commissioner of Official Languages was to supervise the implementation of a federal Official Languages Act. These measures, along with several of lesser import, were called a "new charter for the official languages in Canada" (B\&B Report:1.30, emphasis added). But there was nothing "new" about the "fundamental duality" enshrined in this new Act. It had been around for two hundred years, long enough that, rather than trying to legislate 
for or against it, one might begin to wonder how it worked. One possibility is suggested by Jean Baudrillard's comments on the "tactical doubling of monopoly" in postmodern capitalist societies:

In all domains, duopoly is the final stage of monopoly ... any unitary system, if it wishes to survive, must acquire a binary regulation.... It will never again be a matter of a duel or open competitive struggle, but of couples of simultaneous opposition (Baudrillard 1983a:134).

The days of the fur trade and the battles between the English and French over territory in the New World might be considered the modern phase of "open competitive struggle," while the period after Confederation would see a slow shift towards a system of strategic regulation. As will become apparent, I do not intend to draw a line here, marking the end of the modern and the advent of the postmodern; rather, what one tends to see is a shift in emphasis from one form to another. As the events of the "October Crisis" have shown, even Canada's moat avant-garde Prime Minister was able to respond with physical violence when he felt that state control was threatened.

These caveats acknowledged, I would note that through the process of liberalization, the square of identity from Canadian postwar discourse was officialized, that is, its semantic axis was shifted from <Canadian identity $>$, in the sense of Canadianness or Canadian character, to <official Canadian identity>, which implied that the state would take on the task of not only tolerating, but itself producing signs of that identity. Under the regime of bilingualism and biculturalism, the British and French cultures and languages were granted official identity, as races or nations, with British dominant, as the giver of the gift of equality to the French Other. The contradictory position of that which was both British and French might be seen as taken up by the French outside Quebec and the English within, for even though both of their languages and cultures were official, these hybrids could not be 
given a place within the fundamental duality, and thus could not possess an <official identitys. The Other Ethnic Groups, those who were neither British nor French, occupied the complementary position, where they were allowed to preserve and maintain an ethnicity, that is, a language and culture that were not official, and would not be displayed in state bureaucracies or social, economic, and political institutions. Finally, the Indians, Inuit, Metis, and Half-breeds were not considered as possessing, or lacking, any sort of official identity at all. In being excluded from the process entirely, they once again disappeared from view.

Figure 8.1 - Official identity in Canadian bilingualism and biculturalism

$<$ possessing official identity: races, nation $>$

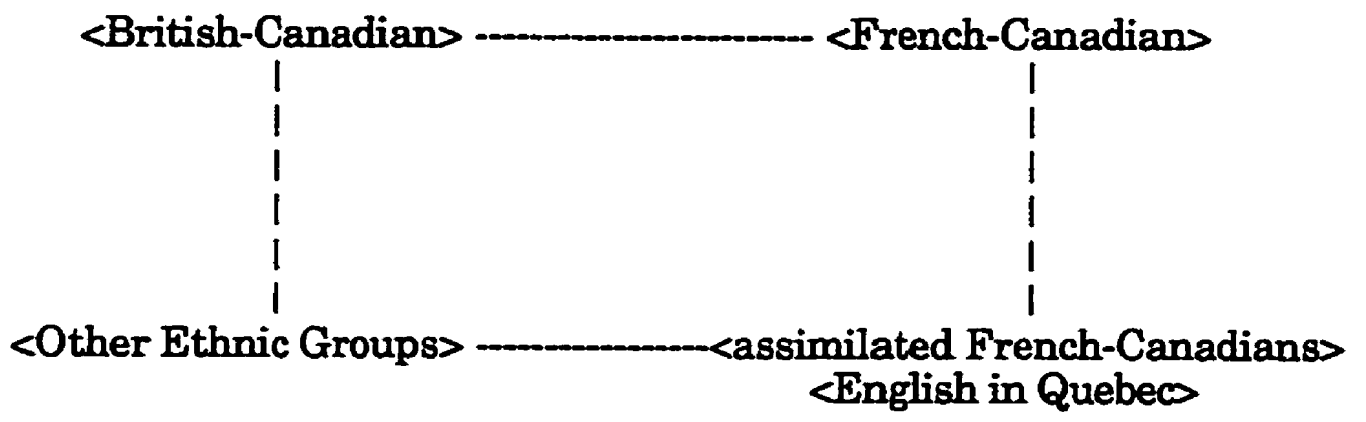

<lacking official identity: ethnic groups>

Such was the regime of official identity within the policy of bilingualism and biculturalism. While most of the old rules of the game of identity were preserved in this policy, it also contributed to an ongoing evolution, by increasing the extent to which Canadians of all types were to be manufactured and scrutinized. If the Canadian Citizenship Act and its associated bureaucratic supports formed a machine for the production of citizens, the Official Languages Act added a part that specialized in the production of French-English bilingual citizens. While 'old' Canadians had previously been required only to tolerate signs of Otherness, they were now being told that they must take them on themselves in order to remain 
canonical. As Jean Burnet has noted, however, just as soon as [British?] Canadians "began to accustom themselves to a new model of Canadian society ... Prime Minister Pearson and others started to speak of Canada not as bicultural but as multicultural" (Burnet 1975:205). With the policy of "multiculturalism in a bilingual framework', the present of Canadian diversity began to catch up with its past, and the world of official Canadian Selfhood began to go through the same process of multiplication that had been lamented for so many years in the realm of official Otherness.

\section{Multiculturalism in a Bilingual Framework as Strategic Simulation of Assimilation to the Problematic Other}

After convincing itself that it once again needed Immigrants, the Canadian state quickly abandoned official bilingualism and biculturalism in favour of what came to be known as "multiculturalism in a bilingual framework." In this section I will show how this change involved certain reproductions of, and innovations in, the terms of the Canadian discourse on diversity. First, the means of differentiating the problematic population was shifted from race and ethnic group to ethnocultural origin, allowing the state to claim that multiculturalism was about 'equality' because the discourse on diversity now used the same name for all groups in the system. This was accompanied by a dissociation of language and culture which, I will argue, allowed the policy to be seen as both protecting the particularity of incoming Others and assuring canonical Canadians that these Others would be rendered into Selves. Finally, a productive confusion of assimilation and integration allowed the French colonial method of strategic simulation of assimilation to the Other (see chapter 4) to be recovered as the basis for handling problematic diversity within state policy. The work of this section, then, is to show how the policy of multiculturalism in a bilingual framework creatively reproduced the discourse on Canadian diversity as it existed in 
the 1960 's, and to prepare the way for a further discussion of the extent to which this creative reproduction can be seen as a 'break with' or 'overcoming of its past.

In a 1966 White Paper on Immigration (Dept. of Manpower and Immigration 1966) those who spoke for the Canadian state made it clear that they had not lost their desire for an increased population to manage. Assuming that there was "little dissent from the proposition that Canada still needs immigrants" (5), the White Paper invoked some favourite tropes from previous centuries and millenia:

Canada is an under-populated country by most standards of measurement. It must appear almost barren of people to many of the countries of Africa and Asia with their teeming millions... Many Canadians are attracted to the theory that [we should] fill up our empty spaces as rapidly as possible with any and all immigrants willing to cast their lot with us... (7, emphasis added).

But despite the wishes of "many Canadians," their government would not play at dice. The question, as always, was "what number and kind of immigrants should be sought in the years ahead, and from what sources" (5).

Oddly enough, the Canadian government had supposedly eliminated the consideration of "sources" in its 'colour blind' immigration policy announced in 1962, just before the Royal Commission on Bilingualism and Biculturalism had begun its work. According to Ellen Fairclough, the Minister of Citizenship and Immigration at the time, the new policy was supposed to ensure that "any suitably qualified person, from any part of the world," could be considered for immigration to Canada "entirely on his own merit, without regard to his race, colour, national origin or the country from which he comes" (DHC Jan. 19, 1962:9). It should not be surprising that the policy did not live up to the pronouncement, as this path had been followed many times before: by Frank Oliver in presenting the 1910 Immigration Act (DHC: March 21, 1910:5505), and by Clifford Sifton, in his policy of the late 1800s: "We have not been disposed to exclude foreigners of any nationality who seemed likely to become 
successful agriculturalists (Sifton to Laurier, 1901, in Knowles 1997:62). In 1962, as in 1910 and 1901, the Minister was simply not telling the whole truth. And little could she afford to do so. Every time the Canadian government had set out to acquire Foreign bodies, it had encountered a nativist reaction from existing Canadians, which, though it may have been correlated with internal class warfare, external national warfare, or simply fear of incoming Otherness, always placed responsibility for Canada's problems on the incoming or already arrived Other. This happened before WWI, after WWII, and could reasonably be expected to occur again in the 1960's and 70's.

A similar state of dreary repetition had been reached with regard to the Indian problem and its attempted solution through various Indian Acts. Leslie \& Maguire note that "for one hundred and forty years, essentially the same policy has been 'rediscovered' and redefined to serve government objectives. However, it has only sustained failure in accomplishing what it set out to do..." (1978:191 - 2). In its 1969 White Paper, the Canadian government announced that it was going to disrupt this continuity by washing its hands of the Indian problem and thereby make a "break with the past" (Canada. Dept. of Indian Affairs and Northern Development 1969:5). It only ended up reproducing this past, of course, but this time using much of the same rhetoric as had been employed in the End of History in immigration policy: "The Government believes that its policies must lead to the full, free, and nondiscriminatory participation of the Indian people in Canadian society" (5). Ottawa planned to offload responsibility for the Indians to the provinces (9) and dismantle the Department of Indian Affairs (10). After several hundred years of abusive tutelage and failed attempts at extermination, assimilation, and integration, the Indians were now offered the gift of a "framework within which, in an atmosphere of freedom," they could "with other Canadians, work out their own destiny" (13). Of 
course, there would be a "transitional period," but the government hoped to solve the Indian problem within five years (13).

Unfortunately for the Canadian state, a large number of Indians recognized what was going on immediately. They had never wanted to become Canadian, still did not want to become Canadian, and saw this move, in Howard Cardinal's words, as "a thinly disguised programme of extermination through assimilation" (Cardinal 1969:1):

Before the Canadian government tries to feed us hypocritical policy statements, more empty promises, more forked tonguistics, our people want, our people, the Indians, demand just settlement of all our treaty and aboriginal rights. Fulfilment of Indian right by the queen's government must come before there can be any future co-operation between the Indians and the government. We demand nothing more. We expect nothing less (28).

Something had to be done to solve the problems of the French, the Immigrant, and the Indian once and for all. This something was called 'multiculturalism'.

As a state policy, multiculturalism emerged out of Book IV of the $B \& B$ Report, which was entitled The Cultural Contribution of the Other Ethnic Groups (see Burnet 1975; Kallen 1982: 52 - 56; Lewycky 1992: 372 - 5). In presenting its report, the Commission cited its terms of reference as a justification for limiting its study to "the part played by these groups in the country's history and the contribution they make to Canadian life" ( $B \& B$ Report:4.xxv). This is immediately recognizable as the sort of treatment given by Woodsworth and Kirkconnell, and perpetuated by the Department of Citizenship and Immigration in pamphlets like Our History (1948) and The Canadian Family Tree (1960). The Commissioners picked up on this limited acknowledgment of particularity and relevance, and put it to good use in their denial of the existence of a "third force" in Canadian politics of identity. All that the Other Ethnic Groups had in common, according to the writers of the $B \& B$ Report, was their Otherness: 
In approaching our subject this way we are not implying the existence in Canada of a 'third force', made up of all those of ethnic origin other than British or French. It should be remembered that the census lists some 30 different ethnic origin categories and still does not list them all, and that there are great differences in numbers, concentration, time of arrival, and degree of group awareness among the different cultural groups (B\&B Report:435).

With the help of the Canadian census and a rich horde of academic studies, 2 the common ground of the OEGs was skillfully delimited 80 as to allow them all to be managed under one policy, while being denied the right to commonly resist this policy.

The official adoption of multiculturalism was announced in Pierre Trudeau's famous speech to the House of Commons on the day the White Paper on Multiculturalism was released. Always a master of political oratory, Trudeau began with a joyous revelation:

Mr. Speaker, I am happy this morning to be able to reveal to the House that the government has accepted all those recommendations of the Royal Commission on Bilingualism and Biculturalism which are contained in Volume IV of its reports directed to federal departments and agencies (DHC October 8, 1971: 8545, emphasis added).

This was a very creative reading of the White Paper, which clearly showed a reluctance to commit state resources to a new regime of ethnocultural identification. Out of the Commission's sixteen recommendations, seven were dismissed as superfluous, five were said to be out of federal jurisdiction, three were relegated to a "research program," and only one, suggesting increased funding for linguistic assimilation, was to be implemented (Sessional Paper 283-4 / 101B, DHC October 8, 1971, Appendix: 8583 - 4). Despite all of the fanfare regarding this 'new' policy, there was, by the government's own estimation, very little for it to do, other than place a different label on programs that had been in place since the 1940's. 
But this did not stop Pierre Trudeau, who immediately began to erect a scaffolding of high-sounding rhetoric over the emptiness of his announcement, making use of the well-worn planks of liberté, égalité, fraternité:

The individual's freedom would be hampered if he were locked for life within a particular cultural compartment by the accident of birth or language. No citizen or group of citizens is other than Canadian, and all should be treated fairly (8545).

This line was picked up and enhanced by later multiculturalism policy documents. Liberty: multiculturalism "entrenches the idea of freedom of choice, which is a basic tenet of our democracy" (MCBC:19). Equality: "recognizing multiculturalism to be a central feature of Canadian citizenship ... acknowledges the essential equality of all our people ..." (19). Community: "multiculturalism has evolved as a powerful bonding agent for Canadians... It helps unite us and identify us" (9). This claim to have implemented the goals of the French revolution allowed Canadian multiculturalism to be portrayed as something different from "those distasteful, sometimes shameful, and always heart-breaking injustices in Canadian history which left members of various minority groups frustrated or humiliated or outraged" (5). That is, multiculturalism as state policy was presented as an overcoming of the history of Canadian diversity. This is a claim that is easily evaluated, with reference to the key features of the discourse on Canadian diversity that I have worked with throughout this dissertation: the means of differentiation of human types; the hierarchization and problematization of the differentiated system of types; and the modes of solution adopted to solve the problem.

Multiculturalism is certainly not an overcoming of the history of Canadian diversity in the sense that it has ceased to differentiate human types based on signs of difference that can be observed from a distance. Having moved through humanity and civilization, to race, culture, and ethnicity, differentiation within Canadian 
multiculturalism as state policy is accomplished with the help of yet another category: ethnocultural origin. In order to understand what this term means, I will turn to the glossary in Multiculturalism: Building the Canadian Mosaic (MCBCM). To begin at the highest level of abstraction:

MULTICULTURALISM: Recognition of the diverse cultures of a plural society based on three principles: we all have an ethnic origin (equality); all our cultures deserve respect (dignity); and cultural pluralism needs official support (community) (MCBCM:87).

If "we all have an ethnic origin", then it would be important to know just what an "ethnic origin" is. The text obliges:

ETHNOCULTURAL/ETHNIC ORIGIN: Cultural, national, or racial origin of a person. Every Canadian has an ethnic origin. (The use of the word "ethnic" as a noun e.g. "an ethnic" or "the ethnics" is generally a slang term and is sometimes considered derogatory. "Ethnic" as an adjective is generally acceptable) (87).

As long as one uses the correct grammatical construct, it is generally acceptable to mark out differences between human types based on their presumed "cultural, national, or racial origin." But what does this mean? Neither "cultural origin" nor "national origin" are seen as key terms in need of definition, and so we are left to assume that these origins would be detected, in the traditional Herodotan way, through such Visible signs as skin colour, clothing, mode of government, and so on. Racial origin, however, is seen as worthy of a definition, through its root word, race: "RACE: Working term to describe ethnic origin of peoples defined on the basis of certain common physical features. Examples are Whites or Caucasians, South Asians, Blacks, Chinese or South East Asians (87)." A strange, frustrating, but definitely working circularity occurs here: ethnic origin is defined as dependent upon cultural, national and racial origin, and race is said to depend upon ethnic origin! This 'confusion' is of course very informative, as it provides evidence of the arbitrary 
nature of these categories. It also exposes the Canadian state's attempt to find an "acceptable" language in which to express the will to categorization of Others that, despite much protestation to the contrary, continues to permeate Canadian state policy.

Thus, while the exact nature of the categories has shifted, and the weird and wonderful diversity of types is found inside rather than outside the safely striated space of civilization, there is a definite line of descent from Herodotus to Linnaeus to J.S. Woodsworth, and on to Canadian multiculturalism as state policy. Notes on the Canadian Family Tree, first published in 1960 by the Canadian Citizenship Branch, describes itself as "an attempt to provide factual information on many of the ethnic groups that comprise the Canadian population" (1960:i). This goal will be familiar to readers of Strangers Within Our Gates, who will recognize immediately the table of contents arranged according to national / ethnic types, and the ensuing enumeration of history, characteristics, and contributions to Canada. ("The Japanese are very fond of picnics," we are told on page 83.) The groups are presented in alphabetical order, following Kirkconnell's egalitarian innovation in Canadians All (1941), and number 23 in the first edition. This edition is also of interest because it did not include either the British or the French, "groups on which ... much material is available in other forms" (i). This omission of the two Founding races from the Canadian family tree may at first seem odd, but makes good sense when one realizes that it is not the Invisible Self groups that are being described here: it is the familiar, but still strange and problematic, diversity of Visible, audible, and olfactory Others.

A new edition of the Canadian Family Tree was produced for the 1967 centennial of Confederation. Like the immigration logbooks of the late 1800's, which showed a steady increase in the number of categories of Immigrant Otherness, the new edition of the Family Tree was able to display 47 types of Canadian, including the French and the British, broken down into the Wales / Ireland / Scotland / England 
subgroups. The alphabetical arrangement remained unchanged, as did the narrative form of history, characteristics, and contributions. By the 1979 edition, 78 groups were listed, bringing the number of categories of contributing cultures more or less in line with the number of Immigrant ethnicities. The form of the Canadian Family Tree can thus be traced, in a creative evolution, from Woodsworth's Strangers Within Our Gates to the stable pattern reached in 1979 and used ever since. This stability can be attributed to the achievement of a substantive rhetoric of presentation adequate to the political rhetoric of multiculturalism: alphabetization replaced arrangement by the Great Chain of Race, signifying equality; all of the same signs of difference were noted, but the basis for the comparison, the canonical English Canadian Self, was not; the Invisible Self groups were listed along with the Visible Others, covering for the silent basis of differentiation, and furthering the notion that all Canadians were Immigrants; and, finally, consistent and unabashed xenophilia replaced an equally unbalanced xenophobia, giving the impression that tolerance, harmony, and mutual love reigned from sea to sea.

In the face of such perfection of form, one must, to be fair, consider the possibility that one is not in the presence of art, but of an earnest and authentic change of heart on the part of canonical Canadians and their state. Although the will to categorize was obviously still going strong, perhaps Canadians had finally come to consider their Others, though different, to be equal. At the very least, while human types were still being differentiated according to assigned ethnocultural characteristics, and the assumption that individuals designated as members of these groups would display the assigned characteristics had not changed, it did seem that the Great Chain of Race, or the hierarchical ordering of these types, had really been abandoned. Unfortunately, we need only set our sights a little to the west of Ottawa to see that this was not the case. The Year of Official Multiculturalism was also the centennial of BC's entry into Confederation, and the celebration gave rise to 
Strangers Entertained: A History of the Ethnic Groups of British Columbia (Norriss 1971). This volume featured Ken Adachi writing on the Japanese, Rosemary Brown on the Negroes and, except for the chapter on Native Indians, followed a rule whereby a reader trained in ethnocultural identification by surname would see that the section on each group had been written by someone who was likely a member of that group. However, despite all of this attention to rhetoric of presentation, the table of contents was arranged according to the Great Chain of Race, from Americans, British and French, through the European continent from northwest to southeast, then to the Chinese and Japanese, finally ending with the Negroes. The hierarchy of the White, Yellow, Black, and Red races was preserved, with the exception of the Native Indians, who were placed first. The value of this honour was dubious, however, as the sections on the Two Founding Races were full of heroic stories of Discovery and Colonization. Whatever was going on in Ottawa, British Columbians had yet to understand, or perhaps even read, the past thirty years of Citizenship propaganda, and did not even know how to cover the tracks of racism when producing a celebratory pamphlet on ethnocultural contributions.

Despite the claims of a new era, repeated incessantly since the 1960 's, and supposedly legislated in the Multiculturalism Act of 1988, the ethnocultural hierarchy has still not been eliminated from official Canadian discourse even at the federal level. In the latest census for which data has been processed and published (1991), state-sponsored social science is still reproducing the ancient European scheme - and ignoring 50 year-old innovations in mass communication of state policy - by presenting its table of "Population by Ethnic Origin and Sex" in the order that would be given by the Great Chain of Race: British and French are followed by Western, Northern, Eastern, and Southern European; next come West Asian, East Asian, and Latin and Central America; then Black, Aboriginal and, finally, Multiple Origins (StatsCan 1993: Table 1A). This information' of course finds its way into a 
myriad of other sources, and is sometimes reproduced by writers whose critical position on issues of ethnicity would suggest that they would not be happy with this connection (e.g. Hiller 1996:232). Based on this differentiation and hierarchization by the Great Chain of Race, I would suggest that multiculturalism as state policy represents a creative reproduction, rather than an overcoming, of the history of Canadian diversity with regard to this crucial feature.

The same can be said for the currently preferred mode of solving the problem created by the work of differentiation. Integration, the method of difference management that emerged out of the Nationalities Branch and the Department of Citizenship and Immigration, was taken over by multiculturalism as a "social policy for handling diversity" because it "works better than assimilation or other models" (MCWR:9). Before integration could move on from its quiet existence in state policy documents and departmental reports, however, an innovation was required. Under the regime of bilingualism and biculturalism, federal policy was based on the assumption of a strong link between language and culture. Many statements on this subject can be found in the $B \& B$ Report. For example:

... language is at the core of the intellectual and emotional life of every individual (B\&B Report:1.xxix).

...language is the most evident expression of a culture. In terms of our mandate, this means that the problems of bilingualism and biculturalism are inseparably linked (1.xxx).

Culture and the language that serves as its vehicle cannot be dissociated (4.13).

Thus, when the French were supposedly granted equality with the English, it was assumed that the business of the state would have to be conducted in both languages, that the state would have to become French. The Canadian state was now poised to give the gift of equality to the Other Ethnic Groups, but was apparently not 
ready to become Ukrainian, Sikh, Chinese.... Pierre Trudeau announced the solution of this problem, however, by showing that language and culture could indeed be dissociated - and even had the temerity to imply that the members of the B\&B Commission supported him in this move:

It was the view of the Royal Commission, shared by the government, and, I am sure, by all Canadians, that there cannot be one cultural policy for Canadians of British and French origin, another for the original peoples, and yet a third for all others. For although there are two official languages, there is no official culture, nor does any ethnic group take precedence over any other (DHC October 8, 1971:8545, emphasis added).

While the $B \& B$ Report held that culture could only be present through language, Trudeau's speech marked the dawn of a new policy era by dissociating these two aspects of modernist identity formation.

Trudeau's dissociation of language and culture not only appears to negate the fundamental premise of several centuries of Eurocolonial and Canadian state policy, but also contradicts some of the most influential analyses of the rise of modern nation-states. Benedict Anderson has noted how what he calls "national print languages" were "of central ideological and political importance" to early European nationalism (Anderson 1991:67), and E.J. Hobsbawm has argued that national languages - though they were "almost always semi-artificial constructs" -- were crucial to what he calls the "popular proto-nationalism" of the modern nation (1990:54). In a discussion of the current Canadian context, Charles Taylor also assumes the existence of a "language/culture that we need for our identity" (1993:52), and notes that "English Canadian spokespersons have taken refuge in the crassly philistine contention that language is just a medium of communication" (56). Bracketing the question of whether language 'really is' intimately connected with culture and nation, I will focus upon the possibilities that were opened up by their dissociation within the Canadian discourse on diversity. 
First, the dissociation of language and culture enabled the claim that even though two languages were officially Canadian, this did not grant a superior position to the cultures associated with them. This effect will simply be noted for now, but will be discussed further in the next section. Dissociation also allowed the claim - again to be discussed in detail in the next section -- that even though a given language might not possess an official state articulation, the culture associated with it could still be considered as one of many 'Canadian' cultures, through its official recognition. Finally, in the sense that no culture was acknowledged to possess an official state articulation, it could be claimed that there was "no official culture" at all. The dissociation of language and culture thus allowed the Other Ethnic Groups to be granted a form of limited state articulation through simple recognition of their existence. This gift was granted by making use of the law of individual identification an individual is his group - and the mass-democratic notion that one individual can adequately 'represent' a large number of other individuals. Its medium was the ethnocultural organizations, emergent forms that, from the Second World War on, had been identified by the Canadian state as possible pathways to the bodies of Immigrant Others (see chapter 7). The canonical case here is the UkrainianCanadian identity, whose trajectory displays the full series of transformations under state supervision, from its creation as the "frowzy Galician" of the early twentieth century, its repression as a haven for Communists during World War II, its multiplication in the years up to 1970 as a large and cohesive group seeking more power in Canadian society, and finally its incorporation as the "earliest proponent of the multicultural movement" (Lupul 1993:12).

How did the official policy of integration of ethnocultural groups differ from the previous mode of assimilation of races? Why did it "work better than assimilation or other models" (MCWR:9)? The following definitions are given in the Glossary of Key Terms included with Multiculturalism: Building the Canadian Mosaic: 
ASSIMILATION: A process, clearly distinct from integration, of eliminating distinctive group characteristics; this may be encouraged as a formal policy (e.g. American "melting pot.")

INTEGRATION: A process, clearly distinct from assimilation, by which groups and/or individuals become able to participate fully in the political, economic, social, and cultural life of the country (MCBCM:87).

In these definitions, assimilation and integration are presented as a binary oppositional pair, each defined as not the other. It is interesting to note that while a clear distinction between the two is claimed, the means by which one might make such a distinction are not provided. Certainly, in both cases a separation between Self and Other groups is assumed. In assimilation, this appears in the assumption of "distinctive group characteristics" that need to be "eliminated." In integration, it appears in the assumption that unintegrated groups and individuals are unable to "participate fully in the political, economic, social, and cultural life of the country." Each method is thus based upon the transformation of a problematic Other into a non-problematic -- "eliminated" or "participating" - Self. Where integration and assimilation differ is in the means by which this transformation is to be effected. Since integration is defined negatively with regard to assimilation, in which distinctive group characteristics are eliminated, one must assume that, in integration, distinctive group characteristics are left in place. Yet, at the same time, integrated groups are to become able to "participate fully." How do they achieve this? Under assimilation it's obvious - they give up their Otherness and take on signs of Selfhood. Under integration it's a little more subtle - they are supposed to take on Selfhood without giving up Otherness. That is, they would have to occupy a paradoxical position as simultaneously both Us and Them, both problematically "distinctive" and canonically "participating."

The role assigned to the "bilingual framework" of Canadian multiculturalism helps to clarify the state's position with regard to the links between language and 
culture, and allows us to see how multiculturalism as state policy is an implementation of what I have called, in the previous chapter, a constrained emergence theory of identity. In a list of "common questions" about the policy, Multiculturalism: What is it Really About? includes "How do we make sure that immigrants integrate and become Canadians?" (MCWR:16). The answer is that "the strategy [of integration] emphasizes language training and helping immigrants learn about Canadian values" (16). If there is no link between language and culture, what would be the point of emphasizing language training? Why, in order to become a citizen, must immigrants "show that they have learned some English or French?" (17). And, if there is "no official culture," what could possibly be considered a “Canadian value?" These aspects of the policy seem to indicate that the Canadian state does not fully follow Trudeau's theory in its practice; that, in fact, language and culture have not been dissociated. With the policy of multiculturalism in a bilingual framework, "minorities" can appear to enjoy the freedom to maintain certain aspects of their own identities, and to 'contribute' these to the Canadian 'mix'. This would be the realm of emergence. But, through the use of the official languages in their everyday lives, canonical Canadians are told that they can expect the "integration" of these Others into one of the two dominant systems of striation -whether they are called 'cultures', 'nations', 'races', or 'societies' - to proceed at a steady pace. This would be the realm of constraint. The question of whether either of these expectations is 'realistic' or 'objectively verifiable' is of less importance than their coexistence within the policy of multiculturalism in a bilingual framework. Based upon this strategic contradiction within the discourse itself, and the reproduction of a hierarchy of problematized human types upon which it depends, I would suggest that integration within multiculturalism in a bilingual framework is best seen as a creative reproduction of the colonial method of strategic simulation of assimilation to the Other, and not as an overcoming or break with this past. 
As I noted in the introduction to this dissertation, I am not the first person to make this observation. "Although our [halfbreed] ancestors had been conquered by a superior military," Howard Adams has written, "in the long run it was the weapon of a political culture that kept us perpetually in a state of subjugation and exploitation" (1995:8). Karl Peter has noted that "Canada has been horsetrading for the preservation of an obsolete political structure, for an empty political shell derived from colonial conquests whose internal contradictions led to the mutual retardation of all for the benefit of a few" (1981:67). This point of view has also been forcefully expressed by Himani Bannerji:

Europeans continue the same solidarity of ruling and repression, blended with competitive manipulations, that they practised from the dawn of their conquests and state formations. The Anglo-French rivalry therefore needs to be read through the lens of colonialism (1996:107).

At the present juncture, however, where I wish to continue to assess the claim that multiculturalism offers up the benefits of the French revolution to all Canadian citizens, the words of Kogila Moodley seem most appropriate:

[W]ith a festive aura of imaginary consensus, multiculturalism implies that Canadian society offers equality of opportunity in the public sphere, regardless of private ethnic classification. Hence the usage of 'ethnic' to refer to all cultural sub-groups including 'dominant ethnics' thereby obfuscating the cultural hierarchy and redefining ethnicity until it is meaningless (1983:320).

It is to this question of equality of opportunity -- and the related issues of how rights and freedoms are allocated within the ethnocultural hierarchy of Canadian multiculturalism - that I will now turn my attention. 


\section{Multiculturalism, Liberal Pluralism, and the Politics of Recognition}

While some analysts support the claim that multiculturalism in a bilingual framework is a creative reproduction of colonial policy, those who have advanced the cause of multiculturalism as a "non-procedural" liberal pluralism most certainly do not. ${ }^{3}$ Charles Taylor, one of the main proponents of this position, has described multiculturalism as a response to a "politics ... which turns on the need, sometimes the demand, for recognition ... on behalf of minority or 'subaltern' groups" (1992:25). In an essay entitled "Impediments to a Canadian Future," when he is "dreaming in colours" (1993:197), Taylor expresses his view that "a Canada that survived" into the twenty-first century would contain "two major societies, each defined by its own dominant language," each of which "within itself would be more and more diverse" (200). That is, the form of Taylor's Canada of the future would be a continuation or “deepening" (200) of the present state policy of multiculturalism in a bilingual framework. 4

As I have shown in the previous chapters, the Canadian state has been "recognizing" its Others for a very long time. The change that has occurred in Canadian multiculturalism as state policy and non-procedural liberal pluralist philosophy is that these Others are now to be recognized as Selves, to be granted the freedom, equality and community that are supposed to be enjoyed by canonical Canadians. However, as I will show by reading state policy documents and the nonprocedural liberal theory of rights advanced by Taylor and Will Kymlicka, the ancient hierarchy is still in force in the unequal privileges granted to the three classes of identity, i.e. the Founding Races, Other Ethnic Groups, and Aboriginal peoples. This system has been presented as an advance by its proponents, in that it allows certain "collective rights" to be offered by the state. But I will argue that it is also a retardation and a reproduction, as it places a limit on the depth of diversity precisely 
where it might threaten the hegemony of the Canadian state over the territories it currently claims.

I will begin this discussion with the concept of 'recognition', which is crucial to both multiculturalism as state policy and the political philosophy of non-procedural liberalism. As I noted in the previous section, the simulated dissociation of language and culture in multiculturalism as state policy enabled the claim that even though a given language might not possess an official state articulation, a culture associated with it could still be considered as one of many 'Canadian' cultures through official recognition of its existence. I would now like to elaborate upon this point, and upon a shift from "preservation" of difference to "preservation and promotion" that accompanied it. Both of these effects are apparent in the language of the Canadian Multiculturalism Act of 1988 (35-36-37 Elizabeth II), which sets out the government of Canada's commitment to:

.... preserve and enhance the multicultural heritage of Canadians while working to achieve the equality of all Canadians ...

3.(1)(a) recognize and promote the understanding that multiculturalism reflects the cultural and racial diversity of Canadian society;

3.(1)(b) recognize and promote the understanding that multiculturalism is a fundamental characteristic of Canadian heritage and identity; ...

3.(1)(d) recognize the existence of communities whose members share a common origin and their historic contribution to Canadian society, and enhance their development....

The Act produces a hypnotic effect through repetition of this litany of recognition and promotion, which is broken only by the appearance of synonyms like "encourage," "assist," "enhance," and "facilitate." These promises of preservation, recognition, and promotion stand in for the possession of official identity that had been granted to French and English language and culture under bilingualism and biculturalism. Thus a new semiotics of Canadian identity began to emerge, in which 
the semantic axis was shifted from possession of official identity to official recagnition of passession of identity. How was this shift to recognition a 'good thing? It was clearly an improvement upon containment and extermination. But this was not the standard against which the Canadian state compared its new policy:

It is the government's intention that the Canadian Multiculturalism Act will join an amended Citizenship Act and an amended Official Languages Act in providing an enduring statutory basis for Canadians' sense of themselves.... To those ends, the government calls upon all citizens to make a renewed commitment to the principles of equality, diversity, and community and to continue the great task of building their homeland into a free and united country that will continue to be a symbol of hope in a fractious, turbulent world (MCBC:7).

A similar confluence of multiculturalism, recognition, and the principles of Western liberalism can be found in Canadian political philosophy. The terms of the Canadian debate on multiculturalism within liberal political philosophy were set by Charles Taylor, who argued as early as 1979 that:

[t]he self which has arrived at freedom by setting aside all external obstacles and impingements is characterless, and hence without defined purpose, however much this is hidden by such seemingly positive terms as 'rationality' or 'creativity' (1979:157, cited in Kymlicka 1989:47).

This was the "unencumbered" liberal individual, set off from community and culture, seeking its enlightened self-interest and freedom from the ancient hierarchies:

Modern freedom was won by our breaking loose from older moral horizons. People used to see themselves as part of a larger order. In some cases, this was a cosmic order, a 'great chain of Being,' in which humans figured in their proper place along with the angels, heavenly bodies, and our fellow earthly creatures. This hierarchical order in the universe was reflected in the hierarchies of human society (Taylor 1991:3).

Will Kymlicka responded to this critique in his Liberalism Community and Culture (1989), by arguing that "the liberal view is sensitive to the way our individual lives 
and our moral deliberations are related to, and situated in, a shared social context" (2). He thus helped to pave the way for a political philosophy that could be seen as recognizing diversity through granting differentiated group rights, without sacrificing the goals of personal freedom and equality upon which the liberal individual founded his identity. 5

This theme was taken up and expanded in Taylor's essay, "Multiculturalism and the Politics of Recognition" (1992), where he argued that a "politics of equal dignity" that had emerged within "Western civilization" (44) could be put to use in the multicultural context. His argument focused on the notion of 'recognition' which, he said, was rising to prominence because "[n]on recognition or misrecognition can inflict harm, can be a form of oppression, imprisoning someone in a false, distorted, and reduced mode of being" (25). Indeed, Taylor warned, "[m]ultinational societies can break up, in large part because of a lack of perceived recognition of the equal worth of one group by another. This is at present, I believe, the case in Canada" (64). In Taylor's view, achieving recognition of difference and preserving Canada's "multinational society" required that the model of "procedural" liberalism -- which he attributed to "John Rawls, Ronald Dworkin, Bruce Ackerman, and others" (56) - be abandoned:

There is a form of the politics of equal respect, as enshrined in a liberalism of rights, that is inhospitable to difference, because (a) it insists on uniform application of the rules defining these rights, without exception, and (b) it is suspicious of collective goals (60).

In the place of this model, Taylor offered up a "non-procedural" liberalism that would guarantee certain rights to all, but would also distinguish "these fundamental rights from the broad range of immunities and presumptions that have sprung up in modern cultures of judicial review' (61). Put simply, in this version of liberalism, 
individual freedom could be curtailed, and inequalities justified, in the name of the survival of a community.

Will Kymlicka took this position further in his Multicultural Citizenship (1995), where he not only provided support for the theory of non-procedural liberalism, but also took on the task of specifying how it might be implemented in practical contexts. In this way he began to construct a bridge between political philosophy and state policy. Kymlicka's work is of particular interest as it focuses on Canada and the United States, and provides explicit theoretical justification for a clearly defined regime of "differentiated" citizenship rights based on the presumed identification of individuals with ethnocultural groups. Kymlicka argues that "we need to supplement traditional human rights principles with a theory of minority rights" (5), and sets out to show that "minority rights are not only consistent with individual freedom, but can actually promote it" (75). This is so because "for meaningful individual choice to be possible, individuals need not only access to information, the capacity to selectively evaluate it, and freedom of expression and association. They also need access to a societal culturen (84). Kymlicka defines "societal culture" as:

a culture which provides its members with meaningful ways of life across the full range of human activities, including social, educational, religious, recreational, and economic life, encompassing both public and private spheres. These cultures tend to be territorially concentrated, and based on a shared language (76).

Kymlicka goes on to suggest that "[f]or a culture to survive and develop in the modern world, given the pressures towards the creation of a single common culture in each country, it must be a societal culture" (80).

This definition at first appears inconsistent with the dissociation of language and culture carried out by the state policy of multiculturalism in a bilingual framework. Indeed, Kymlicka claims that the term "multicultural" is "vague" and 
"obscures important distinctions" between various sorts of cultural pluralism (6). He wants to set apart "multi-nation" states, where "cultural diversity arises from incorporation of previously self-governing, territorially concentrated cultures into a larger state," and "poly-ethnic" states, where "cultural diversity arises from individual and familial immigration" (6). Canada, he argues, is both multi-national and polyethnic, and thus contains both "national minorities," like the Québecois and Aboriginal peoples, and "ethnic groups" composed of "immigrants who have left their national community to enter another society" (19). It also, of course, contains a "majority" (121), a "we" that would have done the "incorporation" of cultures and immigrants, and would now "need to supplement traditional human rights with a theory of minority rights" (5, cited above).

The division of the population into a national majority - or in Canada's case, majorities -- national minorities, and ethnic groups is crucial to the kinds of rights that Kymlicka will grant to each group of citizens. The most important of these, given Kymlicka's own definition of the prerequisites of identity and freedom, would be the right to one's own societal culture. On this point, however, he equivocates. In chapter 5, he presents a sustained argument in which he claims to have "tried to show that liberals should recognize the importance of people's membership in their own societal culture, because of the role it plays in enabling meaningful individual choice and in supporting self-identity" (105, emphasis added). At the beginning of the next chapter, however, he claims to have "argued that access to $a$ societal culture is essential for individual freedom" (107, emphasis added). It soon becomes apparent that Kymlicka is in fact advocating a return to the $B \& B$ Report regime of a strong association between language and culture, but only for certain groups. Some will be allowed access to "their own" societal culture, while others will only be allowed "a" societal culture - that of the "majority." 
Kymlicka provides a historical justification for his ideas regarding which groups are to be granted their own societal culture by drawing a distinction between Colonizers, Colonized, and Immigrants. "English-speaking colonists throughout the British Empire, Spanish colonists in Puerto Rico, and French colonists in Quebec ... had no expectation of integrating into another culture, but rather aimed to reproduce their original society in a new land" (15). He notes, quite accurately, that "this is an essential feature of colonization" (15). As part of this "reproduction," the European colonizers "invaded and conquered" the existing nations (11), converting them into Colonized "national minorities." As can be seen in the quote above, Kymlicka separates Colonizers from Immigrants based on what he presumes to be the "expectations" of each. While Kymlicka never says whether Colonizers possess a liberal-theoretical "right" to a societal culture they have obtained through violent means, he does say that Immigrants do not have such a right, "immigration being one way of waiving" it (96). Thus, Kymlicka: "In general ... I believe that national minorities do have societal cultures, and immigrant groups do not" (101). While Kymlicka's distinctions are undoubtedly historically accurate and honest, some liberals might balk at what appears to be a theoretical justification for and validation of what I have called the power law of sign flow. Certainly, his formula begs the question of whether an invading force could provide itself with a liberal justification for displacing an existing societal culture - say that of the Canadian or American "majority" - by claiming that it "expected" to reproduce its own. This possibility becomes particularly intriguing if one begins to think about a liberal acceptance of violent internal decolonization by national minorities expecting to reassert the hegemony of their societal cultures.

While its justification may be questionable to some liberals, Kymlicka's theory of minority rights clearly sets out the privileges that are to be granted to two of the three categories, i.e. national minority (Colonized), and ethnic group (Immigrant). In 
the Canadian case, he notes that "Indian homelands were overrun by French settlers, who were then conquered by the English" (12). This historical 'fact' places the Quebecois and the Aboriginal peoples in the position of national minority. Their occupation of this position, supplanted by theoretical arguments based on principles of equality and diversity, gives them access to the "opportunity to maintain themselves as a distinct culture, if they so choose" (113), and to a limited form of autonomy by way of "self-government" and "external protections." In the case of the Québécois, Kymlicka is of the opinion that something akin to the existing Canadian federation is adequate to the needs of this national minority. He claims that "Quebec ensures self-government for the Quebecois" (29), and that "the right to preserve and promote their culture [is] affirmed in the existing system of federalism" (45). Thus, when applied in practice, his theoretical position leads to no deviation from the status quo established in 1867.

The BNA Act does not meet the needs of the Aboriginal peoples, however, since "federalism can only serve as a mechanism for self-government if the national minority forms a majority in one of the federal subunits," and "this is not true of most indigenous peoples in North America" (29). For the Aboriginal peoples, "selfgovernment claims typically take the form of devolving political power to a political unit substantially controlled by the members of the national minority, and substantially corresponding to their historical homeland or territory" (30). Kymlicka gives the example of the creation of Nunavut here (Nunavut Act , 40-41-42 Elizabeth II c. 28), which is worth considering as an example of a practical implementation of his theoretical perspective. Certainly those Inuit who have been advocating Nunavut see its value as directly correlated to its ability to provide a basis for local striation of the lands, bodies, and souls of the people who inhabit the territories covered by the Act, as spelled out in the terms of a 1983 paper on what would be necessary to achieve self-government: 
1. the maximum Inuit design and management of public services which affect them;

2. genuine political representation in provincial and territorial legislatures and the federal Parliament, and in official bodies which make decisions affecting Inuit;

3. recognition of the Inuit use and occupation of lands, waters and resources ... so that Inuit may ensure their own collective survival;

4. access to adequate revenues enable public bodies in the Inuit homeland to carry out their tasks;

5. access to an economic base for the future, and protection of existing economic resources (e.g. wildlife);

6. structures of government and other public institutions in the Inuit homeland which reflect and provide for the special needs and circumstances of Inuit and their culture, and with full protection for and inclusion of the rights and aspirations of non-Inuit residents in the area. (cited in Nunavut Constitutional Forum 1983:8-9)

Given this statement, it might be interesting to see to what extent the Nunavut Act meets the Inuit criteria. First of all, while the Inuit commonly refer to Nunavut as a Homeland, the Canadian government has established a "territory of Canada, to be known as Nunavut" (Nunavut Act, Article 3). Nunavut is to have a legislature (12), which will have a wide range of powers, including "the administration of justice" (23.1e), taxation (j), some aspects of land use and sale (i, r, s), education $(m)$, and cultural and linguistic affairs $(m, n)$. Most of what the Inuit thought was necessary to achieve self-government seems to be provided in the Nunavut Act. But it is not without clauses that are distinctly colonial in tenor. The territory is to have a "Commissioner," appointed by the Governor in Council, who will take instructions from Ottawa (6.2) and sit in the legislative assembly, though s/he will not be elected. The Commissioner, it seems, is to play the role assigned to Governors within the British Empire. This is most apparent in the powers reserved by the Canadian state: 
28. (1) A copy of every law made by the Legislature shall be transmitted to the Governor in Council within thirty days after its enactment.

\section{Disallowance}

(2) The Governor in Council may disallow any law made by the Legislature or any provision of any such law at any time within one year after its enactment.

Ottawa also reserves for itself the right to appoint the judges of the superior courts in the territory (31). Whatever powers the people and legislature of Nunavut have been granted, their use will be closely scrutinized by a colonial administration, where ultimate power still resides. In eliding this critical issue, multiculturalism as liberal pluralism represents no advance on, and offers no critique of, the emergence, historical operation, and present reproduction of the Canadian colonial system.

Turning to a discussion of the category of Immigrant in Kymlicka's theory, we enter the realm of what he refers to as "polyethnic rights," which are "intended to help ethnic groups and religious minorities express their cultural particularity and pride without it hampering their success in the economic and political institutions of the dominant society" (31). Unlike the rights granted to national minorities, "polyethnic rights are usually intended to promote integration into the larger society, not self-government" (31). The practical implications are clearest here, since Kymlicka directly refers to "the Canadian government's 'multiculturalism' policy" as "promoting polyethnicity rather than assimilation for immigrants" (17). Indeed, in a summary that encapsulates his suggested treatment of both national minorities and ethnic groups, Kymlicka openly endorses current Canadian state policy in its broadest outlines. "Canada, with its policy of multiculturalism in a bilingual framework' and its recognition of Aboriginal rights to self-government, is one of the few countries which has officially recognized and endorsed both polyethnicity and multinationality" (22). 
Curiously, the text is not so clear in setting out the rights that would be granted to the third category - that of majority (Colonizer). The first problem is that Kymlicka tends to avoid naming the majority in his many discussions of actual nation-states. In the Canadian case, he notes that "Indian homelands were overrun by French settlers, who were then conquered by the English" (12). From this statement, and from the discussion about Colonization, one would assume that the societal culture that has become known as Canada would be English. This assumption is further justified by a reference to "the majority Anglophone society in both the United States and Canada" (22). Here, Kymlicka notes that "national groups, as I am using that term, are not defined by race or descent $t^{n}$ (22), but presumably - observing the reference to Anglophone - by language. However, on the next page, Kymlicka writes that "in talking about national minorities ... I am not talking about racial or descent groups, but about cultural groups" (23). It would seem that national majorities, for Kymlicka, are defined through language, while national minorities are distinguished by culture, and neither are defined by race or descent. Following this interpretation of what appears to be a somewhat open question in Kymlicka's text, I will refer to the "national majority" of Canada as "EnglishCanadian" in my discussion.

Unfortunately, the rights to be granted to Canada's majority are even more difficult to discover than its name and the means by which it can be delimited. The index contains only 8 references to "English Canadians," none of which leads to a discussion of what rights they are to be granted. This is scanty treatment when compared to the 29 entries for "French-Canadian" and "Québécois," and 57 for "Aboriginal peoples (Canada)" and "indigenous peoples." Kymlicka does note, though, that "[i]n a democratic society, the majority nation will always have its language and societal culture supported, and will have the legislative power to protect its interests in culture-affecting decisions" (113). Presumably, it would also have the legislative 
power to affect the interests of other nations and ethnic groups, and so would have a very powerful "right" that one might wish to see explicitly theorized. But

Multicultural Citizenship does not oblige here. Instead, there is a constant reference to a passively voiced "we" that will decide what gifts to give to "them:" "I will discuss whether immigrant groups should be given the rights and resources necessary to sustain a distinct societal culture" (76). "If people have a deep bond with their own culture ... should we not allow immigrants to re-create their own societal cultures?" (95). "We should aim at ensuring that all national groups have the opportunity to maintain themselves as a distinct societal culturen (113). By remaining implicit, this "we" forms a silent, Invisible Self group that chooses to give, or not to give, gifts of recognition and self-government to noisy, Visible Others.

This is not to suggest, of course, that those who do not consider themselves to be English-Canadian cannot read Kymlicka's text, but that when they do, they will find themselves constructed as a "them" to the text's implicit "us." They will also find that, despite being 'recognized', they are once again to be placed in an inferior position in a hierarchy of human types differentiated by what is presumed to be their 'origin', and the place assigned to them in a Eurocentric history of colonization and the play of power. One might consider the "Charlottetown accord," a constitution which offered the same gifts as multiculturalism as non-procedural liberal pluralism: it granted the Aboriginal peoples an "inherent right to self-government" (Art. 29, cited in McRoberts \& Monahan 1993:348); it described Quebec as “a distinct society, which includes a French-speaking majority, a unique culture and a civil law tradition" (2c, 315), thereby granting, once again, the gift of limited self-government within a 'federation', as in 1774, 1841, 1867,...; finally, it told the Other Ethnic Groups that “Canadians are committed to racial and ethnic equality in a society that includes citizens from many lands" (2e, 315). Despite the fact that each problematic identity was offered a gift, Canadians rejected this new constitution of non-procedural 
liberalism. The objections raised by those who identified with the various subject positions defined in the referendum suggest that the differential apportionment of rewards created a very Canadian situation in which each identity could feel that it was not being given enough, while others were being given too much. ${ }^{6}$ An unintended effect of non-procedural liberalism? A sign that a majority of Canadians really are "committed to racial and ethnic equality," but of the old, procedural variety, where it stands opposed to inequality and hierarchies?

Thanks to the tradition of the mass secret vote, no one will ever know for sure why or how this constitution was rejected. It is interesting to note, though, how relations between state policy, academic analysis, and popular culture have changed and remained the same since the 1940's, when academics led with theory, the state implemented policy behind a blaze of propaganda, and the population largely resisted or ignored them both. The people are still resisting and ignoring, and there are still strong correlations between the leading philosophy of multiculturalism and state policy, but now the philosophers appear to be following rather than leading. Will Kymlicka has written that, "[]]ike Jay Sigler, I believe that providing a liberal defence of minority rights 'does not create a mandate for a vast change. It merely ratifies and explains changes that have taken place in the absence of theory" (1995:127). In a similar vein, Ian Angus has noted that "the practice of multiculturalism in English Canada has proceeded further in its everyday, institutional, and policy contexts than it has a social and political philosophy" (1997:137). ${ }^{7}$

While it may not represent any great theoretical-philosophical advances, and while Canadians may be at best confused about its meaning and value, 8 multiculturalism as both state policy and liberal pluralism has made important contributions to the discourse on Canadian diversity. The dissociation of language and culture, and the replacement of race and nation with ethnocultural origin, 
allowed the semantic axis to be shifted from possession of official identity, i.e. national language and culture, to recognition of possession of identity, whether official or not. In possessing the crucial connection of their languages with the state apparatus (Kymlicka 1995:80), and in possessing the right to give gifts to Others, the English and French societies occupy the dominant pole of the axis of official recognition, with English still superior and in the position of giving gifts (or not) to the French. This strategic duopoly is counterbalanced by the Other Ethnic Groups, arranged in a complex and ever-changing hierarchy. As was the case with the transfer of the Platonic hierarchy into Christianity, and then into the realm of science, the Great Chain of Race has been shifted from the realm of official Otherness into official Selfhood, through the limited recognition of some races as ethnic groups, and others as Aboriginal peoples on the way to "full participation in Canadian society."

Figure 8.2 - Official recognition of identity in multiculturalism as state policy. <possessing official recognition>

$<$ British-Canadian nation $>$ <Other Ethnic Groups> $<$ French-Canadian nation>

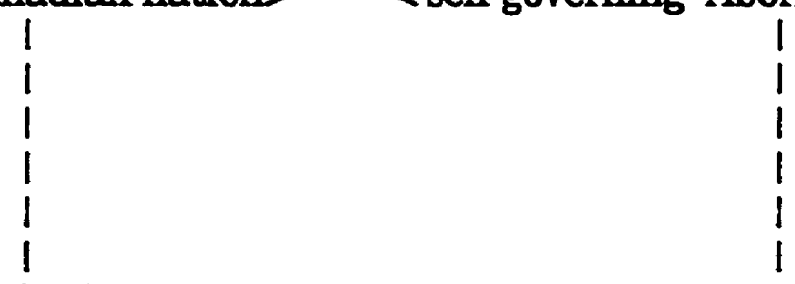

<nationalist Québécois> $<$ people of any multiple origins> <non-integrating Aboriginal peoples> <lacking official recognition

While this system of inclusion might appear 'complete', several identities can still be found within the territories claimed by the Canadian state that do not have official recognition. Nationalist Québécois who have had enough of the Canadian federation immediately come to mind, as do Aboriginal people who continue to display no interest in receiving the gift of integration into a Eurocolonial society. The newest 
- and most interesting - identity of all, though, is the one created by those who responded to the census or immigration officer by specifying a multiple identity that could not be resolved by the differentiation system of the ethnocultural economy. In 1986, when it finally became possible to do so, $28 \%$ of Canadians occupied this position, making it the largest 'ethnic group' of all (StatsCan 1989:vii). Is this tribe of hybrids just another census artifact, or is it possible that ethnoculture - like humanity, race, and civilization before it - is already losing its ability to differentiate the Canadian population?

\section{Multiculturalism - Modern or Postmodern?}

In cultural studies, literary theory, and educational debates, multiculturalism and postmodernism are more and more often appearing together as correlates or in variously theorized cause and effect relationships. ${ }^{9}$ This trend can also be seen in writers who directly address Canadian multiculturalism as state policy. In The Canadian Postmodern: A Study of Contemporary English-Canadian Fiction, Linda Hutcheon argues that "the postmodern 'different' is starting to replace the humanist 'universal' as a prime cultural value. This is good news for Canadians who are not of Anglo or French origin" (1988.ix). Reginald Bibby has also noted the decline of universals, but does not celebrate it: "Relativism has slain moral consensus, ${ }^{n}$ he laments. "It has stripped us of our ethical and moral guidelines, leaving us with no authoritative instruments with which to measure social life" (1990:14). Taking a more cautious position, Janet McLellan and Anthony Richmond suggest that "multicultural Canada is a model of the macroprocess of globalization" and, following Anthony Giddens, warn that "we must 'minimize the dangers and maximize the opportunities that radical or postmodernity offers us" (McLellan and Richmond 1994:679). 
The Canadian state does seem to "value" the presence of an ethnocultural diversity, and the push toward recognition of difference in liberal multiculturalist philosophy could be seen as 'postmodern' in the sense that it presents itself as a coming to awareness of limits to the form of the modern nation-state and the narratives of emancipatory humanism. Although he is dismissive of "half baked neoNietzschean theories ... deriving frequently from Foucault or Derridan (1992:70), Charles Taylor has noted a kind of fear that is "perhaps definitive of the modern age, the fear that the very things that define our break with earlier 'traditional' societies our affirmation of freedom, equality, radical new beginnings, control over nature, democratic self-rule - will somehow be carried beyond feasible limits and will undo us" (1993:60). This fear seems to be quite in line with Nietzsche's critique of modernity, which was picked up by Foucault, Derrida, and others. Thus, it seems to me that although neither Taylor, nor Kymlicka, nor the Canadian state would use the term, they are addressing something similar to what Lyotard has called "the postmodern condition," with its increasing "incredulity toward metanarratives" (1984:xxiv). To be very clear: I am suggesting that the incorporation of the constrained emergence theory of Canadian identity into multiculturalism as state policy, and the emergence of the political philosophy of non-procedural liberalism, are signs of what Hutcheon refers to as the replacement of "the humanist universal by the postmodern different" in Canadian society. In this section I will provide an interpretation of this shift in the Canadian discourse on diversity, with specific reference to the question of whether it might be considered as an overcoming of, or an improvement upon, the role played by state forms within the history of Canadian diversity.

Before proceeding, it will be necessary to provide particular resonances to some overworked terms. Postmodern' and its cognates pose a real challenge, since neither the major writers usually cast as 'postmodernists', nor those who cast them 
as such, seem to be happy with the term. Yet I believe that postmodernism and postmodernity mark shifts that are important to the interpretation of contemporary styles and social conditions, and so I do not wish to abandon them entirely. Zygmunt Bauman has put forward what I consider to be a very useful definition of postmodernity: "The term postmodernity renders accurately the defining traits of the social condition that emerged throughout the affluent countries of Europe and of European descent in the course of the twentieth century, and took its present shape in the second half of that century" (Bauman 1992:187). A key idea here is that postmodernity refers to a social condition, an environment, or "habitat" (192), for embodied subjectivity. Bauman continues:

The term is accurate as it draws attention to the continuity and discontinuity as two faces of the intricate relationship between the present social condition and the formation that preceded and gestated it... modernity - the social formation that emerged in the same part of the world in the course of the seventeenth century, and took its final shape ... during the nineteenth century (187).

The key features of the postmodern social condition are, for Bauman, "institutionalized pluralism, variety, contingency and ambivalence," all of which have been "turned out by modern society in ever-increasing volumes" (187).

Postmodernity, then, 'makes sense' only with reference to modernity, in relation to which it does not represent a simple 'break' or 'end' or 'overcoming'. Rather, says Bauman "postmodernity may be interpreted as a fully developed modernity taking a full measure of the anticipated consequences of its historical work ... -- modernity for itself" (187).

With modernity and postmodernity defined as social conditions, modernism and postmodernism can be reserved for reference to styles of cultural production fiction, state policies, philosophy, sociology, a life - that might serve to heighten or lessen the influence of modern or postmodern tendencies within a given social 
formation. Postmodernism as a style has become canonized to the extent that it can be seen to display qualities of non-linearity, irony, and self-conscious reproduction of the past that Linda Hutcheon has argued can be taken together under the sign of a redefinition of "parody" as "repetition with critical distance that allows ironic signaling of difference at the very heart of similarity" (Hutcheon 1988:26). While I am aware that there are ongoing debates about whether it is 'proper' - or even 'possible' - to 'define' postmodernism, this definition seems to me to capture a certain tendency in cultural production, and also works well with Bauman's notion of postmodernity as "modernity for itself."

A given social formation at the end of the twentieth century, then, could be expected to display signs of modern, postmodern - and of course premodern - social formations and cultural styles to varying degrees, in varying places, at different times. For my purposes, the most important site of struggle is that between states, nations, and individuals. According to modern European thought, nation-states were created when a people - sharing a single common language, culture, economy, and polity - were articulated with a bureaucratic apparatus to form a distinct society. As E.J. Hobsbawm has pointed out, states were expected to expand (1990:30-31), and the greatness of a people was thought to be given in the ongoing continuity and growth of its state apparatus. Thus "[t]he Spartan song -- We are what you were; we will be what you are' - is, in its simplicity, the abridged hymn of every patrie" (Renan 1990:19). Renan's theory of the nation as a "large-scale solidarity" (19) has been taken up by Benedict Anderson in his widely read Imagined Communities (1991). According to Anderson, those who consider themselves to be of a nation participate in an origin myth, and imagine themselves as an entity with an existence. Thus the state became, to use Nietzsche's term, one of the New Idols of the modern age. 
The homogeneity of the state people was always a simulation, of course. Nation-states around the globe are currently undergoing various forms of more or less brutal desimulation, as groups not 'in' the nation, but within the purview of the state, seek to striate their own spaces. This is happening in every historically possible way: decolonization within the overseas Eurocolonial domain, where a relatively 'pure' European population did not achieve numerical hegemony, as in Central America and Africa; claims of sovereignty by minorities within the New World states where a European hegemony was (momentarily) achieved, e.g. the Aboriginal peoples within Canada, and Hawaiian and Puerto Rican nationalisms within the United States; finally, desimulation is ongoing within the European ecumene itself, most notably with the disintegration of the Soviet Union, but also in Great Britain, France, and Spain. This global phenomenon has been named as "ethnic nationalism," whose "fundamental appeal ... is as a rationale for ethnic majority rule, for keeping one's enemies in their place or for overturning some legacy of cultural subordination" (Ignatieff 1993:9) It has, for obvious reasons, become a subject of much concern to the established nation-states.

These states, as adaptive agents, have tried to hang on to their hegemony during this desimulation, primarily through attempts to erect new simulations. In Canada, this has involved changing the meaning of the key terms in the discourse of European nationalism. As I have shown above, culture, which was always taken to be a key aspect of recognition and seen as essential to modern statehood, has been redefined so that one can apparently acquire liberty, equality, and fraternity without having a societal culture articulated with a state apparatus. But even this might not be good enough. Cultures as compartments into which individuals might be placed, or made ready for state articulation, are themselves eroding. In Canada, the British ethnocultural group has been steadily losing its majority status since the turn of the twentieth century, and the largest ethnocultural group in Canada today is the tribe 
of multiple origins - not an ethnocultural group at all. As the following graph, which is becoming as ubiquitous as the Flood tables, shows, the categories are emptying out, all by themselves. Ethnocultural identity is flowing onto the floor, disappearing through the cracks, and seeking the sea from whence it came.

Figure 8.3 - Multiple Origins in Canada, 1986 census

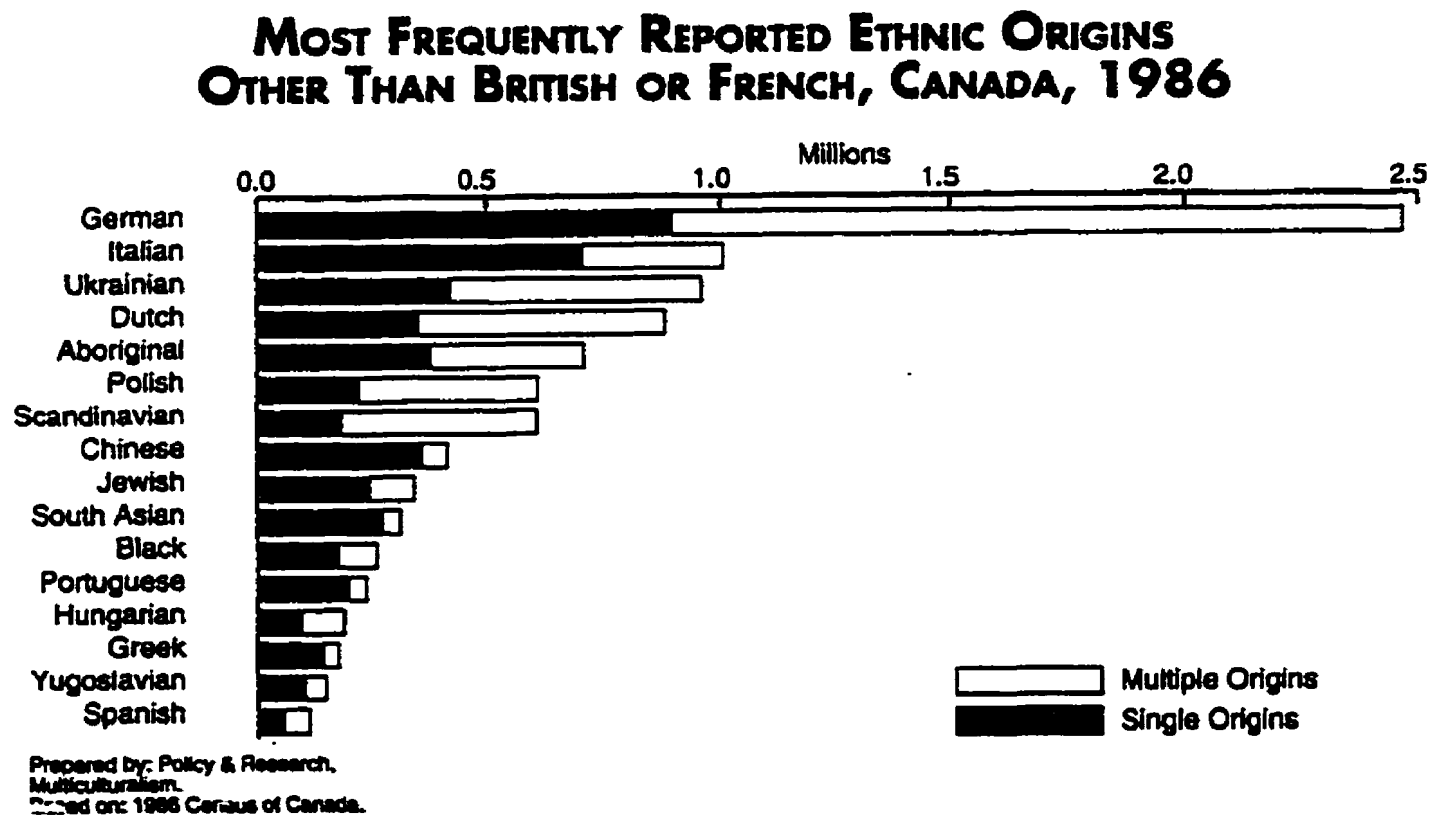

This simultaneous and contradictory rise in both ethnonationalism and hybridity means that the modern form of articulation between state and nation - as people, culture, Us as opposed to Them - is becoming more and more difficult for the existing nation-states to sustain. New methods of articulation will be required if they are to maintain their hegemony and avoid breaking apart into smaller and smaller units of organization.

While it definitely reproduces ancient and modern forms, as I have pointed out in the previous sections, Canadian multiculturalism as state policy can also be seen as a postmodernist attempt at a new form of state articulation appropriate to a social condition of postmodernity. For example, it proceeds primarily by seduction 
and incorporation, rather than by coercion and exclusion, in its (impossible) quest for infinite striation. Instead of trying to transform its Others, the postmodern nationsstate leaves them as they are and articulates them with regimes of rationalbureaucratic discipline, through their identifications with designed positions in the ethnocultural economy. When discussing the $B \& B$ Report, I suggested that Baudrillard's analysis of strategic duopoly might be applicable to the world of official Canadian language and culture at that time. This model seems to work well enough in the context of 'bi' culture and language, but what can be made of the shift to a system of bilingualism in a multicultural framework? Baudrillard again, on the $0 / 1$ binary scansion that permeates postmodern social forms:

This is the nucleus of the simulation processes which dominate us. It can be organized as a play of unstable variations, from polyvalence to tautology, without threatening the strategic bipolar form: it is the divine form of simulation (1983a:135).

Multiculturalism in a bilingual framework; polyvalence (recognition of the Other Ethnic Groups as ethnicities) and tautology (everyone has an ethnicity) integrated with an essential duality (English and French societies, languages, and cultures). Duopoly of language and culture, monopoly of state over language, culture, and selfidentification.

The transition from modern to postmodern forms of discipline has been accompanied by a shift of focus from management of difference to management of what Jacques Derrida has called différance. In his essay of the same name, Derrida writes that differrance "would be said to designate a constitutive, productive, and originary causality, the process of scission and division which would produce or constitute different things or differences" (1983:9).10 Derrida intends this term to play upon both time, in the sense of 'deferring', and space, in the sense of 'differing'. In the broad context of the discourse on Canadian diversity, I would suggest that 
differance produces difference spatially through the operation of a given means of differentiation - humanity, civilization, race, culture, ethnicity, ethnocultural origin. It also produces difference temporally, as that force which leads to the decline of one means of differentiation and the rise of another. In the specific case of Canadian multiculturalism, the will to the management of spatial differance shows up as an insistence upon using British social and political forms, and the English and French languages, as a 'framework' or 'context' - within the terminology I have been using, a constraint - upon the emergence of a Canadian identity. It can also be seen in the preservation and promotion of 'frozen' identities in the form given by Western political anthropology, that is, as unvarying cultural compartments into which individuals might be placed in preparation for state articulation as 'one of the people(s)'.

Out of a differentiated population in which each individual is assigned - and may or may not identify with - a preserved and promoted ethnocultural origin that resists the play of differrance, a further means of differentiation can emerge: that of the citizen. Inasmuch as everyone is supposed to be a citizen, this appears not as a category of differentiation, but as a metacategory of universal similarity. Canadian multiculturalism as state policy and non-procedural liberal philosophy, I would suggest, operates to construct a metacategory of this sort. Where the modern nation-state simulated $a$ unity and dissimulated its multiplicity, the postmodern nations-state dissimulates its unity and simulates a multiplicity. This is to say that there is, and always has been, a great deal of Canadian unity. Canadians both canonical and problematic are being subjected to increasingly powerful normalizing forces in almost every aspect of their lives, so that the only kind of diversity left is on the level of what has been referred to as "symbolic ethnicity" (Gans 1979) - which, as Will Kymlicka notes, is "almost entirely lacking in any real institutionalized corporate existence" (1995:98).11 Thus there remains the task of analyzing the 
practical means by which multiculturalism offers up the gift of mass citizenship to the multiple origin hybrids of the twenty-first century. For this we must return to the Mosaic metaphor for Canadian society, which has risen to prominence in public discourse, gained the status of a cliché - become such a well-established "fact of life" that, from the 1970's up to the present, it has appeared on the cover of almost every state publication dealing with multiculturalism policy.

\section{The Mosaic as the Canadian National Thing}

If Canadian society is thought of as a Mosaic-like "thing", the structure of the Mosaic would provide important information about the designed environment within which Canadians are supposed to live their lives. As the most highly evolved representation to date, what I call the National Jewel (Fig. 1.1) provides an excellent opportunity for deriving an official definition of what and how an official Canadian is to "be." The most useful feature of the Mosaic is its ability to lend an appearance of concrete reality to the abstract conceptual system of multiculturalism, to "fix cultural difference in a containable, visible object" (Bhabha 1994:50). On the National Jewel, diversity is marked by the colours of the component triangles. It is instructive to note that while there are many such components, no single one of them is unique - each is identifiable as a member of one of six colour groups. The Mosaic thereby serves to reinforce the racialist notion that Canadian society "contains" a diversity of person-types that can be grouped together on the basis of their Visible similarity to / difference from one another, and that colour provides a useful means of making this differentiation. Another feature of the National Jewel is that colour provides the only basis for marking out differences among the elements. Each is exactly the same size and shape, and the random placement of the elements on the surface suggests that every position on the Mosaic is of equal importance. Thus, there is no basis for claiming that any colour group occupies a position that is 
structurally 'superior'. These features help to give the impression that the idea of equality is important to a Canadian life.

In addition to diversity and equality, the National Jewel also helps to concretely display the idea of community through 'unity in diversity.' As Kate Foster has pointed out (chapter 7), the various elements of a Mosaic must be arranged according to a consciously planned pattern. In the case of The National Jewel, unity of form is displayed in the strict arrangement of the triangular elements to produce a geodesic sphere or world. Diversity is present, but only in the context of a perfectly structured (integrated) whole. And, if this unity is to be maintained, the individual elements of the Mosaic must be preserved, prevented from exceeding their boundaries. This unity of form highlights an important aspect of life on the Mosaic -the commitment to Canadian nationalism. But, in order to provide a basis for reading the three-dimensional Mosaic as a nationalistic symbol, we must first bring out some of the generic qualities ascribed to objects through language.

The qualities of interest here can be derived from the idea that the surface of an object is somehow separable from its depth. It is generally the case, in the Western tradition, that surface is associated with mere appearance, and depth with truth. This structuration can be seen to operate in theories of representation based on the "mirror of nature" (Rorty 1979), or in everyday English, with its notion of "getting to the bottom of" some matter. The connection of truth with depth could help one to read that the three-dimensional Mosaic, with its added depth, lends an extra increment of validity to the factual existence of Canadian diversity. Another entailment of the surface/depth pair is the association of surface with diversity and depth with universality (Geertz 1986). These associations are of particular interest with regard to the nationalistic appeal of the three-dimensional Mosaic. Achieving a (relative) national unity requires the construction of a set of universal characteristics by which the nation can know itself as such. The three-dimensional 
Mosaic suggests that, despite the appearance of a surface diversity there lies, somewhere deep inside the National Jewel, a universal truth that would be 'for' all Canadians. This is precisely the truth propagated by the Canadian discourse on diversity in all of its manifestations, but most particularly in the efforts of the Canadian state to design a system that fully specifies the parameters of proper citizenship:

It is the government's intention that the Canadian Multiculturalism Act will join an amended Citizenship Act and an amended Official Languages Act in providing an enduring statutory basis for Canadians' sense of themselves and their country (Secretary of State for Multiculturalism 1987:7).

As a technology of governance, Canadian multiculturalism policy helps to construct a seductive model which, it is hoped, those who occupy its territory will adopt and instantiate in their own daily practice. The title of the pamphlet in which the National Jewel image appears says it best: Multiculturalism ... being Canadian.

Objects generally seduce with their surface, but they may seduce with their depth as well. Or, perhaps the surface seduces because it suggests a depth to the incautious beholder. What could be inside the National Jewel? This, I, as a Canadian, can never know. Since I cannot know what is inside the National Jewel, I may assume the presence of that which I most desire, that which I most fear. If I am being Canadian, being an official, multicultural Canadian peering inside the National Jewel, perhaps I would hope to find - my Self? For those who desire a designed national identity, the problem of What It Means To Be Canadian is that 'we' (Canadians) don't know who 'we' are, indeed are prevented from knowing, because there are too many of 'them' around, countering 'our' music with 'their' noise, overpowering 'our' perfume with their stench, continually Swamping 'our' carefully tilled cultural fields. As we have seen, these feelings have given rise to various forms of nativism and racism throughout Canada's history. Slavoj Zizek sees this kind of 
resentment as the product of a battle over possession of what he calls the "national Thing:"

What is at stake in ethnic tensions is always the possession of the national Thing: the 'other' wants to steal our enjoyment (by ruining our 'way of life') and/or it has access to some secret, perverse enjoyment (Zizek 1991:165).

Thus, it may be that what the official Canadian finds most disturbing about the Others is that they seem to possess, without any effort at all, what the Canadian most shamefully lacks: a set of typical characteristics, an identity ... a Self.

The project of creating good Canadians was hampered from the outset, and is still plagued, by the lack of a clear idea of just what and how a good Canadian is. If 'we' could only make them' like 'us', the problem of national unity would be solved. But 'we' can't do this, because 'we' don't know who 'we' are. It's a circle, a beautiful and perfect circulation, and there seems to be no hope of getting out of it. This circling about a goal, while never quite attaining it, is reminiscent of the Lacanian notion of the quest for the objet petit a:

Is the Freudian [national] Thing a kind of "fatal attractor," perturbing the regular functioning of the psychic apparatus, preventing it from establishing an equilibrium? Is not the very form of the "strange attractor" a kind of physical metaphor for the Lacanian objet petit a?... The art of the theory of chaos consists in allowing us to see the very form of chaos, in allowing us to see a pattern where ordinarily we see nothing but a formless disorder (Zizek 1991:38).

To understand the National Jewel as a fatal attractor, we must explicate the categories of need, demand, and desire. For Lacan, following Freud, need relates only to biological necessities such as hunger or thirst, which can be satisfied by the attainment of a required object: "The wild animal emerges from its hole querens quem devoret, and when he has found what he has to eat, he is satisfied, he digests it" (Lacan 1981:165). But this is a special case that does not admit of generalization to 
the human condition, for individuals in society are required to demand (ask for) what they think they need from an Other. It is here, in the perpetual disjunction between need and its expression that desire arises: "the function of desire is a last residuum of the effect of the signifier in the subject" (Lacan 1981:154). Since the result of demand never quite meets the need, satisfaction is impossible and desire is fundamentally insatiable.

If the function of desire is not to achieve satisfaction, then what is it for? In one sense, desire is that which allows human beings to confirm or refute their theories about the attitudes of the Other towards them. Those who at least make an attempt to respond to our demand thereby verify that we exist and matter: this is why Lacan insists that the subject is constituted in the Other. But there is more than this to the role of desire in Lacanian theory, and to get at its further significance we must consider the category of drive (Trieb), which Lacan claims to take directly from Freud, along with its division into four subcomponents: Drang (impulse); Quelle (the source); Objekt (the object, or goal); Ziel (the aim). Lacan says that "the use of the function of the drive has for me no other purpose than to put in question what is meant by satisfaction" (Lacan 1981:166). In a trick reminiscent of the flow of desire itself, he shifts the ground from satisfaction to pleasure, or enjoyment. This move is nicely summarized by Zizek in the following passage:

Lacan's point is that the real purpose of the drive is not its goal (full satisfaction) but its aim: the drive's ultimate aim is simply to reproduce itself as drive, to return to its circular path, to continue its path to and from the goal. The real source of enjoyment is the repetitive movement of this closed circuit (Zizek 1991:5).

If we see the National Jewel as the impossible object of the quest for a Canadian identity, then the chaotic and endless trajectories around it, displayed in the history of Canadian diveristy, take on an order they would not otherwise appear to have. We are led to an intriguing possibility - that the circulation itself is the 
identity. Through its existence as a coveted but unobtainable simulation model, the National Jewel serves double duty: to naturalize Canadian diversity, but also to give substance to an impossible, but unifying, quest for unity, identity, and recognition:" [T] he ideal leveling of all social differences, the production of the citizen, the subject of democracy, is possible only through an allegiance to some particular national Cause" (Zizek 1991:165). From this point of view, the Canadian state seems to be "breaking the rules" of nation building by trying to create a national Thing that has no particular ethnic affliation. However, we can see that Canada is actually following this rule if we note that, at least on the level of multiculturalism policy, Canada is attempting to create, not a nation-state, but a nations-state, in which all ethnicities in general, and therefore no ethnicity in particular, can seek their enjoyment in the simultaneous possession and loss of a simulacrum of identity. If Canadian multiculturalism is seen as a technology of governance, this technology must be seen as rather perversely constraining / seducing individual bodies into becoming nothing at all.

In the sense that it provides a single normative option for proper citizenship through state articulation, one might say that multiculture is no more or less exclusive and repressive than monoculture. The means used to mark out differences between person-types, and the methods invoked to handle the problems created by the work of differentiation, have changed, but the assumption of a problematic diversity of human types has remained stubbornly in place. In its creative reproduction of the discourse on Canadian diversity within the context of the postmodern condition, we see the Canadian state acting as an intelligent' agent, following the singularities of the space of demography, immigration, and diaspora in pursuit of its goal. It 'knows' that the modern notion of identity as essence is becoming outmoded and will no longer allow a successful articulation of bodies, nations, and the state. And so it tries to adapt, in the hope of maintaining and 
expanding its ability to structure the daily lives of the people who live in the territories it claims. In that it displays signs of acknowledging the current social condition in its practice, multiculturalism as state policy is most certainly 'liberal' and 'postmodern'. However, as a continuation and heightening of the hegemony of the state form, it is just as certainly not an overcoming of the modern will to rationalbureaucratic domination and the microcontrol of individual lives associated with the form of the nation-state. It is best considered, therefore, as a hypermodern disciplinary regime that seeks to maintain a precarious articulation between the Canadian state, two dominant nations and cultures, and a variety of other nations and cultures clipped back as ethnicities. Through its articulation with these designed mass identities, the state acquires access to the bodies and souls of individuals who identify with them, and thereby maintains its ability to successfully striate the spaces it claims as its own. While classical liberalism might be updated so that this context can appear as 'freedom', I will argue in the final chapter that an 'overcoming' - or as I would prefer, a step away from - the history of Canadian diversity cannot be achieved as long as multiculturalism remains a tool of the state form.

\section{Notes}

1 Subsequent references will refer to the "B \& B Commission" and the "B \& B Prelim. Report."

2 Book IV of the $B \& B$ Report boasts a six page academic bibliography, many entries in which were funded by the Royal Commission itself.

3 I feel compelled to note that $I$ do not in any way claim to be engaging in or adding to the debates on multiculturalism as liberal pluralism here. Rather, I will simply attempt to point out how certain regularities can be observed across two subfields, i.e. Canadian political philosophy and the state policy discourse, and to show how these regularities can be used to shed light upon the larger field of Canadian diversity to which they both contribute.

4 The reader will note that I have not claimed that Taylor intends to reproduce or advocate the current state policy. I have simply pointed out that his 'vision' aligns quite closely with the current state policy.

5 This intervention in the "communitarian-liberal" debate is crucial to Kymlicka's position. He is trying to ward off the argument, as one commentator has put it, that 
"the democratic way conflicts with any rigid idea of, or absolute right to, cultural survival" (Rockefeller 1992:92). In the form to which Kymlicka particularly objects, the communitarian argument holds that the nation provides "too vast a scale across which to cultivate the shared self-understanding necessary to community in the ... constitutive sensen (Sandel 1984:93). Obviously, if he is to argue for the mutual coexistence of majorities, national minorities, and ethnicities within a single state, Kymlicka must defend some conception of a greater common -- but changeable -- notion of the good life, which he does explicitly on p. 91 of Multicultural Citizenship. A similar stance against communitarianism has been taken by Chantal Mouffe, who also advocates building a political society out of a number of identities that are not mutually exclusive, but oriented to a changing common cause of radical democracy. "The communitarian insistence on a substantive notion of the common good and shared moral values is incompatible with the pluralism that is constitutive of modern democracy ..." (Mouffe 1995:324). Interestingly, communitarian and radical-democratic theorists each accuse the other of being antidemocratic.

6 See the essays in (McRoberts \& Monahan 1993) for an overview of these issues.

7 While Angus refers to "social and political philosophy" and Kymlicka to "theory," it seems to me that these observations can realistically be construed as addressing the same referent. Kymlicka's Multicultural Citizenship is subtitled "A Liberal Theory of Minority Rights," and clearly presents a normative argument that would attempt to persuade the reader into adopting a particular stance with regard to questions that would be considered 'philosophical'. Indeed, Kymlicka is a professor of philosophy, and Charles Taylor refers to him, on the back cover of the book, as "a first-class philosophical mind." My point here is that, whether they are doing philosophy or theory, the Canadian academics who have been leading the current debate on multiculturalism have been trying to "catch up to" the Canadian state's policy moves over the past few years, rather than providing new ideas that the state might draw upon for its policies.

8 Evidence supporting this observation is presented in chapter 2 of this dissertation, in the section on "Canadian Diversity and Popular Culture."

9 For an overview of the theoretical arguments and positions, see Mark Poster's "Postmodernity and the Politics of Multiculturalism: The Lyotard-Habermas Debate Over Social Theory" (Poster 1992:567).

10 In providing a 'definition', I do not propose to exhaust or fully circumscribe the resonances of this term as it is used within Derrida's texts -- such a project would be foolish indeed - but rather to produce enough limitation to allow it to be used 'successfully' in the context of this dissertation.

11 For Kymlicka, of course, this does not represent a 'problem', for, as I have shown, he believes that immigrants have "waived their right" to such an existence by not coming to Canada as Colonizers. 


\section{Chapter 9}

\section{Conclusion}

In this chapter a summary of the work of the central chapters will be presented, showing the continuity and change between ancient Ionian Hellenism and contemporary Canadian multiculturalism within the tradition of Western political anthropology. This summary will be used to make the claim that Canadian multiculturalism is in a state of fulfilled nihilism that offers a series of false choices as a means of maintaining the articulation of the Canadian state with its target population. The chapter will conclude with a suggestion that, rather than pursuing a line of incorporation by the Canadian state through identification with a singular - or even a multiple or hybrid - race, nation, culture, ethnicity, or citizenship model, one might become what one is through taking a line of flight away from these mass forms. 1

\section{The History of Canadian Diversity - Reprise}

It is forty-four years since I came here and I find that we are still struggling to bring about unity.

- Mr. Hason, M.P. for Skeena, (DHC April 27, 1944:2415).

The problem of Canadian diversity began simply enough, as the British and French arrived in the New World, bringing with them a system that posited their own group as human and civilized, in opposition to the Savages, who were not seen as

possessed of these attributes. From ancient Ionian Hellenism the Europeans had inherited both a method of differentiating between human types, and a way of ordering these types through a system of hierarchies within binary oppositions, contradictions, and complementary relations. They also inherited a tendency to act 
as Invisible Selves gaining distant knowledge about Visible Others, whom they assumed were, or should be, frozen in space and time on the margins of the polis. From the Romans, they adopted a system of incorporation of external Otherness that was both conservative and acquisitive, counting each incorporated sign as a measure of its own greatness. From the same source came a tendency towards legally codified attempts at repressing and transforming internal Others who were too repulsive, or too independent, to be incorporated.

Confronted with the problematic difference of the New World Savage, the British and French evolved coping strategies, some based on their experiences in the Old World, and some particular to the changed context. Primarily, they tried to physically eliminate signs of difference through ignorance, displacement, transportation, containment, extermination and, in New France, assimilation. But these Others were equally interested in perpetuating their own style of life, and so they resisted European striation of their spaces, bodies, and souls, in part by taking on European technologies. The French were creative in their turn, evolving a strategy of simulated assimilation to the Savage way, followed, as soon as possible, by attempts to reverse the flow of signs in their own favour. With this strategy they managed some conversions, but also gave rise to a hybrid race of nomadic individuals who were even more frightening and problematic. The British, in both Newfoundland and the Hudson Bay region, had relied primarily upon keeping their Others at a distance. But they eventually learned, from the French, how to work with the existing population to extract wealth in the form of furs, and thus evolved within their system the category of Indian, or Useful external Other of the New World. With greater contact and infiltration into the continent, the British began to evolve systems of rational-bureaucratic microcontrol that allowed them, to the degree possible given the technologies at hand, to striate large spaces from their distant 
base of power. They too, despite their xenophobia, gave rise to a race of hybrid Halfbreeds, who were again considered dangerous and problematic.

With the Conquest / Cession of Acadia and Quebec, the French were transformed from colonizers to colonized, and the British took them on as an additional management problem - a population to be disciplined, appeased, transported, exterminated, assimilated and, when that failed, integrated under the terms of the Quebec Act. The arrival of the American loyalists brought a truly English Canada into existence for the first time, and gave rise to the ritualistic process of separation and recombination of the English and French Canadas which continues to the present day. The Savage Other - renamed the Indian -- was no longer ignored, but subjected to an increasing degree of tutelage under British rule, as expansion into Upper Canada progressively displaced and contained the Native peoples of Canada on micromanaged reserves.

After Confederation -- in which the French were restored to Self status, or continued as internal Others, according to one's reading of history - a 'united' Canada sought to expand its Dominion along British-Roman lines. Invoking the medieval European doctrine of terra nullius, the infant empire annexed the Northwest territories by way of brute force, seduction, and rational-legal trickery. In exchange for this prize, the Half-breed and Metis identities were added to the list of problematic internal Others that Canada inherited from the British colonial period. The consequent effort to 'fill' the 'empty' Northwest expanded the problem of Canadian diversity, as government-sponsored immigration brought in large numbers of individuals who were identified by existing Canadians as Foreigners of different racial origin. By 1903 Canadian immigration records contained no less than seventy-nine categories of origin (National Archives of Canada, Immigration Record Books, RG 26 Series C.1 Vol. 26 Book 3), causing British and French Canadian nativists, in fear of being 'swamped' by the 'flow' of incoming Otherness, to demand further governmental 
action to limit immigration to human types near the apex of the Great Chain of Race. With the apparent failure of privately sponsored attempts at assimilation of the Immigrant Other to a British ideal, more coercive measures were adopted during the two World Wars, including disenfranchisement, internment, displacement, transportation, and surveillance.

In 1941, a new policy era began, with the creation of the Nationalities Branch of the Department of National War Services, which was given the task of seductively integrating Immigrant Others, who were increasingly marked out in terms of culture and ethnicity rather than race. While this bureaucracy lived on into the 1960's as the Citizenship Branch, the problem of the Immigrant Other was overshadowed by a revival of Québecois nationalism, which was to be assuaged by the policy of official bilingualism and biculturalism. Now, abandoning implicit British monoculture and language, both the British and French became official Self groups, with the Other position taken up, quite literally, by the later Immigrants under the name of 'the other ethnic groups'. These excluded Others were incorporated in 1971, to produce a policy of multiculturalism in a bilingual framework, which at first included everyone but the Native peoples. Before long, these too were included, except for the Metis, who had always been ambiguously classified as both Native and European, and thus had to fight to be included in the Canadian system of identity as one of 'the Aboriginal peoples'. Now, in the 1990's, "every Canadian has an ethnic origin" (MCBCM:87), and "there are two official languages ... and no official culture" (Pierre Trudeau DHC October 8, 1971:8545).

Like the ancient Roman Empire, the postmodern Dominion of Canada presents each incorporation of the culture of an Immigrant, each gift of limited selfgovernment to the Aboriginal or Québécois peoples, as a sign of the present and future greatness of the Canadian way, and thereby attempts to disguise its proliferation of the problem of human diversity as a solution to the problem itself. 
While it is now unlikely that after-dinner speakers will exhort Canadians to greatness by invoking their connections with the Greeks, I hope to have shown in this dissertation how the means and methods of ancient political anthropology deeply structure thought and action in contemporary Canada. In Canadian state policy, popular culture, and mainstream academic analyses, as in Herodotus, Pliny, Polo, Columbus and Champlain, a set of categories is constructed and used as a basis of evaluation and comparison of various peoples. These categories rely upon what can be seen from a distance, and provide information about what is supposed to be the 'nature' of a people, which is also presumed to be influenced by the land they occupy. In all comparisons, a Self people provides a base of normality, with signs of similarity to the Self group counting as possession of a good, and signs of difference indicative of a lack or deficiency. Finally, the nature of a people is assumed to be displayed in all individuals who are of that people, so that to know one is to know all and vice versa. Within this tradition, the Others are always assumed to have 'caused' a problem of diversity by their presence (Visibility), from the Barbarians and Savages to the Québecois and the Other Ethnic Groups. The Selves, through their Invisibility, take on the role of offering up gifts to the Others -- destruction, civilization, humanity via religious convertibility, political recognition - which are then presented as solutions to the problem. There has always been a hub at the centre of the wheel. 
Figure 9.1 - The Herodotan wheel of identity and difference

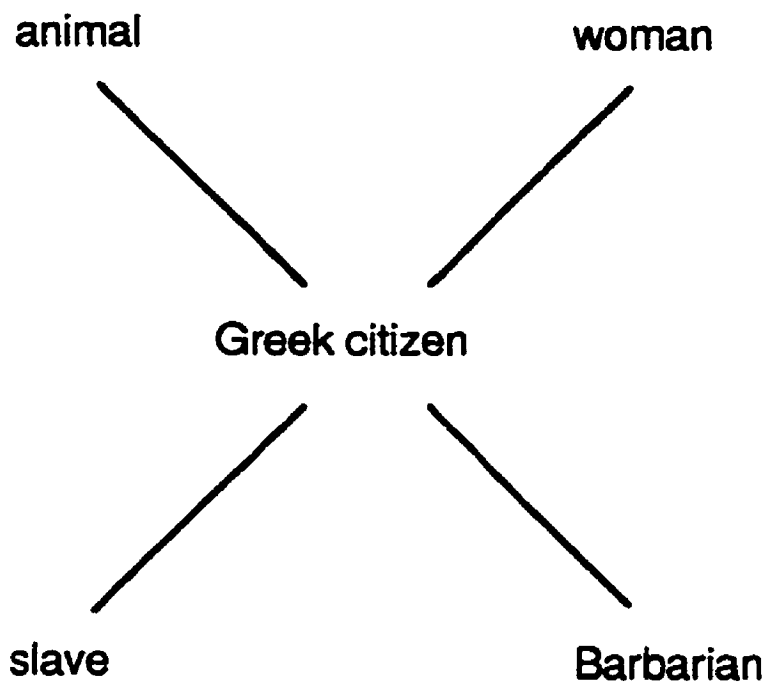

Figure 9.2 - The Canadian wheel of identity and difference

sovereigntist

Quebecois \&

Aboriginal

peoples

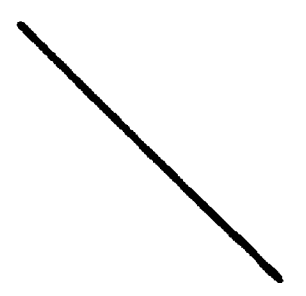

nationalist

nomadic

Canadian citizen

capitalist multiculturalist

communist, anarchist, tribal

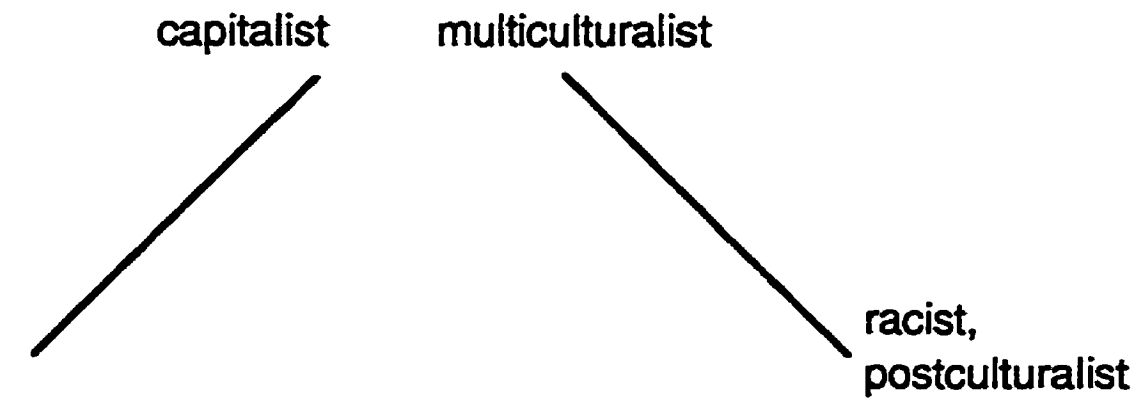


Thus I would suggest that it is not the parade of problematic Others, but the normal English-Canadian Self that is to blame' for the creation, perpetuation, and proliferation of the problem of Canadian diversity. This is to say that, without a will to an impossible and largely undesired unity under the banner of English Canada, there would be no problem of Canadian diversity. Of course, the failure to solve the problem of diversity is undoubtedly a success, as all who are willing to play the game of multiculturalism, who take up a position on the National Jewel, become EnglishCanadian by virtue of their articulation with that silent hidden no-thing at its centre, and make their bodies and souls accessible to rational-bureaucratic discipline.

While there might be a strong -- but generally unremarked -- continuity between ancient Ionian Hellenism and contemporary Canadian multiculturalism, there is a crucial difference between the Greek and English-Canadian identities as they signify within these systems. The former was proud and self-conscious, while the latter has cloaked itself in shame after its humiliating failure to assimilate the French, the Savages, the Indians, the Half-breeds, the Immigrants, and now the Multiple Origins. In the sense that it has exhausted its own possibilities and is recycling the same old solutions to the same old problems, and to the extent that it has expanded its realm such that all identities can signify in relation to it only by being incorporated by it, Canadian multiculturalism has reached a state of fulfilled nihilism. In its decadence it presents a series of false choices: between assimilation and integration; ethnic and civic nationalism; procedural and non-procedural liberalism; unequal particularity and equal uniformity; and, most importantly, between a Self constructed through mass identification and no Self at all. The perpetuation of this fear seduces the individual into seeking an identity through articulation with a race, nation, culture, or model of citizenship - that is, through $a$ mass society under the discipline of a state form. This system certainly can, and likely will, continue for some time. But there is another possibility which, while it is 
obviously not for "everyone," might provide a way out of the trap for those who wish to take it. It is to this possibility that I wish to make a parting gesture.

\section{Citizen / Smith}

We are free to be ourselves. But this must not be left to chance.

- Pierre Trudeau

(DHC October 8, 1971:8546).

To become what one is, one must not have the faintest notion what one is.

-- Friedrich Nietzsche (1967c:254).

The will that gets to the zero-point of Canadian multiculturalism, to the line, is the will to the end associated with passive nihilism, the citizen, and modernity; that which can push through zero, cross the line, is the active nihilism of the postmodern condition and the smith. The style of the smith comes from Deleuze and Guattari and, like all of their notions, its significance is intended to be broad and incomplete. However, drawing upon the essay Nomadology: The War Machine (1986), and making use of what Deleuze and Guattari call the "differential method" (88), it is possible to assign certain characteristics to the smith that would distinguish it from the citizen. In order to do this, yet a third position must be recalled: that of the nomad, which I discussed in chapter 2. Within Western political anthropology, the nomad is seen as the contrary of the citizen, as one of those Barbarians who "sow not, nor have any tillage; ... [are] without habitation, having no dwellings but caves and hollow trees... (D'Avity, cited in Hodgen 1964:201). Deleuze and Guattari maintain an opposition between the citizen and the nomad, but also revalue the latter position in a number of ways, e.g. with reference to its mode of occupying space: 
The nomad distributes himself in a smooth space, he occupies, inhabits, holds that space; that is his territorial principle. It is therefore false to define the nomad by movement. Toynbee is profoundly right to suggest that the nomad is on the contrary he who does not move (1986:51, emphasis in original).

When one considers the breakneck speed at which the modern sedentary plunges headlong into a life of increasingly arcane futility, is it not he, rather than the nomad, who appears to have no fixed abode?

The smith exists in a complex relation to both the sedentary citizen and the nomad, in one aspect as their complement.

There are no nomadic or sedentary smiths. The smith is ambulant, itinerant. Particularly important in this respect is the way in which the smith lives: his space is neither the striated space of the sedentary, nor the smooth space of the nomad. The smith may have a tent, he may have a house, he inhabits them in the manner of an 'ore bed' (gite) shelter, home, mineral deposit... They are cave dwellers not by nature but by artistry and need (106, emphasis added).

In another aspect, the smith takes up a contradictory position:

[T]t is by virtue of his itineracy, by virtue of his inventing a holey space, that he necessarily communicates with the sedentaries and with the nomads (and with others besides...). $\mathrm{He}$ is in himself a double: a hybrid, an alloy, a twin formation (107-8, emphasis in original).

Where the practice of the citizen is oriented to 'staying on the road', as it were, the smith is guided by an alchemical, metallurgical will to the "involuntary invention" (90) of new forms, which rather than attempting to dominate by imposing allencompassing norms, seeks to innovate by tracking and exploiting singularities in existing forms. "[M]en of war reappear, with many ambiguities: they are all those who know the uselessness of violence, but who are adjacent to a war machine to be recreated ... workers also reappear who do not believe in work, but who are adjacent 
to a work machine to be recreated, one of active resistance and technological liberation" (89). The figures of the hacker, the monkeywrencher, and the Invisible hero of If on a Winter's Night a Traveler ... all come to mind. Of course science military, political, sociological, bureaucratic - has always made its revolutionary Discoveries through a metallurgical method, though it has seen fit to provide itself with a sedentary myth of control and purposeful advance. “A sombre caricature already precedes them [the smiths], the mercenary or mobile military instructor, and the technocrat or transhumant analyst, the CIA and IBM" (89). The style of the smith is not a reflection of an essence, any more than is the citizen or the nomad; a style can be put to the service of any sort of life. The life of the smith is thus a "pure possibility, a mutation," as "the borrowings between warfare and the military apparatus, work and free action, always run in both directions, for a struggle that is all the more varied" (90).

This variety of struggle has made itself apparent in the history of Canadian diversity through the evolution of a line of incorporation that can be traced across the semiotic square of Canadian identity, from absolute external Other (1), to conditional external Other (2), to conditional internal Self (3). Inscribed on a timebased square, the line of incorporation would look like this:

Figure 9.3 - Line of Incorporation

internal>

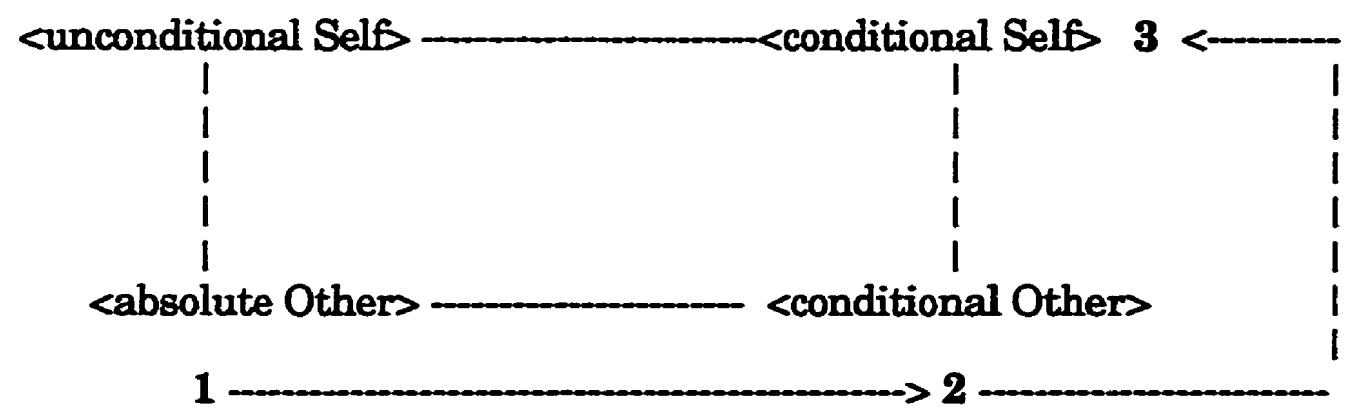

<external> 
In chapters 3 through 8, I have provided several examples of subject positions that have followed this line of incorporation: the Savage to the Indian to the integrated Aboriginal person; the subject of the King of France in Quebec, to the inhabitant of the British colony of Quebec, to the French-Canadian; the Galician, to the leftist Ukrainian, to the Ukrainian-Canadian as epitomal multicultural citizen. These examples show how simple 'hybridity' by itself, or by definition, provides no guarantee of safety from incorporation by state forms, as the movement to sedentary citizenship can be carried out only with the permission of those who already possess an articulation with a state.

To understand why hybridity is not enough, we must note that incorporation also requires a will to incorporation on the part of the citizen herself. This suggests that the line of incorporation can also be followed in reverse, in which case it constitutes what Deleuze and Guattari have called a line of flight, and comprises the process whereby nomads and smiths escape the empire $(3,2,1)$. Taking a line of flight can, and often does, require an individual act of will, since by definition it involves resistance to state striation in all of its modes. Now, if the completion of Canadian multiculturalism requires the involuntary and free play of smiths, if alchemy is forbidden and absurd, and if all lines of flight are guarded by armed sentries, one might think that Canada is doomed to stay forever at its multicultural zero-point. Where, in a place that has always been devoted to order and survival might smiths be found? How could they possibly emerge? Whatever one might have to say about multiculturalism as liberal pluralism, at least it possesses a historical basis in Our History, and therefore a claim to a certain sort of possibility as a guide for the future. But, if one allows one's gaze to shift from those who have constructed Canada to those who have been (unsuccessfully) shoved out of its way, a long and determined line of metallurgists comes into view. Certainly the coureurs de bois were exemplary smiths, operating in an environment in which, at first, every move would have to be 
invented, tried out as an experiment whose failure could be disastrous. (The postmodern sedentary knows this feeling upon having strayed into the wrong part of a decaying megacity, or losing his tour group on a visit to some 'exotic' land.) Day-today life at Hudson's Bay Company trading posts, to the extent that it was not in accord with directives from London, was also full of invention and risk. To the extent that the French and English-Canadian states have treated these hybrid forms as problems to be solved, they have robbed themselves of their own particularity, of precisely what they needed in order to achieve their dreams of identity and unity.

Of course, smiths and nomads are not only figures of the past. The Québecois is without doubt a smith-like identity, having survived the centuries by intelligent adaptation to the English-Canadian environment, tracking the singularities of culture, society, polity, and economy as they have arisen. By abandoning first the (dubious) position of unconditional Self (member of a Founding Race), then that of conditional articulation as a French-Canadian, and by refusing to join the ranks of the Multiple Origins, the Quebécois nationalist opts for a line of flight that becomes easier to follow the more often it is taken. Indeed, in the limiting case of the achievement of Quebec sovereignty, those who have been smiths will again become citizens, and will almost certainly return to their sedentary ways. Many Aboriginal people are still fleeing the Canadian state - not physically now, but semiotically - by refusing the position of integrated Aboriginal-Canadian in favour of membership in a historically located and identified nation. In some cases these nations maintain lines of communication between nomadic and sedentary forms, e.g. through subsistence hunting and gathering from a reserve base combined with cautious capitalism, and thus contain the most interesting long-term possibilities for life within the territories claimed by the Canadian state. It is hardly the case, then, that there are no smiths in Canada; the English-Canadian citizen is actually surrounded by people taking a line of flight from the National Jewel, and this is what makes him so insecure. 
Hypermodern liberal pluralism is without doubt one practice immanent in the history of Canadian diversity. It might serve to assuage English-Canadian anxiety for a time, and will almost certainly ensure the perpetuation of the problem of Canadian diversity. But it isn't the only form that can be seen through the mists and, speaking theoretically, it's far from the most interesting. Hybridity, impurity, and innovation are just as Canadian as 'peace, order and good government', but while the latter have been a source of pride, the former have been shamefully repressed. Canadians have long been flirting with a free emergence theory of identity, but the designerless Mosaic, in which existing particularity would be left free to generate new social, political, and economic forms that might even become hegemonic -- that is, which could not be incorporated by the Canadian state in its current form, and would challenge its very existence -- has never been an option in official Canada. If the modernist nihilism inherent in the project of Canadian unity is to be completed, if the face of the National Jewel is not to become as empty as its center, it is time to take multiculturalism to its logical and historical limits as a state-free emergence theory of identity. Perhaps, after so much worry, Canada will Discover that it has always had an identity after all, as a society of smiths?

1 Of course, taking a line of flight could not allow one to escape all forms of rational bureaucratic domination forever. One could quite easily, for example, leave the face of the Canadian National Jewel only to land on an object created by a Québécois imaginary. I am using this notion simply to point out that there are possibilities other than the 'no identity' or 'state-designed identity' dichotomy that I see being presented in multiculturalism as state policy. 


\section{Abbreviations Used in the Text}

B \& B Report: Canada. Royal Commission on Bilingualism and Biculturalism. (1969) Report of the Royal Commission on Bilingualism and Biculturalism, Ottawa: Supply and Services Canada.

Bagot Report: "Report on the Affairs of the Indians in Canada, Laid Before the Legislative Assembly, March $201845,{ }^{n}$ in Journals of the Legislative Assembly of Canada, 8 Victoria 1844-5, Appendix EEE.

CIHM: Canadian Institute for Historical Microreproductions.

CNW: Oliver, E.H. ed. (1914) The Canadian Northwest: Its Early Development and Legislative Records, Publications of the Canadian Archives No. 9, Ottawa: Government Printing Bureau.

CSY: Canada. Dept. of Agriculture (1886 - 1905) The Statistical Year-Book of Canada, Ottawa: Government of Canada.

Canada. Statistics Canada. (1906 - ) The Canada Year Book, Ottawa: Statistics Canada.

DC\&I: Department of Citizenship and Immigration.

DHC: Canada. Parliament. House of Commons. (1867 - ) Official Report of Debates, the House of Commons, Ottawa: Government of Canada.

DRCHC: Shortt A. and Doughty G. eds. (1907) Documents Relating to the Constitutional History of Canada, Ottawa: King's Printer.

HBRSS: Hudson's Bay Record Society (1938 - ). Hudson's Bay Record Society Series, London: The Champlain Society.

JHC: Canada. Parliament. House of Commons. (1867 - ) Journals of the House of Commons of the Dominion of Canada, Ottawa : Government of Canada.

MCBC: Canada. Department of the Secretary of State. (1987) Multiculturalism ... being Canadian Ottawa: Supply and Services Canada.

MCBCM: Canada. Standing Committee on Multiculturalism. (1987) Multiculturalism: Building the Canadian Mosaic, Ottawa: Supply and Services Canada.

MCWR: Canada. Ministry of State for Multiculturalism and Citizenship (1991) Multiculturalism: What is it Really About? Ottawa: Supply and Services Canada.

NAC: National Archives of Canada. 
NAW: Quinn, D.B. (1979) New American World: A Documentary History of North America to 1612, New York: Amo Press.

PD-NYCD: Paris Documents I. in Documents Relating to the Colonial History of NewYork, Vol XX, CIHM 53992.

Relations: Thwaites, R.G. (1897 - ) The Jesuit Relations and Allied Documents Cleveland: Burrows Brothers.

RSC: Canada. (1985) Revised Statutes of Canada, Ottawa: Government of Canada.

SC: Canada. (1867 - ) Statutes of Canada, Ottawa: Government of Canada.

SPC: Canada. Parliament. (1841 - 1867) Statutes of the Province of Canada, Quebec: Stewart Derbishire \& George Desbarats.

SPHC: Canada. Parliament. (1868 - 1925) Sessional Papers of the Dominion of Canada, Ottawa: Government of Canada.

StatsCan: Canada. Statistics Canada. 


\section{Bibliography}

Adachi, K. (1976) The Enemy that Never Was: A History of the Japanese Canadians, Toronto: McLelland and Stewart.

Adams, H. (1995) A Tortured People: The Politics of Colonization, Penticton BC: Thetus Books.

--. (1989) Prison of Grass: Canada from a Native Point of View, Saskatoon: Fifth House Publishers.

Adorno. T. and Horkheimer, M. (1995) The Dialectic of Enlightenment, New York: Continuum.

Akins, T.B. (1972) Papers Relating to the Acadian French 1714 - 1755, Cottonport Louisiana: Polyanthos.

- (1849) A sketch of the rise and progress of the Church of England in the British North American Provinces, Halifax: W. Cunnabell.

Allen, R. (1971) The Social Passion: Religion and Social Reform in Canada 1914-28, Toronto: University of Toronto Press.

Anderson, B. (1991) Imagined Communities, London: Verso.

Anderson, J.T.M. (1918) The Education of the New Canadian: A treatise on Canada's greatest educational problem, Toronto: J.M. Dent.

Angus, H.F. (1934) "Canadian Immigration: The Law an its Administration," in The American Journal of International Law, 28:1.

Angus, I. (1997) A Border Within: National Identity, Cultural Plurality, and Wilderness, Montreal \& Kingston: McGill-Queen's Press.

-. (1988a) (ed) Ethnicity in a Technological Age, Edmonton: Canadian Institute of Ukrainian Studies.

-. (1988b) "Oral Tradition as Resistance," in M. Lupul (ed) Continuity and Change: The Cultural Life of Alberta's First Ukrainians, Edmonton: Canadian Institute of Ukrainian Studies.

Angus Reid Group. (1991) Multiculturalism and Canadians: Attitude Survey 1991, Hull: Multiculturalism and Citizenship Canada.

Antonides, H. (1985) Stones for Bread: The Social Gospel and its Contemporary Legacy, Jordan Station, Ontario: Paideia Press.

Archer, A. (1875) A History of Canada for the Use of Schools, London: Nelson \& Sons. 
Aristotle. (1981) Politics, Harmondsworth: Penguin.

Armour, L. (1981) The Idea of Canada and the Crisis of Community, Ottawa: Steel Rail.

Arsenault, B. (1966) History of the Acadians, Montreal: Le Conseil de la vie francaise en Amérique.

Augustine, St. (1972) Concerning the City of God against the Pagans, Harmondsworth: Penguin.

Avery, D. (1995) Reluctant Host: Canada's Response to Immigrant Workers, 1896 1994, Toronto: McLelland \& Stewart.

-. (1979) Dangerous Foreigners: European Immigrant Workers and Labour Radicalism in Canada 1896 - 1932, Toronto: McLelland and Stewart.

Bailey, A.G. (1969) The Conflict of European and Eastern Algonkian Cultures 1504 1700, Toronto: University of Toronto Press.

Bakhtin, M. (1984) Problem of Dostoevsky's Poetics, Minneapolis: University of Minnesota Press.

Bannerji, H. (1996) "On the Dark Side of the Nation: Politics of Multiculturalism and the State of 'Canada'," Journal of Canadian Studies 31:3.

-. (ed) (1993) Returning the Gaze, Toronto: Sister Vision Press.

Barth, F. (ed) (1969) Ethnic Groups and Boundaries: The Social Organization of Cultural Difference, London: Allen and Unwin.

Bartholomaeus. (1975) On the Properties of Things: John Trevista's translation of Bartholomaeus Anglicus De Proprietatabus Rerum, Volume II, Oxford: Clarendon Press.

Bartlett, R. (1990) Indian Reserves and Aboriginal Lands in Canada, Saskatoon: University of Saskatchewan Native Law Centre.

Baudrillard, J. (1990) Fatal Strategies, New York: Semiotext(e).

-. (1988) The Ecstasy of Communication, New York: Semiotext(e).

-.. (1983a) Simulations, New York: Semiotext(e).

-. (1983b) In the Shadow of the Silent Majorities, New York: Semiotext(e).

Bauman, Z. (1992) Intimations of Postmodernity, London: Routledge.

-. (1987) Legislators and Interpreters, New York: Cornell University Press. 
Begg, A. (1871) The Creation of Manitoba; or, A History of the Red River Troubles, Toronto: A.H. Hovey.

Berger, C. (1970) The Sense of Power: Studies in the Ideas of Canadian Imperialism 1867 - 1914, Toronto: University of Toronto Press.

Berger, T. (1991) A Long and Terrible Shadow, Vancouver: Douglas and McIntyre.

Bergeron, L. (1975) The History of Quebec, A Patriote's Handbook, Toronto: NC Press.

Berry, J. et al (1977) Multiculturalism and Ethnic Attitudes in Canada Ottawa: Supply \& Services Canada.

Bhabha, H. (1994) The Location of Culture, London: Routledge.

-. (ed) (1991) Nation and Narration, London: Routledge.

Bibby, R. (1990), Mosaic Madness Toronto: Stoddart.

Biggar, H.P. (ed) (1925) The Works of Samuel de Champlain, Toronto: The Champlain Society.

-. (ed) (1911) The Precursors of Jacques Cartier, Ottawa: Government Printing Bureau.

Bilde, P. (ed) (1911) The Precursors of Jacques Cartier 1497 - 1534, Ottawa: Government Printing Bureau.

Bishop, C.A. (1976) "Henley House Massacres," in The Beaver 307:2, Winnipeg: Hudson's Bay Company.

Bissoondath, N. (1994) Selling Illusions: The Cult of Multiculturalism in Canada, Toronto: Penguin.

Bolaria, B. and Li, P. (1985) Racial Oppression in Canada, Toronto: Garamond Press.

Booth, W. (1961) The Rhetoric of Fiction, Chicago: University of Chicago Press.

Bourdieu, P. (1992) An Invitation to Reflexive Sociology, Chicago: University of Chicago Press.

-. (1990) In Other Words: Essays Towards a Reflexive Sociology, Stanford: Stanford University Press.

-. (1988) "Vive La Crise" in Theory \& Society 17:773-78.

--. (1984) Distinction, Chicago: University of Chicago Press. 
--. (1977) Outline of a Theory of Practice, Cambridge, Mass: Harvard University Press.

Brotz, H. (1980) "Multiculturalism in Canada: A Muddle," in Canadian Public Policy 6(1).

Brown, J. (1980) Strangers in Blood: Fur Trade Company Families in Indian Country, Vancouver: University of British Columbia Press.

--. and Peterson, J. (eds) (1985) The New Peoples: Being and Becoming Métis in North America, Lincoln: University of Nebraska Press.

Brown, R.C. and Cook, R. (1974) Canada 1896 - 1921: A Nation Transformed, Toronto: McLelland and Stewart.

Bryce, G. (1968) The Remarkable History of the Hudson's Bay Company, New York: Burt Franklin.

Buchignani, N. (1982) "Canadian Ethnic Research and Multiculturalism," in Journal of Canadian Studies 17:1.

Buchignani, N. and Engel, J. (1983) Cultures in Canada: Strength in Diversity, Edmonton: Weigl Educational Publishers Inc.

Burrage, H.S. (1930) Early English and French Voyages Chiefly from Hakluyt 15341608, New York: Scribners.

Burnet, J. (1975) "The Policy of Multiculturalism within a Bilingual Framework: An Interpretation, in A. Wolfgang (ed) Education of Immigrant Students: Issues and Answers, Toronto: OISE.

Butler, J. (1990) Gender Trouble, London: Routledge.

Cambel, A.B. (1993) Applied Chaos Theory: A Paradigm for Complexity, Boston: Academic Press.

Canada. (1969) Statement of the Government of Canada on Indian Policy, 1969, Ottawa: Queen's Printer.

-. (1891) Indian Treaties and Surrenders from 1680 to 1890, Ottawa: Queen's Printer.

-. (1876) Description of the Country Between Lake Superior and the Pacific Ocean, on the line of the Canadian Pacific Railway, Ottawa: Government of Canada, in History of the Canadian Northwest Microfilm Series, Reel 5, PNW 362. 
--. (1858) Report on the Exploration of the Country between Lake Superior and the Red River Settlement, Toronto: John Lovell, in History of the Canadian Northwest Microfilm Series, Reel 5, PNW 361.

Canada. Dept. of Agriculture (1886 - 1905) The Statistical Year-Book of Canada, Ottawa: Government of Canada.

Canada. Dept. of Citizenship and Immigration. (1953 - 1965) Report, issued yearly, Ottawa: King's Printer.

--. (1951b) Report of the Department of Citizenship and Immigration for the Fiscal Year Ended March 31, 1951, Ottawa: King's Printer.

-. (1951a) Report of the Department of Citizenship and Immigration for the Fiscal Year Ended March 31, 1950, Ottawa: King's Printer.

Canada. Dept. of Citizenship and Immigration. Canadian Citizenship Branch. (1961) Our History, Ottawa: Queen's Printer.

---. (1960) Notes on the Canadian Family Tree, Ottawa: Queen's Printer.

Canada. Dept. of Citizenship and Immigration. Integration Branch. (1996) A Look at Canada, Ottawa: Queen's Printer.

Canada. Dept. of Employment and Immigration. (1991) Guidelines for the Immigrant Investor Program, Ottawa: Supply and Services Canada.

-. (1985) The revised selection criteria for independent immigrants, Ottawa: Supply and Services Canada.

Canada. Dept. of Manpower and Immigration. (1966) White Paper on Immigration, Ottawa: Minister of Government Services.

Canada. Dept. of National War Services. (1940) A Call to Canadian Unity, Ottawa: Director of Public Information.

Canada. Dept. of the Secretary of State. (1946 - 1949) Report, Ottawa: King's Printer.

Canada. Dept. of the Secretary of State. Canadian Citizenship Branch. (1967) The Canadian Family Tree, Ottawa: Queen's Printer.

Canada. Dept. of the Secretary of State. Multiculturalism Directorate. (1979) The Canadian Family Tree: Canada's People's, Ottawa: Queen's Printer.

Canada. Dominion Bureau of Statistics. (1951) Ninth Census of Canada, 1951, Instructions for Enumerators, Ottawa: King's Printer.

--. (1936) Seventh Census of Canada, 1931, Summary (v. 1), Ottawa: King's Printer. 
Canada. House of Commons. Special Committee on the Participation of Visible Minorities in Canadian Society. (1984) Equality Now! Report of the Special Committee on Visible Minorities in Canadian Society, Ottawa: Supply and Services Canada.

Canada. Ministry of State for Multiculturalism and Citizenship (1991) Multiculturalism: What is it Really About? Ottawa: Supply and Services Canada.

Canada. Parliament. (1865) Parliamentary Debates on the Subject of the Confederation of the British North American Provinces, Quebec: Hunter, Rose \& Co.

Canada. Privy Council (1939) Defence of Canada Regulations, Ottawa: King's Printer.

Canada. Royal Commission on Bilingualism and Biculturalism. (1973) Bilingualism and Biculturalism: An Abridged version of the Royal Commission Report, $\mathrm{R}$. Innis (ed), Toronto: McLelland and Stewart.

--. (1969) Report, Ottawa: Supply and Services Canada.

--. (1965) Preliminary Report, Ottawa: Supply and Services Canada.

Canada. Standing Committee on Multiculturalism. (1987) Multiculturalism ... Building the Canadian Mosaic, Ottawa: Supply and Services Canada.

Canada. Statistics Canada. (1996) Canadian Economic Observer Historical Statistical Supplement, 1995/1996, Ottawa: Minister of Industry, Statistics Canada Catalogue no. 11-010-XPB.

--. (1993) Ethnic Origin, 1991 Census of Canada, Ottawa: Industry, Science, and Technology Canada, Statistics Canada Catalogue no. 93-315.

-. (1989) Ethnicity, Immigration, and Citizenship, 1986 Census of Canada, Ottawa: Minster of Supply and Services, Statistics Canada Catalogue no. 93-109.

-. (1906 - ) The Canada Year Book, Ottawa: Statistics Canada.

-. (1887) Census of Manitoba, 1885-6, Ottawa, Statistics Canada Catalogue no. 98$1886 \mathrm{~F}$.

Canadian Club of Vancouver. (1907) Addresses Delivered Before the Canadian Club of Vancouver, Vancouver: Canadian Club of Vancouver.

Canadian Historical Publishing Co. (1888) The New West: Wealth and Growth, Winnipeg: Canadian Historical Publishing Co. in History of the Canadian Northwest Microfilm Series, Reel 12, PNW 440. 
Cardinal, H. (1969) The Unjust Society, Edmonton: M.G. Hurtig Ltd.

Cardozo, M. and Musto L. (eds) (1997) The Battle Over Multiculturalism: Does it help or hinder Canadian unity?, Ottawa: Pearson - Shoyama Institute.

Castoriadis, C. (1987) The Imaginary Institution of Society, Baltimore: Johns Hopkins.

Cell, G. (1982) Newfoundland Discovered: English Attempts at Colonisation, 16101630, London: Hakluyt Society.

Chapais, T. (1964) The Great Intendant, Toronto: University of Toronto Press.

Charlevoix, P.F.X (1870) History and General Description of New France, J. Shea tr., Chicago: Loyola University Press.

Chatterjee, P. (1993) The Nation and its Fragments, Princeton: Princeton University Press.

Clark, W. (ed.) (1904) Empire Club Speeches, Toronto: William Briggs.

Clifton, R. and Roberts, L. (1981) "Exploring the Ideology of Canadian Multiculturalism," in Canadian Public Policy, 8(1).

Cockloft, J. (1960) Cursory Observations Made in Quebec, 1811, Toronto: Oxford University Press.

Colby, C. (1908) Canadian Types of the Old Regime, New York: Henry Holt.

Cole, C.W. (1964) Colbert and a Century of French Mercantilism, Hamden, Connecticut: Archon Books.

Collins, D. (1987) Immigration: Parliament vs. the People, 2nd edition, Toronto: Citizens for Foreign Aid Reform.

-. (1979) Immigration: The Destruction of English Canada, Richmond Hill: BMG Publishing.

Columbus, C. (1961) Four Voyages to the New World, New York: Corinth Books.

Connor, R. (1909) The Foreigner, Toronto: The Westminster Company.

Connor, W. (1994) Ethnonationalism, Princeton: Princeton University Press.

Conseil de la vie française en Amerique. (1967) Nothing More, Nothing Less: A FrenchCanadian View of Bilingualism and Biculturalism, Toronto, Montreal: Holt Rinehart. 
Cook, R. (1993) The Voyages of Jacques Cartier, Toronto: University of Toronto Press.

- (1985) The Regenerators: Social Criticism in Late Victorian English Canada , Toronto: University of Toronto Press.

Craig, G.M. (1963) Upper Canada: The Formative Years 1784 - 1841, Toronto: McLelland \& Stewart.

Creighton, D. (1966) "The Myth of Biculturalism or The Great French-Canadian Sales Campaign," in Saturday Night, Sept. 1966, 35 - 39.

-.. (1955) John A. Macdonald: The Old Chieftain, Toronto: Macmillan.

Cruikshank, E.A. (1923) The Correspondence of Lieut. Governor John Graves Simcoe, Toronto: Ontario Historical Society.

Cumming, P. and Mickenburg, N. (eds) (1972) Native Rights in Canada, Toronto: Indian-Eskimo Association of Canada, in association with General Publishing.

Dahlie, J. and Fernando, T. (eds) (1981) Ethnicity, Power, and Politics in Canada, Toronto: Methuen.

Dawson, R.A.M. (1870) Our Strength and Their Strength: The North West Territory, Ottawa: Times Office.

De Landa, M. (1991) War in the Age of Intelligent Machines, New York: Zone Books.

Deleuze, G. and Guattari, F. (1988) A Thousand Plateaus: Capitalism and Schizophrenia, London: Athlone.

-. (1986) Nomadology: The War Machine, New York: Semiotext(e).

Derrida, J. (1982) "Différance," in Margins of Philosophy, Chicago: University of Chicago Press.

--. (1976) of Grammatology, Cambridge: Polity Press.

Dench, E. (1995) From Barbarians to New Men: Greek, Roman, and Modern Perceptions of Peoples of the Central Apennines, Oxford: Clarendon.

Dickason, O. (1984) The Myth of the Savage and the Beginnings of French Colonialism in the Americas, Edmonton: University of Alberta Press.

Diubaldo, R. (1985) The Government of Canada and the Inuit 1900 - 1967, Ottawa: Department of Indian and Northern Affairs.

Dreisziger, N.F. (1988) "The Rise of a Bureaucracy for Multiculturalism: The Origins of the Nationalities Branch, 1939 - 1941," in On Guard for Thee: War, 
Ethnicity, and the Canadian State, 1939 - 1945, Ottawa: Ministry of Supply and Services.

Driedger, L. (1996) Multi-Ethnic Canada: Identities \& Inequalities, Toronto: Oxford University Press.

duBois, P. (1991) Centaurs and Amazons: Women and the Pre-History of the Great Chain of Being, Ann Arbor: University of Michigan Press.

Dyck, N. (1991) What is the Indian Problem: Tutelage and Resistance in Canadian Indian Administration, St. John's: ISER.

Dyke, C. (1988) The Evolutionary Dynamics of Complex Systems: A Study in Biosocial Complexity, New York: Oxford.

Eccles, W.J. (1969) The Canadian Frontier 1534-1760, Montreal: Holt Rinehart.

--. (1966) The Ordeal of New France, Montreal: Canadian Broadcasting Service.

Elliot, J.L. \& Fleras A. (1992) Unequal Relations: An Introduction of Race and Ethnic Dynamics in Canada, Scarborough: Prentice Hall.

England, R. (1980) Living, Learning, Remembering: Memoirs of Robert England, Vancouver: Centre for Continuing Education.

--. (1929) The Central European Immigrant in Canada, Toronto: Macmillan.

Ferguson, T. (1975) A White Mans' Country: An Exercise in Canadian Prejudice, Toronto: Doubleday.

Fisher, R. (1988) "The Image of the Indian," in K. Coates, K. and R. Fisher (eds) (1988) Out of the Background, Toronto: Copp Clark.

Foster, K. (1926) Our Canadian Mosaic, Toronto: YWCA.

Foster, W. (1890) Canada First, Toronto: Hunter, Rose and Co.

Foucault, M. (1985) "Nietzsche, Genealogy, History," in P. Rabinow (ed) The Foucault Reader, New York: Pantheon Books.

-. (1982) "The Subject and Power," in H.L. Dreyfus and P. Rabinow (eds), Michel Foucault: Beyond Structuralism and Hermeneutics, Sussex: The Harvester Press.

-. (1980) "Truth and Power," in Power/Knowledge: Selected Interviews and Other Writings 1972-1977, C. Gordon (ed.) New York: Pantheon Books.

-. (1979) Discipline and Punish: the Birth of the Modern Prison, Hammondsworth: Penguin. 
--. (1978) The History of Sexuality Volume I, New York: Vintage.

--. (1972) The Archaeology of Knowledge, New York: Random House.

-. (1970) The Order of Things, New York: Random House.

Francis, D. \& Morantz, T. (1983) Partners in Furs: A History of the Fur Trade in Eastern James Bay 1600 - 1870, Kingston \& Montreal, McGill-Queen's University Press.

Fraser, B.J. (1988) The Social Uplifters: Presbyterian Progressives and the Social Gospel in Canada, 1875 - 1915, Waterloo: Wilfrid Laurier University Press.

Frideres, J. (1992) "Changing Dimensions of Ethnicity in Canada," in V. Satzewich (ed) Deconstructing a Nation: Immigration, Multiculturalism and Racism in 90's Canada, Halifax: Fernwood.

Friedman, J.B. (1981) The Monstrous Races in Medieval Art and Thought, Cambridge, Mass and London: Harvard University Press.

Gagnon, S. (1982) Quebec and its Historians 1840 to 1920, Montreal: Harvest House.

Gans, H. (1979)"Symbolic Ethnicity: The Future of Ethnic Groups and Cultures in America," in Ethnic and Racial Studies 2:1, 1-20.

Garneau, F.X. (1874) History of Canada, from the time of its discovery till the union year 1840-41, Montreal: John Lovell, CIHM 12525.

Gates, L.F. (1968) Land Policies of Upper Canada, Toronto: University of Toronto Press.

Geertz, C. (1986) "Distinguished Lecture: Anti Anti-Relativism," American Anthropologist, 86(2).

Gellner, E. (1983) Nations and Nationalism, Oxford: Basil Blackwell.

Georges, P. (1994) Barbarian Asia and the Greek Experience: From the Archaic Period to the Age of Xenophon, Baltimore and London: Johns Hopkins University Press.

Gibbon, J.M. (1938) Canadian Mosaic: The Making of a Northern Nation, Toronto: McLelland and Stewart.

Gleick, J. (1987) Chaos: Making a New Science, New York: Viking.

Goerner, S. (1994) Chaos and the Evolving Ecological Universe, Langhorne, PA: Gordon and Breach. 
Goldberg, T. (1993) Racist Culture: Philosophy and the Politics of Meaning, Oxford \& Cambridge: Blackwell.

Gosse, R. et. al. (1994) Continuing Poundmaker and Riel's Quest, Saskatoon: Purich Publishing.

Grant, G. (1969) Technology and Empire: Perspectives on North America, Toronto: Anansi.

Great Britain. Parliament. House of Commons. (1857) Report from the Select Committee on the Hudson's Bay Company, CHHM 48795.

Gregorovich, J. B. (1983) Ukrainian Canadians in Canada's Wars: Materials for Ukrainian Canadian History, Volume I, Toronto: Ukrainian Canadian Research Foundation.

Green, B. (1983) Knowing the Poor, Boston: Routledge.

Green, V. (1996) A New History of Christianity, New York: Continuum.

Greenfeld, L. (1992) Nationalism: Five Roads to Modernity, Cambridge: Harvard Press.

Greimas, A.J. (1987) On Meaning, London: Pinter.

Griffiths, N.E.S. (1969) The Acadian Deportation: Deliberate Perfidy or Cruel Necessity?, Toronto: Copp Clark.

Gusfield, J. (1981) The Culture of Public Problems: Drinking-Driving and the Symbolic Order, Chicago: University of Chicago Press.

Haarhoff, T.J. (1948) The Stranger at the Gate: Aspects of Exclusiveness and Cooperation in Ancient Greece and Rome, with some Reference to Modern Times, Oxford: Basil Blackwell.

Habermas, J. (1991) Moral Consciousness and Communicative Action, Cambridge: MIT Press.

-. (1989) The Theory of Communicative Action, Boston: Beacon Press.

Hakluyt, R. (1907) The principal navigations, voyages, traffiques and discoveries of the English nation, London: J.M. Dent.

Hale, Sir M. (1677) The Primitive Origination of Mankind, Considered and Examined according to the Light of Nature, London: William Bodgid.

Hall, D.J. (1981) Clifford Sifton. Volume One: The Young Napoleon 1861 - 1900, Vancouver: University of British Columbia Press. 
Hall, E. (1989) Inventing the Barbarian: Greek Self-Definition through Tragedy, Oxford: Clarendon Press.

Hall, S. (1991) "Cultural Identity and Diaspora" in Colonial Discourse and PostColonial Theory: A Reader, New York, London: Harvester Wheatsheaf.

-. (1987) "Minimal Selves" in Identity: The Real Me, London: ICA.

Halli, S. et al. (eds) (1990) Ethnic Demagraphy: Canadian Immigrant, Racial, and Cultural Variations, Ottawa: Carleton University Press.

Harvey, D.C. (1936) The Colonization of Canada, Toronto: Clarke, Irwin \& Co.

Hawkes, A. (1919) The Birthright: A Search for the Canadian Canadian and the Larger Loyalty, Toronto: J.M. Dent.

Hayles, N.K. (1990) Chaos Bound, Ithaca \& London: Cornell University Press.

Hayward, V. (1922) Romantic Canada, Toronto: Macmillan.

Heidegger, M. (1958) The Question of Being, New Haven, Conn.: College and University Press.

Henderson, W.B. (1980) Canada's Indian Reserves: Pre-Confederation, Ottawa: Ministry of Indian Affairs and Northern Development.

Herodotus. (1954) The Histories, Harmondsworth: Penguin.

Higham, N. J. (1989) "Roman and Native in England North of the Tees: Acculturation and its Limitations," in J. Barret et al (eds) Barbarians and Romans in North-West Europe from the later Republic to late Antiquity, Oxford: B.A.R.

Hilgarth, J. N. (1986) Christianity and Paganism, 350 - 750: The Conversion of Western Europe, Philadelphia: University of Pennsylvania Press.

Hiller, H. (1996) Canadian Society: A Macro Analysis, Scarborough: Prentice Hall.

Hind, H.Y. (1859) Northwest Territory. Reports of Progress; Together with a Preliminary and General Report on the Assiniboine and Saskatchewan Exploring Expedition, Toronto: John Lovell, by order of the Legislative Assembly of the Province of Canada.

Hippocrates (1923) “Airs, Waters, Places" in Hippocrates Vol. 1, Harvard \& London: Harvard University Press.

Hobsbawm, E. J. (1992) Nations and Nationalism Since 1780, New York: Cambridge Press. 
Hodgen, M. (1964) Early Anthropology in the 16th and 17th Centuries, Philadelphia: University of Pennsylvania Press.

Hopkins, J.C. (1912) The Story of Our Country, Toronto: John C. Winston Co.

--. (ed) (1911) Empire Club Speeches, Toronto: Saturday Night Press.

--. (ed) (1910) Empire Club Speeches, Toronto: Warwick Bros. \& Rutter.

Howley, J.P. (1974) The Beothucks or Red Indians: The Aboriginal Inhabitants of Newfoundland, Toronto: Coles Publishing Co.

Hudson's Bay Record Society. (1965) Letters from Hudson Bay 1703-40, ed K.G.

Davies, London: Hudson's Bay Record Society (v. 25).

--. (1957) Copy Booke of Letters Commissions Instructions Outward, 1688 - 1696, London: Hudson's Bay Record Society (v. 20).

-(1951) Cumberland and Hudson House Journals 1775 - 82, London: Hudson's Bay Record Society (v. 14).

-- (1948) Copy-Book of Letters Outward \&c, 1680 - 1687, London: Hudson's Bay Record Society (v. 11).

- (1946) Minutes of the Hudson's Bay Company 1679 - 1684, London: Hudson's Bay Record Society (v. 9).

Hughes, D.R. and Kallen, E. (eds) (1974) The Anatomy of Racism: Canadian Dimensions, Montreal: Harvest House.

Humphreys, S.C. (1978) Anthropology and the Greeks, London: Routledge.

Hutcheon, L. (1988) The Canadian Postmodem: A Study of Contemporary EnglishCanadian Fiction, Toronto: Oxford University Press.

Hryniuk, S. and Luciuk, L. (1993) Multiculturalism and Ukrainian Canadians, Polyphony Series Volume 13, Toronto: University of Toronto Press.

Ignatieff, M. (1993) Blood and Belonging, Toronto: Penguin.

Isaacs, H. (1975) Idols of the Tribe, New York: Harper \& Row.

Jaenen, C.J. (1991) "French Sovereignty and Native Nationhood during the French Régime," in JR. Miller (ed) Sweet Promises: A Reader on Indian-White Relations in Canada, Toronto: University of Toronto Press.

Jenson, J. (1993) "Naming Nations: Making nationalist claims in Canadian public discourse," in Canadian Review of Sociology and Anthropology, 30:3. 
Kallen, E. (1982) "Multiculturalism: Ideology, Policy, and Reality," Journal of Canadian Studies, 17:1, 51 - 63.

Kelly, E. (1974) Murder for Fun, Cobalt, Ontario: Highway Book Shop.

Kingsford, W. (1968) [1887] The History of Canada, Vol. III, New York: AMS Press.

Kirkconnell, W. (1967) A Slice of Canada:Memoirs, Wolfville, N.S.: published for Acadia University by University of Toronto Press.

-. (1943) "Our Communists and the New Canadians," address delivered before the Canadian Club of Toronto, Feb. 1 1943, Toronto: Southam Press.

--. (1941) Canadians All: A Primer of Canadian National Unity, Ottawa: Director of Public Information.

Kirke, H. (1871) The First English Conquest of Canada, London: Bemrose and Sons.

Knowles, V. (1997) Strangers at Our Gates: Canadian Immigration and Immigration Policy, 1540 - 1997, Toronto: Dundurn Press.

Kymlicka, W. (1995) Multicultural Citizenship: A Liberal Theory of Minority Rights, Oxford: Clarendon Press.

-. (1989) Liberalism, Community and Culture, Oxford: Clarendon Press.

Labaree, L.W. (1967) Royal Instructions to the British Governors 1670 - 1776, New York: Octagon Books.

Lacan, J. (1981) The Four Fundamental Concepts of Psycho-analysis, New York: Norton.

-. (1968) Speech and Language in Psychoanalysis, Baltimore: Johns Hopkins University Press.

Laclau, E. (1996) Emancipations, London: Verso.

-. and Mouffe, C. (1985) Hegemony and Socialist Strategy, London: Verso.

Lacombe, D. (1996) "Reforming Foucault: a critique of the social control thesis," British Journal of Sociology, 47:2, 332 - 352.

Lafitau, Father J.F. (1974) Customs of the American Indians Compared with the Customs of Primitive Times, Toronto: The Champlain Society.

Lahontan, Baron de. (1940) The Oakes Collection: New Documents by Lahontan, concerning Canada and Newfoundland, Ottawa: J. O. Patenaude, Printer to the King's Most Excellent Majesty. 
-. (1703) New Voyages to North America, London: H. Bonwicke, CIHM 37429.

Lakoff, G. and Johnson, M. (1980) Metaphors We Live By, Chicago: University of Chicago Press.

Légaré, E. I. (1995) "Canadian Multiculturalism and Aboriginal People: Negotiating a Place in the Nation, ${ }^{n}$ in Identities 1(4), 347 - 366.

Lehmann, H. (1986) The German Canadians 1750 - 1937: Immigration, Settlement \& Culture, St. John's: Jesperson Press.

Lescarbot, M. (1907 [1618]) The History of New France, Toronto: The Champlain Society.

Leslie, J. and Maguire, R. (eds) (1978) The Historical Development of the Indian Act, Ottawa: Ministry of Indian Affairs and Northern Development, 2nd edition.

Levitt, J. (1970) Henri Bourassa on Imperialism and Bi-culturalism, 1900 - 1918, Toronto: Copp Clark.

-. (1969) Henri Bourassa and the Golden Calf: The Social Program of the Nationalists of Quebec (1900 - 1914), Ottawa: Les Éditions de l'université d'Ottawa.

Lewin, R. (1992) Complexity: Life at the Edge of Chaos, New York: Macmillan.

Lewycky, L. (1992) "Multiculturalism in the 1990s and into the 21st Century: Beyond Ideology and Utopia," in V. Satzewich (ed) Deconstructing a Nation: Immigration, Multiculturalism, and Racism in 90's Canada, Halifax: Fernwood.

Li, P. (1990) Race and Ethnic Relations in Canada, Toronto: Oxford University Press.

London Times (1886) A Canadian Tour: A Reprint of Letters from the Special Correspondent of the Times, London: G.E. Wright, in History of the Canadian Northwest Microfilm Series, Reel 5, PNW 363.

Long, T. (1986) Barbarians in Greek Comedy, Carbondale and Edwardsville: Southern Illinois University Press.

Lovejoy, A. O. (1936) The Great Chain of Being: A Study of the History of an Idea, Cambridge, Mass.: Harvard University Press.

Lower, A.M. (1946) Colony to Nation: A History of Canada, Don Mills, Ont.: Longmans Canada.

Lucas, C. (1912) Lord Durham's Report on the Affairs of British North America, New York: Augustus M. Kelly. 
Luciuk, L. (ed) (1994) Righting an Injustice: The Debate Over Redress or Canada's First National Internment Operations, Toronto: The Justinian Press.

-. (1988) A Time for Atonement: Canada's First National Internment Operations and the Ukrainian Canadians, Kingston: Limestone Press.

Lupul, M. (1993) “A Question of Identity: Canada's Ukrainians and Multiculturalism," in Polyphony 13, 8 - 13.

--. (1982) "The Political Implementation of Multiculturalism," Journal of Canadian Studies, 17:1, 93 - 102.

-.. (ed) (1978) Ukrainian Canadians, Multiculturalism, and Separatism: An Assessment, Edmonton: The University of Alberta Press.

Lyotard, J.-F. (1984) The Postmodern Condition, Minneapolis: University of Minnesota Press.

MacBeth, R.G. (1912) Our Task in Canada, Toronto: The Westminster Co.

MacDonald, N. (1966) Canada: Immigration and Colonization 1841 - 1903, Toronto: Macmillan.

-- (1939) Canada, 1763 - 1841 Immigration and Settlement, Toronto: Longmans, Green and Co.

Major, R.H. (ed) (1961) Christopher Columbus: Four Voyages to the New World, Letters and Selected Documents, New York: Corinth Books.

Manning, H.T. (1962) The Revolt of French Canada 1800 - 1835, London: Macmillan.

Marshall, I. (1996) A History and Ethnography of the Beothuk, Montreal \& Kingston: McGill-Queen's University Press.

-. (1989) Reports and Letters by George Christopher Pulling, Relating to the Beothuk Indians of Newfoundland, St. John's: Breakwater Press.

Martin, J. (1972) The Durham Report and British Policy: A Critical Essay, Cambridge: Cambridge University Press.

Martin, R. M. (1837) Colonial Policy of the British Empire, London: Gilbert \& Rivington, CIHM 36870.

Maseres, F. (1772) Collection of several commissions and other public proclamations proceeding from His Majesty..., London: W. \& J. Richards.

Mauss, M. (1967) The Gift: Forms and Functions of Exchange in Archaic Societies, New York: Norton. 
McLean, D. (1987) Home from the Hill: A History of the Métis in Western Canada, Regina: Gabriel Dumont Institute.

McLellan, J. and Richmond, A. (1994) "Multiculturalism in Crisis: a postmodern perspective on Canada," in Ethnic and Racial Studies 17:4, 662-83.

McNaught, K. (1959) A Prophet in Politics, Toronto: University of Toronto Press.

McRoberts, K. and Monahan, P. (1993) The Charlottetown Accord, the Referendum, and the Future of Canada, Toronto: University of Toronto Press.

Mealing, S.R. (ed) (1963) The Jesuit Relations and Allied Documents: A Selection, Toronto: McLelland \& Stewart.

Melnycky, P. (1983) "The Internment of Ukrainians in Canada," in Frances Swyripa and J.H. Thompson (eds) Loyalties in Conflict: Ukrainians in Canada During the Great War, Edmonton: Canadian Institute of Ukrainian Studies.

Miller, J.R. ed. (1991) Sweet Promises: A Reader on Indian-White Relations in Canada, Toronto: University of Toronto Press.

-. (1989) Skyscrapers Hide the Heavens: A History of Indian-White Relations in Canada, Toronto: University of Toronto Press.

Millot, B. (1988) "Symbol, Desire, and Power," in Theory, Culture \& Society, Vol. 5, $675-694$.

Minh-ha, Trinh T. (1991) When the Moon Waxes Red, New York: Routledge.

Monk, J. (1789) State of the present form of government of the province of Quebec, London: J. Debrett, CIHM 38007.

Moodley, K (1983) "Canadian Multiculturalism as Ideology," in Ethnic and Racial Studies 6(3), 320 - 331.

Morton, A.S. (1973) A History of the Canadian West to 1870-71, Toronto: University of Toronto Press.

Mouffe, C. (1993) "Feminism, Citizenship, and Radical Democratic Politics," in L. Nicholson and S. Seidman (eds) Social Postmodernism, Cambridge: Cambridge University Press.

Neilsen, G. and Jackson, J. (1991) "Cultural studies, a sociological poetics: institutions of the Canadian imaginary," in Canadian Review of Sociology and Anthropology, 28:2.

Newman, P. (1985) Company of Adventurers, Markham Ontario: Viking.

Nietzsche, F. (1969) Thus Spoke Zarathustra, Harmondsworth: Penguin. 
-. (1967a) On the Genealogy of Morals, New York: Random House.

-.. (1967b) The Will To Power, New York: Random House.

--. (1967c) Ecce Homo, New York: Random House.

Nish, C. (1966) The French Canadian 1759 - 1766: Conquered? Half-Conquered? Liberated?, Toronto: Copp Clark.

Norris, J. (ed) (1971) Strangers Entertained: A History of the Ethnic Groups of British Columbia, Vancouver: British Columbia Centennial 71 Committee.

Norriss, W. (1875) The Canadian Question, Montreal: Lovell Printing and Publishing Co.

Nunavut Constitutional Forum. (1983) Building Nunavut, Ottawa: The Forum.

Nute, G.L. (1943) Caesars of the Wilderness, New York: D. Appleton.

-. (1935) "Radisson and Groseilliers' Contribution to Geography," in Minnesota History 16: 414-426.

Oliver, E.H. (ed) (1914) The Canadian Northwest: Its Early Development and Legislative Records, Publications of the Canadian Archives No. 9, Ottawa: Government Printing Bureau.

Onufrijchuk, R. (1988) "Post-modern or Perednovok: Deconstructing Ethnicity," in I. Angus (ed) Ethnicity in a Technological Age, Edmonton: Canadian Institute of Ukrainian Studies.

Optima Consultants in Applied Social Research Inc. (1988) Analysis of Thompson Lightstone Survey of Public Attitudes Towards Multiculturalism, Ottawa: Secretary of State, Multiculturalism.

Osborn, H.F. (1929) From the Greeks to Darwin: The Development of the Evolution Idea through Twenty-Four Centuries, New York: Scribners.

Ostergard, U. (1992) "What is National and Ethnic Identity?" in P. Bilde (ed) Ethnicity in Hellenistic Egypt, Aarhus: Aarhus University Press.

Ouellet, F. (1980) Lower Canada 1791 - 1840: Social Change and Nationalism, Toronto: McLelland \& Stewart.

Palmer, H. (1991) Ethnicity and Politics in Canada Since Confederation, Ottawa: Canadian Historical Association.

-. (1982a) Patterns of Prejudice: A History of Nativism in Alberta, Toronto: McLelland and Stewart. 
--. (1982b) "Canadian Immigration and Ethnic History in the 1970s and 1980s," in Journal of Canadian Studies, 17:1.

--. (ed) (1975) Immigration and the Rise of Multiculturalism, Toronto: Copp Clark.

-.. (1973) "Nativism and Ethnic Tolerance in Alberta 1920 - 1972," Canadian Theses on Microfilm \#17136.

Parkman, F. (1915) The Jesuits in North America in the Seventeenth Century, New York: Scribner's.

--. (1890) The Old Regime in Canada, Boston: Little, Brown.

Patel, D. (1980) Dealing with Interracial Conflict: Policy Alternatives, Montreal: Institute for Research on Public Policy.

Pedley, C. (1863) The History of Newfoundland From the Earliest Times to the Year 1860, London: Longman, Green, Roberts, \& Green.

Peter, K. (1981) "The Myth of Multiculturalism and Other Policitical Fables," in J. Dahlie and T. Fernando (eds) Ethnicity, Power, and Politics in Canada, Toronto: Methuen.

Peterson, J. (1985) "Many Roads to Red River: Métis Genesis in the Great Lakes Region, 1680 - 1815," in J. Peterson and J. Brown (eds) The New Peoples: Being and Becoming Métis in North America, Winnipeg: University of Manitoba Press.

Petty, Sir W. (1967) The Petty Papers, New York: Augustus M. Kelley.

Plato. (1980) The Laws, T. Pangle (tr) New York: Basic Books.

-. (1965) Timaeus and Critias, Harmondsworth: Penguin.

-. (1955) The Republic, Harmondsworth: Penguin.

Pliny. (1940) Natural History, London \& Cambride: Harvard University Press.

Plotinus. (1969) The Enneads, S. McKenna (tr) London: Faber.

Polo, Marco (1968) The Travels of Marco Polo, New York: AMS Press.

Porter, J. (1975) "Ethnic Pluralism in Canadian Perspective," in N. Glazer and P. Moynihan (eds) Ethnicity: Theory and Experience, Cambridge: Harvard University Press.

-. (1969) "Bilingualism and the Myths of Culture," in The Canadian Review of Sociology and Anthropology, 6 (2). 
-. (1965) The Vertical Mosaic: An analysis of Social Class and Power in Canada, Toronto: University of Toronto Press.

Poster, M. (1992) "Postmodernity and the Politics of Multiculturalism: The LyotardHabermas Debate over Social Theory," in Modern Fiction Studies, 38:3.

Prigogine, I. (1989) Exploring Complexity: An Introductory Text, New York: W.H. Freeman.

--. (1984) Order Out of Chaos, New York: Bantam.

Prowse, D.W. (1895) A History of Newfoundland From the English, Colonial, and Foreign Records, London: Macmillan \& Co.

Purchas, S. (1965) Hakluytus Posthumus or Purchas His Pilgrimes v. 13,14,19, New York: AMS Press.

Purich, D. (1992) The Inuit and Their Land, Toronto: James Lorimer \& Co.

--. (1988) The Métis, Toronto: James Lorimer \& Co.

Quinn, D.B. (1979) New American World: A Documentary History of North America to 1612, New York: Amo Press.

Radisson, P.E. (1885) Voyages of Peter Esprit Radisson, New York: Burt Franklin.

Renan, E. (1991) "What is a Nation?" in H. Bhabha (ed) Nation and Narration, London: Routledge.

Repka, W. and Repka, K. (1982) Dangerous Patriots: Canada's Unknown Prisoners of War, Vancouver: New Star.

Resnick, P. (1994) Thinking English Canada, Toronto: Stoddart.

Rich, E.E. (1967) The Fur Trade and the Northwest to 1857, Toronto: McClelland and Stewart.

-. (1958) The History of the Hudson's Bay Company 1670 - 1870, London: The Hudson's Bay Record Society (v. 21 \& 22 of series).

Richtik, J.M. (1973) Manitoba Settlement: 1870 to 1886. Ann Arbor, Michigan: University Microfilms.

Rioux, M. (1971) Quebec in Question, Toronto: James Lewis \& Samuel.

Roberts, B. (1988) Whence They Came: Deportation from Canada $1900-1935$, Ottawa: University of Ottawa Press. 
Robertson, R.W. (1970) Sir John A. Builds a Nation: The Expansion of Confederation 1867 - 1873, Toronto: Burns and MacEachern.

Rocher, G. (1976) "Multiculturalism: The Doubts of a Francophone," in Canadian Consultative Council on Multiculturalism, Conference Report, Multiculturalism as State Policy, Ottawa: Supply and Services Canada.

-. (1969) Le Canada: un pays à rebátir?" in The Canadian Review of Sociology and Anthropology, 6 (2).

Rockefeller, S. (1992) "Comment," in A. Gutman (ed) Multiculturalism and the Politics of Recognition, Princeton: Princeton University Press.

Ross, A. (1972) The Red River Settlement: It's Rise, Progress, and Current State, Rutland, Vermont: Charles E. Tuttle.

Roger, C. (1856) The Rise of Canada, from Barbarism to Wealth and Civilization, Quebec: Peter Sinclair.

Rorty, R. (1985) "Habermas and Lyotard on Postmodernity," in R. Bernstein (ed.) Habermas and Modernity London: Polity Press

-. (1979) Philosophy and the Mirror of Nature, Princeton: Princeton University Press.

Rowe, F. (1977) Extinction: The Beothuks of Newfoundland, Toronto: McGraw-Hill Ryerson.

Ryder, N.B. (1955) "The Interpretation of Origin Statistics," in The Canadian Journal of Economics and Political Science, 21:4 466-479.

Sandel, M. (1984) "The Procedural Republic and the Unencumbered Self," in Political Theory 12:1, 81-96.

Sapir, E. (1912) "The Work of the Division of Anthropology of the Dominion Government," in Queen's Quarterly 20:1.

Satzewich, V. (ed) (1992) Deconstructing a Nation: Immigration, Multiculturalism \& Racism in 90's Canada, Halifax: Fernwood Publishing.

Schleifer, R. (1987) A.J. Greimas and the Nature of Meaning, London: Croom Helm.

Scott, J. (1992) “Multiculturalism and the Politics of Identity," in October \#61.

Shortt, A and Doughty, G. (eds) (1907) Documents Relating to the Constitutional History of Canada, Ottawa: King's Printer.

Silverman, K. (1983) The Subject of Semiotics, London, New York: Oxford University Press. 
Singh, Narinder. (1994) Canadian Sikhs: History, religion, and Culture of Sikhs in North America, Ottawa: Canadian Sikhs' Studies Institute.

Smith, A.D. (1986) The Ethnic Origins of Nations, New York: Basil Blackwell.

Smith, D.B. "The Dispossession of the Mississauga Indians: a Missing Chapter in the Early History of Upper Canada," in Johnson \& Wilson eds. (1989) Historical Essays on Upper Canada: New Perspectives, Ottawa: Carleton University Press.

Smith, L.A.H. (1969) "Le Canadien and the British Constitution, 1806-1810," in R. Cook (ed) Constitutionalism and Nationalism in Lower Canada, Toronto: University of Toronto Press.

Smith, Melvin H. (1995) Our Home or Native Land?, Victoria: Crown Western.

Smith, W.G. (1919) A Study in Canadian Immigration, Toronto: Ryerson.

Society for the Propagation of the Gospel in Foreign Parts. (1882) The Results of 180 years of work, as set for in letters of colonial and missionary bishops, Westminster, S.W.: The Society CIHM 64610.

Stanley, F.G. (1961) The Birth of Western Canada: A History of the Riel Rebellions, Toronto: University of Toronto Press.

-. (1950) "The First Indian 'Reserves' in Canada," in Revue d'Histoire de l'Amerique Francaise, 4:1, June 1950.

--. (1949) "The Policy of 'Francisation as Applied to the Indians During the Ancien Regime," in Revue d'Histoire de l'Amerique Francaise, 3:3, December 1949.

Tacitus, C. (1954) Agricola, H. Mattingly (tr), Harmondsworth: Penguin.

Taylor, C. (1993) Reconciling the Solitudes: Essays on Canadian Federalism and Nationalism, Montreal \& Kingston: McGill-Queen's University Press.

-. (1992) "The Politics of Recognition," in A. Gutman (ed) Multiculturalism and the Politics of Recognition, Princeton: Princeton University Press.

-. (1991) "Shared and Divergent Values," in D. Brown \& R. Watts (eds) Options for a New Canada, Toronto: University of Toronto Press.

Thompson, J.H. (1991) Ethnic Minorities During Two World Wars, Ottawa: Canadian Historical Association.

Thompson, L.A. (1989) Romans and Blacks, Norman and London: University of Oklahoma Press. 
Thorson, J.T. (1971) Wanted: A Single Canada, Toronto: McLelland \& Stewart.

Thwaites, R.G. (1897) The Jesuit Relations and Allied Documents Cleveland: Burrows Brothers.

Tobias, J.L. (1991) "Protection, Civilization, and Assimilation: An Outline of Canada's Indian Policy," in J.R. Miller (ed) Sweet Promises, Toronto: University of Toronto Press.

Todorov, T. (1993) On Human Diversity: Nationalism, Racism, and Exoticism in French Thought, Cambridge \& London: Harvard University Press.

-. (1984) The Conquest of America: The Question of the Other, New York: Harper \& Row.

Trigger, B. (1985) Natives and Newcomers: Canada's "Heroic Age" Reconsidered, Kingston \& Montreal: McGill-Queen's University Press.

Trudel, M. (1973) The Beginnings of New France, Toronto: McLelland \& Stewart.

Tully, J. (1995) Strange Multiplicity: Constitutionalism in an Age of Diversity, Cambridge: Cambridge Toronto Press.

Tyrrell, J.B. (ed) (1931) Documents Relating to the Early History of Hudson Bay, Toronto: Champlain Society.

Upton, L.F.S. (1992) "The Extermination of the Beothucks of Newfoundland, in J.R. Miller (ed) Sweet Promises, Toronto: University of Toronto Press.

Urquhart, M.C. (ed) (1965) Historical Statistics of Canada, Toronto: Macmillan.

Vachon, R. and Langlais, J. (eds) (1983) Who is a Quebecois? Ottawa: Tecumseh Press.

Vattimo, G. (1991) The End of Modernity, Baltimore: Johns Hopkins University Press.

Virgil. (1962) The Aenid, IR. Lind (tr) Bloomington: Indiana University Press.

Vlastov, G. (1981) Platonic Studies, Princeton: Princeton University Press.

Wakefield, E.G. (1929) A Letter from Sydney and Other Writings, London: J.M. Dent.

Waldrop, M. (1983) Complexity: The Emerging Science at the Edge of Order and Chaos, New York: Simon \& Schuster.

Walker, J. (1980) A History of Blacks in Canada, Ottawa: Minister of State for Multiculturalism. 
Wallace, W.S. (1927) The Growth of Canadian National Feeling, Toronto: Macmillan.

Ward, P. (1978) White Canada Forever: Popular Attitudes and Public Policy Toward Orientals in British Columbia, Montreal: McGill-Queen's University Press.

Wardman, A. (1982) Religion and Statecraft Among the Romans, Baltimore: Johns Hopkins University Press.

Weber, M. (1946) From Max Weber, New York: Oxford University Press.

Whitaker, R. (1991) Canadian Immigration Policy Since Confederation, Ottawa: Canadian Historical Association.

--. (1987) Double Standard: The Secret History of Canadian Immigration, Toronto: Lester \& Orpen Denys Limited.

Whitbourne, R. (1971) A Discourse and Discovery of New-Found-Land, Amsterdam \& New York: Da Capo Press.

Whittaker, M. (1984) Jews and Christians: Graeco-Roman Views, Cambridge: Cambridge University Press.

Wilden, A. (1981) "Semiotics and Praxis: Strategy and Tactics," Recherches Semiotiques/Semiotic Inquiry, Vol. 1 No. 1, 1-34.

-. (1980) System and Structure: Essays in Communication and Exchange, London: Tavistock, Second Edition.

--. (1980a) The Imaginary Canadian, Vancouver: Pulp Press.

Williamson, J.A. (1929) The Voyages of the Cabots and the English Discovery of North America, London: The Argonaut Press.

Woodsworth, J.S. (1972a) Strangers Within Our Gates, or Coming Canadians, Toronto: University of Toronto Press.

-. (1972b) My Neighbour, Toronto, University of Toronto Press.

Wright, J. (ed) (1839) Debates of the House of Commons in the year 1774, on the Bill for making more effectual provision for the government of the Province of Quebec, London: Ridgway, Piccadilly, CIHM 48438.

Wrong, G.M. (1928) The Rise and Fall of New France, Toronto: Macmillan.

Young, R. (1995) Colonial Desire: Hybridity in theory, culture, and race, New York: Routledge.

Yuzyk, P. (1965) “Canada: A Multicultural Nation," in Canadian Slavonic Papers 7:25-31, Toronto: University of Toronto Press. 
Zaslove, J. (1994) "Constituting Modernity: The Epic Horizons of Constitutional Narratives," in Public \#9.

Zizek, S. (1991) Looking Awry: An Introduction to Jacques Lacan Through Popular Culture Cambridge, Mass: MIT Press.

-. (1990) "Beyond Discourse-Analysis" in E. Laclau (ed) New Reflections on the Revolution of Our Times, London: Verso. 
IMAGE EVAIUIAT!ON
TEST TARGET (QA-3)
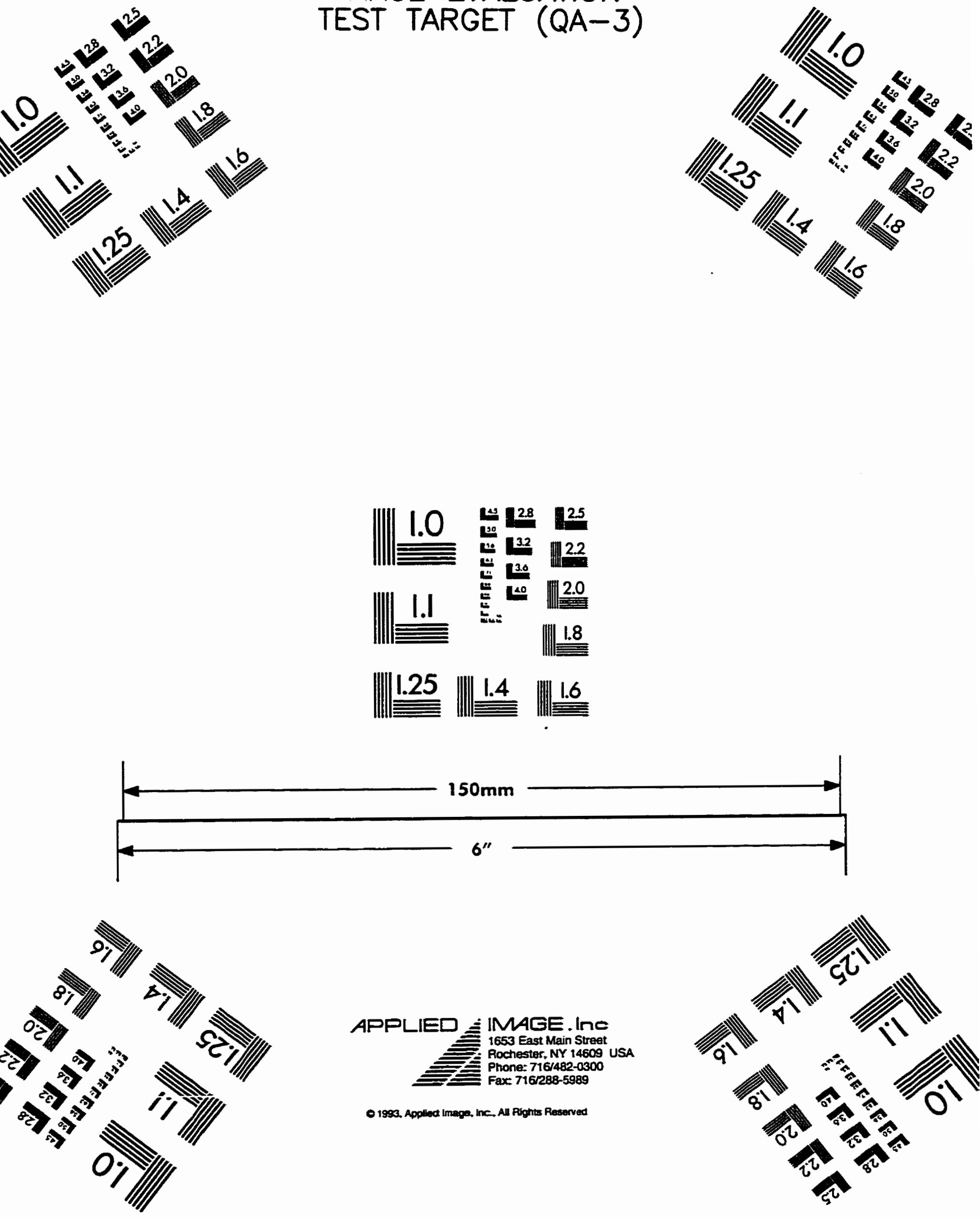